\title{
Toric Intraocular lenses in cataract surgery
}

Citation for published version (APA):

Visser, N. (2016). Toric Intraocular lenses in cataract surgery. [Doctoral Thesis, Maastricht University]. Maastricht University. https://doi.org/10.26481/dis.20161209nv

Document status and date:

Published: 01/01/2016

DOI:

$10.26481 /$ dis.20161209nv

Document Version:

Publisher's PDF, also known as Version of record

\section{Please check the document version of this publication:}

- A submitted manuscript is the version of the article upon submission and before peer-review. There can be important differences between the submitted version and the official published version of record.

People interested in the research are advised to contact the author for the final version of the publication, or visit the DOI to the publisher's website.

- The final author version and the galley proof are versions of the publication after peer review.

- The final published version features the final layout of the paper including the volume, issue and page numbers.

Link to publication

\footnotetext{
General rights rights.

- You may freely distribute the URL identifying the publication in the public portal. please follow below link for the End User Agreement:

www.umlib.nl/taverne-license

Take down policy

If you believe that this document breaches copyright please contact us at:

repository@maastrichtuniversity.nl

providing details and we will investigate your claim.
}

Copyright and moral rights for the publications made accessible in the public portal are retained by the authors and/or other copyright owners and it is a condition of accessing publications that users recognise and abide by the legal requirements associated with these

- Users may download and print one copy of any publication from the public portal for the purpose of private study or research.

- You may not further distribute the material or use it for any profit-making activity or commercial gain

If the publication is distributed under the terms of Article $25 \mathrm{fa}$ of the Dutch Copyright Act, indicated by the "Taverne" license above, 
TORIC INTRAOCULAR LENSES

IN CATARACT SURGERY

Nienke Visser 
ISBN: 978-90-9030010-8

Printing: Drukwerkconsultancy

Cover photograph: Tall tree \& the eye (Anish Kapoor, Guggenheim Museum Bilbao), by Rudy Mareel/ Shutterstock.com

(C) 2016 Nienke Visser

Financial support for the publication of this thesis was kindly provided by: Rotterdamse Stichting Blindenbelangen, Stichting Blindenhulp, Allergan, AMO Netherlands, Bayer, Carl Zeiss, Laméris Ootech, Ophtec, Synga Medical, Théa Pharma and Ursapharm.

All right reserved. No part of this thesis may be reproduced or transmitted in any form or by any means, electronic, or mechanical, including photocopying, recording or any information storage or retrieval system, without permission in writing from the author, or, when appropriate, from the publishers of the publications. 


\title{
TORIC INTRAOCULAR LENSES IN CATARACT SURGERY
}

\author{
PROEFSCHRIFT
}

ter verkrijging van de graad van doctor aan de Universiteit Maastricht, op gezag van de Rector Magnificus, Prof dr. Rianne M. Letschert, volgens het besluit van het College van Decanen, in het openbaar te verdedigen op

vrijdag 9 december 2016 om 12:00

door

Nienke Visser 


\section{Promotor}

Prof. dr. R.M.M.A. Nuijts

\section{Copromotor}

Dr. N.J.C. Bauer

\section{Beoordelingscommissie}

Prof. dr. C.D. Dirksen (voorzitter)

Prof. dr. O. Findl (Hanusch Krankenhaus, Wenen, Oostenrijk)

Prof. dr. G.P.M. Luyten (Leids Universitair Medisch Centrum)

Prof. dr. L.W. van Rhijn

Prof. dr. C.A.B. Webers

The studies in this thesis are supported by a grant from ZonMW - The Netherlands Organisation for Health Research and Development. 
Voor mijn ouders 


\section{Contents}

List of Abbreviations

Chapter 1 Introduction and literature review

J Cataract Refract Surg. 2013; 39: 624-637.

Chapter 2 Comparability and repeatability of corneal astigmatism measurements using different measurement technologies J Cataract Refract Surg. 2012; 38: 1764-1770.

Chapter 3 Evaluation of the comparability and repeatability of four wavefront aberrometers

Invest Ophthalmol Vis Sci. 2011; 52: 1302-1311.

Chapter 4

Accuracy of toric intraocular lens alignment in cataract and refractive surgery J Cataract Refract Surg. 2011; 37: 1394-1402.

Chapter $5 \quad$ Toric versus aspherical control intraocular lenses in patients with cataract and corneal astigmatism: A randomized controlled trial JAMA Ophthalmol. 2014; 132: 1462-1468.

Chapter 6

Cataract surgery with toric intraocular lens implantation in patients with high corneal astigmatism J Cataract Refract Surg. 2011; 37: 1403-1410.

Chapter 7

Visual outcomes and patient satisfaction after cataract surgery with toric multifocal intraocular lens implantation J Cataract Refract Surg. 2011; 37: 2034-2042.

Chapter $8 \quad$ Vector analysis of corneal and refractive astigmatism changes following toric pseudophakic and toric phakic intraocular lens implantation Invest Ophthalmol Vis Sci. 2012; 53: 1865-1873. 
Chapter $9 \quad$ Cataract surgery with toric intraocular lens implantation in keratoconus: A case report

Cornea 2011; 30: 720-723.

Chapter 10 Residual astigmatism following toric intraocular lens implantation related to pupil size: A case report

J Refract Surg. 2012; 28: 729-732.

Chapter 11 General discussion

Chapter 12 Valorisatie addendum

Summary/ Samenvatting

Dankwoord 195

Curriculum vitae 199

List of publications 


\section{List of Abbreviations}

ACD Anterior chamber depth

$A E \quad$ Angle of error

AK Arcuate keratotomies

ANOVA Analysis of variance

ATR Against-the-rule

CA Corneal aberrations

CDVA Corrected distance visual acuity

$\mathrm{Cl} \quad$ Confidence interval

CIVA Corrected intermediate visual acuity

CNVA Corrected near visual acuity

D Diopters

DV Difference vector

ETDRS Early treatment diabetic retinopathy study

FE Flattening effect

HOA Higher order aberrations

IOL Intraocular lens

K Keratometry

LoA Limits of agreement

LogMAR Logarithm of the minimum angle of resolution

LRI Limbal relaxing incisions

MANOVA Multivariate analysis of variance

ME Magnitude of error

$\mathrm{N} \quad$ Number

$\mathrm{OCCl} \quad$ Opposite clear corneal incisions

OR Odds ratio

PCC Pearson's correlation coefficient

$\mathrm{PCl} \quad$ Partial coherence interferometry

pIOL Phakic intraocular lens

PKP Post-keratoplasty

PRK Photorefractive keratectomy

RCT Randomized controlled trial

RMS Root mean square

SD Standard deviation

SIA Surgically induced astigmatism 
SICA Surgically induced corneal astigmatism

$\mathrm{S}_{\mathrm{w}} \quad$ Within-subject standard deviation of 3 repeated measurements per eye

TIA Target induced astigmatism

TOA Total ocular aberrations

UDVA Uncorrected distance visual acuity

UIVA Uncorrected intermediate visual acuity

UNVA Uncorrected near visual acuity

WTR With-the-rule 


\section{Chapter 1}

\section{Introduction and Literature overview}

Nienke Visser, Noël J.C. Bauer and Rudy M.M.A. Nuijts Partly published as review: Journal of Cataract \& Refractive Surgery 2013; 39: 624-637 


\section{Cataract Surgery}

The refractive power of the eye is determined by the cornea and lens. The crystalline lens provides a clear medium for light transmission, refraction of light rays and accommodation. With normal ageing, the lens increases in weight and thickness and loses its accommodative power. Compression, hardening and chemical modifications in the lens lead to lens opacification, or cataract, and result in a decrease in vision. Cataract surgery, or phacoemulsification, consists of emulsification and removal of the crystalline lens using ultrasonic energy. This is followed by implantation of an intraocular lens in the capsular bag. Cataract surgery is the most frequently performed surgery in the Netherlands. ${ }^{1}$ Approximately 180.000 cataract surgeries were performed in the Netherlands in $2013 .{ }^{2}$ In modern cataract surgery, spectacle freedom is becoming more and more desirable. Emmetropia can be achieved for patients with myopic or hyperopic refractive errors by selecting the appropriate spherical lens power. However, approximately $20 \%$ to $30 \%$ of patients who undergo cataract surgery have a substantial amount of corneal astigmatism. In corneal astigmatism, the horizontal and vertical meridians of the cornea have a different curvature and therefore a different power. Not correcting the astigmatism component at the time of cataract surgery fails to achieve spectacle independency. Toric intraocular lenses (IOLs) provide an opportunity to correct corneal astigmatism at the time of cataract surgery and achieve spectacle independency for distance vision. It has been shown that the presence of 1.0 diopter (D) or more of astigmatism in eyes with a multifocal IOL compromised both distance and near visual acuities, indicating the importance of an optimal astigmatism correction in these patients. ${ }^{3}$ Therefore, the introduction of multifocal toric IOLs offers patient with corneal astigmatism the opportunity not only to achieve spectacle independency for distance vision, but also for near and intermediate vision.

\section{Toric Intraocular Lenses}

\section{Historical overview}

The first toric IOL was developed by Shimizu et al. in 1992. ${ }^{4}$ This three-piece IOL was made of non-foldable poly-methyl methacrylate (PMMA) and required a $5.7 \mathrm{~mm}$ incision for implantation. It was available in cylinder powers of either 2.0 D or 3.0 D. Postoperatively, UDVA and residual refractive astigmatism outcomes were not described, but CDVA was $20 / 25$ or better in $77 \%$ of eyes. ${ }^{4}$ However, about $20 \%$ of the IOLs rotated 30 degrees or more and almost $50 \%$ of IOLs rotated more than 10 
degrees. In 1994, the first foldable one-piece toric IOL became available. This IOL was made of silicone material and could be implanted through a much smaller incision of $3.2 \mathrm{~mm} .^{5-8}$ The first clinical results with this IOL were promising: $23 \%$ of patients achieved an UDVA of $20 / 25$ or better compared with $4 \%$ of patients with a standard IOL. ${ }^{5}$ However, a drawback of this IOL was still a relatively high postoperative rotation rate: in 20 to $30 \%$ of eyes a rotation of more than 10 degrees occurred. ${ }^{7-9}$ A 10 degree error in rotation results in a $35 \%$ residual error in the magnitude of astigmatism. Since 1994, many advancements have been made in toric IOL technology, including improvements in IOL material and design and refinements in surgical technique. These advances have led to an improved postoperative rotational stability and consequently improved visual outcomes following toric IOL implantation.

\section{IOL material}

Currently, many different monofocal and multifocal toric IOL models are available (Table 1.1 and 1.2). Toric IOLs are made of either hydrophobic acrylic, hydrophilic acrylic, silicone or PMMA biomaterial. The IOL biomaterial influences possible postoperative rotation of the IOL. After implantation in the capsular bag, the anterior and posterior capsules fuse with the IOL, thereby preventing IOL rotation. ${ }^{10}$ Strong IOL adhesions to the capsular bag are thought to prevent IOL rotation. Several in vitro studies have examined the interactions between different IOL biomaterials and the capsular bag. Lombardo et al. used atomic force microscopy to determine IOL optic surface adhesiveness of different IOL biomaterials and found that hydrophobic acrylic IOLs showed the highest adhesive properties, followed by hydrophilic acrylic IOL, PMMA IOLs and finally silicone IOLs. ${ }^{11}$ A study in rabbits who underwent phacoemulsification with IOL implantation showed the strongest IOL-capsular bag adhesions for acrylic IOLs, followed by PMMA and silicone IOLs. ${ }^{12}$ Linnola et al. hypothesized that IOL biomaterials show differences in IOL adhesion due to a different affinity to proteins in the capsular bag. ${ }^{13}$ Extracellular matrix proteins, such as fibronectin, vitronection and collagen type IV, are available in the aqueous humor following cataract surgery and may be involved in IOL adhesion to the capsular bag. Especially fibronectin is thought to play a major role in IOL-capsular bag adhesion. ${ }^{10}$ Acrylic IOLs explanted from human autopsy eyes contained significantly more fibronectin compared to silicone or PMMA eyes. ${ }^{14}$ These results indicate that acrylic IOLs generally form the strongest adhesions with the capsular bag. 
IOL design

The IOL design is important in achieving stability in the capsular bag and avoiding postoperative IOL rotation. The overall IOL diameter and haptic design have been shown to be a major factor in the prevention of $10 \mathrm{~L}$ rotation. ${ }^{15-17}$ Chang et al. compared two different sizes of the same silicone toric IOL: a smaller model with a diameter of $10.8 \mathrm{~mm}$ and a longer model with a diameter of $11.2 \mathrm{~mm} .{ }^{16}$ The longer model was found to have a much better rotational stability compared to the smaller model: $10 \%$ of the longer IOLs rotated more than 10 degrees compared to $45 \%$ for the smaller IOLs. Currently available toric IOLs have a total IOL diameter ranging from 11.0 $\mathrm{mm}$ to $13.0 \mathrm{~mm}$. Regarding the IOL haptics design, two different haptic designs are available: plate haptic and loop haptic. A randomized controlled trial (RCT) has been performed to compare postoperative rotation of plate and loop haptic silicone IOLs. Postoperative rotation was significantly higher in loop haptic IOLs compared to plate haptic IOLs: 6.8 degrees versus 0.6 degrees. ${ }^{15}$ Patel et al. hypothesized that loop haptic IOLs may be more susceptible to rotation due to an asymmetric fusion of the capsular bag with the IOL haptics. ${ }^{15}$ However, Prinz et al. recently compared plate and loop haptic acrylic IOLs and did not find a significant difference in postoperative rotation. ${ }^{18}$ This indicates that plate and loop haptics acrylic IOL demonstrate equally good rotational stability.

\section{Patient Selection}

Toric IOLS

Patients with regular bow-tie astigmatism are most suitable for toric IOL implantation.

To detect possible irregular astigmatism, corneal topography should be performed preoperatively in all patients. This can be performed using either placido-disk videokeratoscopy or Scheimpflug imaging. Scheimpflug imaging is preferred since this allows for an evaluation of both the anterior and posterior corneal surfaces and the corneal thickness. ${ }^{19}$ Some corneal ectatic disorders, such as keratoconus, present with changes on the posterior corneal surface before any changes may be seen on the anterior corneal surface. ${ }^{20,21}$ Although toric IOLs are most effective in the correction of regular astigmatism, these IOLs have also been shown to be effective in patients with irregular corneal astigmatism, including keratoconus ${ }^{22}$, pellucid marginal degeneration ${ }^{23}$ and post-keratoplasty eyes ${ }^{24,25}$. However, toric IOL implantation should only be considered in patients with mild to moderate amounts of irregular astigmatism who can be satisfactory corrected using spectacles. It is not a suitable option in patients who require rigid gas permeable contact lenses to correct high levels of irregular astigmatism. ${ }^{26}$ 

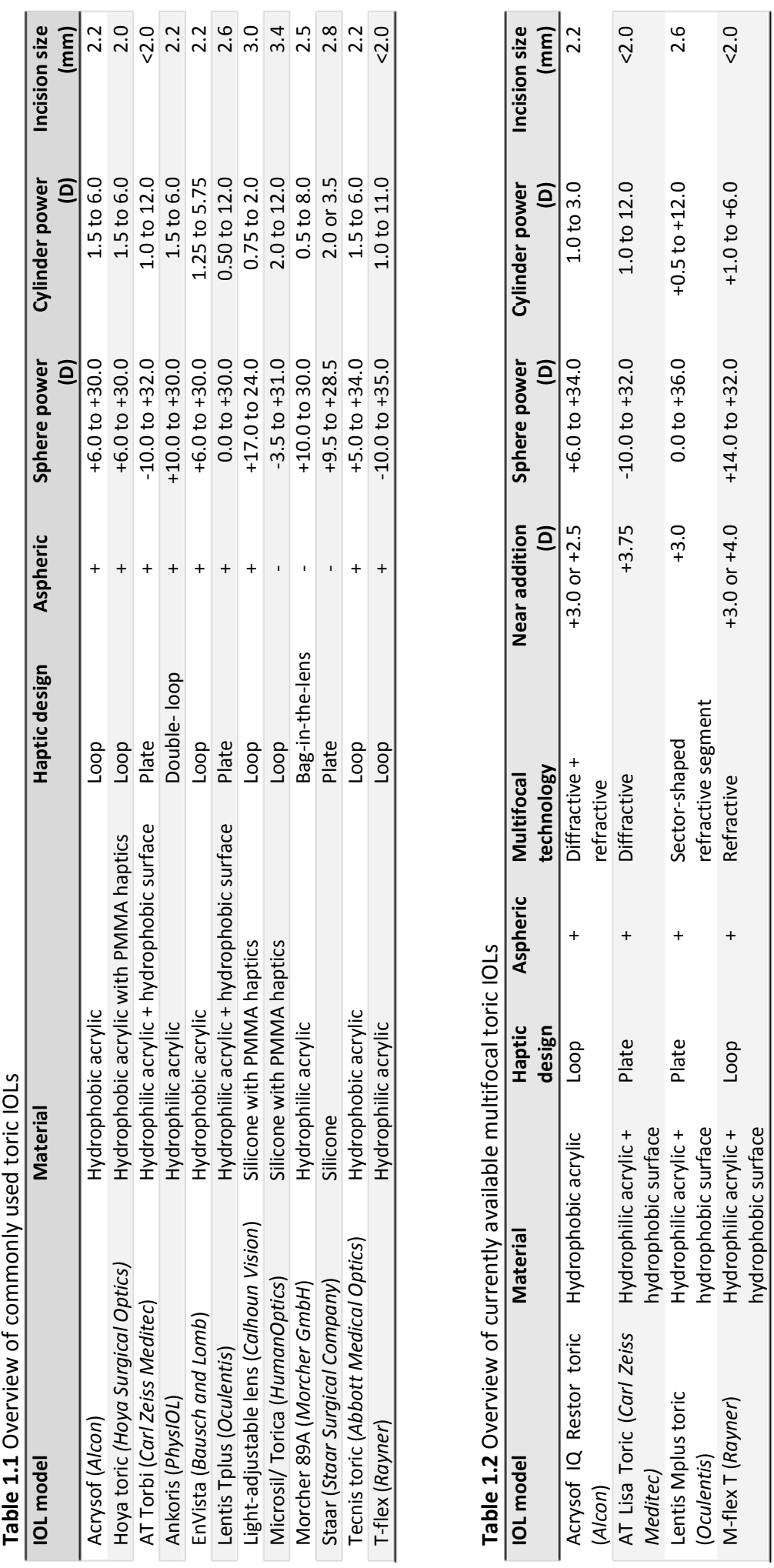

INTRODUCTION 
Toric IOL implantation is a suitable option in keratoconus patients only if the risk of progression is minimal. Other pre-existent ocular pathologies may be a relative or absolute contraindication for toric IOL implantation. Patients with Fuchs' endothelial dystrophy or another corneal dystrophy might need a keratoplasty in the future which may alter corneal astigmatism. These patients are therefore not good candidates for toric IOL implantation. Patients with potential bag instability like patients with pseudoexfoliation syndrome or trauma induced zonulolysis are not suitable for toric IOL implantation, since zonular weakness affects the lens stability and may result in rotation or decentration of the toric IOL.

\section{Multifocal toric IOLs}

Patient selection is crucial for achieving success with multifocal toric IOLs. The ideal patient is motivated for achieving spectacle independency for both distance and near vision, understands the limitations of multifocal IOLs and has realistic expectations. ${ }^{27}$ The second step is to exclude possible ocular co-morbidities. Multifocal IOLs split the available light between distance and near foci. Therefore, ocular co-morbidities that affect visual acuity or quality of vision are a relative or absolute contraindication for multifocal toric IOLs. These include amblyopia, corneal pathologies (such as keratoconus or a corneal scar), maculopathies (such as age-related macular degeneration or diabetic retinopathy), glaucoma and uveitis. $^{27,}{ }^{28}$ An extensive preoperative ophthalmic examination is therefore required, including corneal topography, fundoscopy and preferably optical coherence tomography.

\section{Toric IOL Calculation}

\section{Keratometry}

Preoperatively, accurate measurements of corneal astigmatism must be obtained in order to achieve an effective astigmatism correction. Clinical studies on toric IOLs have described various methods to measure corneal astigmatism, including automated keratometry $^{29,30}$, manual keratometry ${ }^{31,32}$, corneal topography ${ }^{29}$ and Scheimpflug imaging $^{33}$. These devices have been shown to be comparable in measuring astigmatism. ${ }^{34-37}$ In addition, toric IOL calculations using either automated keratometry or manual keratometry resulted in comparable residual refractive astigmatism values. ${ }^{36}$ Scheimpflug imaging has the advantage of measuring both the anterior and posterior corneal surfaces. However, even though simulated keratometry values obtained with Scheimpflug imaging correlated well with other devices, parameters that are based on both the anterior and posterior corneal curvature and true refractive 
indices for cornea and aqueous have been shown to result in significantly different values compared to keratometry or topography. These values should therefore not be used in current toric IOL calculations. ${ }^{37,38}$

\section{Surgically induced corneal astigmatism}

Another aspect to consider when calculating a toric IOL is the (vector) change in corneal astigmatism induced by the surgery itself. The expected amount of surgically induced corneal astigmatism (SICA) has to be incorporated into the toric IOL power calculation in order to select the most appropriate toric IOL model and alignment axis. However, the amount of SICA is difficult to predict and depends on several factors. The location of the incision is an important factor to consider, since corneal incisions lead to both flattening of the incised meridian and steepening of the orthogonal meridian due to the coupling effect. ${ }^{39,40}$ The size of the incision has also been shown to influence the amount of SICA: smaller incisions generally produce less SICA. ${ }^{41-43}$ Other factors which may be of influence are the amount of preoperative corneal astigmatism, suture use and patients' age. ${ }^{44,45}$ As shown in Table 1.1, commonly used toric IOLs require a 1.8 to $3.4 \mathrm{~mm}$ incision. The amount of SICA for a $2.2 \mathrm{~mm}$ incision has been reported to range from $0.19 \mathrm{D}$ to $0.31 \mathrm{D}$ for a temporal incision ${ }^{30,46-48}$ and $0.40 \mathrm{D}$ for a superior incision ${ }^{30,49}$. Goggin et al. showed that the test-retest variability

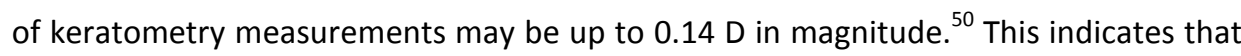
a significant proportion of the SICA reported in previous studies may be due to testretest variation in keratometry measurements.

\section{IOL calculation}

The power of the toric IOL may be calculated using either a calculation scheme ${ }^{48,51}$, or using a calculator program provided by the manufacturer. The toric IOL cylinder power is chosen based on the amount of corneal astigmatism. The effective cylinder power of the IOL at the corneal plane is a function of the estimated lens position and spheroequivalent power of the IOL. The IOL cylindrical and spherical power must first be converted into the two principal lens powers, after which both lens powers are calculated to the corneal plane using a standard vertex formula. The difference between both lens powers at the corneal plane should be used to select the most appropriate IOL cylinder power. ${ }^{52}$ Therefore, the relation between cylinder power at the IOL plane and at the corneal plane is not a fixed amount, as currently used by some manufacturers in toric IOL calculations. For example, the IOL cylinder power to correct $2 \mathrm{D}$ of corneal astigmatism is $2.20 \mathrm{D}$ for an IOL with a spheroequivalent of $10 \mathrm{D}, 2.40 \mathrm{D}$ for an IOL with a spheroequivalent of $22 \mathrm{D}$ and $2.60 \mathrm{D}$ for an IOL with a 
spheroequivalent of $30 \mathrm{D}$. Goggin et al. compared the manufacturers prediction of a fixed corneal plane cylinder power with a calculated corneal cylinder power that takes into account the estimated lens position (anterior chamber depth plus pachymetry) and IOL spheroequivalent power. ${ }^{53}$ This study demonstrated that for a hydrophobic acrylic toric IOL, the fixed IOL cylinder power at the corneal plane was significantly different from the calculated value. ${ }^{53}$ Recently, a new toric IOL calculator became available which considers the estimated lens position and predicts posterior corneal astigmatism based on anterior corneal astigmatism. ${ }^{54}$

\section{Surgical Technique}

\section{Marking technique}

Exact alignment of the toric $\mathrm{IOL}$ at the calculated alignment axis is necessary in order to achieve an effective astigmatism correction. Preoperatively, markings should be performed with the patient in an upright position in order to prevent cyclotorsion in the supine position. Cyclotorsion of the eye from the upright to supine position is approximately 2 to 4 degrees on average, but can be up to 15 degrees in individual patients. ${ }^{55-57}$ Cyclotorsion is a well-known aspect in refractive surgery and generally compensated for during laser refractive surgery. ${ }^{57}$ Most clinical studies on toric IOLs describe a 3-step marking procedure for toric IOL implantation. The first step usually consists of preoperative markings of the horizontal axis of the eye with the patient sitting upright. This may be done with the patient seated at the slitlamp and with a coaxial thin slit turned to $0-180$ degrees. ${ }^{58-60}$ The limbus is then marked at the horizontal position with either a sterile ink pen or a needle. Another technique to mark the horizontal axis is by using a bubble-marker. ${ }^{31,48,61}$ Intraoperatively, the preoperative horizontal marks are used to position an angular graduation instrument and mark the alignment axis. Some studies described a one-step marking technique to directly mark the alignment axis using either a slitlamp or a gravity marker. ${ }^{48,62-64}$

\section{Surgical procedure}

A standard phacoemulsification technique may be performed with a sub 2.0 to $3.4 \mathrm{~mm}$ limbal incision, depending on the toric IOL model to be implanted. A well-centered capsulorrhexis with 360 degree overlap of the IOL optic should be achieved to ensure optimal centration of the IOL and to reduce the incidence of posterior capsule opacification. The optic diameter is $6.0 \mathrm{~mm}$ for the majority of IOLs (Acrysof, AF-1 toric, AT Torbi, Lentis Tplus, Tecnis toric, LAL, MicroSil and Staar IOLs), 5.75 or $6.25 \mathrm{~mm}$ for Rayner toric IOLs and $5.0 \mathrm{~mm}$ for Morcher bag-in-the-lens IOLs. The ideal 
capsulorrhexis diameter should be adjusted to the IOL optic diameter and ranges from approximately 4.5 to $5.5 \mathrm{~mm}$ to maintain an overlap of the anterior edge of the IOL by the capsulorrhexis. After completion of the phacoemulsification, the ophthalmic viscosurgical device is injected and the foldable toric IOL is inserted through the limbal incision. The marks on the toric IOL indicate the flat meridian or plus cylinder axis of the toric IOL and should be aligned with the marked alignment axis. First, gross alignment is achieved by rotating the IOL clockwise while it is unfolding, until approximately 20 to 30 degrees short of the desired position. After the ophthalmic viscosurgical device is removed, the $\mathrm{IOL}$ is rotated to its final position by exact alignment of the reference marks on the toric IOL with the alignment axis marks. In the event of a complication during surgery that might compromise the stability of the toric IOL, such as zonular damage, vitreous loss, capsulorrhexis tear, or capsular rupture, conversion to a standard non-toric IOL may be required.

\section{Literature Overview}

Uncorrected distance visual acuity

Table 1.3 shows a literature overview of uncorrected distance visual acuity (UDVA) results following toric IOL implantation. Several RCTs have been performed comparing toric IOLs with monofocal IOLs ${ }^{32,65-68}$, other toric IOL models ${ }^{69,70}$, relaxing incisions or arcuate keratotomies ${ }^{71-78}$ and photorefractive keratectomy ${ }^{79}$. Regarding the RCTs comparing toric with monofocal IOLs, an UDVA of $20 / 25$ or better was achieved in $63 \%$ to $76 \%$ of eyes following toric IOL implantation, compared to $31 \%$ to $46 \%$ following monofocal IOL implantation. ${ }^{32,66,67}$ Table 1.3 shows the pooled estimates for each IOL model regarding an UDVA of $20 / 25$ or better. This was achieved in $65 \%$ of eyes with an Acrysof toric IOL, $61 \%$ of eyes with an AT Torbi IOL, $34 \%$ of eyes with a Rayner toric IOL, and $41 \%$ of eyes with a Tecnis toric IOL. Table 1.3 also shows the mean postoperative UDVA in LogMAR. Reported results are generally between 0.00 and 0.15 LogMAR. In one arm of the study of Waltz et al., patients with low amounts of corneal astigmatism $(0.75$ to 1.50 D) were randomized for either toric or monofocal IOL implantation. ${ }^{68}$ Patients with more than $1.50 \mathrm{D}$ of corneal astigmatism were included in the non-randomized open label arm and all received toric IOL implantation. In the randomized controlled arm, UDVA was significantly better in the toric group compared to the control group $(0.10 \pm 0.14$ versus $0.16 \pm 0.16 \operatorname{LogMAR}){ }^{68}$ Miyake et al. performed a large (378 eyes) prospective study evaluating the long-term results (up to 2 years) of toric IOL implantation and reported a substantially lower UDVA ( $0.35 \pm 0.38$ LogMAR, comparable to 0.45 Snellen). ${ }^{80}$ The cause of this suboptimal UDVA is unclear: 
CDVA was $-0.07 \pm 0.11$ LogMAR, misalignment rates were low and no over- or undercorrection occurred. ${ }^{80}$ A recent meta-analysis performed by Kessel et al. shows that toric IOL implantation results in a better UDVA compared to non-toric IOL implantation (-0.10 LogMAR mean difference) and compared to relaxing incisions (0.06 LogMAR mean difference). ${ }^{81}$

Residual refractive astigmatism

RCTs comparing toric and monofocal IOLs have reported a residual refractive astigmatism of $1.0 \mathrm{D}$ or less in 74 to $96 \%$ of eyes with toric IOLs compared to 30 to $70 \%$ of eyes with monofocal IOLs. ${ }^{32,66-68}$ For each toric lens model, the pooled estimates for a residual refractive astigmatism of $1.0 \mathrm{D}$ or less and $0.5 \mathrm{D}$ or less are shown in Table 1.4. A residual astigmatism of $0.5 \mathrm{D}$ or less was achieved in $69 \%$ of eyes with an Acrysof toric IOL, $91 \%$ with an AT Torbi IOL, $48 \%$ with a Staar toric IOL, and $65 \%$ of eyes with a Tecnis toric IOL.

Several studies have included a vector analysis comparing postoperative refractive astigmatism with preoperative (corneal) astigmatism and showed a substantial astigmatism reduction following toric IOL implantation. ${ }^{75,82-87} \mathrm{~A}$ vector analysis according to Alpins has been performed in several studies to determine the efficacy of astigmatism correction. Results are varied, ranging from an undercorrection

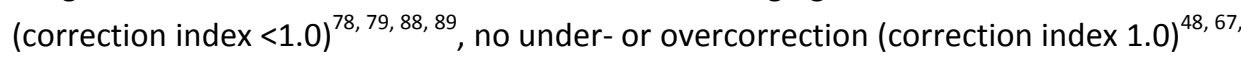
${ }^{80}$ to overcorrection (correction index $\left.>1.0\right)^{53,66}$. A meta-analysis shows a lower residual astigmatism following toric IOL implantation compared to non-toric IOL implantation ($0.75 \mathrm{D}$ mean difference) and relaxing incisions (-0.37 D mean difference). ${ }^{81}$

\section{Spectacle independency}

Spectacle use for distance vision following toric and monofocal IOL implantation has been evaluated in several RCTs. ${ }^{32,65,66,68}$ In the study of Waltz et al., spectacle independence was evaluated only for patients with bilateral study IOL implantation. ${ }^{68}$ In the randomized controlled arm, $83 \%$ versus $71 \%$ of patients in the toric and monofocal group achieved spectacle independence for distance vision. ${ }^{68}$ In the open label arm, 78\% of patients were spectacle independent for distance vision. ${ }^{68}$ Zhang et al. reported spectacle independence for distance vision in all patients with bilateral toric IOLs, compared to $67 \%$ of patients with bilateral monofocal IOLs. ${ }^{65}$ Visser et al. found spectacle independence following bilateral toric IOL implantation in $84 \%$ of patients in the toric group, compared to $31 \%$ in the monofocal group. ${ }^{66}$ In the RCT of Holland et al., spectacle independence following toric IOL implantation was reported in approximately $60 \%$ of patients implanted with a toric IOL, compared to $36 \%$ of patients 
implanted with a control IOL. ${ }^{32}$ However, patients in this study received unilateral toric IOL implantation. Lane et al. offered patients from the study of Holland et al. felloweye implantation with the same IOL (toric or non-toric IOL), allowing bilateral examination of spectacle independency, but introducing a possible selection bias. ${ }^{90}$ Almost all patients (97\%) with a toric IOL reported spectacle independency for distance vision, compared to half of the patients in the control group. ${ }^{90}$

\section{Complications}

Crucial to the efficacy of toric IOLs is the position of the IOL with regards to the intended alignment axis, since every degree of misalignment contributes to residual astigmatism. Currently, a misalignment of more than 10 degrees is generally regarded as the indication for surgical repositioning. Table 1.5 shows for each IOL model the pooled estimates for a misalignment of more than 10 degrees: $3 \%$ of eyes with an Acrysof toric IOL, $6 \%$ with an AT Toribi IOL, $8 \%$ with a Microsil IOL, $11 \%$ with a Rayner IOL, $17 \%$ with a Staar IOL and $2 \%$ of eyes with a Tecnis toric IOL. Regarding the Lentis toric IOL, a misalignment of more than 10 degrees was reported in $33 \%$ of eyes. Mean misalignment at 1 hour after surgery was $5 \pm 5$ degrees, compared to $20 \pm 14$ degrees at 9 months postoperatively. ${ }^{74}$ This indicates a high postoperative rotation rate of this toric IOL model. Consequently, it has been removed from the market. Other complications reported in the literature are those generally associated with cataract surgery and IOL implantation: posterior capsule opacification, cystoid macular edema, peripheral vitreous detachment, macular hole, retinal tear and retinal detachment. ${ }^{7,29,}$ $32,62,66,68,97$

\section{Conclusion}

Toric IOL implantation seems a safe and effective treatment option to correct corneal astigmatism at the time of cataract surgery. This statement is based on a limited number of RCTs available in the literature including the data in this thesis, that all show better spectacle independency after bilateral toric versus non-toric monofocal IOL implantation. 


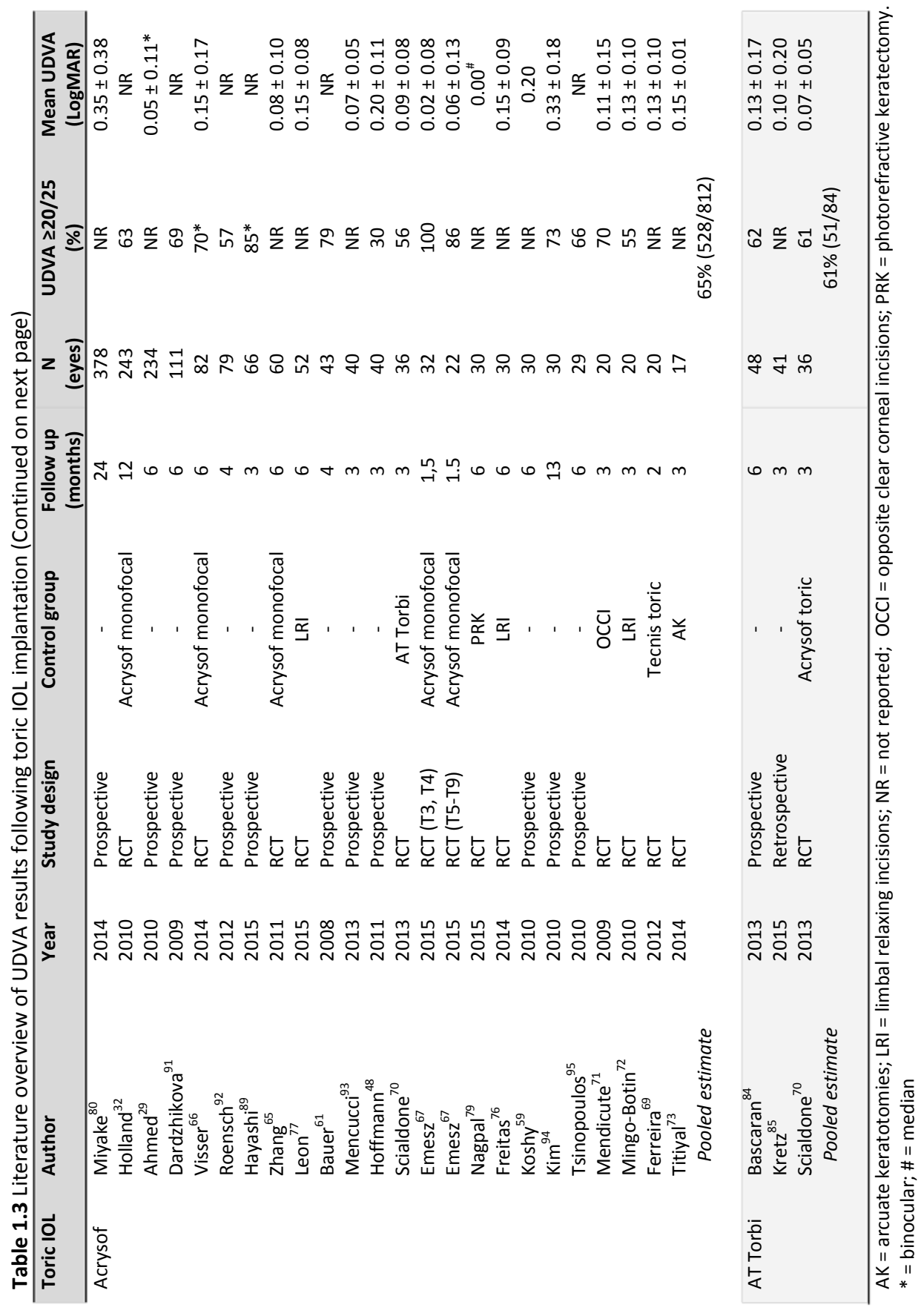




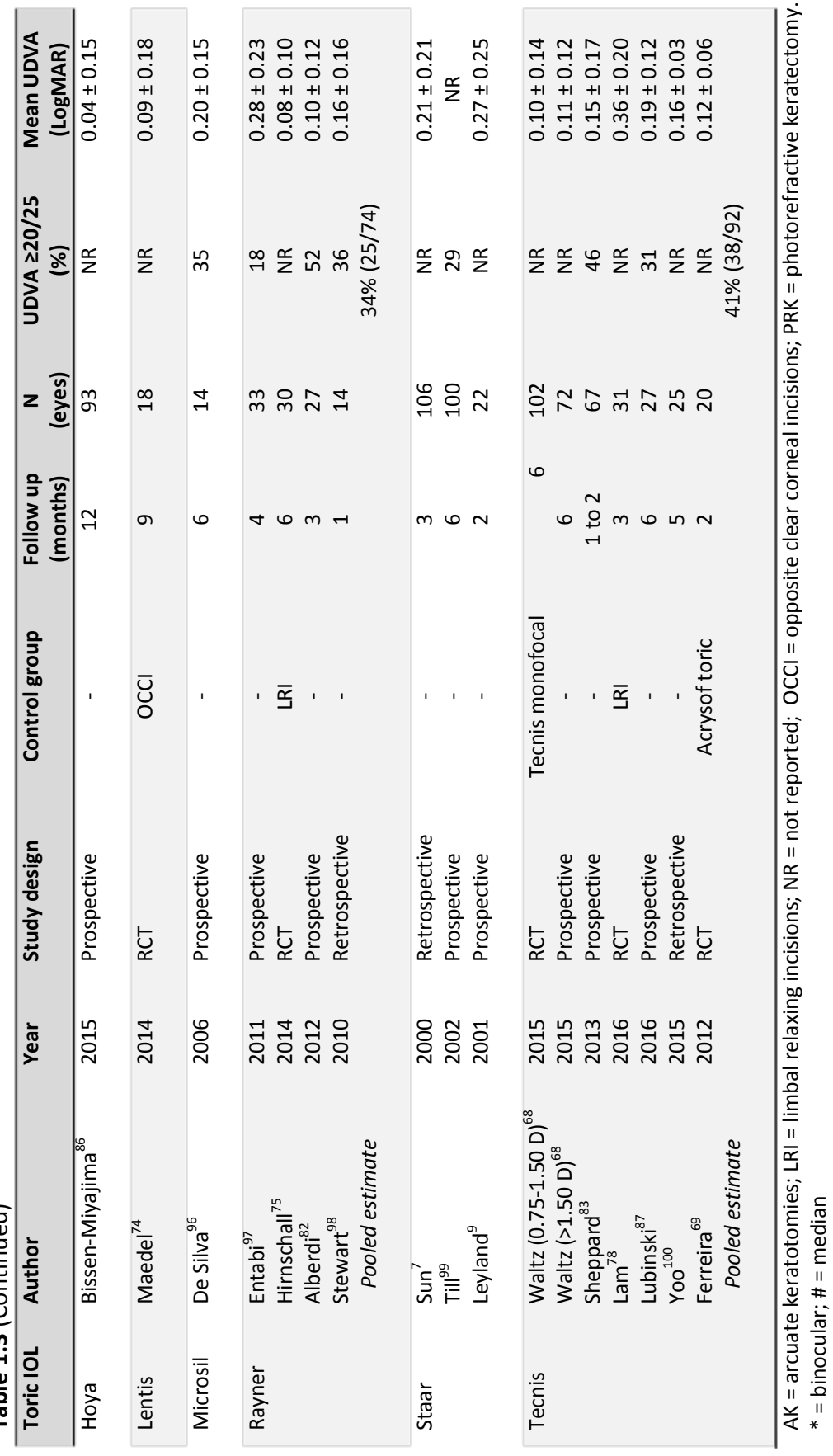


Table 1.4 Literature overview of residual refractive astigmatism following toric IOL implantation

\begin{tabular}{|c|c|c|c|c|c|c|}
\hline \multirow[t]{2}{*}{ Toric IOL } & \multirow[t]{2}{*}{ Author } & \multirow[t]{2}{*}{ Year } & \multirow{2}{*}{$\begin{array}{l}\text { Follow-up } \\
\text { (months) }\end{array}$} & \multirow{2}{*}{$\begin{array}{c}\mathrm{N} \\
\text { (eyes) }\end{array}$} & \multicolumn{2}{|c|}{ Residual refractive astigmatism } \\
\hline & & & & & $\leq 0.5 \mathrm{D}(\%)$ & $\leq 1.0 \mathrm{D}(\%)$ \\
\hline \multirow[t]{18}{*}{ Acrysof } & Holland $^{32}$ & 2010 & 12 & 242 & 53 & 88 \\
\hline & Ahmed $^{29}$ & 2010 & 6 & 164 & 71 & 90 \\
\hline & Ernest $^{47}$ & 2011 & 0.5 to $>6$ & 185 & 92 & 100 \\
\hline & Dardzhikova $^{91}$ & 2009 & 6 & 111 & NR & 94 \\
\hline & Visser $^{66}$ & 2014 & 6 & 82 & 46 & 74 \\
\hline & Poll $^{101}$ & 2011 & 1 & 77 & 77 & 88 \\
\hline & Hayashi $^{89}$ & 2015 & 3 & 66 & 36 & 79 \\
\hline & Visser $^{30}$ & 2011 & 6 & 60 & NR & 81 \\
\hline & Bauer $^{61}$ & 2008 & 4 & 43 & NR & 91 \\
\hline & Lane $^{90}$ & 2009 & 6 & 40 & 60 & 95 \\
\hline & Emesz $(T 3, T 4)^{67}$ & 2015 & 1.5 & 32 & 81 & 96 \\
\hline & Emesz (T5-T9) & 2015 & 1.5 & 22 & 77 & 86 \\
\hline & Nagpal $^{79}$ & 2015 & 6 & 30 & 87 & 100 \\
\hline & $\mathrm{Kim}^{94}$ & 2010 & 13 & 30 & 87 & 100 \\
\hline & Mingo-Botin $^{72}$ & 2010 & 3 & 20 & NR & 90 \\
\hline & Ferreira ${ }^{69}$ & 2012 & 2 & 20 & 85 & 95 \\
\hline & Titiyal $^{73}$ & 2014 & 3 & 17 & NR & 100 \\
\hline & Pooled estimate & & & & $69 \%(659 / 957)$ & $90 \%(1091 / 1208)$ \\
\hline \multirow[t]{3}{*}{ AT Torbi } & Bascaran $^{84}$ & 2013 & 6 & 48 & 95 & 100 \\
\hline & Kretz $^{85}$ & 2015 & 3 & 41 & 86 & 95 \\
\hline & Pooled estimate & & & & $91 \%(81 / 89)$ & $98 \%(87 / 89)$ \\
\hline Hoya & Bissen-Miyajima ${ }^{86}$ & 2015 & 12 & 93 & 53 & 84 \\
\hline Rayner & Hirnschall $^{75}$ & 2014 & 6 & 30 & 52 & 96 \\
\hline \multirow[t]{4}{*}{ Staar } & Till $^{99}$ & 2002 & 6 & 100 & 48 & 75 \\
\hline & Ruhswurm $^{8}$ & 2000 & 20 & 37 & 49 & 78 \\
\hline & Leyland $^{9}$ & 2001 & 2 & 22 & NR & 63 \\
\hline & Pooled estimate & & & & $48 \%(66 / 137)$ & $74 \%(118 / 159)$ \\
\hline \multirow[t]{5}{*}{ Tecnis } & Waltz $(0.75-1.50 \mathrm{D})^{68}$ & 2015 & 6 & 102 & 72 & 94 \\
\hline & Waltz $(>1.50 \mathrm{D})^{68}$ & 2015 & 6 & 72 & 53 & 84 \\
\hline & Sheppard ${ }^{83}$ & 2013 & 1 to 2 & 67 & NR & 95 \\
\hline & Ferreira $^{69}$ & 2012 & 2 & 20 & 75 & 100 \\
\hline & Pooled estimate & & & & $65 \%(125 / 192)$ & $91 \%(236 / 259)$ \\
\hline
\end{tabular}

$\mathrm{NR}=$ not reported 
Table 1.5 Literature overview of misalignment rates following toric IOL implantation

\begin{tabular}{|c|c|c|c|c|c|}
\hline Toric IOL & Author & Year & $\begin{array}{l}\text { Follow-up } \\
\text { (months) }\end{array}$ & $\mathbf{N}$ & $\begin{array}{c}\text { Misalignment } \\
>10 \text { degrees (\%) }\end{array}$ \\
\hline \multirow[t]{22}{*}{ Acrysof } & Miyake $^{80}$ & 2014 & 24 & 378 & $\geq 2$ \\
\hline & Holland $^{32}$ & 2010 & 12 & 243 & 7 \\
\hline & Ahmed $^{29}$ & 2010 & 6 & 217 & 1 \\
\hline & Dardzhikova $^{91}$ & 2009 & 6 & 111 & 5 \\
\hline & Visser $^{66}$ & 2014 & 6 & 82 & 5 \\
\hline & Chang $^{102}$ & 2008 & 1 & 100 & 1 \\
\hline & Roensch $^{92}$ & 2012 & 4 & 79 & 0 \\
\hline & Hayashi $^{89}$ & 2015 & 3 & 66 & 9 \\
\hline & Visser $^{30}$ & 2011 & 6 & 67 & 1 \\
\hline & Bauer $^{61}$ & 2008 & 4 & 53 & 0 \\
\hline & Hoffmann ${ }^{48}$ & 2011 & 3 & 40 & 3 \\
\hline & Goggin $^{103}$ & 2011 & 2 & 38 & 0 \\
\hline & Scialdone $e^{70}$ & 2013 & 3 & 36 & 0 \\
\hline & Emesz $^{67}$ & 2015 & 1.5 & 54 & 0 \\
\hline & Koshy $^{59}$ & 2010 & 6 & 30 & 27 \\
\hline & $\mathrm{Kim}^{94}$ & 2010 & 13 & 30 & 3 \\
\hline & Tsinopoulos $^{95}$ & 2010 & 6 & 29 & 0 \\
\hline & Mingo-Botin $^{72}$ & 2010 & 3 & 20 & 0 \\
\hline & Mendicute $^{71}$ & 2009 & 3 & 20 & 0 \\
\hline & Ferreira ${ }^{69}$ & 2012 & 2 & 20 & 0 \\
\hline & Titiyal $^{73}$ & 2014 & 3 & 17 & 0 \\
\hline & Pooled estimate & & & & $3 \%(49 / 1462)$ \\
\hline \multirow[t]{5}{*}{ AT Torbi } & Bascaran $^{84}$ & 2013 & 6 & 48 & 13 \\
\hline & Kretz $^{85}$ & 2015 & 3 & 41 & 2 \\
\hline & Scialdone $e^{70}$ & 2013 & 3 & 36 & $\geq 3$ \\
\hline & Alio $^{88}$ & 2010 & 3 & 21 & 0 \\
\hline & Pooled estimate & & & & $6 \%(7 / 110)$ \\
\hline Hoya & Bissen-Miyajima $^{86}$ & 2015 & 12 & 93 & 3 \\
\hline Lentis & Maedel $^{74}$ & 2014 & 9 & 18 & 33 \\
\hline \multirow[t]{3}{*}{ Microsil } & Dick $^{62}$ & 2006 & 3 & 68 & 7 \\
\hline & De Silva $^{96}$ & 2006 & 6 & 21 & 10 \\
\hline & Pooled estimate & & & & $8 \%(7 / 89)$ \\
\hline \multirow[t]{4}{*}{ Rayner } & Entabi $^{97}$ & 2011 & 4 & 33 & 9 \\
\hline & Alberdi ${ }^{82}$ & 2012 & 3 & 27 & 7 \\
\hline & Stewart $^{98}$ & 2010 & 1 & 14 & 21 \\
\hline & Pooled estimate & & & & $11 \%(8 / 74)$ \\
\hline \multirow[t]{5}{*}{ Staar } & Sun $^{7}$ & 2000 & 3 & 106 & 33 \\
\hline & Chang $^{102}$ & 2008 & 1 & 90 & 9 \\
\hline & Chang $^{16}$ & 2003 & 1 & 61 & 13 \\
\hline & Leyland $^{9}$ & 2001 & 2 & 22 & 23 \\
\hline & Pooled estimate & & & & $17 \%(48 / 279)$ \\
\hline \multirow[t]{7}{*}{ Tecnis } & Waltz $^{68}$ & 2015 & 6 & 174 & 3 \\
\hline & Sheppard ${ }^{83}$ & 2013 & 1 to 2 & 67 & 1 \\
\hline & $\operatorname{Lam}^{78}$ & 2016 & 3 & 31 & 0 \\
\hline & Lubinski $^{87}$ & 2016 & 6 & 27 & 0 \\
\hline & Yoo $^{100}$ & 2015 & 5 & 25 & 0 \\
\hline & Ferreira $^{69}$ & 2012 & 2 & 20 & 0 \\
\hline & Pooled estimate & & & & $2 \%(6 / 344)$ \\
\hline
\end{tabular}




\section{Aim and outline of this thesis}

The aim of this thesis is to evaluate the safety and efficacy of toric IOLs and to evaluate factors to further improve clinical outcomes with these IOLs.

In Chapters 2 and 3, different technologies to measure astigmatism are compared. In chapter 2, we compare different devices and techniques to measure corneal astigmatism. In Chapter 3, we compare ocular aberrations and corneal aberrations measured with different devices.

In chapter 4, the accuracy of a commonly used 3-step ink-marking method for toric IOL alignment is evaluated.

Chapters 5, 6 and 7 evaluate the clinical use of toric IOLs. Chapter 5 describes the results of a randomized controlled trial comparing spectacle use following bilateral toric versus control IOL implantation. Chapter 6 evaluates the effectiveness of toric IOLs in correcting high amounts of corneal astigmatism. Chapter 7 evaluates the outcomes following toric multifocal IOL implantation.

In chapter 8 the efficacy of astigmatism correction following toric IOL and toric phakic IOL implantation in patients with no previous ocular surgery and in post-keratoplasty eyes is evaluated.

Chapters 9 and 10 describe the use of toric IOLs in special cases. In Chapter 9, toric IOL implantation in cataract surgery was evaluated in patients with irregular corneal astigmatism due to keratoconus. In Chapter 10 we evaluate possible sources for residual astigmatism following toric IOL implantation.

\section{References}

1. Operaties in het ziekenhuis; soort opname, leeftijd en geslacht, 1995-2010: Centraal Bureau voor de Statistiek; 5-2-2014.

2. Henry Y. Cataract Kwaliteitsregistratie. Nederlands Oogheelkundig Gezelschap. Groningen; 2015.

3. Hayashi K, Manabe S, Yoshida M, Hayashi $\mathrm{H}$. Effect of astigmatism on visual acuity in eyes with a diffractive multifocal intraocular lens.
$J$ Cataract Refract Surg. Aug 2010;36(8):1323-1329.

4. Shimizu K, Misawa A, Suzuki Y. Toric intraocular lenses: correcting astigmatism while controlling axis shift. J Cataract Refract Surg. Sep 1994;20(5):523-526.

5. Grabow HB. Early results with foldable toric IOL implantation. Eur J Implant Ref Surg. 1994;6:177-178. 
6. Grabow HB. Toric intraocular lens report. Annals of Ophthalmology. 1997;29(3):161163.

7. Sun $X Y$, Vicary D, Montgomery P, Griffiths $M$. Toric intraocular lenses for correcting astigmatism in 130 eyes. Ophthalmology. Sep 2000;107(9):1776-1781; discussion 1781-1772.

8. Ruhswurm I, Scholz $U$, Zehetmayer $M$, Hanselmayer G, Vass C, Skorpik C. Astigmatism correction with a foldable toric intraocular lens in cataract patients. J Cataract Refract Surg. Jul 2000;26(7):10221027.

9. Leyland $M$, Zinicola $E$, Bloom $P$, Lee $N$. Prospective evaluation of a plate haptic toric intraocular lens. Eye. Apr 2001;15(Pt 2):202205.

10. Linnola RJ, Werner L, Pandey SK, EscobarGomez M, Znoiko SL, Apple DJ. Adhesion of fibronectin, vitronectin, laminin, and collagen type IV to intraocular lens materials in pseudophakic human autopsy eyes. Part 1: histological sections. J Cataract Refract Surg. Dec 2000;26(12):1792-1806.

11. Lombardo M, Carbone G, Lombardo G, De Santo MP, Barberi R. Analysis of intraocular lens surface adhesiveness by atomic force microscopy. J Cataract Refract Surg. Jul 2009;35(7):1266-1272.

12. Oshika T, Nagata T, Ishii Y. Adhesion of lens capsule to intraocular lenses of polymethylmethacrylate, silicone, and acrylic foldable materials: an experimental study. Br J Ophthalmol. May 1998;82(5):549553.

13. Linnola RJ, Sund M, Ylonen R, Pihlajaniemi T. Adhesion of soluble fibronectin, vitronectin, and collagen type IV to intraocular lens materials. J Cataract Refract Surg. Jan 2003;29(1):146-152.

14. Linnola RJ, Werner L, Pandey SK, EscobarGomez M, Znoiko SL, Apple DJ. Adhesion of fibronectin, vitronectin, laminin, and collagen type IV to intraocular lens materials in pseudophakic human autopsy eyes. Part 2: explanted intraocular lenses. J Cataract Refract Surg. Dec 2000;26(12):1807-1818.

15. Patel CK, Ormonde S, Rosen PH, Bron AJ. Postoperative intraocular lens rotation: a randomized comparison of plate and loop haptic implants. Ophthalmology. Nov 1999;106(11):2190-2195; discussion 2196.

16. Chang DF. Early rotational stability of the longer Staar toric intraocular lens: fifty consecutive cases. J Cataract Refract Surg. May 2003;29(5):935-940.

17. Shah GD, Praveen MR, Vasavada AR, Vasavada VA, Rampal G, Shastry LR. Rotational stability of a toric intraocular lens: Influence of axial length and alignment in the capsular bag. J Cataract Refract Surg. Jan 2011;38(1):54-59.

18. Prinz A, Neumayer T, Buehl W, et al. Rotational stability and posterior capsule opacification of a plate-haptic and an openloop-haptic intraocular lens. J Cataract Refract Surg. Feb 2011;37(2):251-257.

19. Belin MW, Khachikian SS. An introduction to understanding elevation-based topography: how elevation data are displayed - a review. Clin Experiment Ophthalmol. Jan 2009;37(1):14-29.

20. Tomidokoro A, Oshika T, Amano S, Higaki S, Maeda N, Miyata K. Changes in anterior and posterior corneal curvatures in keratoconus. Ophthalmology. Jul 2000;107(7):1328-1332.

21. Ambrosio R, Jr., Alonso RS, Luz A, Coca Velarde LG. Corneal-thickness spatial profile and corneal-volume distribution: tomographic indices to detect keratoconus. J Cataract Refract Surg. Nov 2006;32(11):1851-1859.

22. Visser N, Gast ST, Bauer NJ, Nuijts RM. Cataract surgery with toric intraocular lens implantation in keratoconus: a case report. Cornea. Jun 2011;30(6):720-723.

23. Luck J. Customized ultra-high-power toric intraocular lens implantation for pellucid marginal degeneration and cataract. J Cataract Refract Surg. Jul 2010;36(7):12351238.

24. Kersey JP, O'Donnell A, Illingworth CD. Cataract surgery with toric intraocular lenses can optimize uncorrected postoperative visual acuity in patients with marked corneal astigmatism. Cornea. Feb 2007;26(2):133-135.

25. Stewart CM, McAlister JC. Comparison of grafted and non-grafted patients with corneal astigmatism undergoing cataract extraction with a toric intraocular lens implant. Clin Experiment Ophthalmol. May 24 2010;38(8):747-757.

26. Goggin $M$, Alpins N, Schmid LM. Management of irregular astigmatism. Curr Opin Ophthalmol. Aug 2000;11(4):260-266.

27. Assil KK, Christian WK, Aker AB, Dell SJ, Chang DF, Packer M. Patient Selection and Education. In: Chang DF, ed. Mastering Refractive IOLs: The Art and Science. 
Thorofare, USA: SLACK Incorporated; 2008:331-431.

28. Kohnen T, Kook D, Auffarth GU, Derhartunian V. [Use of multifocal intraocular lenses and criteria for patient selection]. Ophthalmologe. Jun 2008;105(6):527-532.

29. Ahmed I, Rocha G, Slomovic AR, et al. Visual function and patient experience after bilateral implantation of toric intraocular lenses. J Cataract Refract Surg. Apr 2010;36(4):609-616.

30. Visser N, Ruiz-Mesa R, Pastor F, Bauer NJ, Nuijts RM, Montes-Mico R. Cataract surgery with toric intraocular lens implantation in patients with high corneal astigmatism. J Cataract Refract Surg. Aug 2011;37(8):14031410.

31. Gayton JL, Seabolt RA. Clinical Outcomes of Complex and Uncomplicated Cataractous Eyes After Lens Replacement with the AcrySof Toric IOL. J Refract Surg. Apr 14 2010;14:1-7.

32. Holland E, Lane S, Horn JD, Ernest P, Arleo R, Miller KM. The AcrySof Toric Intraocular Lens in Subjects with Cataracts and Corneal Astigmatism A Randomized, SubjectMasked, Parallel-Group, 1-Year Study. Ophthalmology. Sep 14 2010;117(11):21042111.

33. Pouyeh B, Galor A, Junk AK, et al. Surgical and refractive outcomes of cataract surgery with toric intraocular lens implantation at a resident-teaching institution. I Cataract Refract Surg. Sep 2011;37(9):1623-1628.

34. Santodomingo-Rubido J, Mallen EA, Gilmartin B, Wolffsohn JS. A new noncontact optical device for ocular biometry. Br J Ophthalmol. Apr 2002;86(4):458-462.

35. Shirayama M, Wang L, Weikert MP, Koch DD. Comparison of corneal powers obtained from 4 different devices. Am J Ophthalmol. Oct 2009;148(4):528-535 e521.

36. Hill W, Osher R, Cooke D, et al. Simulation of toric intraocular lens results: Manual keratometry versus dual-zone automated keratometry from an integrated biometer. J Cataract Refract Surg. Dec 2011 ;37(12):2181-2187.

37. Visser N, Berendschot TTJM, Verbakel F, Brabander de J, Nuijts RMMA. Comparability and repeatability of corneal astigmatism measurements using different measurement technologies J Cataract Refract Surg. 2012;38(38):1764-1770.
38. Symes RJ, Ursell PG. Automated keratometry in routine cataract surgery: comparison of Scheimpflug and conventional values. J Cataract Refract Surg. Feb 2011;37(2):295-301.

39. Tejedor J, Murube J. Choosing the location of corneal incision based on preexisting astigmatism in phacoemulsification. $\mathrm{Am} \mathrm{J}$ Ophthalmol. May 2005;139(5):767-776.

40. Borasio E, Mehta JS, Maurino V. Surgically induced astigmatism after phacoemulsification in eyes with mild to moderate corneal astigmatism: temporal versus on-axis clear corneal incisions. J Cataract Refract Surg. Apr 2006;32(4):565572.

41. Kohnen T, Dick B, Jacobi KW. Comparison of the induced astigmatism after temporal clear corneal tunnel incisions of different sizes. J Cataract Refract Surg. Jul 1995;21(4):417-424.

42. Oshika T, Nagahara K, Yaguchi S, et al. Three year prospective, randomized evaluation of intraocular lens implantation through 3.2 and $5.5 \mathrm{~mm}$ incisions. J Cataract Refract Surg. Apr 1998;24(4):509-514.

43. Masket S, Wang L, Belani S. Induced astigmatism with 2.2 - and $3.0-\mathrm{mm}$ coaxial phacoemulsification incisions. J Refract Surg. Jan 2009;25(1):21-24.

44. Lyhne N, Corydon L. Two year follow-up of astigmatism after phacoemulsification with adjusted and unadjusted sutured versus sutureless $5.2 \mathrm{~mm}$ superior scleral incisions. J Cataract Refract Surg. Dec 1998;24(12):1647-1651.

45. Storr-Paulsen A, Madsen H, Perriard A. Possible factors modifying the surgically induced astigmatism in cataract surgery. Acta Ophthalmol Scand. Oct 1999;77(5):548551.

46. Lee KM, Kwon HG, Joo CK. Microcoaxial cataract surgery outcomes: comparison of $1.8 \mathrm{~mm}$ system and $2.2 \mathrm{~mm}$ system. J Cataract Refract Surg. May 2009;35(5):874880.

47. Ernest P, Potvin R. Effects of preoperative corneal astigmatism orientation on results with a low-cylinder-power toric intraocular lens. J Cataract Refract Surg. Apr 2011;37(4):727-732.

48. Hoffmann PC, Auel S, Hutz WW. Results of higher power toric intraocular lens implantation. J Cataract Refract Surg. Aug 2011;37(8):1411-1418. 
49. Wang J, Zhang EK, Fan WY, Ma JX, Zhao PF. The effect of micro-incision and smallincision coaxial phaco-emulsification on corneal astigmatism. Clin Experiment Ophthalmol. Sep 2009;37(7):664-669.

50. Goggin M, Patel I, Billing K, Esterman A. Variation in surgically induced astigmatism estimation due to test-to-test variations in keratometry. J Cataract Refract Surg. Oct 2010;36(10):1792-1793.

51. Langenbucher A, Viestenz A, Szentmary N, Behrens-Baumann W. Toric intraocular lenses--theory, matrix calculations, and clinical practice. J Refract Surg. Jul 2009;25(7):611-622.

52. Novis C. Astigmatism and the toric intraocular lens and other vertex distance effects. Surv Ophthalmol. Nov-Dec 1997;42(3):268-270.

53. Goggin M, Moore S, Esterman A. Outcome of toric intraocular lens implantation after adjusting for anterior chamber depth and intraocular lens sphere equivalent power effects. Arch Ophthalmol. Aug 2011;129(8):998-1003.

54. Barrett GD. Barrett Toric Calculator. www.ascrs.org/barrett-toric-calculator. Accessed 20-5-2016.

55. Chang J. Cyclotorsion during laser in situ keratomileusis. J Cataract Refract Surg. Oct 2008;34(10):1720-1726.

56. Arba-Mosquera S, Merayo-Lloves J, de Ortueta D. Clinical effects of pure cyclotorsional errors during refractive surgery. Invest Ophthalmol Vis Sci. Nov 2008;49(11):4828-4836.

57. Febbraro JL, Koch DD, Khan HN, Saad A, Gatinel D. Detection of static cyclotorsion and compensation for dynamic cyclotorsion in laser in situ keratomileusis. J Cataract Refract Surg. Oct 2010;36(10):1718-1723.

58. Mendicute J, Irigoyen C, Aramberri J, Ondarra A, Montes-Mico R. Foldable toric intraocular lens for astigmatism correction in cataract patients. J Cataract Refract Surg. Apr 2008;34(4):601-607.

59. Koshy JJ, Nishi $\mathrm{Y}$, Hirnschall $\mathrm{N}$, et al. Rotational stability of a single-piece toric acrylic intraocular lens. J Cataract Refract Surg. Oct 2010;36(10):1665-1670.

60. Alio JL, Pinero DP, Tomas J, Aleson A. Vector analysis of astigmatic changes after cataract surgery with toric intraocular lens implantation. J Cataract Refract Surg. Jun 2011;37(6):1038-1049.
61. Bauer NJ, de Vries NE, Webers CA, Hendrikse F, Nuijts RM. Astigmatism management in cataract surgery with the AcrySof toric intraocular lens. I Cataract Refract Surg. Sep 2008;34(9):1483-1488.

62. Dick HB, Krummenauer F, Trober L. [Compensation of corneal astigmatism with toric intraocular lens: results of a multicentre study]. Klin Monatsbl Augenheilkd. Jul 2006;223(7):593-608.

63. Zuberbuhler B, Signer T, Gale R, Haefliger E. Rotational stability of the AcrySof SA60TT toric intraocular lenses: a cohort study. $B M C$ Ophthalmol. 2008;8:8.

64. Tassignon MJ, Gobin L, Mathysen D, Van Looveren J. Clinical results after spherotoric intraocular lens implantation using the bagin-the-lens technique. J Cataract Refract Surg. May 2011;37(5):830-834.

65. Zhang JS, Zhao JY, Sun Q, Ma LW. Distance vision after bilateral implantation of AcrySof toric intraocular lenses: a randomized, controlled, prospective trial. Int $J$ Ophthalmol. 2011;4(2):175-178.

66. Visser N, Beckers HJ, Bauer NJ, et al. Toric vs Aspherical Control Intraocular Lenses in Patients With Cataract and Corneal Astigmatism: A Randomized Clinical Trial. JAMA Ophthalmol. Dec 1 2014;132(12):1462-1468.

67. Emesz M, Dexl AK, Krall EM, et al. Randomized controlled clinical trial to evaluate different intraocular lenses for the surgical compensation of low to moderateto-high regular corneal astigmatism during cataract surgery. J Cataract Refract Surg. Dec 2015;41(12):2683-2694.

68. Waltz KL, Featherstone K, Tsai L, Trentacost D. Clinical outcomes of TECNIS toric intraocular lens implantation after cataract removal in patients with corneal astigmatism. Ophthalmology. Jan 2015;122(1):39-47.

69. Ferreira TB, Almeida A. Comparison of the visual outcomes and OPD-scan results of AMO Tecnis toric and Alcon Acrysof IQ toric intraocular lenses. J Refract Surg. Aug 2012;28(8):551-555.

70. Scialdone A, De Gaetano F, Monaco G. Visual performance of 2 aspheric toric intraocular lenses: comparative study. $J$ Cataract Refract Surg. Jun 2013;39(6):906914.

71. Mendicute J, Irigoyen C, Ruiz M, Illarramendi I, Ferrer-Blasco T, Montes-Mico R. Toric intraocular lens versus opposite clear 
corneal incisions to correct astigmatism in eyes having cataract surgery. J Cataract Refract Surg. Mar 2009;35(3):451-458.

72. Mingo-Botin D, Munoz-Negrete FJ, Won Kim HR, Morcillo-Laiz R, Rebolleda G, Oblanca N. Comparison of toric intraocular lenses and peripheral corneal relaxing incisions to treat astigmatism during cataract surgery. J Cataract Refract Surg. Oct 2010;36(10):1700-1708.

73. Titiyal JS, Khatik M, Sharma N, et al. Toric intraocular lens implantation versus astigmatic keratotomy to correct astigmatism during phacoemulsification. J Cataract Refract Surg. May 2014;40(5):741747.

74. Maedel S, Hirnschall N, Chen YA, Findl O. Rotational performance and corneal astigmatism correction during cataract surgery: aspheric toric intraocular lens versus aspheric nontoric intraocular lens with opposite clear corneal incision. J Cataract Refract Surg. Aug 2014;40(8):13551362.

75. Hirnschall N, Gangwani V, Crnej A, Koshy J, Maurino V, Findl O. Correction of moderate corneal astigmatism during cataract surgery: toric intraocular lens versus peripheral corneal relaxing incisions. J Cataract Refract Surg. Mar 2014;40(3):354-361.

76. Freitas GO, Boteon JE, Carvalho MJ, Pinto RM. Treatment of astigmatism during phacoemulsification. Arq Bras Oftalmol. JanFeb 2014;77(1):40-46.

77. Leon P, Pastore MR, Zanei A, et al. Correction of low corneal astigmatism in cataract surgery. Int J Ophthalmol. 2015;8(4):719-724.

78. Lam DK, Chow VW, Ye C, Ng PK, Wang Z, Jhanji V. Comparative evaluation of aspheric toric intraocular lens implantation and limbal relaxing incisions in eyes with cataracts and $</=3$ dioptres of astigmatism. Br J Ophthalmol. Feb 2016;100(2):258-262.

79. Nagpal R, Sharma N, Vasavada V, et al. Toric intraocular lens versus monofocal intraocular lens implantation and photorefractive keratectomy: a randomized controlled trial. Am J Ophthalmol. Sep 2015;160(3):479-486 e472.

80. Miyake T, Kamiya K, Amano R, lida Y, Tsunehiro S, Shimizu K. Long-term clinical outcomes of toric intraocular lens implantation in cataract cases with preexisting astigmatism. J Cataract Refract Surg. Oct 2014;40(10):1654-1660.
81. Kessel L, Andresen J, Tendal B, Erngaard D, Flesner P, Hjortdal J. Toric Intraocular Lenses in the Correction of Astigmatism During Cataract Surgery: A Systematic Review and Meta-analysis. Ophthalmology. Feb 2016;123(2):275-286.

82. Alberdi T, Macias-Murelaga B, Bascaran L, Goni N, de Arregui SS, Mendicute J. Rotational stability and visual quality in eyes with Rayner toric intraocular lens implantation. J Refract Surg. Oct 2012;28(10):696-701.

83. Sheppard AL, Wolffsohn JS, Bhatt U, et al. Clinical outcomes after implantation of a new hydrophobic acrylic toric IOL during routine cataract surgery. J Cataract Refract Surg. Jan 2013;39(1):41-47.

84. Bascaran L, Mendicute J, Macias-Murelaga $\mathrm{B}$, Arbelaitz N, Martinez-Soroa I. Efficacy and stability of AT TORBI 709 M toric IOL. J Refract Surg. Mar 2013;29(3):194-199.

85. Kretz FT, Breyer D, Klabe K, Auffarth GU, Kaymak H. Clinical Outcomes and Capsular Bag Stability of a Four-Point Haptic Bitoric Intraocular Lens. J Refract Surg. Jul 2015;31(7):431-436.

86. Bissen-Miyajima H, Negishi K, Hieda O, Kinoshita S. Microincision Hydrophobic Acrylic Aspheric Toric Intraocular Lens for Astigmatism and Cataract Correction. J Refract Surg. Jun 2015;31(6):358-364.

87. Lubinski W, Kazmierczak B, GronkowskaSerafin J, Podboraczynska-Jodko K. Clinical Outcomes after Uncomplicated Cataract Surgery with Implantation of the Tecnis Toric Intraocular Lens. J Ophthalmol. 2016;2016:3257217.

88. Alio JL, Agdeppa MC, Pongo VC, El Kady B. Microincision cataract surgery with toric intraocular lens implantation for correcting moderate and high astigmatism: pilot study. J Cataract Refract Surg. Jan 2010;36(1):4452.

89. Hayashi K, Masumoto M, Takimoto $M$. Comparison of visual and refractive outcomes after bilateral implantation of toric intraocular lenses with or without a multifocal component. J Cataract Refract Surg. Jan 2015;41(1):73-83.

90. Lane SS, Ernest P, Miller KM, Hileman KS, Harris B, Waycaster CR. Comparison of clinical and patient-reported outcomes with bilateral AcrySof toric or spherical control intraocular lenses. J Refract Surg. Oct 2009;25(10):899-901. 
91. Dardzhikova A, Shah CR, Gimbel HV. Early experience with the AcrySof toric IOL for the correction of astigmatism in cataract surgery. Can J Ophthalmol. Jun 2009;44(3):269-273.

92. Roensch MA, Charton JW, Blomquist $\mathrm{PH}$, Aggarwal NK, McCulley JP. Resident experience with toric and multifocal intraocular lenses in a public county hospital system. J Cataract Refract Surg. Mar 15 2012;38(5):730-731.

93. Mencucci R, Giordano C, Favuzza E, Gicquel JJ, Spadea L, Menchini U. Astigmatism correction with toric intraocular lenses: wavefront aberrometry and quality of life. Br J Ophthalmol. May 2013;97(5):578-582.

94. Kim MH, Chung TY, Chung ES. Long-term efficacy and rotational stability of AcrySof toric intraocular lens implantation in cataract surgery. Korean J Ophthalmol. Aug 2010;24(4):207-212.

95. Tsinopoulos IT, Tsaousis KT, Tsakpinis D, Ziakas NG, Dimitrakos SA. Acrylic toric intraocular lens implantation: a single center experience concerning clinical outcomes and postoperative rotation. Clin Ophthalmol. 2010;4:137-142.

96. De Silva DJ, Ramkissoon YD, Bloom PA. Evaluation of a toric intraocular lens with a Z-haptic. J Cataract Refract Surg. Sep 2006;32(9):1492-1498.

97. Entabi M, Harman F, Lee N, Bloom PA. Injectable 1-piece hydrophilic acrylic toric intraocular lens for cataract surgery: Efficacy and stability. J Cataract Refract Surg. Feb 2011;37(2):235-240.

98. Stewart CM, McAlister JC. Comparison of grafted and non-grafted patients with corneal astigmatism undergoing cataract extraction with a toric intraocular lens implant. Clin Experiment Ophthalmol. Nov 2010;38(8):747-757.

99. Till JS, Yoder PR, Jr., Wilcox TK, Spielman JL. Toric intraocular lens implantation: 100 consecutive cases. J Cataract Refract Surg. Feb 2002;28(2):295-301.

100. Yoo A, Yun S, Kim JY, Kim MJ, Tchah H. Femtosecond Laser-assisted Arcuate Keratotomy Versus Toric IOL Implantation for Correcting Astigmatism. J Refract Surg. Sep 2015;31(9):574-578.

101.Poll JT, Wang L, Koch DD, Weikert MP. Correction of astigmatism during cataract surgery: toric intraocular lens compared to peripheral corneal relaxing incisions. $J$ Refract Surg. Mar 2011;27(3):165-171.

102.Chang DF. Comparative rotational stability of single-piece open-loop acrylic and platehaptic silicone toric intraocular lenses. J Cataract Refract Surg. Nov 2008;34(11):1842-1847.

103.Goggin M, Moore S, Esterman A. Toric Intraocular Lens Outcome Using the Manufacturer's Prediction of Corneal Plane Equivalent Intraocular Lens Cylinder Power. Arch Ophthalmol. Aug 2011;129(8):10041008. 


\section{Chapter 2}

\section{Comparability and repeatability of corneal astigmatism measurements using different measurement technologies}

Nienke Visser, Tos T.J.M. Berendschot, Frenne Verbakel, John de Brabander and Rudy M.M.A. Nuijts Journal of Cataract \& Refractive Surgery 2012; 38: 1764-1770 


\section{Abstract}

PURPOSE: To determine the comparability and repeatability of corneal astigmatism measurements obtained with different devices and to determine the interobserver variability of a new automated keratometer.

Setring: University Eye Clinic, Maastricht University Medical Centre, the Netherlands.

METHODS: Thirty healthy subjects underwent examination of the right eye with 6 devices: IOLMaster (Carl Zeiss Meditec; automated keratometry), Lenstar (Haag-Streit; automated keratometry), Reference Unit (Sensomotoric Instruments; automated keratometry), Javal (Rodenstock; manual keratometry), KR-1W (Topcon; corneal topography) and Pentacam (Oculus; Scheimpflug imaging). An experienced operator obtained 3 repeated measurements per eye. An inexperienced operator obtained 3 additional measurements with the SMI Reference Unit. Astigmatism vector analysis was used to determine the comparability, repeatability and interobserver variability.

RESULTS: Corneal astigmatism vectors measured by automated, manual or simulated keratometry were comparable, except for the Pentacam equivalent $K(p<0.001$, repeated-measures ANOVA). Mean differences between equivalent $K$ and other keratometry values were 0.18 to $0.29 \mathrm{D}$ ( $p<0.05$, Hotelling Trace MANOVA). Mean differences between automated, manual and simulated keratometry were small $(\leq 0.12$ D). The within-subject standard deviation ranged from 0.05 D @ 21 degrees (KR-1W) to 0.18 D @ 23 degrees (Lenstar). The SMI Reference Unit showed small mean differences and a comparable repeatability between experienced and inexperienced operators.

CONCLUSION: Vector analysis showed comparable corneal astigmatism measurements using automated, manual or simulated keratometry. Pentacam equivalent $\mathrm{K}$ values were not comparable to those of the other keratometers. The repeatability of astigmatism magnitudes was acceptable; however the repeatability of astigmatism meridians was moderate. The SMI Reference Unit showed good interobserver variability. 


\section{Introduction}

Toric intraocular lenses (IOLs) are increasingly used in cataract and refractive surgery. Several factors influence the success that may be achieved with toric IOLs, such as accurate placement of the IOL during surgery and rotational stability of the IOL postoperatively. ${ }^{1,2}$ In addition, in order to achieve an effective astigmatism correction, accurate keratometry measurements must be obtained preoperatively. Several studies have been performed to compare corneal astigmatism measurements obtained with different keratometers ${ }^{3-5}$, Placido-disk videokeratoscopes ${ }^{6-8}$ and Scheimpflug imaging ${ }^{6,}$ 8,9 . However, these studies generally only compared astigmatism magnitudes with no regards of the astigmatism meridian. Since astigmatism is a vector with a magnitude and a direction, a vector analysis is required to compare astigmatism data. ${ }^{10,11}$

The purpose of this study was to use an astigmatism vector analysis to determine the comparability and repeatability of corneal astigmatism measurements obtained with different devices (automated keratometry, manual keratometry, corneal topography and Scheimpflug imaging). In addition, the interobserver variability of a new automated keratometer (SMI Reference Unit, Sensomotoric Instruments) was evaluated.

\section{Methods}

In this prospective cohort study, healthy volunteers were recruited from Maastricht University and the University Eye Clinic Maastricht. Informed consent was obtained from all subjects after the nature of the experiment had been explained. The tenets of the Declaration of Helsinki were followed and investigational review board approval was obtained.

Exclusion criteria were a history of ocular pathology or ocular surgery. All subjects underwent measurement of the right eye with six devices. Three repeated measurements were obtained by an experienced operator while the subject remained seated and positioned in a chin- and forehead rest. Subjects were instructed to fixate at the fixation target of the device and asked to blink prior to each measurement. An inexperienced operator obtained 3 additional repeated measurements with the SMI Reference Unit. An experienced operator was defined as a person who had performed a minimum of 25 measurements with the particular device. An inexperienced operator was a medical student with basic knowledge of ophthalmology and no previous experience with the SMI Reference Unit. They received an oral instruction and 
demonstration, and were supervised to ensure that 3 good quality measurements were obtained.

\section{Devices}

The IOLMaster (Carl Zeiss Meditec) uses automated keratometry to measure the anterior corneal curvature. Six spots of light are projected onto the cornea in a hexagonal pattern within a $2.3 \mathrm{~mm}$ diameter. A refractive index of 1.3375 is used to convert the anterior radius of curvature $(\mathrm{mm})$ into corneal power in diopters (D).

The Lenstar (Haag-Streit) measures the anterior corneal curvature using automated keratometry. Thirty-two light spots, divided into 2 rings with a diameter of $1.65 \mathrm{~mm}$ and $2.30 \mathrm{~mm}$, are projected onto the cornea. The index of refraction is 1.3320 .

The Surgery Guidance platform (Sensomotoric Instruments) consists of 2 units: the SMI Reference Unit, which is used to measure the patient preoperatively, and the SMI Surgery Pilot, which is used to align the toric IOL during surgery. In this study, only the SMI Reference Unit was evaluated. This non-contact device acquires a digital image of the eye and simultaneously performs automated keratometry. Corneal curvature is measured using the optical reflections of 12 light emission diodes arranged in a ring with a diameter of $1.9 \mathrm{~mm}$. This device uses a refractive index of 1.3320 .

The Javal-Schiötz keratometer (Rodenstock) is a manual keratometer that requires subjective alignment of 2 keratometer mires (a red square and a green staircase) along the principal meridians of the cornea. The refractive power of the cornea is determined using the reflections from these illuminated mires from the central $3.4 \mathrm{~mm}$ of the cornea, using an index of a refraction of 1.3375 .

The KR-1W Wavefront Analyzer (Topcon) is a combined wavefront analyzer and corneal topographer. Placido-disk videokeratoscopy is performed using the optical reflections of 19 illuminated rings on the anterior surface of the cornea. Simulated keratometry is calculated based on the central $3.0 \mathrm{~mm}$ of the cornea, using a refractive index of 1.3375 .

The Pentacam (Oculus Optikgeräte; software version 1.17r120) consists of a rotating Scheimpflug camera, which allows measurement of both the anterior and posterior corneal radius. To compare Pentacam measurements to those of other devices simulated keratometry values were used; these values are based on measurement of the anterior central $3.0 \mathrm{~mm}$ zone of the cornea. A refractive index of 1.3375 is used to calculate the corneal power. In addition, the equivalent $\mathrm{K}$ of the $3.0 \mathrm{~mm}$ zone was used; this value is based on both the anterior and posterior corneal curvatures. This parameter uses correct refractive indices to calculate the anterior and posterior 
corneal powers (1.376 for cornea; 1.336 for aqueous) and also adjusts for the error that standard keratometry creates regarding the anterior to posterior corneal ratio.

\section{Sample size}

A sample size calculation was performed using an $\alpha$ of 0.007 ( 0.05 divided by 7 parameters) and a power of $90 \%$. A mean difference of $0.25 \mathrm{D}$ was considered to be clinically relevant. In a pilot study, the mean measurement error was of $0.30 \mathrm{D}$ for automated keratometry. This resulted in a minimal calculated sample size of 22.

\section{Data analysis}

For all devices the corneal powers were calculated using the same refractive index of 1.3320. Equivalent $\mathrm{K}$ values are not calculated using a refractive index of 1.3375 or 1.3320 and these values have not been recalculated. Corneal astigmatism data were analyzed using a vector analysis. Individual astigmatism magnitude (D) and meridian (degrees) values were transformed into Cartesian coordinates ( $x$ and $y$ ) according to the method described by Holladay et al. ${ }^{10}$ These Cartesian coordinates may be used in mathematical and statistical calculations. ${ }^{11}$ After the calculations were finished, the Cartesian coordinates were transformed back to the standard notation for corneal astigmatism (D@ meridian).

All data were collected in a database (Excel; Microsoft Office 2003; Microsoft Inc.) and transferred to SPSS (Version 16.0, SPSS Inc.) for data analysis. The Cartesian coordinates ( $x$ and $y$ ) showed a normal distribution ( $p>0.05$, Kolmogorov Smirnov). A one-way repeated-measures analysis of variance (ANOVA) with Bonferroni correction was used to compare astigmatism vectors ( $x$ and $y$ coordinates) between devices. Mean differences in measurements were calculated and evaluated for statistical significance using a Hotelling Trace multivariate analysis of variance (MANOVA; significant difference from zero). According to Bland and Altman, the repeatability of devices was determined by calculating the within-subject standard deviation within each series of three repeated measurements per eye $\left(s_{w}\right) .{ }^{12}$ The repeatability between devices was compared using a repeated-measures ANOVA. Finally, the interobserver repeatability of the SMI Reference Unit was determined by comparing mean astigmatism vectors (repeated-measures ANOVA), mean difference (Hotelling Trace MANOVA), and $S_{w}$ (Hotelling Trace MANOVA) of measurements obtained by experienced and inexperienced operators. $\mathrm{P}<0.05$ was considered to be statistically significant. 


\section{Results}

Thirty healthy volunteers (19 female and 11 male) with a mean age of $26.6 \pm 9.0$ years (range 20 to 64 years) were included.

\section{Comparability}

Table 2.1 shows the vector mean of corneal astigmatism measurements obtained with the devices. Significantly lower astigmatism values were measured with the Pentacam equivalent K, compared to all other devices ( $p<0.001$, repeated-measures ANOVA). Automated, manual and simulated $K$ values were comparable $(p>0.05$, repeatedmeasures ANOVA).

Table 2.2 shows the mean magnitudes of differences in corneal astigmatism vectors between devices. Mean difference between the Pentacam equivalent $\mathrm{K}$ and other $\mathrm{K}$ values ranged from $0.18 \pm 0.27 \mathrm{D}$ to $0.29 \pm 0.31 \mathrm{D}$ in magnitude and were significantly different from zero $(p<0.001$, Hotelling Trace MANOVA). In addition, the mean difference between the SMI Reference Unit and KR-1W (0.11 \pm 0.19 D) was significantly different from zero ( $p=0.030$, Hotelling Trace MANOVA). Other mean differences ranged from $0.00 \pm 0.23 \mathrm{D}$ (SMI Reference Unit versus Javal) to $0.12 \pm 0.26$ D (SMI Reference Unit versus Pentacam simulated K), and were not significantly different from zero ( $p>0.05$, Hotelling Trace MANOVA).

\section{Repeatability}

Table 2.1 shows the repeatability. A smaller $s_{w}$ indicates a better repeatability. The $s_{w}$ of the KR-1W was significantly lower compared to all other devices. The $s_{w}$ ranged from $0.05 \pm 0.04 \mathrm{D} @ 21 \pm 12$ degrees (KR-1W) to $0.18 \pm 0.12 \mathrm{D} @ 23 \pm 11$ degrees (Lenstar).

\section{Refractive index}

Table 2.3 shows the mean differences between corneal powers calculated with a refractive index of 1.3320 and 1.3375 . For all devices, this mean difference was $0.01 \pm$ $0.01 \mathrm{D}$ in magnitude ( $\mathrm{p}<0.005$ compared to zero; Hotelling Trace MANOVA).

Interobserver variability of the SMI Reference Unit

The astigmatism vector mean of measurements obtained by experienced and inexperienced operators was $0.54 \pm 0.58 \mathrm{D} @ 90 \pm 28$ degrees and $0.50 \pm 0.58 \mathrm{D} @ 90$ \pm 30 degrees, respectively, which was not significantly different $(p=0.377$, repeatedmeasures ANOVA). Mean difference between these measurements was $0.04 \pm 0.15 \mathrm{D}$ 
( $p=0.139$ compared to zero, Hotelling Trace MANOVA). Finally, the $s_{w}$ of measurements obtained by experienced and inexperienced operators was comparable: $0.14 \pm 0.08 \mathrm{D}$ versus $0.21 \pm 0.14 D$, respectively ( $p=0.062$, Hotelling Trace MANOVA).

\section{Discussion}

The purpose of this study was to compare corneal astigmatism measurements obtained by automated keratometry, manual keratometry, corneal topography and Scheimpflug imaging. This comparison was done using a vector analysis which accounts for both astigmatism magnitude and astigmatism meridian. As described by Holladay et al. and Alpins, astigmatism is a vector with a magnitude and a direction. ${ }^{10,11}$ A vector analysis is therefore required to compare astigmatism data. We compared devices that have been reported to be most commonly used in toric IOL power calculations: automated keratometry $^{13,14}$, manual keratometry ${ }^{13,15}$, corneal topography ${ }^{16}$ and Scheimpflug imaging ${ }^{17,18}$.

Anterior corneal curvature in this study is measured using different techniques and different measurement zones of the anterior cornea. The SMI Reference Unit uses the smallest measurement zone $(1.9 \mathrm{~mm})$, followed by the IOLMaster and Lenstar (both $2.3 \mathrm{~mm}$ ), the KR-1W and Pentacam (both $3.0 \mathrm{~mm}$ ) and finally the Javal $(3.4 \mathrm{~mm}$ ). Because the normal cornea is aspheric, the central cornea is steeper than the peripheral cornea. In theory, these different measurement zones may lead to differences in the measurement of corneal power. In our study, mean differences between devices that measure the anterior corneal power were relatively small $(\leq 0.12$ $D$ in magnitude), and we believe that they are not clinically relevant.

Few studies have used a vector analysis to compare corneal astigmatism measurements between devices. Santodomingo-Rubido et al. compared mean differences in corneal curvature measurements between the IOLMaster, Javal and a corneal topographer using a spherocylindrical power vector analysis according to Thibos and Horner. ${ }^{19,} 20$ Mean differences between the IOLMaster and Javal (J0: 0.00 $\mathrm{mm}$ and J45: $0.01 \mathrm{~mm}$ ) were found to be comparable to mean difference between the IOLMaster and corneal topographer (J0: $0.01 \mathrm{~mm}$ and J45: $0.03 \mathrm{~mm}$ ).

Read et al. also used power vectors according to Thibos and Horner to analyse corneal astigmatism measurements obtained with the Pentacam and a corneal topographer. ${ }^{21}$ Mean differences between both devices were found to be small: $-0.04 \mathrm{D}$ for J0 and $0.03 \mathrm{D}$ for $\mathrm{J45}$. In addition, Kobashi et al. compared autokeratometry and corneal topography and found comparable power vectors and a small mean difference of 0.01 $\mathrm{D}$ for both $\mathrm{J} 0$ and $\mathrm{J45} .^{22}$ Finally, Shirayama et al. found no significant differences in 


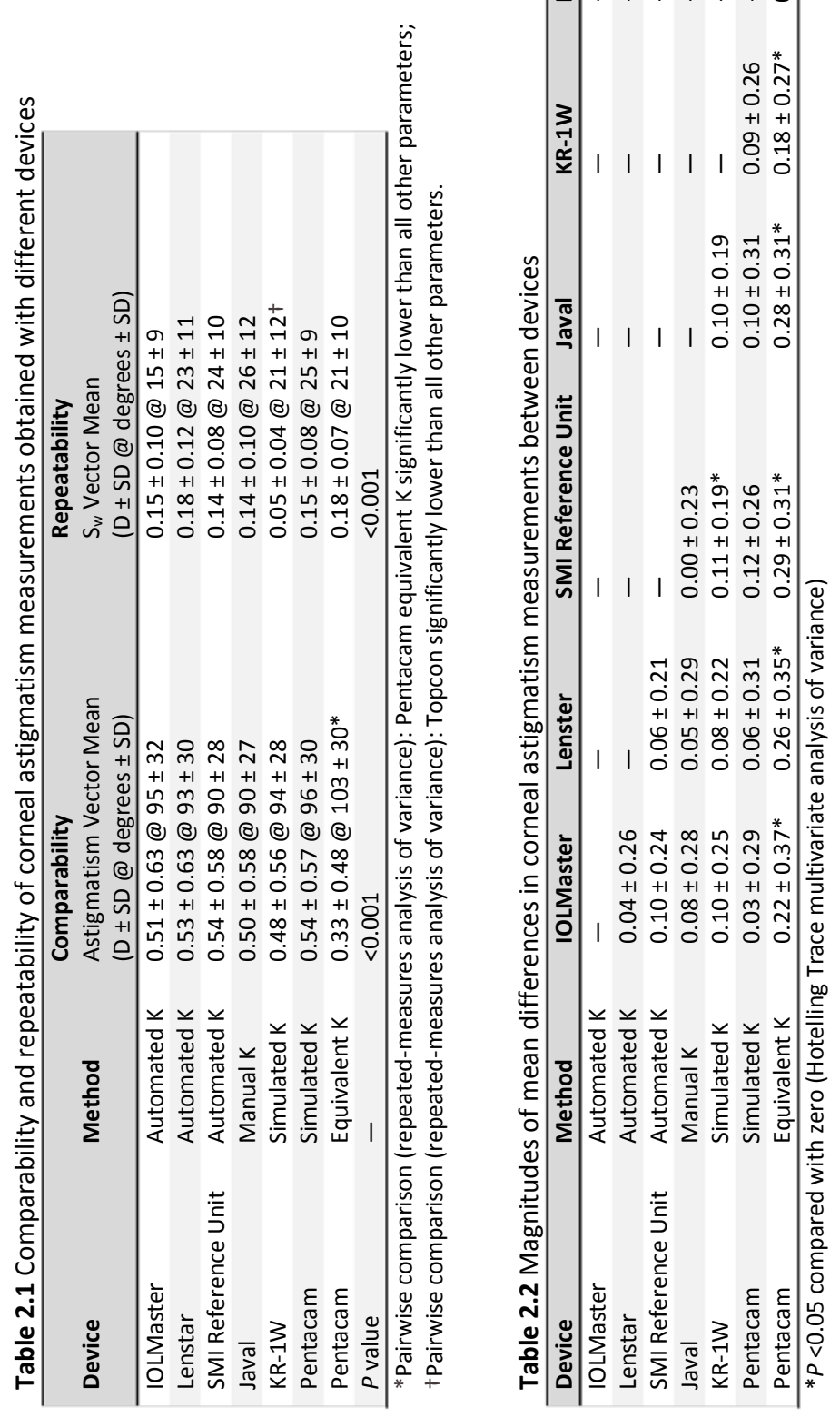


Table 2.3 Mean differences in corneal astigmatism between refractive indices of 1.3320 and 1.3375

\begin{tabular}{llll}
\hline Device & Method & $\begin{array}{l}\text { Astigmatism Vector Mean } \\
(D \pm S D @ \text { degrees } \pm \text { SD })\end{array}$ & P value * \\
\hline IOLMaster & Automated K & $0.01 \pm 0.01 @ 5 \pm 26$ & 0.015 \\
Lenstar & Automated K & $0.01 \pm 0.01 @ 3 \pm 24$ & 0.004 \\
SMI Reference Unit & Automated K & $0.01 \pm 0.01 @ 180 \pm 21$ & 0.010 \\
Javal & Manual K & $0.01 \pm 0.01 @ 180 \pm 20$ & 0.007 \\
KR-1W & Simulated K & $0.01 \pm 0.01 @ 4 \pm 22$ & 0.014 \\
Pentacam & Simulated K & $0.01 \pm 0.01 @ 6 \pm 23$ & 0.008 \\
Pentacam & Equivalent K & - & - \\
\hline
\end{tabular}

${ }^{*}$ Hotelling Trace multivariate analysis of variance; $P$ value of the significant difference from zero.

mean corneal astigmatism measured by IOLMaster automated keratometry, manual keratometry, corneal topography or a dual Scheimpflug system with Placido-disk imaging; mean differences were below $0.11 \mathrm{D}^{23}$

Many studies have compared astigmatism magnitudes ( $\mathrm{K}$ values) without taking the astigmatism meridian into account and generally found a good agreement of measurements obtained by automated keratometry, manual keratometry, corneal topography and Scheimpflug imaging. ${ }^{4,7,9,19,24-26}$ However, some studies have found significant differences between devices. Salouti et al. showed that Lenstar automated keratometry measurements were 0.60 to $0.65 \mathrm{D}$ lower than those determined by IOLMaster automated keratometry or manual keratometry. ${ }^{5}$ Significantly lower mean simulated $\mathrm{K}$ values have also been reported for Scheimpflug imaging compared with corneal topography or automated keratometry. ${ }^{6,27}$ Elbaz et al. found a mean difference of $0.47 \mathrm{D}$ between Scheimpflug imaging and IOLMaster automated keratometry. $^{3}$ A recent study by Módis et al. reports mean differences of $0.30 \mathrm{D}$ (flat meridian)/ $0.50 \mathrm{D}$ (steep meridian) between Scheimpflug imaging and corneal topography and of $0.60 \mathrm{D}$ (flat meridian)/ $0.60 \mathrm{D}$ (steep meridian) between Scheimpflug imaging and automated keratometry. ${ }^{8}$

Corneal power can also be determined based on both the anterior and posterior corneal surface. The Pentacam equivalent $\mathrm{K}$ is a parameter which is based on both the anterior and posterior corneal curvature. In our study, this parameter was found to be significantly different from all automated, manual and simulated $\mathrm{K}$ values. In addition, mean differences were large ( 0.18 to $0.29 \mathrm{D}$ in magnitude) and clinically relevant. Ho et al. used a vector analysis and found that incorporating the posterior corneal curvature into corneal power calculations resulted in a significantly different value compared to simulated keratometry. ${ }^{28}$ Several other studies have compared equivalent $K$ values to simulated or automated $K$ values, but did not use a vector analysis. $^{9,29-31}$ Two of these studies indicated that the magnitude of the equivalent $K$ 
value was comparable to automated keratometry. ${ }^{30,31}$ However, Symes et al. showed a significant difference of $0.53 \mathrm{D}(\mathrm{p}<0.001)$ in astigmatism measurement between equivalent and automated $\mathrm{K}$ values. We believe that even though equivalent $\mathrm{K}$ values represent a more exact description of the true corneal shape, this parameter should not be used in the calculation of toric IOL cylinder power. A recent study by Goggin et al. showed that the manufacturer's toric IOL calculation results in a magnitude of error of $+0.21 \pm 0.70 \mathrm{D}$ (Alpins analysis), indicative for an overcorrection of astigmatism. ${ }^{32}$ Using equivalent $\mathrm{K}$ values in toric $\mathrm{IOL}$ calculation would result in the calculation of toric IOLs with a lower cylinder power. More research is needed to determine whether this may decrease the overcorrection of astigmatism.

The devices in this study determine corneal astigmatism based on either 6, 12 or 32 light spots (IOLMaster, SMI Reference Unit and Lenstar, respectively), two illuminated mires (Javal), 19 illuminated rings (KR-1W) or a rotating Scheimpflug camera (Pentacam). Since the KR-1W and Pentacam gather more data points, we expected that the repeatability of these devices would be superior to the others. We assessed the repeatability using the (vector) $s_{w}$, which is an estimation of the size of the measurement error. ${ }^{12}$ With all devices, the $s_{w}$ was below $0.20 \mathrm{D}$ with a mean meridian of approximately 20 degrees. The $\mathrm{KR}-1 \mathrm{~W}$ had a significantly better repeatability compared to the other devices. However, in our opinion, a maximum repeatability of $0.20 \mathrm{D}$ in measuring corneal astigmatism magnitude is acceptable and of little clinical relevance. However, with all devices, the repeatability of the astigmatism meridian was approximately 20 degrees, which may be clinically relevant when calculating toric IOL power and implantation axis. Read et al. determined the repeatability of the Pentacam and a corneal topographer using power vectors. ${ }^{21}$ The repeatability coefficients of the individual power vectors J0 and J45 were $0.15 \mathrm{D}$ and $0.14 \mathrm{D}$, respectively, for the Pentacam and $0.12 \mathrm{D}$ and $0.12 \mathrm{D}$, respectively, for the corneal topographer, indicating a good repeatability. Other studies have measured the $\mathrm{s}_{w}$ of $\mathrm{K}$ values, without regarding the astigmatism meridian. The $s_{w}$ has been reported to be $0.04 \mathrm{D}$ (3 repeated measurements) for the IOLMaster and $0.02 \mathrm{D}$ (3 repeated measurements) to $0.14 \mathrm{D}$ (5 repeated measurements) for the Lenstar. ${ }^{4,23,24}$ For manual keratometry, reported $s_{w}$ range from $0.08 \mathrm{D}$ (3 repeated measurements) to $0.10 \mathrm{D}$ (10 repeated measurements). ${ }^{23,33}$ The $\mathrm{s}_{w}$ of the Pentacam in measuring the anterior corneal radius has been reported to be $0.02 \mathrm{~mm}$ ( 3 repeated measurements), which corresponds to a $s_{w}$ of $0.8 D^{34}$ To our knowledge, no previous studies have examined the repeatability of measurements obtained with the SMI Reference Unit or KR-1W corneal topographer. Ideally, before calculating the toric IOL cylinder power in each patient, a series of repeated measurements should be obtained to ensure that 
the repeatability of both the astigmatism magnitude and meridian is acceptable. In our opinion, the repeatability of the magnitude should be below $0.25 \mathrm{D}$ and for the meridian below 5 degrees.

The devices tested in this study use different indices of refraction to calculate the corneal power: 1.3375 (IOLMaster, Lenstar, KR-1W, Pentacam) and 1.3320 (Lenstar, SMI Reference Unit). Traditionally, a refractive index of 1.3375 is used. However, Olsen recommends using a refractive index of the cornea of 1.3315 , based on the schematic eye model of Gullstrand. ${ }^{35}$ One should realize which index of refraction is used, since this may result in different corneal powers. For example, using refractive indices of 1.3375 and 1.3320 , an anterior radius of curvature of $7.50 \mathrm{~mm}$ is converted into corneal powers of $45.0 \mathrm{D}$ and $44.3 \mathrm{D}$, respectively. However, in our study, refractive indices of 1.3375 and 1.3320 resulted in small differences in the overall astigmatism magnitude (mean $0.01 \pm 0.01 \mathrm{D}$ ). Even though this value was statistically significant, we do not believe it is clinically relevant. We also performed all analyses with the true refractive indices and found comparable astigmatism measurements for all devices, except the Pentacam equivalent $\mathrm{K}$ (results not shown).

An additional purpose of this study was to evaluate the keratometry measurements obtained with the SMI Reference Unit. This unit is part of a new Surgery Guidance system that can be used during surgery to align toric IOLs without the use of inkmarkings. ${ }^{2}$ In the current study, we found that corneal astigmatism measurements obtained with the SMI Reference Unit are comparable to other commonly used automated or manual keratometers, corneal topographers and Scheimpflug imaging. Finally, operator experience did not influence measurements obtained with the SMI Reference Unit.

In conclusion, using an astigmatism vector analysis we showed that corneal astigmatism measurements obtained by automated, manual, and simulated keratometry were comparable. However, equivalent $\mathrm{K}$ values obtained with the Pentacam were not comparable to those obtained by automated, manual and simulated keratometry. The repeatability of astigmatism magnitudes was acceptable for all devices; however the repeatability of astigmatism meridians was moderate. This may be clinically relevant when calculating toric IOL power and implantation axis. Finally, the SMI Reference Unit was found to have a good interobserver variability.

\section{References}

1. Weinand F, Jung A, Stein A, Pfutzner A, Becker R, Pavlovic S. Rotational stability of a single-piece hydrophobic acrylic intraocular lens: new method for high-precision rotation control. J Cataract Refract Surg. May 2007;33(5):800-803. 
2. Visser N, Berendschot TT, Bauer NJ, Jurich J, Kersting O, Nuijts RM. Accuracy of toric intraocular lens implantation in cataract and refractive surgery. J Cataract Refract Surg. Aug 2011;37(8):1394-1402.

3. Elbaz U, Barkana Y, Gerber Y, Avni I, Zadok D. Comparison of different techniques of anterior chamber depth and keratometric measurements. Am J Ophthalmol. Jan 2007;143(1):48-53.

4. Cruysberg LP, Doors $M$, Verbakel $F$, Berendschot TT, De Brabander J, Nuijts RM. Evaluation of the Lenstar LS 900 non-contact biometer. $\mathrm{Br} J$ Ophthalmol. Jan 2009;94(1):106-110.

5. Salouti $R$, Nowroozzadeh $\mathrm{MH}$, Zamani $\mathrm{M}$, Ghoreyshi M, Salouti R. Comparison of the ultrasonographic method with 2 partial coherence interferometry methods for intraocular lens power calculation. Optometry. Mar 2011;82(3):140-147.

6. Savini G, Barboni P, Carbonelli M, Hoffer KJ. Accuracy of Scheimpflug corneal power measurements for intraocular lens power calculation. J Cataract Refract Surg. Jul 2009;35(7):1193-1197.

7. Shirayama M, Wang L, Koch DD, Weikert MP. Comparison of accuracy of intraocular lens calculations using automated keratometry, a Placido-based corneal topographer, and a combined Placido-based and dual Scheimpflug corneal topographer. Cornea. Oct 2010;29(10):1136-1138.

8. Modis L, Jr., Szalai E, Kolozsvari B, Nemeth G, Vajas A, Berta A. Keratometry evaluations with the Pentacam high resolution in comparison with the automated keratometry and conventional corneal topography. Cornea. Jan 2012;31(1):36-41.

9. Symes RJ, Ursell PG. Automated keratometry in routine cataract surgery: comparison of Scheimpflug and conventional values. J Cataract Refract Surg. Feb 2011;37(2):295-301.

10. Holladay JT, Dudeja DR, Koch DD. Evaluating and reporting astigmatism for individual and aggregate data. J Cataract Refract Surg. Jan 1998;24(1):57-65.

11. Alpins NA, Goggin M. Practical astigmatism analysis for refractive outcomes in cataract and refractive surgery. Surv Ophthalmol. Jan-Feb 2004;49(1):109-122.

12. Bland JM, Altman DG. Measurement error. Bmj. Sep 21 1996;313(7059):744.

13. Ahmed I, Rocha G, Slomovic AR, et al. Visual function and patient experience after bilateral implantation of toric intraocular lenses. J Cataract Refract Surg. Apr 2010;36(4):609-616.

14. Visser N, Ruiz-Mesa R, Pastor F, Bauer NJ, Nuijts RM, Montes-Mico R. Cataract surgery with toric intraocular lens implantation in patients with high corneal astigmatism. J Cataract Refract Surg. Aug 2011;37(8):14031410.

15. Holland E, Lane S, Horn JD, Ernest P, Arleo R, Miller KM. The AcrySof Toric Intraocular Lens in Subjects with Cataracts and Corneal Astigmatism A Randomized, SubjectMasked, Parallel-Group, 1-Year Study. Ophthalmology. Sep 14 2010;117(11):21042111.

16. Tassignon MJ, Gobin L, Mathysen D, Van Looveren J. Clinical results after spherotoric intraocular lens implantation using the bagin-the-lens technique. J Cataract Refract Surg. May 2011;37(5):830-834.

17. Visser N, Gast ST, Bauer NJ, Nuijts RM. Cataract surgery with toric intraocular lens implantation in keratoconus: a case report. Cornea. Jun 2011;30(6):720-723.

18. Pouyeh B, Galor A, Junk AK, et al. Surgical and refractive outcomes of cataract surgery with toric intraocular lens implantation at a resident-teaching institution. I Cataract Refract Surg. Sep 2011;37(9):1623-1628.

19. Santodomingo-Rubido J, Mallen EA, Gilmartin B, Wolffsohn JS. A new noncontact optical device for ocular biometry. Br J Ophthalmol. Apr 2002;86(4):458-462.

20. Thibos LN, Horner D. Power vector analysis of the optical outcome of refractive surgery. J Cataract Refract Surg. Jan 2001;27(1):8085.

21. Read SA, Collins MJ, Iskander DR, Davis BA. Corneal topography with Scheimpflug imaging and videokeratography: comparative study of normal eyes. J Cataract Refract Surg. Jun 2009;35(6):10721081.

22. Kobashi H, Kamiya $K$, Igarashi $A$, et al. Comparison of corneal power, corneal astigmatism, and axis location in normal eyes obtained from an autokeratometer and a corneal topographer. J Cataract Refract Surg. Apr 2012;38(4):648-654.

23. Shirayama M, Wang L, Weikert MP, Koch DD. Comparison of corneal powers obtained from 4 different devices. Am J Ophthalmol. Oct 2009;148(4):528-535 e521.

24. Buckhurst PJ, Wolffsohn JS, Shah S, Naroo SA, Davies LN, Berrow EJ. A new optical low 
coherence reflectometry device for ocular biometry in cataract patients. $\mathrm{Br} \mathrm{J}$ Ophthalmol. Jul 2009;93(7):949-953.

25. Rohrer K, Frueh BE, Walti R, Clemetson IA, Tappeiner C, Goldblum D. Comparison and evaluation of ocular biometry using a new noncontact optical low-coherence reflectometer. Ophthalmology. Nov 2009;116(11):2087-2092.

26. Hoffer KJ, Shammas HJ, Savini G. Comparison of 2 laser instruments for measuring axial length. J Cataract Refract Surg. Apr 2010;36(4):644-648.

27. Huang J, Pesudovs K, Wen D, et al. Comparison of anterior segment measurements with rotating Scheimpflug photography and partial coherence reflectometry. J Cataract Refract Surg. Feb 2011;37(2):341-348.

28. Ho JD, Tsai CY, Liou SW. Accuracy of corneal astigmatism estimation by neglecting the posterior corneal surface measurement. Am J Ophthalmol. May 2009;147(5):788-795, 795 e781-782.

29. Savini G, Barboni P, Carbonelli M, Hoffer KJ. Agreement between Pentacam and videokeratography in corneal power assessment. J Refract Surg. Jun 2009;25(6):534-538.
30. Shammas HJ, Hoffer KJ, Shammas MC Scheimpflug photography keratometry readings for routine intraocular lens power calculation. J Cataract Refract Surg. Feb 2009;35(2):330-334.

31. Symes RJ, Say MJ, Ursell PG. Scheimpflug keratometry versus conventional automated keratometry in routine cataract surgery. J Cataract Refract Surg. Jul 2010;36(7):11071114.

32. Goggin M, Moore S, Esterman A. Toric Intraocular Lens Outcome Using the Manufacturer's Prediction of Corneal Plane Equivalent Intraocular Lens Cylinder Power. Arch Ophthalmol. Aug 2011;129(8):10041008.

33. Moura RC, Bowyer BL, Stevens SX, Rowsey JJ. Comparison of three computerized videokeratoscopy systems with keratometry. Cornea. Sep 1998;17(5):522528.

34. Miranda MA, Radhakrishnan H, O'Donnell C. Repeatability of oculus pentacam metrics derived from corneal topography. Cornea. Jul 2009;28(6):657-666.

35. Olsen T. On the calculation of power from curvature of the cornea. $\mathrm{Br} J$ Ophthalmol. Feb 1986;70(2):152-154. 


\section{Chapter 3}

\section{Evaluation of the comparability and repeatability of four wavefront aberrometers}

Nienke Visser, Tos T.J.M. Berendschot, Frenne Verbakel, Annelie N. Tan, John de Brabander and Rudy M.M.A. Nuijts Investigative Ophthalmology \& Visual Science 2011; 52: 1302-1311 


\section{Abstract}

PURPOSE: To compare total ocular aberrations and corneal aberrations measured with four different aberrometers; and to determine the repeatability and interobserver variability.

Setring: University Eye Clinic, Maastricht University Medical Centre, the Netherlands.

MEtHods: In this prospective comparative study, 23 healthy subjects underwent bilateral examination with four aberrometers: the Irx3 (Imagine eyes; HartmannShack), Keratron (Optikon; Hartmann-Shack), iTrace (Tracey technologies; Ray-tracing) and OPD-Scan (Nidek; Automated retinoscopy). Six images per eye were obtained. Second-order, third-order and fourth-order spherical aberration were exported for 5.0 mm pupils.

RESULTS: Significant differences in measurements were found for several total ocular aberrations (defocus $(2,0)$, astigmatism $(2,2)$, trefoil $(3,-3)$, trefoil $(3,3)$ and spherical aberration $(4,0)$ ) and corneal aberrations (defocus $(2,0)$ and astigmatism $(2,2)$ ). The Irx3 showed the highest repeatability in measuring total ocular aberrations, followed by the Keratron, OPD-Scan and iTrace. The repeatability of corneal aberration measurements was highest for the iTrace, followed by the Keratron and OPD-Scan. The OPD-Scan showed a lower interobserver variability, compared with the Irx3, Keratron and iTrace.

ConcLuSION: Total ocular and corneal aberrations are not comparable when measured with different aberrometers. Hartmann-Shack aberrometers showed the best repeatability for total ocular aberrations and iTrace for corneal aberrations. It would be worthwhile in the future to evaluate aberrometers in patients with more aberrant eyes. 


\section{Introduction}

Wavefront analysis allows for a detailed evaluation of imperfections in the optical system of the eye, caused by the refractive surfaces of the anterior and posterior cornea and the lens. It provides an estimation of the optical quality of the eye that extends beyond the description of spherical and cylindrical refractive errors. Measurement of higher-order aberrations has changed from a laboratory or research application to a clinical application and may be used for example in wavefront-guided excimer laser surgery, lens implantation surgery and contact lens fitting. ${ }^{1-4}$ Wavefront analysis may be performed to design an ideal refractive correction, which corrects not only lower-order aberrations (sphere and cylinder), but also higher-order aberrations. In addition, it may be used to evaluate eyes with abnormal optics due to ageing or corneal disorders such as keratoconus and pellucid marginal degeneration. ${ }^{5}$ However, the success of clinical applications of wavefront analysis depends on the accuracy and reliability of the aberrometers.

Three different wavefront measuring principles are available to measure aberrations: (1) Hartmann-Shack, (2) Tscherning or ray-tracing, and (3) automated retinoscopy. A Hartmann-Shack aberrometer is an outgoing wavefront aberrometer. It measures the shape of the wavefront that is reflected out of the eye from a point source on the fovea. An array of microlenslets is used to subdivide the outgoing wavefront into multiple beams which produce spot images on a video sensor. The displacement of each spot from the corresponding nonaberrated reference position is used to determine the shape of the wavefront. ${ }^{5,6} \mathrm{~A}$ Tscherning, or ray-tracing, aberrometer is an ingoing instrument. It projects a thin laser beam into the eye, parallel to the visual axis and determines the location of the beam on the retina by using a photodetector. Once the position of the first light spot on the retina is determined, the laser beam is moved to a new position and the location of the second light spot on the retina is determined. Aberrations in the optical system cause a shift in the location of the light spot on the retina. ${ }^{5,7}$ The third type, automated retinoscopy, is based on dynamic skiascopy. The retina is scanned with a slit-shaped light beam and the reflected light is captured by an array of rotating photodetectors over a 360 degree area. The time difference of the reflected light is used to determine the aberrations. ${ }^{8}$

Total ocular aberrations are the result of corneal and internal ocular aberrations. Combined wavefront aberrometry and corneal topography can differentiate between aberrations caused by the anterior cornea or by the internal ocular system. In this study, we compare 4 different wavefront aberrometers, out of which 3 are combined with a corneal topographer. The purpose of this study is to compare measurements 
obtained with 4 different wavefront aberrometers and to determine the repeatability and interobserver variability.

\section{Methods}

In this prospective comparative study, 23 healthy volunteers were recruited from the Department of Ophthalmology, University Hospital Maastricht. Informed consent was obtained from all subjects after the nature of the experiment had been explained. The study adhered to the tenets of the Declaration of Helsinki.

None of the subjects had a history of ocular surgery or ocular disease. All subjects were measured bilaterally with 4 different aberrometers. Per eye, 6 consecutive good quality images were obtained: 3 by an expert and 3 by a nonexpert. An expert was defined as a person who had performed a minimum of 25 measurements with each aberrometer. Nonexperts were medical students with basic knowledge of ophthalmology and no previous experience with any of the aberrometers. They received an oral instruction and demonstration of the aberrometers. To ensure goodquality images, every nonexpert was supervised while performing the examinations.

Natural pupil dilation was obtained in all subjects under mesopic light condition $(<1$ lux). No extrapolation was used and subjects were excluded if the natural pupil diameter was less than $5 \mathrm{~mm}$ (measured with all aberrometers). Head positioning and eye alignment were carefully checked before every measurement. Immediately before each measurement, subjects were instructed to blink and then hold their eyes wide open.

\section{Devices}

The Irx3 (Imagine eyes) aberrometer (no corneal topography features) uses the Hartmann-Shack principle to measure aberrations of the whole eye. A light source with a wavelength of $780 \mathrm{~nm}$ is used. Accommodation is inhibited by automatically adding a fogging of +0.5 diopters (D) to the measured sphere power. The Irx3 has been described in more detail previously. ${ }^{9}$

The Keratron Onda (Optikon) is a combined Hartmann-Shack aberrometer and Placido disc videokeratoscope. For the wavefront analysis, an infrared light beam of $840 \mathrm{~nm}$ is used. Before aberrometry was performed, the defocus equivalent of the eye was determined, using the autorefraction function of this device, and subsequently +1.0 D of fogging was applied to inhibit accommodation. The Keratron Onda became commercially available in spring 2010 and has not been studied previously. However, 
the corneal topographer, which is incorporated in the Keratron Onda is described elsewhere. $^{10}$

The iTrace (Tracey technologies) is a combined ray-tracing aberrometer and Placido disc videokeratoscope. It has a laser with a wavelength of $632 \mathrm{~nm}$. Accommodation is inhibited by allowing the patient to view through the device at a target image at optical infinity. It is described in more detail elsewhere. ${ }^{11}$

The OPD-Scan (Nidek) aberrometer is a combined automated retinoscope and Placido disc videokeratoscope. It has an infrared light beam with a $808 \mathrm{~nm}$ wavelength. Fogging of $+1.6 \mathrm{D}$ is used to inhibit accommodation. Details are available elsewhere. ${ }^{12}$

\section{Data Analysis}

Aberrations were exported for a $5.0 \mathrm{~mm}$ pupil in the form of Zernike coefficients $(Z(x, x))$, according to the standards of the Optical Society of America and the American National Standards Institute. ${ }^{13}$ The following total ocular and corneal aberrations were exported: oblique astigmatism $Z(2,-2)$, defocus $Z(2,0)$, main axis astigmatism $Z(2,2)$, vertical trefoil $Z(3,-3)$, vertical coma $Z(3,-1)$, horizontal coma $Z(3,1)$, horizontal trefoil $Z(3,3)$, and spherical aberration $Z(4,0)$.

All data were collected in an Excel database (Microsoft Office 2003, Microsoft Inc.) and transferred to SPSS (SPSS for Windows, version 16.0, SPSS Inc.) for data analysis. Data were normally distributed and allowed us to use parametric tests. To determine a relationship between measurements of 2 devices, we performed bivariate correlations to determine the Pearson's correlation coefficient. The agreement between two devices was studied by using the method described by Bland and Altman. ${ }^{14}$ This method computes $95 \%$ limits of agreement (LOA), defined as the mean difference \pm $1.96 *$ SD. A repeated-measures analysis of variance (ANOVA) with Bonferroni correction was used to compare total ocular aberrations and corneal aberrations between devices and to determine whether these are significantly different. The repeatability of devices was determined by calculating the standard deviation within each series of 6 repeated measurements per eye $\left(s_{w}\right)$. The interobserver variability of each device was determined by comparing the correlations (Pearson's correlation coefficient), measurements (paired t-test) and repeatability $\left(s_{w}\right)$ of measurements obtained by experts and nonexperts. A p-value less than 0.05 was considered to be statistically significant. 


\section{Results}

Twenty-three subjects (12 male and 11 female) underwent bilateral examinations with the Irx3, Keratron, iTrace, and OPD-Scan. The mean age was $25.1 \pm 6.0$ years (range 21.8 to 48.9 years). The total ocular aberrations could not be measured in $4(9 \%)$ eyes with the Irx3, 2 (4\%) eyes with the Keratron, and 5 (11\%) eyes with the OPD-Scan, due to a minor nystagmus in 1 eye and continuous measurements of smaller pupil size than $5 \mathrm{~mm}$ in remaining eyes. All eyes could be measured with the iTrace.

\section{Correlation of measurements}

Table 3.1 shows the pair-wise correlations between measurements obtained with different aberrometers. All four aberrometers showed significant correlations for all total ocular aberrations, with Pearson's correlation coefficients $(r)$ ranging from 0.574 to 0.975 . Measurements of corneal aberrations obtained with the Keratron and iTrace correlated significantly with Pearson's correlation coefficients ranging from 0.592 to 0.961. Measurements between the Keratron and OPD-Scan did not correlate for defocus, trefoil $Z(3,-3)$, trefoil $Z(3,3)$, and spherical aberration. Pearson's correlation coefficients of the significant correlations ranged from 0.361 to 0.729 . Corneal aberrations obtained with the iTrace and OPD-Scan did not correlate for trefoil $Z(3,3)$. Other aberrations showed correlations with Pearson's correlation coefficients ranging from 0.309 to 0.776 .

\section{Agreement of measurements}

The 95\% LoA and the span of the 95\% LoA of the pair-wise comparisons are shown in Table 3.2. Most pair-wise comparisons of total ocular aberrations had 95\% LoA with a span of less than $1.0 \mu \mathrm{m}$. All pair-wise comparisons, except the comparison of Irx3 versus iTrace, showed a span of more than $1.0 \mu \mathrm{m}$ when measuring defocus. Regarding corneal aberrations, the 95\% LoA were wider than $1.0 \mu \mathrm{m}$ for multiple aberrations in the comparison of Keratron versus OPD-Scan, and in the comparison of iTrace versus OPD-Scan.

\section{Comparison of measurements}

The results of the comparison of the four aberrometers are shown in Table 3.3. Total ocular aberrations were significantly different for defocus $Z(2,0)$, astigmatism $Z(2,2)$, trefoil $Z(3,-3)$, trefoil $Z(3,3)$, and spherical aberration $Z(4,0)$. No significant differences were found for astigmatism $Z(2,-2)$, coma $Z(3,-1)$ and coma $Z(3,1)$. When we use the different defocus $Z(2,0)$ measurements to calculate the corresponding spherical error, 
this corresponds to a spherical error of $-0.89 D,-1.91 D,-1.29 D$ and $-1.02 \mathrm{D}$ for the Irx3, Keratron, iTrace and OPD-Scan, respectively.

Most corneal aberrations measured with the iTrace, Keratron and OPD-Scan were not significantly different, except for defocus $Z(2,0)$ and astigmatism $Z(2,2)$. When we use the different defocus $Z(2,0)$ measurements to calculate the corresponding spherical error, this corresponds to a spherical error of $-0.23 D,-0.66 D$ and $-0.49 D$ for the Keratron, iTrace and OPD-Scan, respectively.

\section{Repeatability of devices}

Figure 3.1 shows the repeatability results. A smaller $\mathrm{s}_{\mathrm{w}}$ indicates a better repeatability. The Irx3 showed the highest repeatability for all total ocular aberrations (Figure 3.1A). The Keratron showed a significantly lower repeatability, compared to the Irx3, for defocus $Z(2,0)$ ( $p<0.001$ ). The iTrace showed a significantly lower repeatability, compared to the Irx3, for the following Zernikes: astigmatism $Z(2,-2) \quad(p=0.003)$, defocus $Z(2,0)(p=0.009)$, coma $Z(3,-1)(p=0.002)$, coma $Z(3,1)(p<0.001)$, trefoil $Z(3,3)$ $(p=0.003)$, and spherical aberration $Z(4,0)(p=0.015)$. The OPD-Scan had a significantly lower repeatability, compared to the Irx3, for trefoil $Z(3,-3)(p=0.012)$, coma $Z(3,-1)$ $(p<0.001)$, and trefoil $Z(3,3)(p<0.001)$.

The repeatability of corneal aberrations is shown in Figure 3.1B The iTrace showed the highest repeatability for all Zernike coefficients. The Keratron had a significantly lower repeatability, compared to the iTrace, for astigmatism $Z(2,-2)(p=0.001)$, astigmatism $Z(2,2) \quad(p=0.004)$, coma $Z(3,-1) \quad(p<0.001)$, coma $Z(3,1) \quad(p=0.011)$, and spherical aberration $\mathrm{Z}(4,0)(p<0.001)$. As indicated in Figure $3.1 \mathrm{~B}$, the $\mathrm{s}_{\mathrm{w}}$ of all corneal aberration measurements obtained with the OPD-Scan was much higher than with the iTrace and Keratron, indicating a lower repeatability. However, due to the large variability in measurements obtained with the OPD-Scan, this difference did not reach statistical significance.

\section{Interobserver variability}

To determine whether operating experience influenced measurements, we compared the differences in measurements and the $s_{w}$ of measurement obtained by experts and nonexperts. The results are shown in Table 3.4. With the Irx3, Keratron and iTrace, we found high correlations, no significant differences and a high repeatability of measurements obtained by experts and nonexperts. However, with the OPD-Scan we found a significantly lower repeatability in measuring total ocular aberration, if measurements were obtained by a nonexpert, compared to an expert. No differences in interobserver variability were found when measuring corneal aberrations. 


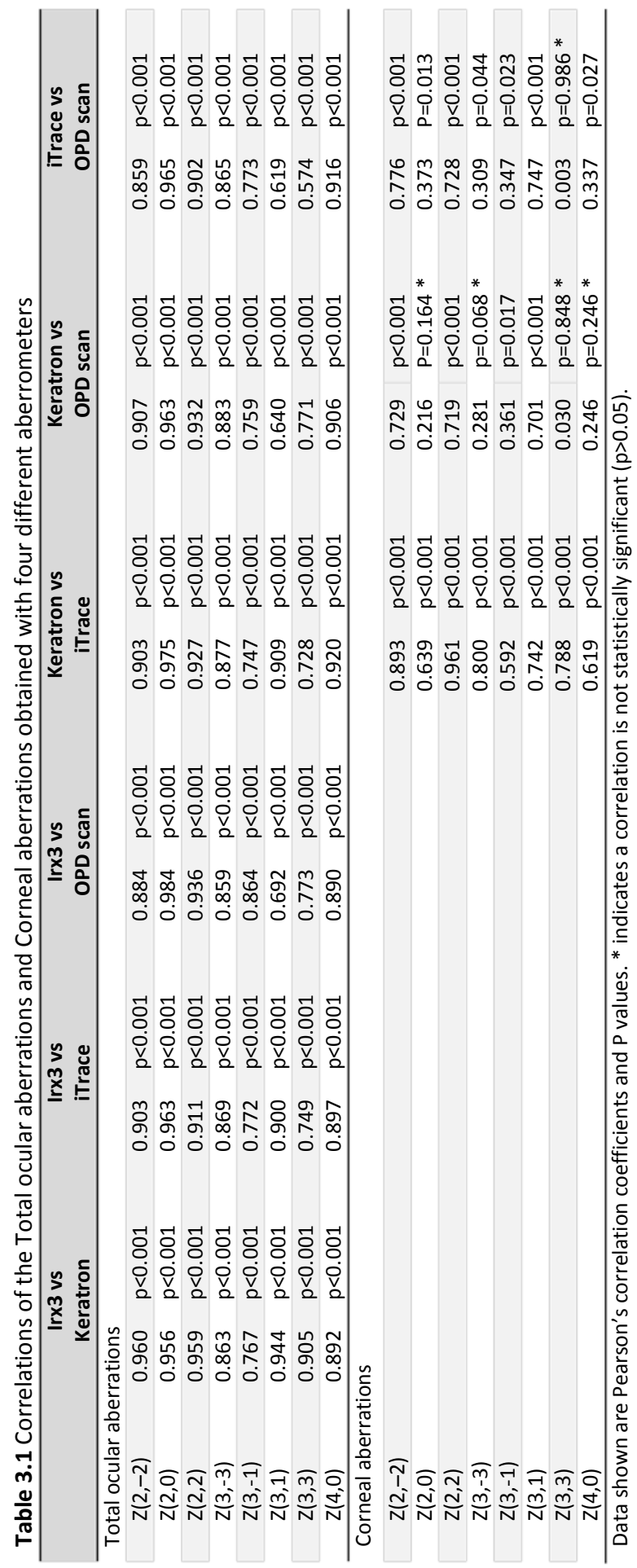




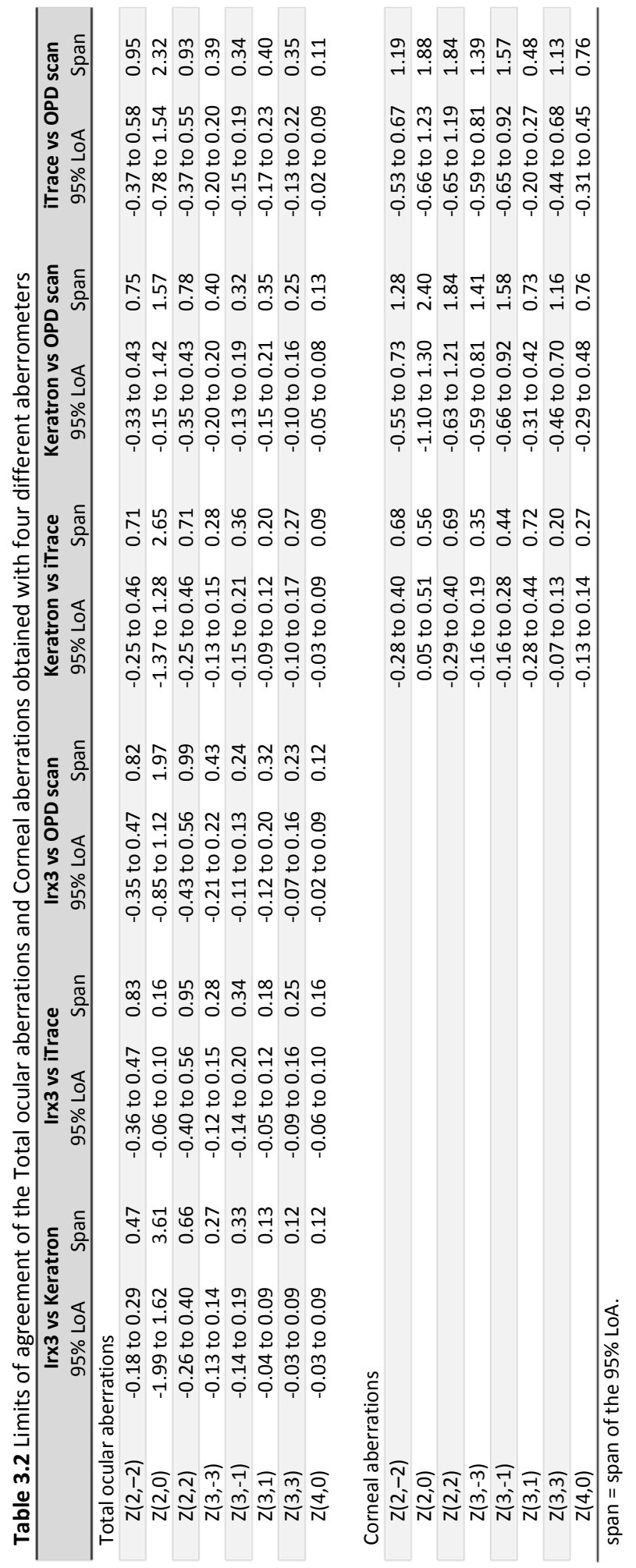




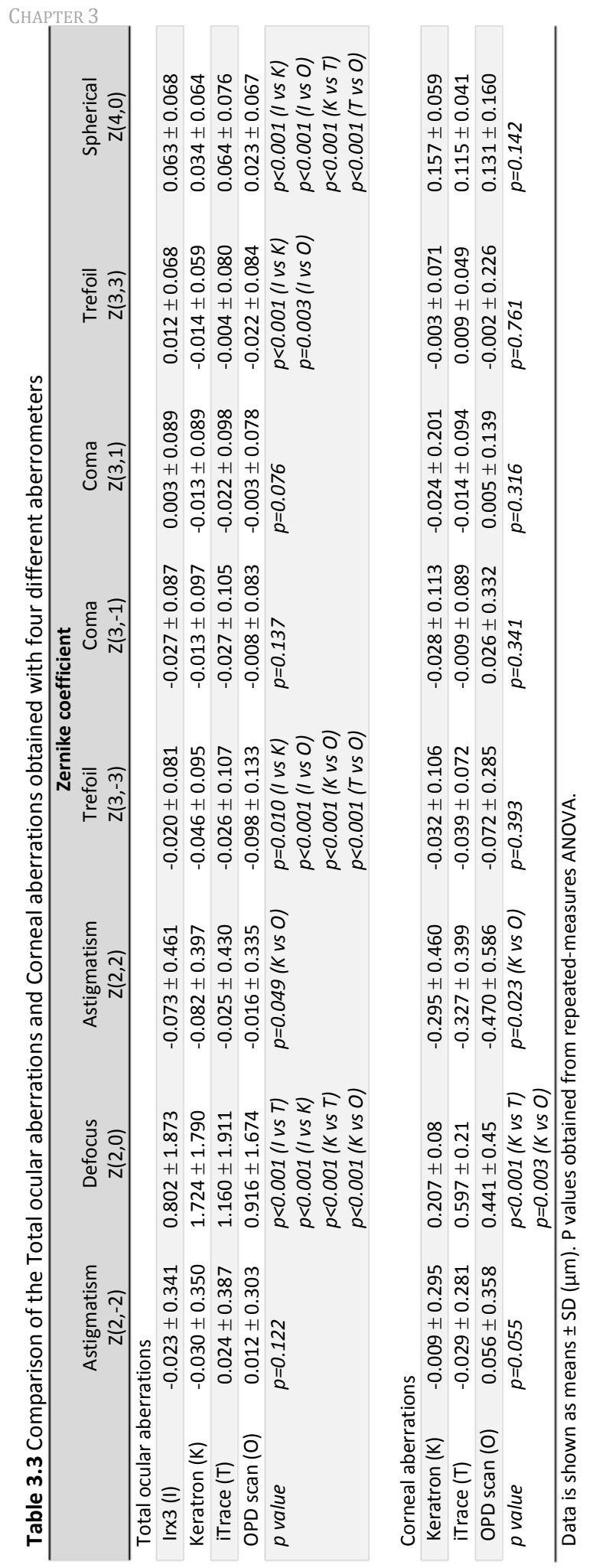


Table 3.4 Interobserver variability: differences in measurements obtained by experts and nonexperts (pupil size $5 \mathrm{~mm}$ ) (Continued on next page)

\begin{tabular}{|c|c|c|c|c|c|}
\hline & & \multicolumn{4}{|c|}{ Zernike coefficients } \\
\hline & & $\begin{array}{c}\text { Astigmatism } \\
\mathrm{Z}(2,-2)\end{array}$ & $\begin{array}{c}\text { Defocus } \\
Z(2,0)\end{array}$ & $\begin{array}{c}\text { Astigmatism } \\
\mathrm{Z}(2,2)\end{array}$ & $\begin{array}{l}\text { Trefoil } \\
Z(3,-3) \\
\end{array}$ \\
\hline \multicolumn{6}{|l|}{ Irx3 } \\
\hline \multirow[t]{4}{*}{ TOA } & Correlation $(P C C ; P)$ & $0.968(p<0.001)$ & $0.994(p<0.001)$ & $0.998(p<0.001)$ & $0.962(p<0.001)$ \\
\hline & Mean difference $(\mu \mathrm{m})$ & $0.008 \pm 0.052$ & $-0.025 \pm 0.194$ & $0.014 \pm 0.045$ & $0.001 \pm 0.022$ \\
\hline & Expert $S_{w}(\mu \mathrm{m})$ & $0.033 \pm 0.020$ & $0.126 \pm 0.141$ & $0.050 \pm 0.020$ & $0.023 \pm 0.015$ \\
\hline & Non-expert $S_{w}(\mu \mathrm{m})$ & $0.036 \pm 0.020$ & $0.097 \pm 0.079$ & $0.047 \pm 0.025$ & $0.023 \pm 0.012$ \\
\hline \multicolumn{6}{|c|}{ Keratron } \\
\hline \multirow[t]{4}{*}{ TOA } & Correlation $(P C C ; P)$ & $0.985 ; p<0.001$ & $0.981 ; p<0.001$ & $0.940 ; p<0.001$ & $0.752 ; p<0.001$ \\
\hline & Mean difference $(\mu \mathrm{m})$ & $0.013 \pm 0.059$ & $0.058 \pm 0.362$ & $0.028 \pm 0.136$ & $0.005 \pm 0.075$ \\
\hline & Expert $S_{w}(\mu \mathrm{m})$ & $0.030 \pm 0.019$ & $0.187 \pm 0.196$ & $0.040 \pm 0.023$ & $0.021 \pm 0.022$ \\
\hline & Non-expert $S_{w}(\mu \mathrm{m})$ & $0.039 \pm 0.041$ & $0.211 \pm 0.204$ & $0.047 \pm 0.041$ & $0.023 \pm 0.023$ \\
\hline \multirow[t]{4}{*}{$C A$} & Correlation $(\mathrm{PCC} ; P)$ & $0.880 ; p<0.001$ & $0.473 ; p<0.001$ & $0.930 ; p<0.001$ & $0.630 ; p<0.001$ \\
\hline & Mean difference $(\mu \mathrm{m})$ & $0.031 \pm 0.153$ & $0.011 \pm 0.095$ & $0.048 \pm 0.195$ & $-0.005 \pm 0.107$ \\
\hline & Expert $S_{w}(\mu m)$ & $0.073 \pm 0.097$ & $0.039 \pm 0.053$ & $0.088 \pm 0.138$ & $0.043 \pm 0.065$ \\
\hline & Non-expert $S_{w}(\mu \mathrm{m})$ & $0.116 \pm 0.180$ & $0.059 \pm 0.076$ & $0.126 \pm 0.214$ & $0.059 \pm 0.158$ \\
\hline \multicolumn{6}{|c|}{ iTrace } \\
\hline \multirow[t]{4}{*}{ TOA } & Correlation $(P C C ; P)$ & $0.834 ; p<0.001$ & $0.989 ; p<0.001$ & $0.881 ; p<0.001$ & $0.910 ; p<0.001$ \\
\hline & Mean difference $(\mu \mathrm{m})$ & $0.033 \pm 0.102$ & $0.042 \pm 0.270$ & $0.025 \pm 0.125$ & $-0.011 \pm 0.036$ \\
\hline & Expert $S_{w}(\mu m)$ & $0.064 \pm 0.064$ & $0.164 \pm 0.232$ & $0.074 \pm 0.044$ & $0.035 \pm 0.024$ \\
\hline & Non-expert $S_{w}(\mu \mathrm{m})$ & $0.057 \pm 0.040$ & $0.131 \pm 0.119$ & $0.067 \pm 0.043$ & $0.036 \pm 0.027$ \\
\hline \multirow[t]{4}{*}{ CA } & Correlation $(\mathrm{PCC} ; P)$ & $0.828 ; p<0.001$ & $0.688 ; p<0.001$ & $0.946 ; p<0.001$ & $0.765 ; p<0.001$ \\
\hline & Mean difference $(\mu \mathrm{m})$ & $0.014 \pm 0.090$ & $-0.023 \pm 0.086$ & $-0.001 \pm 0.077$ & $-0.003 \pm 0.039$ \\
\hline & Expert $S_{w}(\mu m)$ & $0.090 \pm 0.064$ & $0.059 \pm 0.038$ & $0.184 \pm 0.096$ & $0.046 \pm 0.031$ \\
\hline & Non-expert $S_{w}(\mu \mathrm{m})$ & $0.073 \pm 0.055$ & $0.073 \pm 0.131$ & $0.200 \pm 0.093$ & $0.040 \pm 0.033$ \\
\hline \multicolumn{6}{|c|}{ OPD-Scan } \\
\hline \multirow[t]{4}{*}{ TOA } & Correlation (PCC; $P$ ) & $0.890 ; p<0.001$ & $0.958 ; p<0.001$ & $0.965 ; p<0.001$ & $0.934 ; p<0.001$ \\
\hline & Mean difference $(\mu \mathrm{m})$ & $-0.024 \pm 0.146$ & $0.165 \pm 0.484$ & $-0.025 \pm 0.089$ & $-0.013 \pm 0.050$ \\
\hline & Expert $S_{w}(\mu \mathrm{m})$ & $0.078 \pm 0.271$ & $0.097 \pm 0.191$ & $0.061 \pm 0.156$ & $0.031 \pm 0.023$ \\
\hline & Non-expert $S_{w}(\mu m)$ & $0.075 \pm 0.185$ & $0.164 \pm 0.278$ & $0.061 \pm 0.104$ & $0.040 \pm 0.020^{*}$ \\
\hline \multirow[t]{4}{*}{ CA } & Correlation (PCC; $P$ ) & $0.501 ; p=0.001$ & $0.415 ; p=0.005$ & $0.481 ; p=0.001$ & $0.182 ; p=0.236$ \\
\hline & Mean difference $(\mu \mathrm{m})$ & $0.086 \pm 0.440$ & $0.046 \pm 0.728$ & $-0.149 \pm 0.776$ & $-0.049 \pm 0.538$ \\
\hline & Expert $S_{w}(\mu \mathrm{m})$ & $0.036 \pm 0.024$ & $0.122 \pm 0.110$ & $0.048 \pm 0.058$ & $0.023 \pm 0.032$ \\
\hline & Non-expert $S_{w}(\mu m)$ & $0.186 \pm 0.640$ & $0.331 \pm 0.983$ & $0.299 \pm 1.233$ & $0.205 \pm 0.894$ \\
\hline
\end{tabular}

TOA = total ocular aberrations; $C A=$ corneal aberrations; PCC = Pearson's correlation coefficient.

Data is shown as mean $\pm S D$. $S_{w}=$ within-subject SD of 3 repeated measurements per eye;

$*$ = a significant difference between experts and non-experts $(p<0.05)$ 
Table 3.4 (continued)

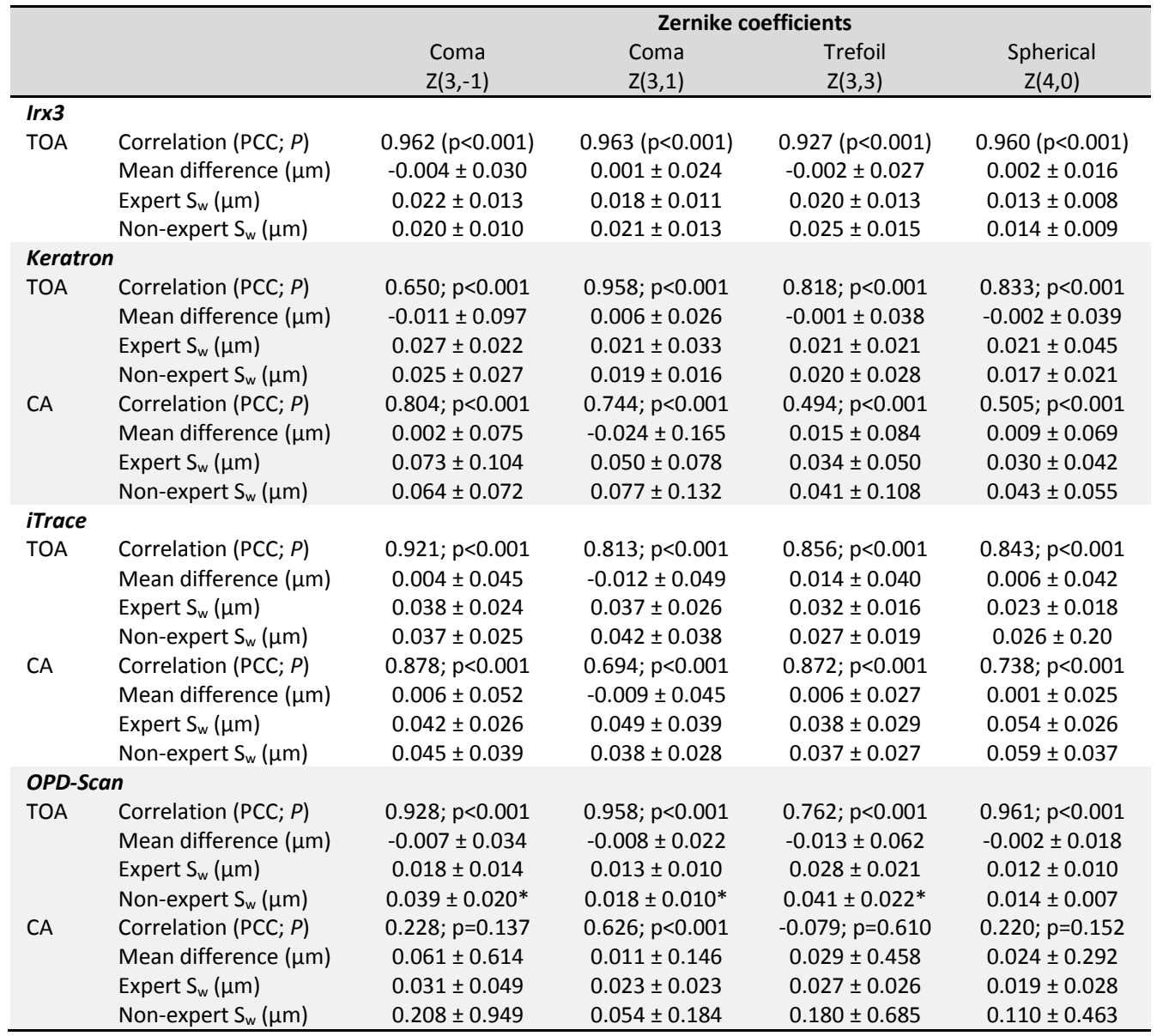

TOA = total ocular aberrations; $C A$ = corneal aberrations; PCC = Pearson's correlation coefficient.

Data is shown as mean $\pm S D$. $S_{w}=$ within-subject SD of 3 repeated measurements per eye;

$*$ = a significant difference between experts and non-experts $(p<0.05)$ 
A.

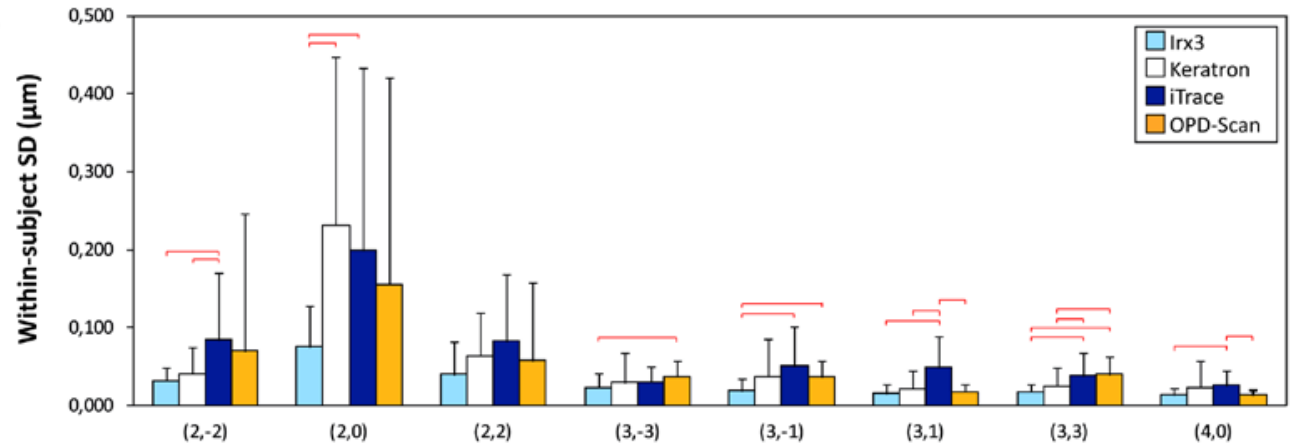

B.

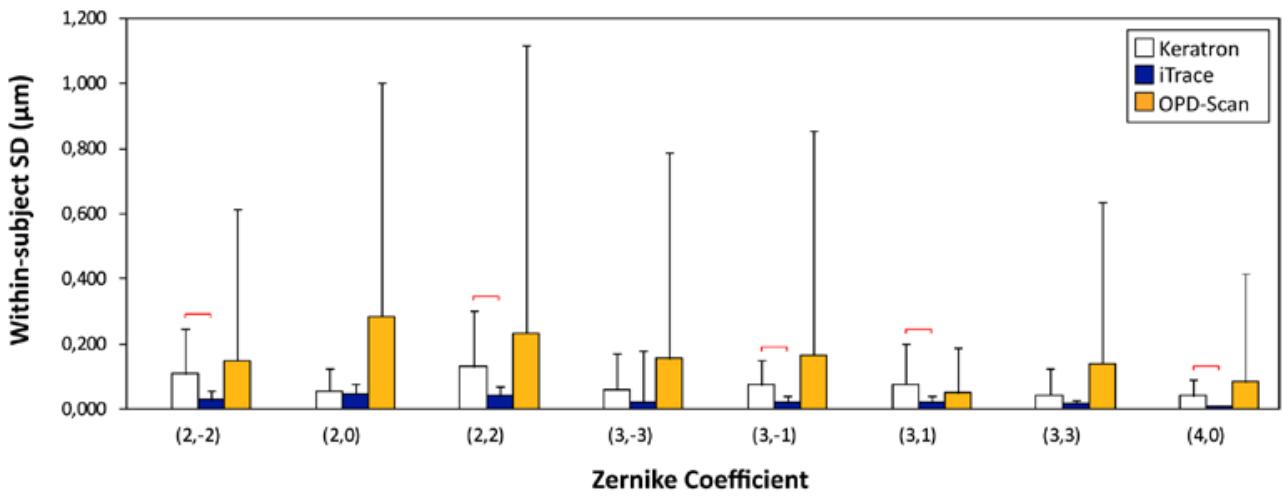

Figure 3.1 Repeatability of the Irx3, Keratron, iTrace and OPD-Scan for total ocular aberrations (A) and corneal aberrations (B). Results are shown for $5 \mathrm{~mm}$ pupils.

Error bars indicate the \pm SD; Significant differences between devices are indicated by red brackets $(p<0.05)$.

\section{Discussion}

Effective correction of higher-order aberrations is only possible if high levels of measurement accuracy are achieved. In this study we examined the correlations, agreement, and comparison of measurements obtained with the Irx3 and Keratron (both Hartmann-Shack aberrometers), the iTrace (a ray-tracing aberrometer) and the OPD-Scan (automated retinoscopy). In addition, we determined the repeatability and interobserver variability of these aberrometers. To perform an effective correction of higher-order aberrations, it is also necessary to discriminate between aberrations caused by the anterior cornea or the internal ocular system, such as the lens. The Keratron, iTrace, and OPD-Scan are combined wavefront aberrometers and corneal topographers and can therefore make this discrimination. If wavefront aberrometry and corneal topography are performed separately using different devices, identical head positioning and realignment of the eye may be difficult. By combining these 
measurements into one device and performing measurements within a short time, potential errors are minimized. However, the Keratron, iTrace and OPD-Scan still require some form of realignment when switching from the aberrometry to the topography mode. This will not be necessary in the Keratron version available since April 2010, but was not available at the time of this study.

In this study, we compared the correlations and agreement of total ocular and corneal aberrations measured with the Irx3, Keratron, iTrace and OPD-Scan. Even though total ocular aberrations showed a good correlation, the agreement for measuring defocus was low. In addition, significant differences between aberrometers were found. Defocus, trefoil and spherical aberration values were significantly different between most aberrometers. If we use the defocus measurements of the total ocular aberrations to calculate the corresponding spherical error, the spherical errors range from -0.89 D (Irx3) to $-1.91 \mathrm{D}$ (Keratron). In our opinion, this is a clinically relevant difference. Corneal aberrations obtained with the OPD-Scan correlated less well with the iTrace and Keratron and the agreement with these aberrometers was relatively low. In addition, significant differences were found in defocus measurements. If we use these defocus measurements of the corneal aberrations to calculate the corresponding sphere, the sphere ranges from -0.23 D (Keratron) to $-0.66 \mathrm{D}$ (iTrace). This difference is not clinically relevant in our opinion. The comparability of higher order corneal aberration was good. Since no golden standard is available to measure wavefront aberrations, it is unclear which device better reflects the patients' ocular aberrations. As far as we are aware of, only one previous study compared the same aberrometers that we have used in this study. Won et al. compared the iTrace and OPD-Scan and also found significant differences in total ocular spherical aberrations. ${ }^{15}$ In addition, internal aberrations (total ocular minus corneal aberrations) were significantly different for coma and trefoil Zernike terms. Several other studies compared other aberrometers, which were mostly not combined with a corneal topographer. All studies show slight differences in aberrometry measurements between devices. ${ }^{16-19}$ For example, Rozema et al. ${ }^{18}$ compared measurements obtained by the OPD-Scan to 5 other (Hartmann-Shack, ray-tracing or automated retinoscopy) aberrometers and found significant differences between devices when measuring astigmatism, defocus, and coma.

The monochromatic wavelengths used by the different devices in our study varied from red to infrared (iTrace $=650 \mathrm{~nm}$, Irx3 $=780 \mathrm{~nm}$, OPD-Scan $=808 \mathrm{~nm}$ and Keratron $=840 \mathrm{~nm}$ ). A previous study indicated that this might cause differences in measurements. ${ }^{17}$ However, since our data did not show a clear trend between the 
lowest and highest wavelength aberrometers, we do not believe this difference in wavelength causes differences in measurements.

Differences in measurements could be explained by errors in converting measurements to smaller pupil sizes. Dai and Schwiegerling have both published algorithms for converting Zernike expansion coefficients from one pupil size to another. $^{20,21}$ For all devices, we calculated the aberrations for a $4 \mathrm{~mm}$ pupil from the aberrations of a $5 \mathrm{~mm}$ pupil using these algorithms. The values were than compared to the values provided by the aberrometers for a $4 \mathrm{~mm}$ pupil. The two approaches yielded the same results for the Irx3, Keratron and iTrace, as expected. However, for the OPD-Scan the results differed significantly (data not shown). We do not have an explanation for this disparity. We could also not get feedback on this issue from Nidek. This issue has been discussed by Rozema et al. ${ }^{12}$ The table in the paper by Schwiegerling has an error in the formula for calculating the first-order Zernike coefficients. $^{20}$ We therefore added Table 3.5 to this article, showing the correct conversions up to order eight.

To study the repeatability of aberrometers, we determined the $s_{w}$ of 6 repeated measurements per eye. The repeatability of aberrometers may be influenced by microfluctuations in accommodation, instability of the tear film, and small eye movements. ${ }^{22}$ To minimize variations in measurement conditions we took repeated measurements in a short period, and instructed subjects to blink immediately before each measurement. In our study, the repeatability varied considerably between different devices. We found that the Irx3 had the highest repeatability in measuring total ocular aberrations, followed by the Keratron, OPD-Scan and finally the iTrace. In measuring corneal aberrations, the iTrace was found to have the highest repeatability and the OPD-Scan the lowest. The high repeatability of the Irx3 in measuring total ocular aberrations is in accordance with a previous study. ${ }^{9}$ Studies using other Hartmann-Shack aberrometers generally show a high repeatability with some variations in aberration measurements higher than the fourth-order. ${ }^{16,23,}{ }^{24}$ No previous study has evaluated the Keratron aberrometer. Repeated measurements obtained with the iTrace in this study showed substantial variation in total ocular aberrations, but an excellent repeatability of corneal aberrations. Win-Hall and Glasser determined the repeatability of the iTrace for total ocular aberrations and found only minor changes during repeatability testing. ${ }^{11}$ However, their study focused only on refraction measurements and not on higher-order aberration measurements. In our study, the repeatability of the OPD-Scan in measuring total ocular aberrations was comparable to other aberrometers, but the repeatability in measuring corneal 
aberrations was low. Previous studies have found moderate to good results for the OPD-Scan when measuring both total ocular and corneal aberrations. ${ }^{19,25,26}$

We determined the interobserver variability by comparing measurements obtained by experts and nonexperts. We found a good interobserver variability for total ocular and corneal aberration measurements obtained with the Irx3, Keratron, and iTrace. However, the interobserver variability for the OPD-Scan was not satisfactory, since significant differences in repeatability were found when measuring total ocular aberrations. We believe this may have been caused by technical properties of the OPDScan, since it was generally easy for nonexperts to perform measurements, but difficult to evaluate if the quality of measurements was satisfactory.

The iTrace was able to measure total ocular aberrations in all eyes in our study, whereas the OPD-Scan, Irx3, and Keratron could not measure $11 \%, 9 \%$ and $4 \%$ of eyes, respectively. This was mainly because of a measured pupil size of less than $5 \mathrm{~mm}$. However, one eye with a minor nystagmus could only be measured with the iTrace and not with the Irx3, Keratron and OPD-Scan. The Hartmann-shack method uses a lenslet array to sample a large number of points across the pupil. However, Hartmann-shack aberrometry has been shown to be more difficult in highly aberrant eyes due to the crossover of spots from a lenslet to a neighbouring lenslet with increasing aberrations. ${ }^{16}$ The ray-tracing method uses sequential measurements and may therefore be more suitable to measure highly aberrant eyes. One study showed $14 \%$ of normal eyes and $50 \%$ of post-laser in situ keratomileusis eyes could not be measured with the Hartmann-Shack aberrometer, whereas the ray-tracing device was able to measure all eyes. ${ }^{16}$ Therefore, a limitation of the present study is that only young, healthy subjects were examined. Our study population consisted of subjects with a mean age of $25.1 \pm 6$ years, ranging from 21.8 to 48.9 years old. In addition, only healthy eyes with no ocular disease or previous ocular surgery were included. It would be worthwhile to compare different wavefront aberrometers in, for example, postrefractive surgery patients, patients with intraocular lenses, and patients with corneal disorders such as keratoconus.

Wavefront aberrations are pupil-size dependent and generally increase with increasing pupil diameter. Older aberrometer types generally used visible light to measure aberrations and required pupil dilation to avoid reflex pupil constriction. However, all aberrometers tested in this study use light wavelengths in the infrared spectrum and do not require pupil dilation. In addition, the application of mydriatic agents may cause differences in wavefront analysis. ${ }^{27,}{ }^{28}$ Apart from pupil size, the location of the pupil center is also an important factor in wavefront analysis, because it may serve as a 


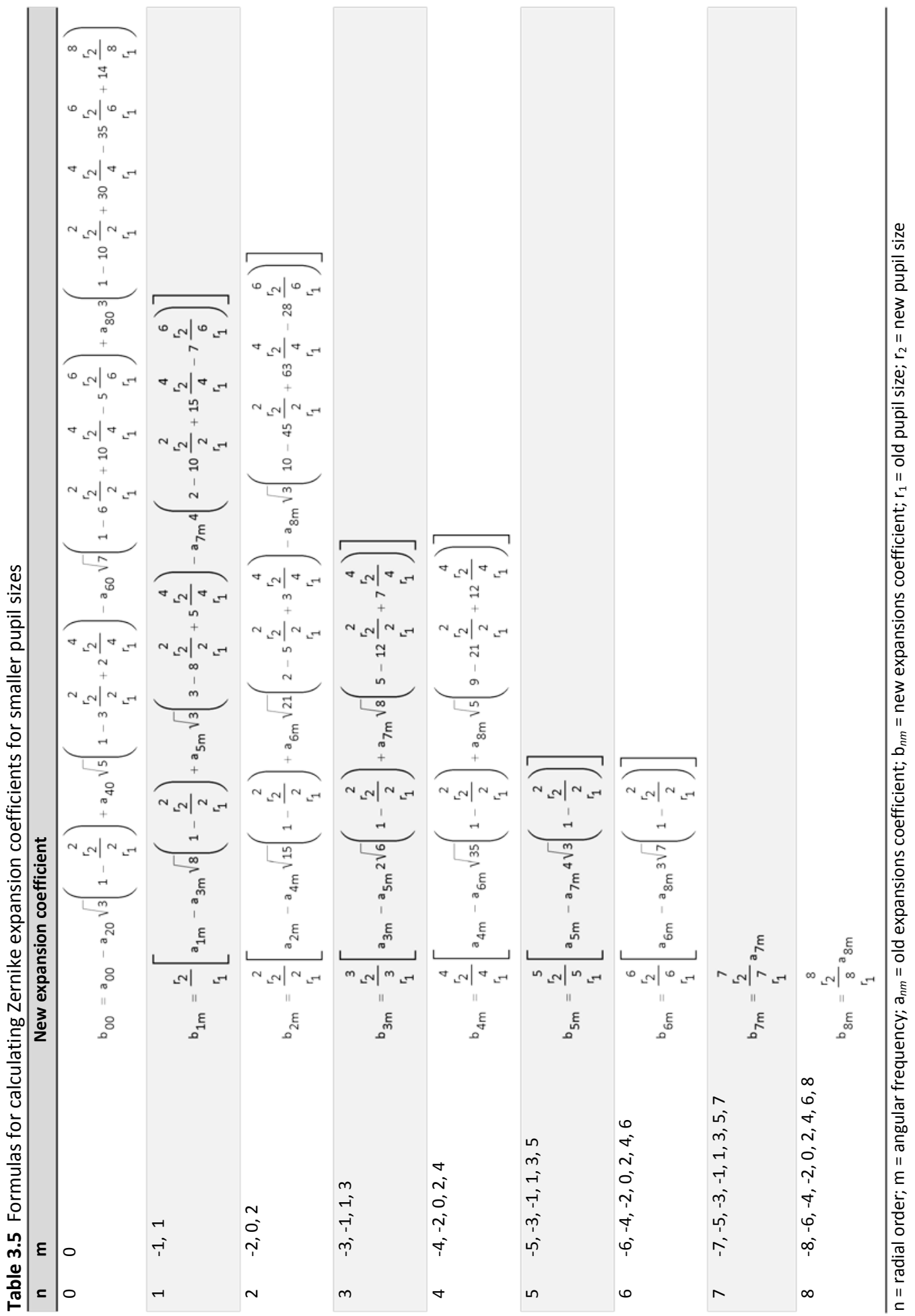


landmark for surgical correction of wavefront aberrations. Pharmacologic pupil dilation may erroneously induce a shift in the location of the pupil center, whereas natural pupil dilation resulted in minor changes in the location of the pupil center. ${ }^{29} \mathrm{We}$ therefore performed the wavefront analysis with natural pupil dilation in mesopic light conditions.

Wavefront aberrations change considerably with accommodation due to the shape changes of the crystalline lens. Aside from changes in lower-order aberrations with accommodation, most change in higher-order aberrations is noticeable in the spherical aberration, which decreases and may even become negative in young adults. ${ }^{30-32}$ It is therefore necessary to eliminate accommodation during measurements. Eliminating accommodation by using cycloplegic agents is not preferable, because this has been shown to significantly alter wavefront aberrations. ${ }^{27,28}$ The aberrometers tested in our study use different methods to prevent accommodation. The Irx3, Keratron and OPDScan use a fogging method that places the target out of focus, so that accommodation will not help one to attain a sharp image. The iTrace allows the patient to view through the device at a target image at optical infinity. In our study, we found significant differences between the devices in spherical aberration, the indicator of accommodation. Spherical aberration measurements obtained with the Keratron and OPD-Scan were significantly lower than those obtained with the Irx3 and iTrace. Hence, it is unclear whether the fogging method (Irx3, Keratron and OPD-Scan) or the method used by the iTrace is most effective in inhibiting accommodation. Even though pharmacologic agents alter wavefront aberrations and should preferably not be used in the clinic, an option in future studies comparing different aberrometers is to eliminate accommodation with cycloplegic agents. This approach would eliminate the influence of the different methods on the inhibition of accommodation and would allow for a more reliable comparison, without the possible influence of accommodation on measurements.

In summary, combined wavefront aberrometry and corneal topography allows discrimination between aberrations caused by the anterior cornea or by the internal ocular system. We found significant differences in total ocular and corneal aberration measurements obtained with the Irx3, Keratron, iTrace, and OPD-Scan in measuring eyes of healthy volunteers. Hartmann-Shack aberrometers showed the best repeatability for total ocular aberrations and the iTrace for corneal aberrations. It would be worthwhile in the future to perform a similar evaluation of aberrometers in more aberrant eyes. 


\section{References}

1. Schallhorn SC, Farjo AA, Huang D, et al. Wavefront-guided LASIK for the correction of primary myopia and astigmatism a report by the American Academy of Ophthalmology. Ophthalmology. Jul 2008;115(7):1249-1261.

2. Kohnen T, Klaproth OK, Buhren J. Effect of intraocular lens asphericity on quality of vision after cataract removal: an intraindividual comparison. Ophthalmology. Sep 2009;116(9):1697-1706.

3. Katsoulos C, Karageorgiadis L, Vasileiou N, Mousafeiropoulos T, Asimellis G. Customized hydrogel contact lenses for keratoconus incorporating correction for vertical coma aberration. Ophthalmic Physiol Opt. May 2009;29(3):321-329.

4. Einighammer J, Oltrup T, Feudner E, Bende $T$, Jean B. Customized aspheric intraocular lenses calculated with real ray tracing. J Cataract Refract Surg. Nov 2009;35(11):1984-1994.

5. Maeda N. Clinical applications of wavefront aberrometry - a review. Clin Experiment Ophthalmol. Jan 2009;37(1):118-129.

6. Thibos LN. Principles of Hartmann-Shack aberrometry. J Refract Surg. Sep-Oct 2000;16(5):S563-565.

7. Molebny VV, Panagopoulou SI, Molebny SV, Wakil YS, Pallikaris IG. Principles of ray tracing aberrometry. J Refract Surg. Sep-Oct 2000;16(5):S572-575.

8. Gualdi L, Cappello V, Giordano C. The use of NIDEK OPD Scan II wavefront aberrometry in toric intraocular lens implantation. J Refract Surg. Jan 2009;25(1 Suppl):S110-115.

9. Miranda MA, O'Donnell C, Radhakrishnan H. Repeatability of corneal and ocular aberration measurements and changes in aberrations over one week. Clin Exp Optom. May 2009;92(3):253-266.

10. Kawamorita T, Nakayama N, Uozato $\mathrm{H}$. Repeatability and reproducibility of corneal curvature measurements using the Pentacam and Keratron topography systems. J Refract Surg. Jun 2009;25(6):539544.

11. Win-Hall DM, Glasser A. Objective accommodation measurements in prepresbyopic eyes using an autorefractor and an aberrometer. J Cataract Refract Surg. May 2008;34(5):774-784.
12. Rozema JJ, Van Dyck DE, Tassignon MJ. Clinical comparison of 6 aberrometers. Part 1: Technical specifications. I Cataract Refract Surg. Jun 2005;31(6):1114-1127.

13. Thibos LN, Applegate RA, Schwiegerling JT, Webb R. Report from the VSIA taskforce on standards for reporting optical aberrations of the eye. J Refract Surg. Sep-Oct 2000;16(5):S654-655.

14. Bland JM, Altman DG. Statistical methods for assessing agreement between two methods of clinical measurement. Lancet. Feb 8 1986;1(8476):307-310.

15. Won JB, Kim SW, Kim EK, Ha BJ, Kim TI. Comparison of internal and total optical aberrations for 2 aberrometers: iTrace and OPD scan. Korean J Ophthalmol. Dec 2008;22(4):210-213.

16. Wang L, Wang N, Koch DD. Evaluation of refractive error measurements of the Wavescan Wavefront system and the Tracey Wavefront aberrometer. J Cataract Refract Surg. May 2003;29(5):970-979.

17. Rodriguez P, Navarro R, Gonzalez L, Hernandez JL. Accuracy and reproducibility of Zywave, Tracey, and experimental aberrometers. J Refract Surg. Nov-Dec 2004;20(6):810-817.

18. Rozema JJ, Van Dyck DE, Tassignon MJ. Clinical comparison of 6 aberrometers. Part 2: statistical comparison in a test group. $J$ Cataract Refract Surg. Jan 2006;32(1):33-44.

19. Bartsch DU, Bessho K, Gomez L, Freeman WR. Comparison of laser ray-tracing and skiascopic ocular wavefront-sensing devices. Eye (Lond). Nov 2008;22(11):1384-1390.

20. Schwiegerling J. Scaling Zernike expansion coefficients to different pupil sizes. J Opt Soc Am A Opt Image Sci Vis. Oct 2002;19(10):1937-1945.

21. Dai GM. Scaling Zernike expansion coefficients to smaller pupil sizes: a simpler formula. J Opt Soc Am A Opt Image Sci Vis. Mar 2006;23(3):539-543.

22. Cheng $X$, Himebaugh NL, Kollbaum PS, Thibos LN, Bradley A. Test-retest reliability of clinical Shack-Hartmann measurements. Invest Ophthalmol Vis Sci. Jan 2004;45(1):351-360.

23. Mirshahi A, Buhren J, Gerhardt D, Kohnen T. In vivo and in vitro repeatability of Hartmann-Shack aberrometry. J Cataract Refract Surg. Dec 2003;29(12):2295-2301. 
24. Dobos MJ, Twa MD, Bullimore MA. An evaluation of the Bausch \& Lomb Zywave aberrometer. Clin Exp Optom. May 2009;92(3):238-245.

25. Barreto J, Jr., Netto MV, Cigna A, Bechara S, Kara-Jose N. Precision of higher order aberration repeatability with NIDEK OPDscan retinoscopic aberrometry. J Refract Surg. Nov 2006;22(9 Suppl):S1037-1040.

26. Holzer MP, Goebels S, Auffarth GU. Precision of NIDEK OPD-scan measurements. J Refract Surg. Nov 2006;22(9 Suppl):S1021-1023.

27. Giessler S, Hammer T, Duncker GI. Aberrometry due dilated pupils--Which mydriatic should be used? Klin Monbl Augenheilkd. Sep 2002;219(9):655-659.

28. Carkeet A, Velaedan S, Tan YK, Lee DY, Tan DT. Higher order ocular aberrations after cycloplegic and non-cycloplegic pupil dilation. J Refract Surg. May-Jun 2003;19(3):316-322.
29. Yang Y, Thompson K, Burns SA. Pupil location under mesopic, photopic, and pharmacologically dilated conditions. Invest Ophthalmol Vis Sci. Jul 2002;43(7):25082512.

30. Ninomiya S, Fujikado T, Kuroda $T$, et al. Changes of ocular aberration with accommodation. Am J Ophthalmol. Dec 2002;134(6):924-926.

31. Lopez-Gil N, Fernandez-Sanchez V, Legras R, Montes-Mico R, Lara F, Nguyen-Khoa JL. Accommodation-related changes in monochromatic aberrations of the human eye as a function of age. Invest Ophthalmol Vis Sci. Apr 2008;49(4):1736-1743.

32. Plainis S, Plevridi E, Pallikaris IG. Comparison of the ocular wavefront aberration between pharmacologically-induced and stimulusdriven accommodation. Ophthalmic Physiol Opt. May 2009;29(3):272-280. 


\section{Chapter 4}

\section{Accuracy of toric intraocular lens alignment in cataract and refractive surgery}

Nienke Visser, Tos T.J.M. Berendschot, Noël J.C. Bauer, Jessica Jurich, Oliver Kersting and Rudy M.M.A. Nuijts Journal of Cataract \& Refractive Surgery 2011; 37: 1394-1402 


\section{Abstract}

PURPOSE: To determine the accuracy of a commonly used 3-step procedure for toric pseudophakic and phakic intraocular lens (IOL) alignment.

Setring: University Eye Clinic, Maastricht University Medical Centre, the Netherlands.

METHODS: In this analysis of toric IOL implantation, 6 preoperative images per eye and the surgery video were obtained using a digital imaging system. All 3 steps for toric IOL implantation were analyzed: reference axis marking, alignment axis marking and IOL alignment. In addition, a vector analysis was used to calculate the errors in toric IOL alignment.

RESULTS: Forty eyes (26 pseudophakic and 14 phakic) were analyzed. The mean errors in reference axis marking, alignment axis marking and toric IOL alignment were $2.4 \pm$ 0.8 (SD) degrees, $3.3 \pm 2.0$ degrees and $2.6 \pm 2.6$ degrees, respectively. Together, these 3 errors lead to a mean total error in toric IOL alignment of $4.9 \pm 2.1$ degrees. Subgroup analysis showed no significant difference in mean error between pseudophakic and phakic toric IOL alignment $(p=0.501)$. Vector analysis showed a mean angle or error of $-2 \pm 8$ degrees (pseudophakic IOLs) and $6 \pm 14$ degrees (phakic IOLS).

ConcLusion: A commonly used 3-step ink-marker procedure to align toric IOLs leads to a mean error in IOL placement of approximately 5 degrees. This error is especially relevant in cases in which a high cylinder power IOL is implanted. Orienting the toric IOL with great accuracy is necessary in all patients to achieve the optimum cylinder correction. 


\section{Introduction}

Toric pseudophakic intraocular lenses (IOLs) and toric phakic IOLs (pIOLs) are increasingly used in cataract and refractive surgery. They provide the opportunity to correct preexisting astigmatism, offering patients optimum distance vision without the use of spectacles or contact lenses. Among the options of regularly used toric pseudophakic IOLs are the Acrysof (Alcon Laboratories) the AT Comfort and AT Lisa multifocal (Carl Zeiss Meditec), and the T-flex and multifocal M-flex T IOLs (Rayner). The options for toric pIOLs include the Artisan and foldable Artiflex (Ophtec) and the toric Intraocular Collamer Lens (Staar Surgical).

Crucial to the efficacy of all toric IOLs is the position of the IOL with regard to the intended alignment axis, since every degree of misalignment leads to residual astigmatism. Misalignment of the IOL may be caused by two factors: inaccurate placement of the IOL, and/ or rotation of the IOL. Rotational stability used to be an issue in toric pseudophakic IOLs made of silicone. ${ }^{1-4}$ However, most currently used pseudophakic IOLs are acrylic and the reported postoperative rotation rate of these IOLS is less than 1 degree. ${ }^{5}$ Because of their design and fixation technique, rotation appears not to be an issue with iris-fixated toric pIOLs. ${ }^{6}$ This indicates that with both toric pseudophakic IOLs and pIOLs, accurate placement of the IOL is the most important factor in avoiding misalignment.

There are several methods to align the toric IOL at the intended axis. ${ }^{2,-11}$ However, most methods follow a 3-step procedure. First, the horizontal axis (0-180 degrees) of the eye is marked preoperatively with the patient sitting upright to correct for cyclotorsion. This is usually done using a reference marker or a slitlamp with a rotating slit. Next, intraoperatively, the desired alignment axis for the toric IOL is marked with an angular graduation instrument. Finally, the toric IOL is implanted and rotated until the IOL markings agree with the alignment marks.

The purpose of this study was to determine the accuracy of a commonly used 3-step ink-marker procedure for toric pseudophakic IOL and pIOL alignment using a new digital imaging system. In addition, vector analysis was performed to provide parallel mathematic confirmation of the physical accuracy of toric IOL alignment.

\section{Methods}

\section{Study Design and Patient Population}

In this prospective study, patients underwent cataract extraction with implantation of a toric pseudophakic IOL (Acrysof toric SN60T3-T9) or a toric pIOL (Artisan or Artiflex). 
Two experienced surgeons (RN and NB) performed all surgeries, between July 2009 and July 2010. All patients provided informed consent, and the tenets of the Declaration of Helsinki were followed.

Preoperatively, patients had a complete ophthalmic evaluation including manifest refraction, slitlamp examination, fundoscopy, applanation tonometry, partial coherence interferometry ( $\mathrm{PCl}$ ) optical biometry (IOLMaster, Carl Zeiss Meditec), corneal topography (Atlas, Carl Zeiss Meditec), and manual keratometry (Javal- Schiötz, Rodenstock). Patients having toric plOL implantation, also underwent noncontact specular microscopy (Noncon Robo SP-9000, Konan Medical Incorporation) and anterior segment optical coherence tomography (Visante, Carl Zeiss Meditec). Three months postoperatively, manifest refraction was performed in all patients.

Inclusion criteria for toric pseudophakic IOL implantation were regular corneal astigmatism of 1.25 diopters (D) or more and cataract. Exclusion criteria were tear-film abnormalities, Fuchs endothelial dystrophy (more than 2+ guttae) and extensive visual loss due to macular disease or glaucoma. Inclusion criteria for toric pIOL implantation were a subjective refractive astigmatism of $1.50 \mathrm{D}$ or more, a stable refractive error during the previous 2 years and unsatisfactory correction with spectacles or contact lenses. Exclusion criteria were an anterior chamber depth (ACD) of less than $3.2 \mathrm{~mm}$ (measured from the epithelium to the crystalline lens), an endothelial cell count less than 2000 cells $/ \mathrm{mm}^{2}$, an abnormal iris or pupil, a history of glaucoma, and chronic or recurrent uveitis.

\section{Toric Intraocular Lens Implantation}

Toric pseudophakic IOL (Acrysof SN60T3-T9) cylinder power and alignment axis were calculated using an online calculator (available at: www.acrysoftoriccalculator.com). This program takes into account the patient's keratometry $(\mathrm{K})$ values, the astigmatism meridians and the expected surgically induced corneal astigmatism. The $\mathrm{K}$ values obtained by optical biometry and the astigmatism steep and flat meridians from either the optical biometer, corneal topographer or manual keratometer were used. If the steep meridians from the optical biometer and corneal topographer were consistent within 5 degrees, the meridians obtained from the optical biometer were used. If the discrepancy was more than 5 degrees, the meridians obtained with the manual keratometer were used. An expected amount of incision-induced astigmatism of $0.5 \mathrm{D}$ ( $2.2 \mathrm{~mm}$ superior incision) was incorporated in the IOL calculation.

The refractive spherical equivalent, subjective refractive cylinder power, ACD and corneal curvature (optical biometer) were inserted into the van der Heijde formula to calculate the power of the toric plOL. ${ }^{12}$ The axis of surgical enclavation was derived 
from the subjective refraction. The Artiflex toric pIOL was implanted through a $3.4 \mathrm{~mm}$ and Artisan toric pIOL through a $5.4 \mathrm{~mm}$ superior corneoscleral incision, as described earlier. ${ }^{13,14}$ All power calculations were performed by Ophtec.

The marking steps for toric pseudophakic IOL and toric pIOL implantation were identical. Preoperatively, after topical anesthesia was administered, the patient was positioned upright to correct for cyclotorsion of the eye and asked to fixate at an object at distance. Limbal reference marks were placed at 0, 180 and 270 degrees (3, 6 and 9 o'clock, respectively) using a Nuijts/Lane toric reference marker with bubblelevel (AE-2791TBL, American Surgical Instruments Corp.). Intraoperatively, the limbal reference marks were used to mark the alignment axis with a Mendez degree gauge (AE-2765N, American Surgical Instruments Corp.) and a Nuijts toric axis marker (AE2740, American Surgical Instruments Corp.). In cases of cataract extraction with toric pseudophakic IOL implantation, a standard phacoemulsification was performed. Finally, the toric IOL was implanted and rotated to its final position by aligning the marks on the toric IOL with the alignment axis marks on the cornea.

\section{Accuracy of toric Intraocular Lens implantation}

The accuracy of toric IOL implantation was evaluated using the Surgery Guidance system (SG3000, Sensomotoric Instruments), which consists of a Reference Unit and a Surgery Pilot. The Reference Unit is a noncontact device that acquires a digital image of the eye (1.3 mega-pixel resolution), in which the limbal vessels, scleral vessels and iris are shown in detail (Figure 4.1A). Simultaneously, the unit performs keratometry using the optical reflections of 12 light emitting diodes arranged in a $1.9 \mathrm{~mm}$ ring. The keratometry results (including the steep and flat meridians of the cornea), and the position and diameter of the limbus and pupil are shown in an overlay on the digital image (Figure 4.1B). The Reference Unit is calibrated horizontally.

At the time of this study, the Surgery Pilot consisted of a microscope camera adapter, connected to a personal computer (PC). The preoperative image is loaded into the PC, and the rotation angle between the preoperative image and the microscope image is automatically detected (based on limbal and scleral vessels and iris characteristics) and overlaid on the microscope. Intraoperatively, the eye tracker provides a real-time update of all overlaid features relative to the camera image. The video of the surgery was recorded using the surgery unit.

Analysis of Errors in Toric Intraocular Lens implantation

Using the Reference Unit, 6 images ( 3 before and 3 after limbal reference marks were applied) were obtained per patient. Between these measurements, the patient left the 
device, underwent reference axis marking, and sat down again. The accuracy of marking the reference axis was assessed by evaluating 2 potential errors: cyclotorsion of the eye (error $A$ ) and error in horizontal placement of the reference marks (error $B$ ). Error A was defined as the cyclotorsion (rotation) of the eye between the preoperative image without reference marks and the preoperative image with reference marks. The rotation angle between these 2 images was determined manually using at least 6 reference points of blood vessel or iris landmarks on opposite sides of the pupil (error A; Figure 4.2). Error B was defined as the deviation (in degrees) of the center of the reference marks with regard to the calibrated horizontal line of the Reference Unit (Figure 4.3).

The accuracy of marking the alignment axis was determined using intraoperative images obtained from the surgery video. The angle between the marked reference axis and the marked alignment axis was determined (Figure 4.4). Subsequently, the difference between this angle and the intended alignment axis (obtained from the IOL calculation) was determined (error C).

The accuracy of the IOL alignment along the marked alignment axis was evaluated using intraoperative images from the surgery video. The angle between the center of the IOL marks and the center of the alignment axis marks was determined (error D; Figure 4.5).

A semiautomatic software tool was used to determine the rotation angle between 2 images (error A) and the angle between 2 lines (errors B, C and D). To determine rotation, 2 images were shown on a monitor next to each other. The examiner (NV) determined matching blood vessel and iris features in both images (at least 6) and marked these features by manually clicking on them. To determine the angle between 2 lines, the examiner manually clicked on the center of the relevant axes marks or IOL marks. The software tool automatically calculated the rotation between 2 images, or angle between 2 lines, based on the manually marked features. The mean total error \pm standard deviation (SD) of the 4 individual errors (errors A, B, C and D) was calculated using the following equations:

Mean total error: $\quad Y=\sqrt{\operatorname{Mean}_{A}{ }^{2}+\operatorname{Mean}_{B}{ }^{2}+\operatorname{Mean}_{C}{ }^{2}+\operatorname{Mean}_{D}{ }^{2}}$

SD of the total error:

$$
S D y=\sqrt{\left(\frac{\text { Mean }_{A} * \mathrm{SD}_{A}}{Y}\right)^{2}+\left(\frac{\text { Mean }_{B} * S_{B}}{Y}\right)^{2}+\left(\frac{\text { Mean }_{C}{ }^{*}{ }^{S D_{C}}}{Y}\right)+\left(\frac{\text { Mean }_{D}{ }^{*} S_{D}}{Y}\right)^{2}}
$$




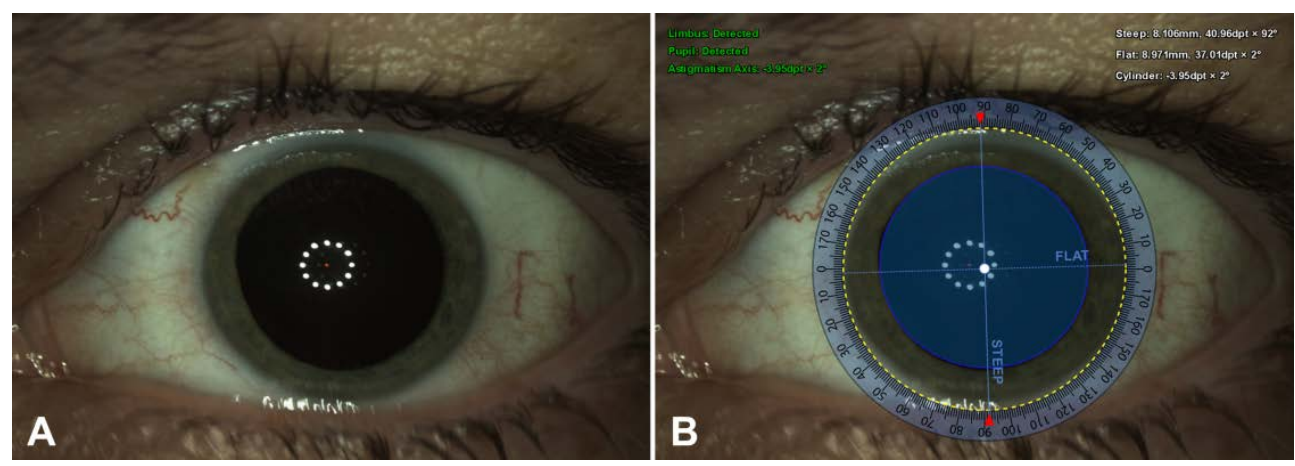

Figure 4.1 Example of an image obtained with the Reference Unit. A: Detailed image of the eye in which the limbal vessels, scleral vessels and iris characteristics are visible. Simultaneously when capturing the preoperative image, keratometry is performed and the keratometry results and the position and diameter of the limbus and pupil are shown in an overlay $(B)$.

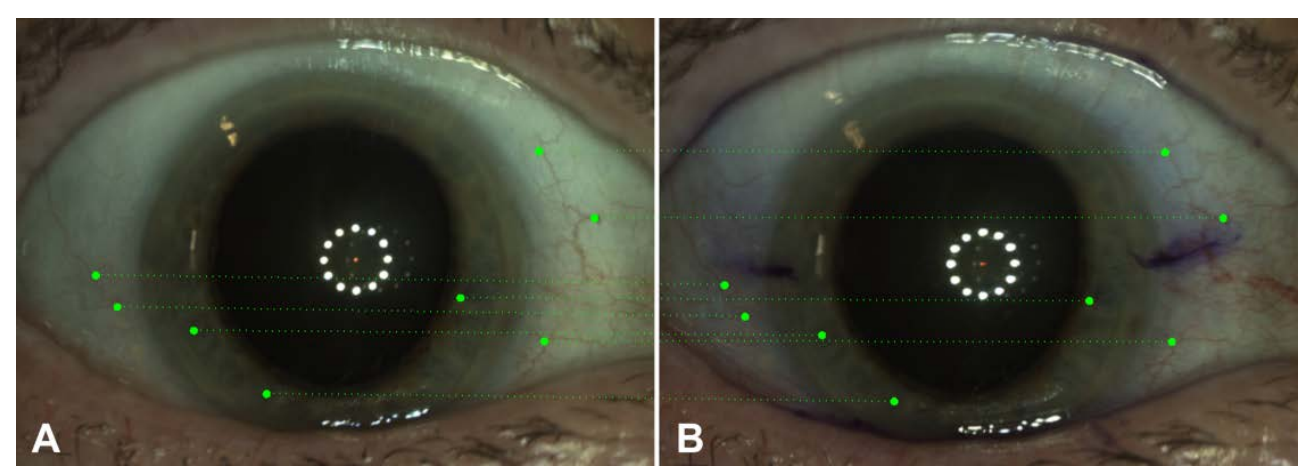

Figure 4.2 Cyclotorsion of the eye between two measurements (error A). First, image A was obtained. Next, the patient left the device and reference marks were applied. Image B was obtained after the patient sat down again. The rotation angle between image $A$ and image $B$ was assessed using blood vessel and iris landmarks (green dots).

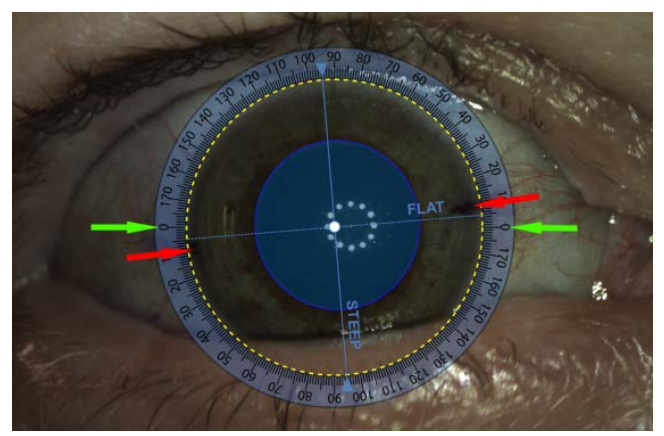

Figure 4.3 The horizontal placement of the reference axis marks was evaluated by determining the deviation (in degrees) of the reference marks (red arrows), with regard to the (calibrated) horizontal line (green arrows) of the Reference Unit (error B). 


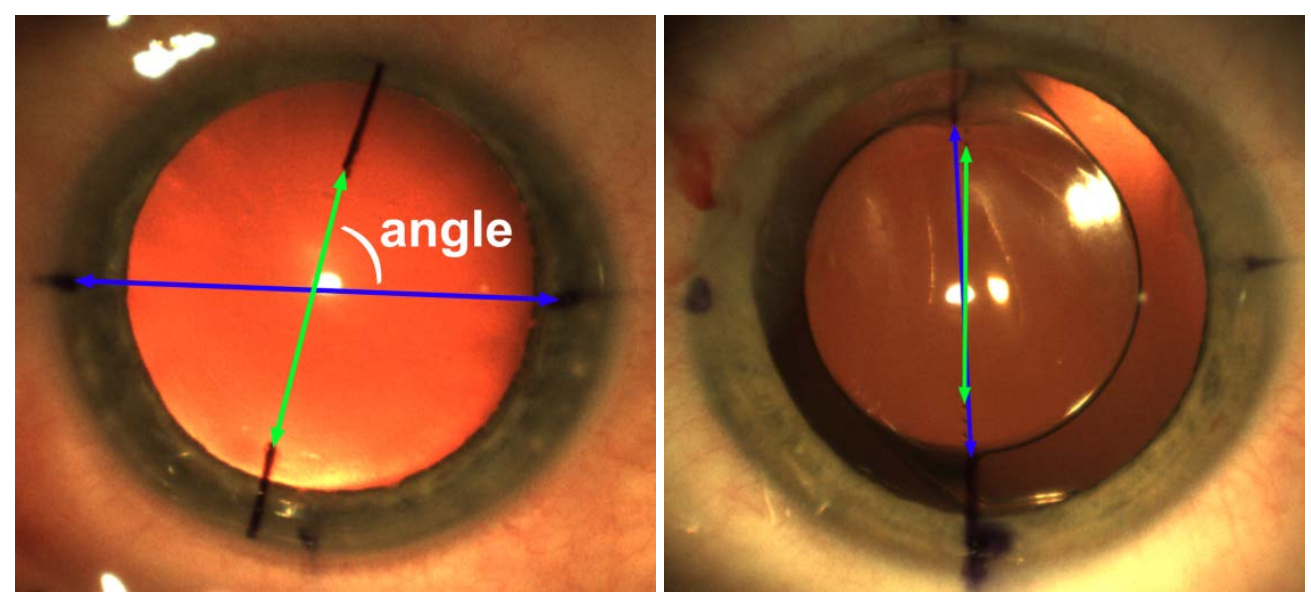

Figure 4.4 (Left) The accuracy of marking the alignment axis was determined by calculating the angle between the marked reference axis (blue arrow) and marked alignment axis (green arrow). Subsequently, the difference between this angle and the intended alignment axis was calculated (error C).

Figure 4.5 (Right) The accuracy of IOL alignment was evaluated by determining the angle between the center of the IOL marks (green arrow) and the centre of the alignment axis marks (blue line) (error D)

\section{Astigmatism Analysis by Alpins Method}

The overall accuracy of the astigmatism correction was calculated using a vector analysis according to Alpins. ${ }^{15}$ Alpins method uses 3 astigmatism parameters: preoperative astigmatism, target astigmatism and achieved astigmatism. In patients with a toric pseudophakic IOL, the postoperative refractive astigmatism was compared with the preoperative keratometric astigmatism from optical biometry. In patients with a toric plOL, the postoperative refractive astigmatism was compared with the preoperative refractive astigmatism. Target astigmatism was zero, because emmetropia was the goal in all patients.

Refractive astigmatism data were calculated to the corneal plane by adjusting for a back vertex distance of $12.0 \mathrm{~mm}$. Individual magnitude (diopters) and axis (degrees) values were transformed into rectangular $\mathrm{x}$ and $\mathrm{y}$ coordinates and used to calculate the following vectors: target induced astigmatism (TIA) vector, which represents the change (by magnitude and axis) the surgery was intended to induce; the surgically induced astigmatism (SIA) vector, which is the astigmatic change the surgery actually induced; and the difference vector, which represents the astigmatic change between the achieved astigmatic outcome and the target astigmatic outcome. The difference vector is an absolute measure of success and is preferably zero. The magnitude of error is defined as the arithmetic difference between the magnitudes of SIA and TIA. 
The magnitude of error is positive for overcorrection and negative for undercorrection. The angle of error is the angle between the SIA and TIA vectors. The angle is positive if the achieved correction is counterclockwise to the intended axis and negative if the achieved correction is clockwise to the intended axis. The flattening effect is the amount of astigmatism reduction achieved at the intended meridian (TIA meridian). The flattening index is calculated by dividing the flattening effect by the TIA and is preferably 1.0. The correction index was calculated by the ratio of the magnitude of SIA to the magnitude of TIA. The correction index is preferably 1.0. It is greater than 1.0 if overcorrection occurred and less than 1.0 if undercorrection occurred. The index of success was calculated by dividing the difference vector by the TIA. This is a relative measure of success and is preferably zero.

\section{Statistical Analysis}

All data were collected in an Excel database (Microsoft Office 2003, Microsoft Inc.). Data analysis using SPSS for Windows (version 16.0, SPSS Inc.) showed a normal distribution and allowed the use of parametric tests. A $P$ value less than 0.05 was considered statistically significant.

\section{Results}

The study enrolled 40 eyes of 31 patients: 26 eyes had implantation of an Acrysof toric IOL, 8 with an Artiflex toric pIOL and 6 with an Artisan toric plOL. Table 4.1 shows the patients' demographics. Patients in the pIOL subgroup were significantly younger than patients in the pseudophakic IOL subgroup.

Table 4.1 Patient demographics and preoperative characteristics

\begin{tabular}{|c|c|c|c|}
\hline & \multirow[b]{2}{*}{ All Toric IOLs } & \multicolumn{2}{|c|}{ Toric IOL subgroup } \\
\hline & & Pseudophakic & Phakic \\
\hline Eyes $(\mathrm{N})$ & 40 & 26 & 14 \\
\hline Patients (N) & 31 & 18 & 13 \\
\hline Female (\%) & $63 \%$ & $69 \%$ & $93 \%$ \\
\hline Age (mean years $\pm S D$ ) & $52.3 \pm 19.1$ & $58.8 \pm 18.2$ & $40.1 \pm 14.7$ \\
\hline \multicolumn{4}{|l|}{ Corneal astigmatism (D) * } \\
\hline Arithmetic mean magnitude ( $D \pm S D)$ & $2.30 \pm 1.13$ & $2.17 \pm 0.82$ & $2.54 \pm 1.56$ \\
\hline Vector mean (D @ degrees) & $1.24 \mathrm{D}$ at $93^{\circ}$ & $1.04 \mathrm{D}$ at $95^{\circ}$ & $1.63 \mathrm{D}$ at $90^{\circ}$ \\
\hline \multicolumn{4}{|l|}{ Refractive astigmatism (D) } \\
\hline Arithmetic mean magnitude ( $D \pm S D)$ & $-2.49 \pm 1.34$ & $-2.18 \pm 1.11$ & $-3.05 \pm 1.58$ \\
\hline Vector mean ( $D @$ degrees) & $1.02 \mathrm{D} @ 94^{\circ}$ & $0.63 \mathrm{D} @ 94^{\circ}$ & $1.73 \mathrm{D} @ 95^{\circ}$ \\
\hline
\end{tabular}


Table 4.2 Physical errors in toric IOL implantation

\begin{tabular}{llll}
\hline Step in toric IOL alignment & \multicolumn{2}{c}{ Toric IOL subgroup } \\
\cline { 2 - 4 } & $\begin{array}{l}\text { All Toric IOLs } \\
(40 \text { eyes) }\end{array}$ & $\begin{array}{l}\text { Pseudophakic } \\
(26 \text { eyes) }\end{array}$ & $\begin{array}{l}\text { Phakic } \\
\text { (14 eyes) }\end{array}$ \\
\hline 1. Reference axis marking (error A + error B) & $2.4 \pm 0.8$ & $2.6 \pm 0.9$ & $2.0 \pm 0.4$ \\
$\quad$ Cyclotorsion (error A) & $1.5 \pm 1.2(5.0)$ & $1.6 \pm 1.4(5.0)$ & $1.2 \pm 0.8(2.4)$ \\
$\quad$ Horizontal placement (error B) & $2.0 \pm 1.8(8.7)$ & $2.0 \pm 1.9(8.7)$ & $1.6 \pm 1.2(2.9)$ \\
2. Alignment axis marking (error C) & $3.3 \pm 2.0(7.7)$ & $3.5 \pm 1.8(7.7)$ & $3.0 \pm 2.3(7.3)$ \\
3. IOL alignment (error D) & $2.6 \pm 2.6(10.5)$ & $2.5 \pm 2.7(10.5)$ & $3.2 \pm 2.4(6.4)$ \\
Sum of errors & $4.9 \pm 2.1$ & $5.0 \pm 2.1$ & $4.8 \pm 2.2$ \\
\hline Data is shown as mean degrees \pm SD (maximum) & &
\end{tabular}

Table 4.2 shows the results of the analysis of the individual steps in toric IOL implantation. The mean cyclotorsion of the eye between images with and without reference marks (error A) was not more than 5 degrees in any case. The reference marks were more than 5 degrees off the calibrated horizontal axis (error $B$ ) in 1 eye. Together, error $A$ and $B$ caused a mean error in reference axis marking of $2.4 \pm 0.8$ degrees. The mean difference between the marked alignment axis and the intended alignment axis (error C) was more than 5 degrees in 6 eyes (15\%); no eye had a difference greater than 10 degrees. The mean error in IOL alignment (error D) was more than 5 degrees in 4 eyes (10\%) and more than 10 degrees in 1 eye (2\%). Together, errors A, B, C and D led to a mean total error in toric IOL alignment of $4.9 \pm$ 2.1 degrees. There was no statistically significant difference in the mean total error between the toric pseudophakic IOL and the toric pIOL subgroups $(P=0.501$; independent samples t-test).

Table 4.3 shows the results of the vectorial astigmatism analysis. The mean angle of error indicated that the mean angle of the SIA vector was $-2 \pm 8$ degrees clockwise to the TIA vector in the toric pseudophakic IOL group and $6 \pm 14$ degrees counterclockwise to the TIA vector in the toric $\mathrm{PIOL}$ group.

\section{Discussion}

Accurate positioning of a toric $\mathrm{IOL}$ is the most important factor determining the efficacy of the astigmatism correction. In this study, we analyzed the accuracy of a commonly used 3-step (inkmarker-based) method for toric IOL implantation. As far as we are aware, no previous studies have examined the accuracy of positioning toric IOLs. Furthermore, we describe a new device that combines eye-tracking technology 
with keratometry measurement, providing the opportunity to align the toric IOL in real-time during surgery.

We found a mean total error of $4.9 \pm 2.1$ degrees in the alignment of toric IOLs in cataract and refractive surgery. Every degree of misalignment contributes to residual astigmatism. At present, there are 2 views in the literature regarding the effect of toric IOL misalignment on remaining astigmatism (Figure 4.6). The first approach is based on the flattening effect. Vector analysis is used to determine the amount of astigmatism reduction achieved at the intended meridian of treatment (Figure $4.6 \mathrm{~A}$ ). ${ }^{16}$ Using this method, an error of 4.9 degrees would lead to $1.5 \%$ of preoperative astigmatism remaining at the intended meridian of treatment (the TIA meridian). The second approach determines the overall magnitude of astigmatism remaining. It is calculated by determining the vector difference between the target and achieved astigmatic outcomes (Figure 4.6B). ${ }^{17,18}$ Using this method, an error of 4.9 degrees would result in a remaining astigmatism magnitude of $17 \%$ of the preoperative astigmatism magnitude. The effect of a mean error of $4.9 \pm 2.1$ degrees is especially relevant when implanting a high-cylinder power toric IOL. In addition, the alignment error may be larger in individual cases due to fading out of the inkmarkings, horizontal or vertical translocation of the inkmarks or even complete washout of the ink-marks at the time of surgery. ${ }^{19}$ We did not have any problems with fading out or disappearing of inkmarks because the preoperative bubblemarker also leaves slight impressions on the cornea.

Table 4.3 Astigmatism analysis by Alpins method

\begin{tabular}{lcc}
\hline Parameter & \multicolumn{2}{c}{ Toric IOL subgroup } \\
\cline { 2 - 3 } & $\begin{array}{c}\text { Pseudophakic } \\
(26 \text { eyes) }\end{array}$ & $\begin{array}{c}\text { Phakic } \\
\text { (14 eyes) }\end{array}$ \\
\hline Target induced astigmatism & & \\
$\quad$ Arithmetic mean magnitude (D \pm SD) & $2.17 \pm 0.82$ & $3.05 \pm 1.58$ \\
$\quad$ Vector result $\left(D 0^{\circ}\right.$ ) & $1.04 @ 5$ & $1.73 @ 5$ \\
Surgically induced astigmatism & & \\
$\quad$ Arithmetic mean magnitude (D \pm SD) & $2.18 \pm 1.04$ & $2.78 \pm 2.22$ \\
$\quad$ Vector result (D @ ${ }^{\circ}$ ) & $1.25 @ 3$ & $1.74 @ 11$ \\
Difference vector & & \\
$\quad$ Arithmetic mean magnitude (D \pm SD) & $0.46 \pm 0.40$ & $1.00 \pm 0.96$ \\
$\quad$ Vector result (D @ ${ }^{\circ}$ ) & $0.24 @ 81$ & $0.38 @ 142$ \\
Magnitude of error (D \pm SD) & $0.00 \pm 0.47$ & $0.09 \pm 0.86$ \\
Angle of error ( ${ }^{\circ} \pm$ SD) & $-2 \pm 8$ & $6 \pm 14$ \\
Flattening effect (D \pm SD) & $2.11 \pm 1.04$ & $2.46 \pm 2.22$ \\
Flattening index & $0.96 \pm 0.28$ & $0.86 \pm 0.45$ \\
Correction Index & $0.99 \pm 0.27$ & $0.98 \pm 0.40$ \\
Index of success & $0.23 \pm 0.24$ & $0.40 \pm 0.28$ \\
\hline
\end{tabular}


We determined the physical accuracy of a commonly used 3-step method for toric IOL implantation by examining each step. The accuracy of reference axis marking is affected by the cyclotorsion (rotation) of the eye between 2 separate measurements (between which the patient left the device and sat down again) (error A). The mean cyclotorsion of the eye between 2 measurements was $1.5 \pm 1.2$ degrees. Cyclotorsion of the eye from the upright to supine position is a well-known aspect and generally compensated for during refractive surgery. Studies examining upright-to-supine cyclotorsion generally report values ranging from 2 to 4 degrees, although the value may be larger. ${ }^{20-22}$ However, cyclotorsion of the eye between 2 measurements, both with the patient in upright position, is less well established. This was recently examined by Wolffsohn and Buckhurst in 107 eyes using conjunctival vessels and iris features as landmarks. They found a mean rotation of $2.2 \pm 1.8$ degrees. $^{23}$ In addition, Viestenz et al. used standard fundus photography to examine eye rotation between 2 measurements in 400 eyes with the patient upright and found a mean rotation of $2.3 \pm$

A.

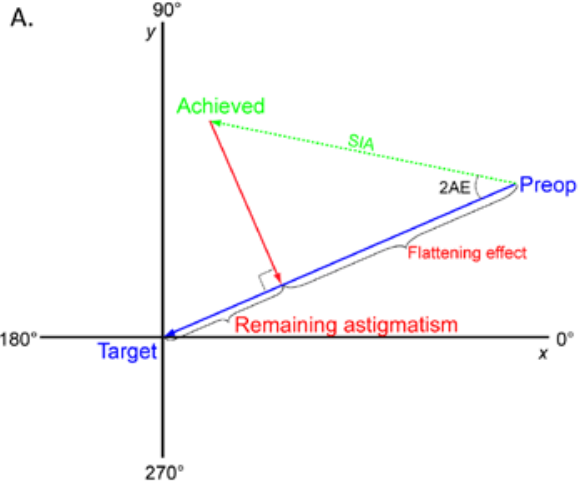

Flattening effect $(D)=S I A * \operatorname{Cos}(2 A E)$

Remaining astigmatism $(D)=$ Preop magnitude - flattening effect

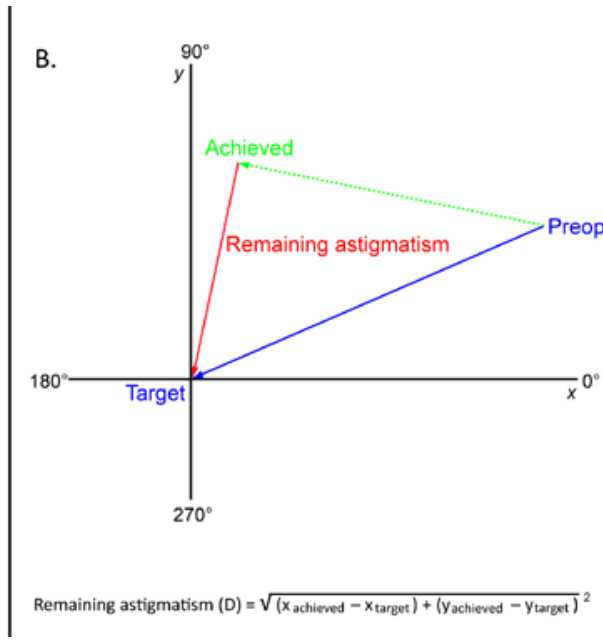

Figure 4.6 Two views in the current literature regarding the effect of toric IOL misalignment on remaining astigmatism. A. Method 1. Remaining astigmatism at the intended meridian of treatment is determined by the amount of astigmatism reduction achieved at the intended meridian of treatment (flattening effect). B. Method 2. Remaining astigmatism magnitude is determined by the magnitude of the vector between achieved and target astigmatism ( $\mathrm{AE}=$ angle of error; SIA = surgically induced astigmatism).

1.7 degrees. ${ }^{24}$ We found a value of $1.5 \pm 1.2$ degrees, which is slightly lower than the values reported by the abovementioned studies. This could be an underestimation because we measured patients within a time frame of approximately 5 minutes, whereas the other studies used time frames of 6 months. ${ }^{23,}{ }^{24}$ In addition, patients in 
our study were measured with their head fixated in a headrest and were able to look at a fixation light binocularly, which has been shown to reduce cyclotorsion. ${ }^{25,26}$ Cyclotorsion of the eye between the preoperative visit, where the biometry measurements are performed, and the surgery visit may introduce errors in alignment axis marking. A second factor that influences the accuracy of reference axis marking is the horizontal placement of the marks (error B). In our study, the mean error was low $(2.0 \pm 1.8$ degrees), indicating that the reference marker (with bubble-level) used in this study is effective in placing the marks horizontally. The mean error in marking the alignment axis (error $\mathrm{C}$ ) was $3.3 \pm 2.0$ degrees, which is relatively small considering that the Mendez gauge used to mark the alignment axis uses 10 degree steps. The IOL alignment along the marked alignment axis (error $D$ ) was off axis by a mean of $2.6 \pm 2.6$ degrees. We believe this is reasonable considering that the marks on the IOL are generally much smaller than the dimensions of the marks on the cornea.

We performed a vector analysis to provide a parallel mathematic confirmation to the physical accuracy of toric IOL alignment. In this analysis, we used the postoperative refractive astigmatism to determine the overall accuracy of toric IOLs in the correction of astigmatism. The mean angle of error between SIA and TIA vectors was $-2 \pm 8$ degrees in patients with a toric pseudophakic IOL and $6 \pm 14$ degrees in patients with a toric pIOL. The angle of error obtained in the vector analysis is not directly comparable to the physical error in toric IOL alignment because of the subjective component of the refractive outcome, the influence of the incision and possibly the effect of other refractive surfaces of the eye (posterior corneal surface and vitreous). However, the relatively large SDs of the calculated angles of error indicate that this angle of error was much larger in individual patients.

Alpins astigmatism analysis provides several indices to determine the overall success of astigmatism correction. The correction indices in our study indicate that $99 \%$ of astigmatism was corrected in the toric pseudophakic IOL group and $98 \%$ in the toric pIOL group. The mean flattening index was 0.96 in the toric pseudophakic IOL group and 0.86 in the toric plOL group, indicating that the toric pseudophakic IOL was more effective in reducing astigmatism at the intended meridian of treatment. In addition, the index of success also showed that the toric pseudophakic IOL was more successful in correcting astigmatism. We believe this may be the result of not incorporating the flattening effect of the incision in the pIOL power calculation. The exact effect of the incision on corneal astigmatism is difficult to predict and depends on the amount of preoperative corneal astigmatism, incision location, incision width, suture use and patient age. ${ }^{27-29}$ Pseudophakic IOLs may be implanted through a $2.2 \mathrm{~mm}$ sutureless corneal incision, which has been shown to induce 0.24 to $0.52 \mathrm{D}$ of flattening at the 
incised meridian. ${ }^{30-32}$ When performing the toric pseudophakic IOL power calculation, we incorporated an incision induced astigmatism of $0.50 \mathrm{D}$ into the $\mathrm{OL}$ power calculation. Toric pIOLs, however, require a much larger incision. The $3.4 \mathrm{~mm}$ and 5.4 $\mathrm{mm}$ incisions required for toric Artiflex and Artisan implantation, respectively, require sutures for wound closure. The incision-induced astigmatism for Artisan implantation is reported to be $0.74 \mathrm{D}^{33}$ However, the pIOL calculations are performed by the manufacturer and the effect of the incision is not incorporated into the plOL power calculation. Future studies should be performed to determine the effect of the $3.4 \mathrm{~mm}$ and $5.4 \mathrm{~mm}$ incisions on corneal astigmatism to incorporate it in the plOL power calculation.

The success of toric IOLs also depends on accurate preoperative measurements of corneal astigmatism (pseudophakic IOLs) and refractive astigmatism (plOLs). Our preferred method for pseudophakic IOLs is to measure corneal astigmatism with the IOLMaster and a corneal topographer. If these values are consistent within 5 degrees, we use the meridians obtained from the IOLMaster. If the discrepancy is more than 5 degrees, we use the meridians obtained by manual keratometry. For plOLs, we used the cylinder values obtained from the subjective refraction. We believe that using the Jackson-cross cylinder, the refractive cylinder axis can be refined with a precision of less than 5 degrees. Digital imaging techniques using iris and blood vessel characteristics have been used in previous studies. ${ }^{5,19,23}$ One report describes the acquisition of a preoperative digital image of the iris, in which the horizontal axis and the alignment axis are shown in an overlay. ${ }^{19}$ A printout of this image is used during surgery to align the toric IOL. Wolfsohn and Buckhurst used a digital imaging technique with blood vessel landmarks and iris features to determine the rotation and centration of toric IOLs. ${ }^{23}$ The repeatability of this technique was high, with a SD of intrasession repeatability of \pm 0.79 degrees. The combination of iris features and blood vessel characteristics, is in our opinion, an optimal combination. Iris features can alter between the undilated and dilated state of the pupil. Due to the anesthesia, a subconjunctival hemorrhage may occur, which can obliterate the vascular landmarks. This occurred in 2 patients in our study but did not lead to problems with eye tracking. By combining eye-tracking technology with keratometry, toric IOL alignment can be performed in real-time during surgery, making the manual marking steps obsolete. Furthermore, it will be possible to use the preoperative keratometry results for both toric IOL calculation and IOL alignment during surgery. In addition, eye-tracking technology may also be used for other aspects in IOL implantation surgery, including planning of the incisions and capsulorrhexis and optimal centration of multifocal IOLs. 
In conclusion, a commonly used 3-step manual (inkmarker) procedure for toric IOL alignment led to a mean error in IOL placement of approximately 5 degrees. However, this error may be higher in individual cases as a result of suboptimal ink-marks. This error is especially relevant in cases in which high cylinder power toric IOLs are implanted. Orienting the toric IOL with great accuracy is necessary in all patients to achieve the most optimum cylinder correction.

\section{References}

1. Chang DF. Early rotational stability of the longer Staar toric intraocular lens: fifty consecutive cases. J Cataract Refract Surg. May 2003;29(5):935-940.

2. De Silva DJ, Ramkissoon YD, Bloom PA. Evaluation of a toric intraocular lens with a Z-haptic. J Cataract Refract Surg. Sep 2006;32(9):1492-1498.

3. Dick HB, Krummenauer F, Trober L. [Compensation of corneal astigmatism with toric intraocular lens: results of a multicentre study]. Klin Monatsbl Augenheilkd. Jul 2006;223(7):593-608.

4. Till JS, Yoder PR, Jr., Wilcox TK, Spielman JL. Toric intraocular lens implantation: 100 consecutive cases. J Cataract Refract Surg. Feb 2002;28(2):295-301.

5. Weinand $F$, Jung $A$, Stein A, Pfutzner A, Becker R, Pavlovic S. Rotational stability of a single-piece hydrophobic acrylic intraocular lens: new method for high-precision rotation control. J Cataract Refract Surg. May 2007;33(5):800-803.

6. Tehrani M, Dick HB, Schwenn O, Blom E, Schmidt AH, Koch HR. Postoperative astigmatism and rotational stability after artisan toric phakic intraocular lens implantation. J Cataract Refract Surg. Sep 2003;29(9):1761-1766.

7. Ahmed I, Rocha G, Slomovic AR, et al. Visual function and patient experience after bilateral implantation of toric intraocular lenses. J Cataract Refract Surg. Apr 2010;36(4):609-616.

8. Bauer NJ, de Vries NE, Webers CA, Hendrikse F, Nuijts RM. Astigmatism management in cataract surgery with the AcrySof toric intraocular lens. J Cataract Refract Surg. Sep 2008;34(9):1483-1488.

9. Carey PJ, Leccisotti A, McGilligan VE, Goodall EA, Moore CB. Assessment of toric intraocular lens alignment by a refractive power/corneal analyzer system and slitlamp observation. I Cataract Refract Surg. Feb 2010;36(2):222-229.

10. Leyland $M$, Zinicola $E$, Bloom $P$, Lee $N$. Prospective evaluation of a plate haptic toric intraocular lens. Eye. Apr 2001;15(Pt 2):202205.

11. Zuberbuhler B, Signer T, Gale R, Haefliger E. Rotational stability of the AcrySof SA60TT toric intraocular lenses: a cohort study. $B M C$ Ophthalmol. 2008;8:8.

12. van der Heijde GL, Fechner PU, Worst JG. [Optical consequences of implantation of a negative intraocular lens in myopic patients]. Klin Monbl Augenheilkd. Jul 1988;193(1):99-102.

13. Doors M, Cals DW, Berendschot TT, et al. Influence of anterior chamber morphometrics on endothelial cell changes after phakic intraocular lens implantation. J Cataract Refract Surg. Dec 2008;34(12):2110-2118.

14. Tahzib NG, Nuijts RM, Wu WY, Budo CJ. Long-term study of Artisan phakic intraocular lens implantation for the correction of moderate to high myopia: tenyear follow-up results. Ophthalmology. Jun 2007;114(6):1133-1142.

15. Alpins NA. New method of targeting vectors to treat astigmatism. J Cataract Refract Surg. Jan-Feb 1997;23(1):65-75.

16. Alpins NA. Vector analysis of astigmatism changes by flattening, steepening, and torque. I Cataract Refract Surg. Dec 1997;23(10):1503-1514.

17. Ma JJ, Tseng SS. Simple method for accurate alignment in toric phakic and aphakic intraocular lens implantation. J Cataract Refract Surg. Oct 2008;34(10):1631-1636.

18. Shimizu K, Misawa A, Suzuki Y. Toric intraocular lenses: correcting astigmatism 
while controlling axis shift. J Cataract Refract Surg. Sep 1994;20(5):523-526.

19. Osher $\mathrm{RH}$. Iris fingerprinting: new method for improving accuracy in toric lens orientation. J Cataract Refract Surg. Feb 2010;36(2):351-352.

20. Arba-Mosquera S, Merayo-Lloves J, de Ortueta D. Clinical effects of pure cyclotorsional errors during refractive surgery. Invest Ophthalmol Vis Sci. Nov 2008;49(11):4828-4836.

21. Chernyak DA. Cyclotorsional eye motion occurring between wavefront measurement and refractive surgery. J Cataract Refract Surg. Mar 2004;30(3):633-638.

22. Swami AU, Steinert RF, Osborne WE, White AA. Rotational malposition during laser in situ keratomileusis. Am J Ophthalmol. Apr 2002;133(4):561-562.

23. Wolffsohn JS, Buckhurst PJ. Objective analysis of toric intraocular lens rotation and centration. J Cataract Refract Surg. May 2010;36(5):778-782.

24. Viestenz A, Seitz B, Langenbucher A. Evaluating the eye's rotational stability during standard photography: effect on determining the axial orientation of toric intraocular lenses. J Cataract Refract Surg. Mar 2005;31(3):557-561.

25. Becker R, Krzizok TH, Wassill H. Use of preoperative assessment of positionally induced cyclotorsion: a video-oculographic study. Br J Ophthalmol. Mar 2004;88(3):417421.

26. Tjon-Fo-Sang MJ, de Faber JT, Kingma C, Beekhuis WH. Cyclotorsion: a possible cause of residual astigmatism in refractive surgery. J Cataract Refract Surg. Apr 2002;28(4):599602.
27. Oshika T, Nagahara K, Yaguchi S, et al. Three year prospective, randomized evaluation of intraocular lens implantation through 3.2 and $5.5 \mathrm{~mm}$ incisions. J Cataract Refract Surg. Apr 1998;24(4):509-514.

28. Storr-Paulsen A, Madsen $H$, Perriard A. Possible factors modifying the surgically induced astigmatism in cataract surgery. Acta Ophthalmol Scand. Oct 1999;77(5):548551.

29. Tejedor J, Perez-Rodriguez JA. Astigmatic change induced by $2.8-\mathrm{mm}$ corneal incisions for cataract surgery. Invest Ophthalmol Vis Sci. Mar 2009;50(3):989-994.

30. Can I, Takmaz T, Yildiz Y, Bayhan HA, Soyugelen G, Bostanci B. Coaxial, microcoaxial, and biaxial microincision cataract surgery: prospective comparative study. J Cataract Refract Surg. May 2010;36(5):740-746.

31. Lee KM, Kwon HG, Joo CK. Microcoaxial cataract surgery outcomes: comparison of $1.8 \mathrm{~mm}$ system and $2.2 \mathrm{~mm}$ system. J Cataract Refract Surg. May 2009;35(5):874880.

32. Wang J, Zhang EK, Fan WY, Ma JX, Zhao PF. The effect of micro-incision and smallincision coaxial phaco-emulsification on corneal astigmatism. Clin Experiment Ophthalmol. Sep 2009;37(7):664-669.

33. Bartels MC, Saxena R, van den Berg TJ, van Rij G, Mulder PG, Luyten GP. The influence of incision-induced astigmatism and axial lens position on the correction of myopic astigmatism with the Artisan toric phakic intraocular lens. Ophthalmology. Jul 2006;113(7):1110-1117. 


\section{Chapter 5}

Toric versus aspherical control intraocular lenses in patients with cataract and corneal astigmatism: A randomized controlled trial

Nienke Visser, Henny J.M. Beckers, Noël J.C. Bauer, Sacha T.J.M. Gast, Bart L.M. Zijlmans, Tos T.J.M. Berendschot, Carroll A.B. Webers and Rudy M.M.A. Nuijts JAMA Ophthalmology 2014; 132: 1462-1468 


\section{Abstract}

PURPOSE: To compare bilateral aspherical toric with bilateral aspherical control intraocular lens (IOL) implantation in patients with cataract and corneal astigmatism.

DESIGN: Randomized controlled trial

SETtING: University Eye Clinic, Maastricht University Medical Center, and the Rotterdam Eye Hospital, the Netherlands.

Methods: 86 subjects with bilateral cataract and bilateral corneal astigmatism of at least $1.25 \mathrm{D}$ were randomized for either bilateral toric (Acrysof aspherical toric IOL SN6AT3-T9; $\mathrm{N}=41$ ) or bilateral control IOL (Acrysof aspherical control IOL SN60WF; $\mathrm{N}=45$ ) implantation. Main outcome measures were: spectacle independency for distance vision, uncorrected distance visual acuity (UDVA), refractive astigmatism, contrast sensitivity, wavefront aberrations and refractive error-related quality of life (RQL-42 questionnaire).

RESULTS: Preoperatively, mean corneal astigmatism was $2.02 \pm 0.95 \mathrm{D}$ and $2.00 \pm 0.84 \mathrm{D}$ in the toric and control group, respectively. Four patients (5\%) were lost to follow-up. At 6 months postoperatively, 70\% of patients in the toric group achieved an UDVA of $20 / 25$ or better, compared to $31 \%$ in the control group ( $P<0.001$, odds ratio $5.23,95 \%$ confidence interval 2.03-13.48). Spectacle independency for distance vision was achieved in $84 \%$ of patients in the toric group, compared to $31 \%$ in the control group $(\mathrm{P}<0.001$, odds ratio $11.44,95 \%$ confidence interval 3.89 to 33.63$)$. Mean refractive astigmatism was $-0.77 \pm 0.52 \mathrm{D}$ and $-1.89 \mathrm{D} \pm 1.00 \mathrm{D}$, respectively. Vector analysis of toric IOLs showed a mean magnitude of error of $+0.38 \mathrm{D}$, indicative of overcorrection. No differences were found in contrast sensitivity, higher-order aberrations or refractive error-related quality of life.

CONCLUSION: In patients with cataract and corneal astigmatism, bilateral toric IOL implantation results in a higher spectacle independency for distance vision compared to bilateral control IOL implantation. No significant differences were found in contrast sensitivity, higher-order aberrations or refractive-error related quality of life following both treatments.

Trial registration: clinicaltrials.gov, ID NCT01075542. 


\section{Introduction}

In modern cataract surgery, spectacle freedom is becoming increasingly important. Emmetropia can be achieved for patients with myopic or hyperopic refractive errors by selecting the appropriate spherical lens power. However, approximately $20 \%$ to $30 \%$ of patients who undergo cataract surgery have corneal astigmatism of at least 1.25 diopters (D). ${ }^{1,2}$ Not correcting the astigmatism component at the time of cataract surgery will fail to achieve spectacle independency in these patients.

Toric IOLs have been shown to be a safe and effective treatment option for correcting astigmatism. ${ }^{3-5}$ However, so far no randomized controlled trials (RCTs) have compared spectacle independency and quality of vision, including contrast sensitivity or higherorder aberrations, following bilateral toric and control IOL implantation. The main purpose of our study was therefore to compare spectacle independency for distance vision following bilateral toric and control IOL implantation. Secondary outcome measures were uncorrected distance visual acuity, refractive astigmatism, contrast sensitivity, wavefront aberrations, and refractive error-related quality of life.

\section{Methods}

This multicentre RCT was conducted at two hospitals in the Netherlands: the University Eye Clinic of the Maastricht University Medical Center and the Rotterdam Eye Hospital. Institutional review boards of both participating centres approved the study. Written informed consent was obtained after the nature of the study had been explained. The study adhered to the tenets of the Declaration of Helsinki and good clinical practice guidelines and was registered in a clinical trial register (clinicaltrials.gov, ID NCT01075542). Patients were included between February 2010 and March 2012.

\section{Subjects}

Inclusion criteria were age 21 years or older, bilateral age-related cataract, and bilateral regular corneal astigmatism of at least $1.25 \mathrm{D}$. Exclusion criteria included irregular corneal astigmatism, Fuchs endothelial dystrophy stage 2 or higher ${ }^{6}$, glaucoma related extensive visual field loss, or an expected postoperative corrected distance visual acuity of less than 20/40. Consecutive patients from the clinical population with cataract and bilateral corneal astigmatism were approached to participate in the study. 


\section{Intervention}

The test lenses consisted of the Acrysof aspherical toric IOL (model SN6AT3-T9; Alcon Laboratories) with cylinder powers from $1.50 \mathrm{D}$ to $6.00 \mathrm{D}$ (0.75 D steps). Available spherical powers range from +6.00 to $+30.00 \mathrm{D}$. The spherical power was calculated using optical biometry (IOLMaster, Carl Zeiss Meditec) and the SRK/T formula (Aconstant 118.9 , target emmetropia). The toric IOL was calculated using a web-based calculator (available at: www.acrysoftoriccalculator.com). The expected surgically induced corneal astigmatism and incision location (superior) were incorporated in the toric IOL calculation. Astigmatism axes measurements obtained by optical biometry and corneal topography (Atlas, Carl Zeiss Meditec; or Keratron Onda, Optikon) were compared. In case of less than 5 degree difference, optical biometry values were used. In case of more than 5 degree difference, manual keratometry (Javal-Schiötz keratometer, Rodenstock) values were used.

The control lens consisted of the Acrysof aspherical IOL model SN60WF (Alcon Laboratories). Available spherical powers range from +6.0 to $+30.0 \mathrm{D}$. This IOL has an identical design compared to the Acrysof toric IOL. The spherical power was calculated using the SRK/T formula (A-constant 118.9) and target emmetropia).

\section{Surgical procedure}

Preoperative and intraoperative marking was performed as previously described. ${ }^{7} \mathrm{~A}$ standard phacoemulsification technique was performed using a superior $2.2 \mathrm{~mm}$ limbal incision. Postoperatively, patients were prescribed a fixed combination eye drop of tobramycin $3 \mathrm{mg} / \mathrm{mL}$-dexamethasone $1 \mathrm{mg} / \mathrm{mL}$ (Alcon) and nepafenac $1 \mathrm{mg} / \mathrm{mL}$ (Alcon) in a tapering dose for 4 weeks.

\section{Outcome measures}

Preoperatively, the following examinations were conducted: slitlamp examination, funduscopy, Goldmann applanation tonometry, visual acuity, objective refraction (Topcon) and subjective refraction. Uncorrected (UDVA) and corrected distance visual acuity (CDVA) were assessed using the 100\% contrast Early Treatment Diabetic Retinopathy Study (ETDRS) chart (Precision Vision) at $4 \mathrm{~m}$. ETDRS scores were determined as follows: the log score of the last row where the patient correctly identified all 5 letters was recorded (e.g. 0.10 log row); next 0.02 log units was subtracted for every letter that was correctly identified beyond the last row (e.g. 0.10 $\log$ row +3 letters on the $0.00 \log$ row $=0.10-\left(3^{*} 0.02\right)=0.04$ LogMAR). Corneal topography was performed using the Atlas (Carl Zeiss Meditec) or Keratron Onda. Both devices are Placido-disk videokeratoscopes and determine anterior corneal curvature 
in the central $3.0 \mathrm{~mm}$ zone. Pre- and postoperative measurements were always performed with the same device. In addition, manual keratometry (Javal-Schiötz keratometer) and biometry (IOLMaster) were performed. Contrast sensitivity was measured using the CSV-1000 contrast test (Vector vision), under photopic conditions $\left(85 \mathrm{~cd} / \mathrm{m}^{2}\right)$ and at $2.5 \mathrm{~m}$ testing distance. We compared our values to those obtained for a normal population with a mean age of 64 years. $^{8}$

Wavefront aberrometry was performed with the Keratron Onda or iTrace (Tracey technologies). The Keratron Onda is a combined Hartmann-Shack aberrometer and Placido-disk videokeratoscope. The iTrace is a combined ray-tracing aberrometer and Placido-disk videokeratoscope. Pre- and postoperative measurements were always performed with the same device. Head positioning and eye alignment were carefully checked before each measurement. Natural pupil dilation was obtained in all subjects under mesopic light condition (<1 lux). Aberrations were exported for a $3.5 \mathrm{~mm}$ pupil as Zernike coefficients $(Z(x, x)) .{ }^{9}$ Root mean square (RMS) values were calculated for lower-order astigmatism $(Z(2, \pm 2))$, coma-like aberrations $(Z(3, \pm 3)+Z(5, \pm 5))$, sphericallike aberrations $(Z(2,0)+Z(4,0)+Z(6,0))$ and higher-order aberrations $(Z(3,-3)$ up to $\mathrm{Z}(7,7))$.

Spectacle use for distance vision was evaluated using a questionnaire. Patients rated spectacle use on a scale of 1 to 5: always (1), usually (2), half of the time (3), sometimes (4), never (5). Refractive error-related quality of life was evaluated using the National Eye Institute Refractive Error Quality of Life (RQL-42) questionnaire. ${ }^{10}$ The RQL-42 questionnaire is a self-administered questionnaire. Each subscale is scored from 0 to 100; a higher score indicating a better quality of life.

Postoperatively at 1 week and 1 month, the UDVA and CDVA were determined, and slitlamp examination was performed in mydriasis to assess toric IOL alignment. Toric IOL alignment was measured using a slitlamp with rotating slit. Accurate head positioning and horizontal eye alignment were ensured before each measurement and patients were asked to fixate at distance. At 3 and 6 months postoperatively, full examinations were performed.

\section{Sample size}

Sample size calculation was based on estimated spectacle independency following bilateral toric or control IOL implantation, based on the study of Holland et al. and Lane et al.: estimated spectacle independence of $80 \%$ following toric IOL implantation and $45 \%$ following control IOL implantation. ${ }^{41}$ Sample size calculation was performed using the PS: Power and Sample Size Calculation Software ${ }^{12}$, based on an $\alpha$ of 0.05 and a power of $90 \%$, and resulted in a sample size of 38 patients per group. Including an 
expected $10 \%$ lost to follow up, the total sample size was calculated at 86 patients. Four patients were lost to follow-up in the toric group (Figure 5.1). The last recorded UDVA in these patients was $0.04 \log M A R, 0.04 \log M A R, 0.12 \log M A R$ and 0.22 LogMAR. The last patient was found to have a macular pucker. No patients were lost to follow-up in the control group.

\section{Randomization}

Consecutive patients were randomized using an online program (TenAlea, FormsVision BV). Patients' gender, age and highest calculated toric IOL power for both eyes were used as stratification factors. The surgeon received the assigned randomization by email. The patient and investigator performing the postoperative examinations were blinded for treatment allocation. Slitlamp examination was performed by a second examiner. Randomization was revealed after 6 months follow-up.

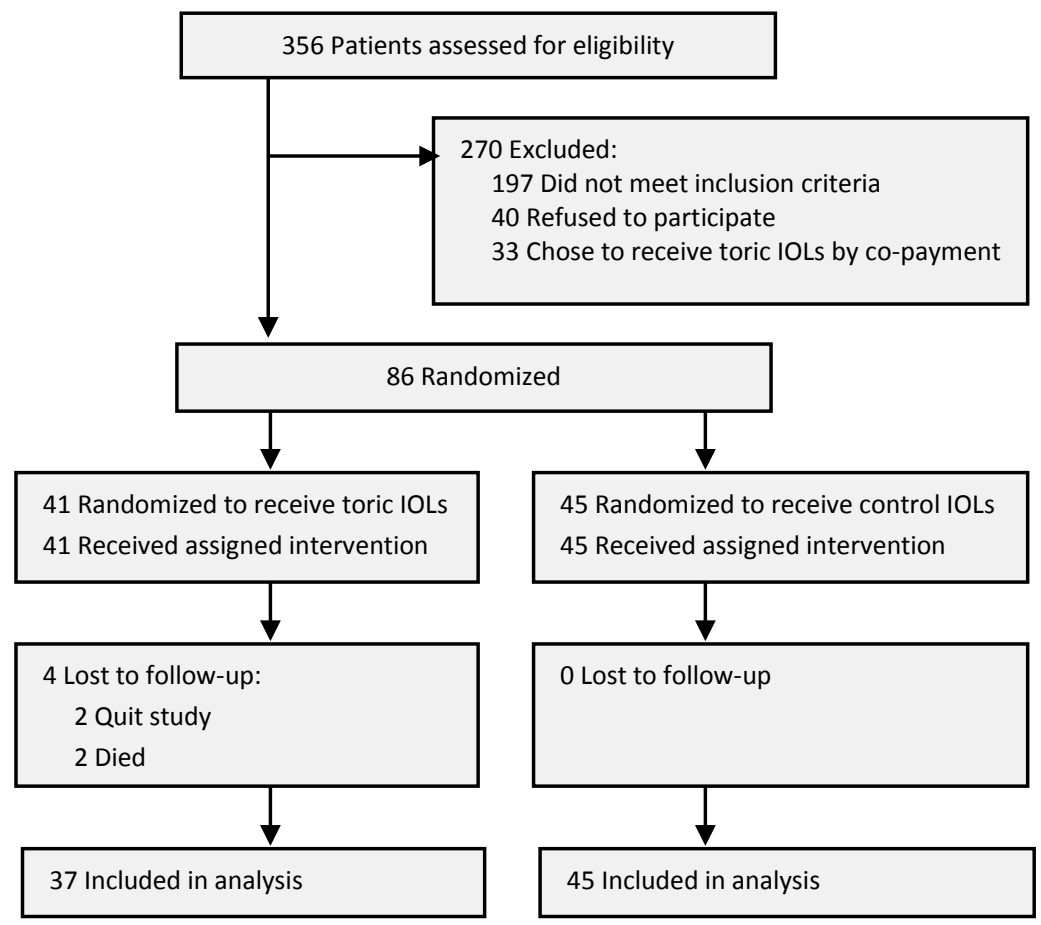

Figure 5.1 Flowchart of patient screening and follow-up. 
Data management and statistics

Data was collected in an online data management system (Macro, InferMed) and analyzed using Excel (Microsoft Office 2007, Microsoft Inc.). LogMAR scores were calculated to the approximate Snellen equivalent. Surgically induced corneal astigmatism was calculated as the vector change between preoperative and postoperative corneal astigmatism (measured by corneal topography). ${ }^{13}$ The effectiveness of astigmatism correction by toric IOLs was determined using Alpins

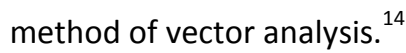

Statistical analyses were performed using SPSS for Windows (version 16.0, SPSS Inc.). Data was analyzed using an intention-to-treat analysis. Parameters showed a normal distribution and allowed us to use parametric tests. Continuous data was analyzed using independent T-tests (mean differences with 95\% confidence intervals; $\mathrm{Cl}$ ). Dichotomous variables were analyzed using Chi-square tests ( $P$-value; and odds ratio (OR) with $95 \% \mathrm{Cl}$ ).

\section{Results}

\section{Participant flow and patient characteristics}

Eighty-six patients were enrolled in this study: 41 in the toric group and 45 in the control group (Figure 5.1). Patient characteristics are shown in Table 5.1.

\section{Visual acuity}

At 6 months postoperatively, 26 of 37 patients (70\%) in the toric group achieved an UDVA of 20/25 (0.1 LogMAR) or better, compared to 14 of 45 patients (31\%) in the control group ( $P<0.001$, OR 5.23, 95\% Cl 2.03-13.48; Figure 5.2A). A CDVA of 20/25 or better was achieved in 33 of 37 patients (89\%) and 41 of 45 patients (91\%) in the toric

Table 5.1 Preoperative patient characteristics

\begin{tabular}{lcc}
\hline & Toric group & Control group \\
\hline Eyes (N) & 82 & 90 \\
Age (mean years; range) & $74(50$ to 88$)$ & $74(49$ to 87$)$ \\
Women, (N, \%) & $21(51 \%)$ & $21(46 \%)$ \\
CDVA (mean \pm SD LogMAR; range) & & \\
$\quad$ Monocular & $0.34 \pm 0.35(0.00$ to 3.00$)$ & $0.34 \pm 0.36(0.04$ to 3.00$)$ \\
$\quad$ Binocular & $0.22 \pm 0.16(0.00$ to 0.72$)$ & $0.19 \pm 0.15(-0.04$ to 0.64$)$ \\
Corneal astigmatism (mean D \pm SD; range) & $2.02 \pm 0.95(1.20$ to 6.15$)$ & $2.00 \pm 0.84(1.23$ to 5.54$)$ \\
Refractive astigmatism (mean D \pm SD; range) & $-2.27 \pm 1.15(-0.50$ to -7.00$)$ & $-2.28 \pm 1.21(0.00$ to -6.25$)$ \\
\hline
\end{tabular}


and control group, respectively ( $P=0.770, O R$ 0.81, 95\% $\mathrm{Cl} 0.19-3.47$, Figure 5.2B). Within both groups, no changes were identified in UDVA and CDVA between 1, 3 and 6 months postoperatively.

\section{Astigmatism}

Preoperatively, no difference was identified in the amount of corneal astigmatism between groups. At 6 months postoperatively, surgically induced corneal astigmatism was $-0.12 \pm 0.72 \mathrm{D}$ at 115 degrees in the toric group and $-0.12 \pm 0.45 \mathrm{D}$ at 94 degrees in the control group. The mean magnitude of refractive astigmatism at 6 months postoperatively was $-0.77 \pm 0.52$ (range 0 to -2.00 ) $D$ in the toric group and $-1.89 \mathrm{D} \pm$ 1.00 (range 0 to -4.50 ) $\mathrm{D}$ in the control group (mean difference $1.12 \mathrm{D} ; 95 \% \mathrm{Cl} 0.87$ 1.37). As shown in Figure 5.3, 55 of 74 eyes (74\%) in the toric group had refractive astigmatism of $1.0 \mathrm{D}$ or less, compared to 27 of 90 eyes $(30 \%)$ in the control group $(P<0.001$, OR $6.75,95 \% \mathrm{Cl} 3.39$ to 13.46$)$. Table 5.2 shows the vector analysis of the effectiveness of astigmatism correction using toric IOLs. The mean magnitude of error was $+0.38 \mathrm{D}$, indicative of an astigmatism overcorrection. Twenty-six of 74 eyes (35\%) showed an overcorrection of 0.5 D or more, and 16 of 74 eyes (22\%) of 1.0 D or more.
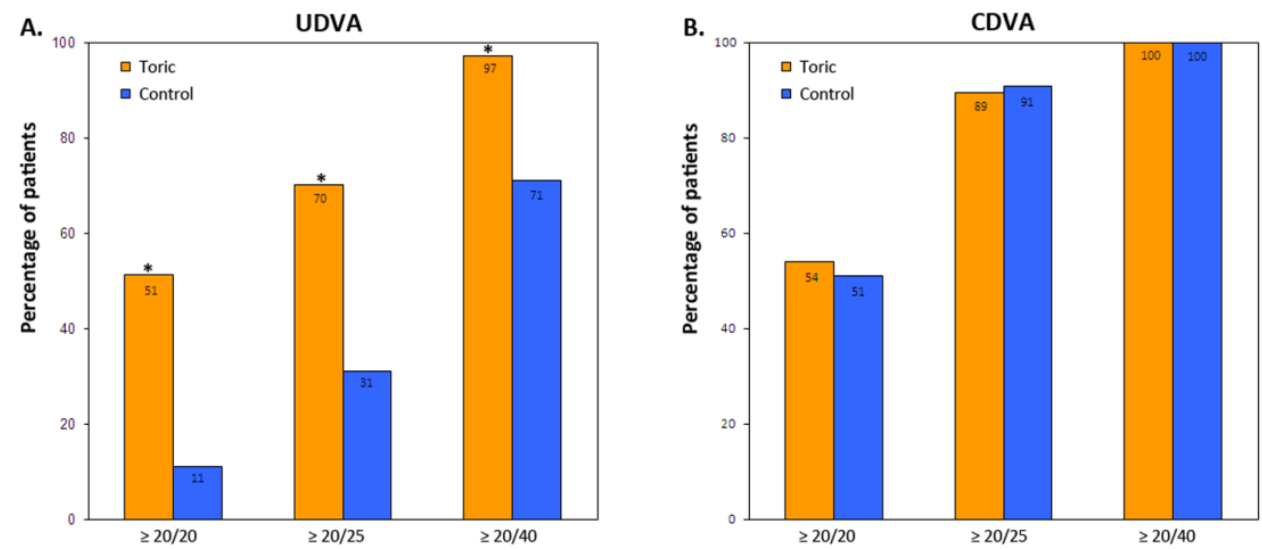

Figure 5.2 Cumulative postoperative binocular uncorrected (A) and corrected (B) distance visual acuity at 6 months postoperatively. ${ }^{*}$ indicates $\mathrm{P}<0.01$ 
Table 5.2 Alpins vector analysis of the effectiveness of astigmatism correction using toric IOLs

\begin{tabular}{lc}
\hline Alpins vector & Result \\
\hline Target induced astigmatism, mean $( \pm$ SD) D & $2.00 \pm 0.93$ \\
Surgically induced astigmatism, mean $( \pm$ SD) D & $2.38 \pm 1.19$ \\
Difference vector, mean $( \pm$ SD) D & $0.75 \pm 0.51$ \\
Magnitude of error, mean $( \pm$ SD) D & $0.38 \pm 0.61$ \\
Angle of error, mean ( \pm SD) degrees & $0 \pm 15$ \\
Absolute angle of error, mean $( \pm$ SD) degrees & $11 \pm 10$ \\
Correction index & 1.20 \\
Index of success & 0.42 \\
\hline
\end{tabular}

Spectacle independence

At 6 months postoperatively, 31 of 37 patients (84\%) in the toric group, compared to 14 of 45 patients (31\%) in the control group reported never using spectacles for distance vision ( $P<0.001$, OR $11.44,95 \% \mathrm{Cl} 3.89$ to 33.63 ). Thirty of 45 patients (67\%) in the control group reported always using spectacles for distance vision, compared to 5 of 37 patients (14\%) in the toric group. Remaining patients reported sometimes using spectacles for distance vision.

\section{Contrast sensitivity}

Preoperatively, contrast sensitivity levels were similar in toric and control groups, but lower compared to the normal population at all spatial frequencies (Figure 5.4). At 6 months postoperatively, contrast sensitivity improved at all special frequencies in both groups, up to values for a normal population. No differences were identified between toric and control groups (Figure 5.4).

\section{Wavefront aberrometry}

Aberrometry data for a $3.5 \mathrm{~mm}$ pupil was available in 51 eyes in the toric group and 73 eyes in the control group. Regarding total ocular aberrations, RMS of lower-order astigmatism was lower in the toric group compared to the control group. No differences were identified in RMS of coma-like aberrations, spherical-like aberrations or total higher-order aberrations (Table 5.3).

Refractive error related quality of life

At 6 months postoperatively, no differences were identified between toric and control groups for any of the subscales, including Far vision, Dependence on correction and Satisfaction with correction (Table 5.4). 


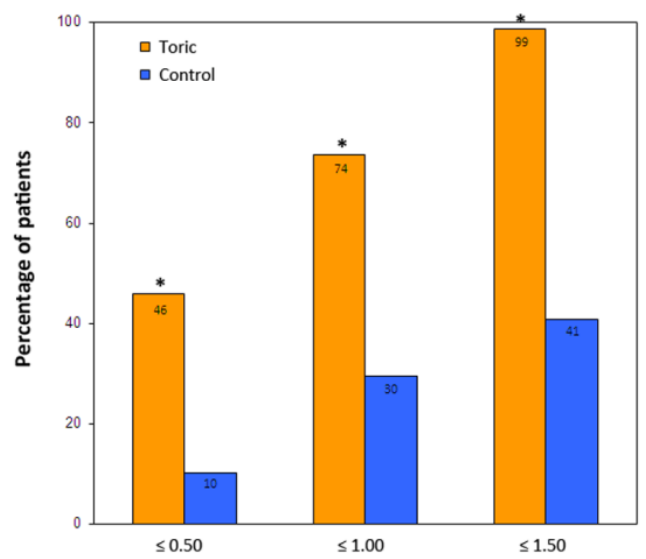

Figure 5.3 Cumulative postoperative residual refractive astigmatism at 6 months postoperatively. ${ }^{*}$ indicates $\mathrm{P}<0.001$

Table 5.3 Corneal and ocular root mean square (RMS) values at 6 months postoperatively

\begin{tabular}{llccr}
\hline Aberrations & RMS & $\begin{array}{c}\text { Toric group } \\
\text { Mean } \mu \pm \text { SD }\end{array}$ & $\begin{array}{c}\text { Control group } \\
\text { Mean } \mu \pm \text { SD }\end{array}$ & Mean difference (95\% Cl) \\
\hline Total ocular & Lower-order astigmatism & $0.256 \pm 0.217$ & $0.490 \pm 0.272$ & $0.233(0.143 ; 0.324)$ \\
& Coma-like & $0.077 \pm 0.077$ & $0.066 \pm 0.038$ & $-0.011(-0.032 ; 0.009)$ \\
& Spherical-like & $0.181 \pm 0.150$ & $0.171 \pm 0.232$ & $-0.009(-0.083 ; 0.064)$ \\
& Total HOA & $0.085 \pm 0.128$ & $0.061 \pm 0.073$ & $-0.024(-0.060 ; 0.011)$ \\
& Lower-order astigmatism & $0.525 \pm 0.258$ & $0.467 \pm 0.202$ & $-0.057(-0.139 ; 0.025)$ \\
& Coma-like & $0.075 \pm 0.088$ & $0.050 \pm 0.028$ & $-0.025(-0.046 ;-0.003)$ \\
& Spherical-like & $0.074 \pm 0.048$ & $0.060 \pm 0.030$ & $-0.014(-0.027 ; 0.000)$ \\
& Total HOA & $0.045 \pm 0.039$ & $0.031 \pm 0.014$ & $-0.014(-0.024 ;-0.004)$ \\
\hline
\end{tabular}

HOA = higher order aberrations.

Data was exported for a $3.5 \mathrm{~mm}$ pupil.

Complications and misalignment

In the toric group, a small anterior capsule tear occurred, which still allowed toric IOL implantation. In the control group, a zonulolysis $(\mathrm{N}=1)$ and a large anterior to posterior capsule tear $(\mathrm{N}=1)$ occurred. In the latter patient, a three-piece IOL (type MN60AC) was implanted in the sulcus. Postoperative complications in the toric group included high intra-ocular pressure $(\mathrm{N}=1)$, cystoid macular edema $(\mathrm{N}=1)$, macular pucker $(\mathrm{N}=1)$, and posterior vitreous detachment with a retinal defect $(\mathrm{N}=1)$. In the control group, high intra-ocular pressure $(\mathrm{N}=2)$, cystoid macular edema $(\mathrm{N}=2)$, anterior uveitis $(\mathrm{N}=1)$ and posterior vitreous detachment without retinal defect $(\mathrm{N}=1)$ occurred.

Mean toric IOL misalignment at 6 months postoperatively was $3.6 \pm 3.2$ degrees. $\mathrm{A}$ misalignment of more than 10 degrees occurred in 4 eyes. In one of these eyes an IOL repositioning was performed to correct a 17 degree misalignment. After $\mathrm{IOL}$ 
repositioning, the UDVA improved from 20/40 to 20/20 Snellen. Other patients were satisfied and did not wish to undergo IOL repositioning.
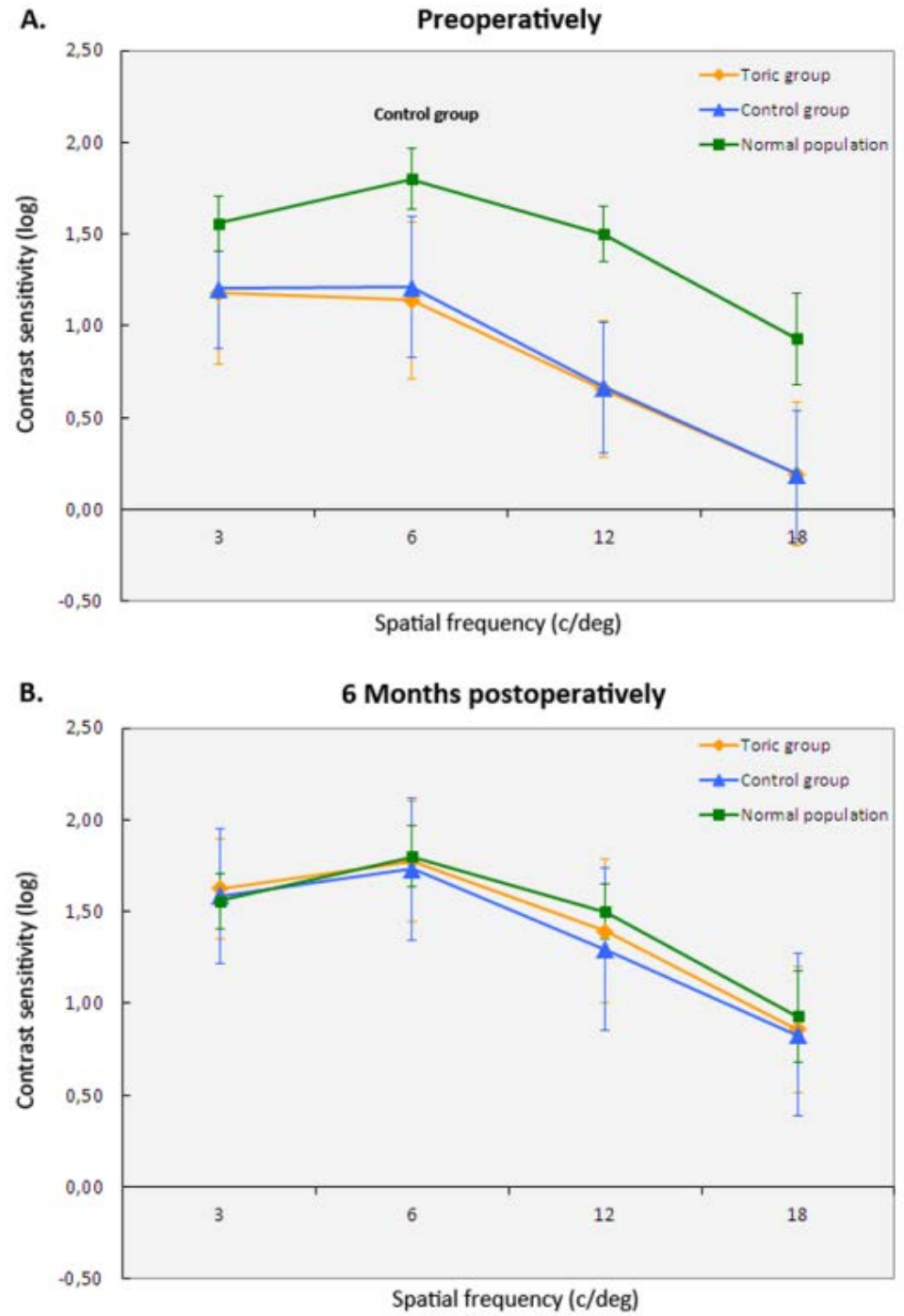

Figure 5.4 Contrast sensitivity preoperatively (A) and 6 months postoperatively (B). 
Table 5.4 Refractive error-related quality of life at 6 months postoperatively (scale $0-100$ )

\begin{tabular}{lcc}
\hline & Toric group & Control group \\
\hline Clarity of vision & 90 & 84 \\
Expectations & 63 & 68 \\
Near vision & 79 & 81 \\
Far vision & 82 & 83 \\
Diurnal fluctuations & 82 & 82 \\
Activity limitations & 93 & 96 \\
Glare & 75 & 74 \\
Symptoms & 73 & 75 \\
Dependence on correction & 35 & 26 \\
Worry & 83 & 75 \\
Suboptimal correction & 92 & 95 \\
Appearance & 80 & 85 \\
Satisfaction with correction & 87 & 83 \\
\hline
\end{tabular}

\section{Discussion}

This is the first RCT comparing spectacle independency for distance vision following bilateral toric IOL and bilateral control IOL implantation. Spectacle independency was achieved in $84 \%$ of patients with toric IOLs compared to $31 \%$ of patients with control IOLs. Holland et al. reported spectacle independency in approximately $60 \%$ of patients with toric IOLs, compared to $36 \%$ of patients with control IOLs. ${ }^{4}$ However, patients in this study underwent unilateral toric or control IOL implantation, which does not allow for an accurate evaluation of spectacle independency. Lane et al. offered patients from the study population of Holland et al. fellow-eye implantation with the same IOL (toric or control IOL), allowing bilateral examination of spectacle independency. ${ }^{11}$ Almost all patients (97\%) with toric IOLs were spectacle independent for distance vision, compared to half of the patients in the control group. However, a selection bias may have occurred in patients who wished to undergo fellow-eye implantation with the same IOL.

We found a better UDVA and lower refractive astigmatism following toric IOL implantation compared to control IOL implantation. We found an UDVA of 20/25 or better in $70 \%$ of patients in the toric group and $31 \%$ in the control group. Previous studies reported an UDVA of $20 / 25$ or better in approximately 60 to $80 \%$ of patients with toric IOLs. ${ }^{4,15-17}$ Regarding refractive astigmatism, the correction index of 1.20 and magnitude of error of $+0.38 \mathrm{D}$ demonstrate a general overcorrection of astigmatism using Acrysof toric IOLs. This has also been demonstrated by Goggin et al. and is 
related to the manufacturers underestimation of the IOL cylinder power at the corneal plane. $^{18}$

We found no substantial differences in quality of vision following toric or control IOL implantation. Quality of vision was evaluated using contrast sensitivity (CSV-1000 chart), aberrometry and refractive-error-related quality of life. At 6 months postoperatively, contrast sensitivity had improved in both groups, up to values for a normal population. Two studies compared contrast sensitivity levels under similar illumination levels following toric IOL implantation or corneal relaxing incisions. ${ }^{19,} 20$ However, a direct comparison of our results with these studies is not possible due to different contrast sensitivity tests and different testing distances. No previous studies have compared contrast sensitivity values between toric and control IOLs.

Wavefront analysis allows for a detailed evaluation of imperfections in the optical system of the eye. Different measurement techniques, including Hartmann-Shack, raytracing and automated retinoscopy, are available but may not be used interchangeably. $^{21}$ To minimize this effect, we measured patients pre- and postoperatively with the same device. Both devices used in this study use light wavelengths in the infrared spectrum and therefore do not require pupil dilation. Also, the application of mydriatic agents may cause differences in wavefront analysis. ${ }^{22,23}$ Mencucci et al. compared aberrometry (Nidek OPD Scan II) following toric or control IOL implantation and found a higher Strehl ratio, which indicates a better image quality. ${ }^{24}$ We identified no differences in higher-order aberrations following toric or control IOL implantation.

We assessed refractive-error related quality of life using the RQL-42 questionnaire, which is developed to measure the effect of refractive error correction on visionrelated functioning and well-being. ${ }^{10}$ This questionnaire has recently been used to evaluate multifocal IOLs, phakic IOLs and laser refractive surgery. ${ }^{25-27}$ However, McAlinden et al. administered this questionnaire to 100 laser refractive surgery patients and demonstrated insufficient psychometric properties for all 13 subscales. ${ }^{28}$ One previous study used the RQL-42 to compared toric and control IOLs. Mencucci et al. found a higher score for subscales Clarity of vision, Far vision, and Satisfaction with correction in patients with toric IOLs. ${ }^{24}$ In our study, we found no substantial differences between toric and control IOLs for any of the subscales of the RQL-42. Aside from the limitation of this questionnaire, this may be related to a limitation of our study. In the Netherlands, patients have the option to choose for toric IOL implantation by means of co-payment. Therefore, patients with a strong wish for spectacle independence were not included in this study. 
Another possible limitation of this study is use of a superior incision in all patients. In the majority of patients, this will be on-axis, thereby reducing corneal astigmatism. However, in patients with against the rule astigmatism, a superior incision may increase astigmatism. In the toric group, this is compensated for in the toric IOL calculation. However, in the control group, this is not compensated for. We chose to use a superior incision in all patients because this is the standard of care for the majority of ophthalmologists in the Netherlands, and therefore results in a fair comparison of treatments. In addition, we have shown in this study and a previous study that the surgically induced corneal astigmatism of a superior $2.2 \mathrm{~mm}$ incision is only about $-0.1 \mathrm{D}^{29}$

Mean toric IOL misalignment was approximately 4 degrees, which is comparable to previous studies. $^{3-5,18}$ The mean absolute angle of error was 11 degrees, which indicates a substantial overall misalignment of treatment. Toric IOL outcomes may be further optimized by incorporating IOL sphere power and estimated lens position in the IOL calculation. ${ }^{30}$ In addition, incorporating the effect of the posterior corneal

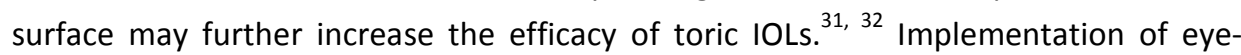
tracking technology may improve the accuracy toric IOL alignment. ${ }^{7}$

In conclusion, in patients with cataract and corneal astigmatism, bilateral toric IOL implantation results in a higher spectacle independency for distance vision compared to bilateral control IOL implantation. No differences were identified in contrast sensitivity, higher-order aberrations or refractive-error related quality of life following both treatments.

\section{References}

1. Ferrer-Blasco T, Montes-Mico R, Peixoto-deMatos SC, Gonzalez-Meijome JM, Cervino A. Prevalence of corneal astigmatism before cataract surgery. J Cataract Refract Surg. Jan 2009;35(1):70-75.

2. Hoffmann PC, Hutz WW. Analysis of biometry and prevalence data for corneal astigmatism in 23,239 eyes. J Cataract Refract Surg. Sep 2010;36(9):1479-1485.

3. Ahmed I, Rocha G, Slomovic AR, et al. Visual function and patient experience after bilateral implantation of toric intraocular lenses. J Cataract Refract Surg. Apr 2010;36(4):609-616.

4. Holland E, Lane S, Horn JD, Ernest P, Arleo R, Miller KM. The AcrySof Toric Intraocular Lens in Subjects with Cataracts and Corneal Astigmatism A Randomized, Subject-
Masked, Parallel-Group, 1-Year Study. Ophthalmology. Sep 14 2010;117(11):21042111.

5. Visser N, Ruiz-Mesa R, Pastor F, Bauer NJ, Nuijts RM, Montes-Mico R. Cataract surgery with toric intraocular lens implantation in patients with high corneal astigmatism. J Cataract Refract Surg. Aug 2011;37(8):14031410.

6. Adamis AP, Filatov V, Tripathi BJ, Tripathi RC. Fuchs' endothelial dystrophy of the cornea. Surv Ophthalmol. Sep-Oct 1993;38(2):149-168.

7. Visser N, Berendschot TT, Bauer NJ, Jurich J, Kersting O, Nuijts RM. Accuracy of toric intraocular lens implantation in cataract and refractive surgery. J Cataract Refract Surg. Aug 2011;37(8):1394-1402. 
8. Pomerance GN, Evans DW. Test-retest reliability of the CSV-1000 contrast test and its relationship to glaucoma therapy. Invest Ophthalmol Vis Sci. Aug 1994;35(9):33573361.

9. Thibos LN, Applegate RA, Schwiegerling JT, Webb R. Report from the VSIA taskforce on standards for reporting optical aberrations of the eye. J Refract Surg. Sep-Oct 2000;16(5):S654-655.

10. Hays RD, Mangione CM, Ellwein L, Lindblad AS, Spritzer KL, McDonnell PJ. Psychometric properties of the National Eye InstituteRefractive Error Quality of Life instrument. Ophthalmology. Dec 2003;110(12):22922301.

11. Lane SS, Ernest $\mathrm{P}$, Miller KM, Hileman KS, Harris B, Waycaster CR. Comparison of clinical and patient-reported outcomes with bilateral AcrySof toric or spherical control intraocular lenses. J Refract Surg. Oct 2009;25(10):899-901.

12. Dupont WD, Plummer WD, Jr. Power and sample size calculations. A review and computer program. Control Clin Trials. Apr 1990;11(2):116-128.

13. Holladay JT, Moran JR, Kezirian GM. Analysis of aggregate surgically induced refractive change, prediction error, and intraocular astigmatism. J Cataract Refract Surg. Jan 2001;27(1):61-79.

14. Alpins NA, Goggin M. Practical astigmatism analysis for refractive outcomes in cataract and refractive surgery. Surv Ophthalmol. Jan-Feb 2004;49(1):109-122.

15. Bauer NJ, de Vries NE, Webers CA, Hendrikse F, Nuijts RM. Astigmatism management in cataract surgery with the AcrySof toric intraocular lens. J Cataract Refract Surg. Sep 2008;34(9):1483-1488.

16. Dardzhikova A, Shah CR, Gimbel HV. Early experience with the AcrySof toric IOL for the correction of astigmatism in cataract surgery. Can J Ophthalmol. Jun 2009;44(3):269-273.

17. Mendicute J, Irigoyen C, Aramberri J, Ondarra A, Montes-Mico R. Foldable toric intraocular lens for astigmatism correction in cataract patients. J Cataract Refract Surg. Apr 2008;34(4):601-607.

18. Goggin M, Moore S, Esterman A. Toric Intraocular Lens Outcome Using the Manufacturer's Prediction of Corneal Plane Equivalent Intraocular Lens Cylinder Power. Arch Ophthalmol. Aug 2011;129(8):10041008.
19. Mingo-Botin D, Munoz-Negrete FJ, Won Kim HR, Morcillo-Laiz R, Rebolleda G, Oblanca N. Comparison of toric intraocular lenses and peripheral corneal relaxing incisions to treat astigmatism during cataract surgery. J Cataract Refract Surg. Oct 2010;36(10):1700-1708.

20. Mendicute J, Irigoyen C, Ruiz M, Illarramendi I, Ferrer-Blasco T, Montes-Mico R. Toric intraocular lens versus opposite clear corneal incisions to correct astigmatism in eyes having cataract surgery. I Cataract Refract Surg. Mar 2009;35(3):451-458.

21. Visser N, Berendschot TT, Verbakel F, Tan AN, de Brabander J, Nuijts RM. Evaluation of the comparability and repeatability of four wavefront aberrometers. Invest Ophthalmol Vis Sci. Nov 4 2010;52(3):1302-1311.

22. Carkeet A, Velaedan S, Tan YK, Lee DY, Tan DT. Higher order ocular aberrations after cycloplegic and non-cycloplegic pupil dilation. J Refract Surg. May-Jun 2003;19(3):316-322.

23. Giessler S, Hammer T, Duncker Gl. Aberrometry due dilated pupils--Which mydriatic should be used? Klin Monbl Augenheilkd. Sep 2002;219(9):655-659.

24. Mencucci R, Giordano C, Favuzza E, Gicquel JJ, Spadea L, Menchini U. Astigmatism correction with toric intraocular lenses: wavefront aberrometry and quality of life. Br J Ophthalmol. May 2013;97(5):578-582.

25. Cillino G, Casuccio A, Pasti M, Bono V, Mencucci R, Cillino S. Working-Age Cataract Patients: Visual Results, Reading Performance, and Quality of Life with Three Diffractive Multifocal Intraocular Lenses. Ophthalmology. Aug 142013.

26. Perez-Cambrodi RJ, Blanes-Mompo FJ, Garcia-Lazaro S, Pinero DP, Cervino A, Brautaset R. Visual and optical performance and quality of life after implantation of posterior chamber phakic intraocular lens. Graefes Arch Clin Exp Ophthalmol. Jan 2013;251(1):331-340.

27. Queiros A, Villa-Collar C, Gutierrez AR, Jorge J, Gonzalez-Meijome JM. Quality of life of myopic subjects with different methods of visual correction using the NEI RQL-42 questionnaire. Eye Contact Lens. Mar 2012;38(2):116-121.

28. McAlinden C, Skiadaresi E, Moore J, Pesudovs K. Subscale assessment of the NEIRQL-42 questionnaire with Rasch analysis. Invest Ophthalmol Vis Sci. Jul 2011;52(8):5685-5694. 
29. Visser N, Berendschot TT, Bauer NJ, Nuijts RM. Vector analysis of corneal and refractive astigmatism changes following toric pseudophakic and toric phakic IOL implantation. Invest Ophthalmol Vis Sci. Apr 2012;53(4):1865-1873.

30. Goggin M, Moore S, Esterman A. Outcome of toric intraocular lens implantation after adjusting for anterior chamber depth and intraocular lens sphere equivalent power effects. Arch Ophthalmol. Aug 2011;129(8):998-1003.

31. Koch DD, Ali SF, Weikert MP, Shirayama M, Jenkins R, Wang L. Contribution of posterior corneal astigmatism to total corneal astigmatism. J Cataract Refract Surg. Oct 12 2012;38:2080-2087.

32. Visser N, Bauer NJ, Nuijts RM. Residual astigmatism following toric intraocular lens implantation related to pupil size. J Refract Surg. Oct 2012;28(10):729-732. 


\section{Chapter 6}

\section{Cataract surgery with toric intraocular lens implantation in patients with high corneal astigmatism}

Nienke Visser, Ramón Ruíz-Mesa, Francisco Pastor, Noël J.C. Bauer, Rudy M.M.A. Nuijts and Robert Montés-Micó Journal of Cataract \& Refractive Surgery 2011; 37: 1403-1410 


\section{Abstract}

PURPOSE: To evaluate the visual and refractive outcomes after toric intraocular lens (IOL) implantation in patients with high amounts of corneal astigmatism.

Setring: University Eye Clinic, Maastricht University Medical Center, the Netherlands; Oftalvist Centro Integral Ocular and Fundación Oftalmológica del Mediterráneo, Spain.

METHODS: This study included patients with cataract and more than $2.25 \mathrm{D}$ of corneal astigmatism who had toric Acrysof SN60T6-T9 (Alcon Laboratories) implantation. The uncorrected (UDVA) and corrected distance visual acuities (CDVA), visual potential index (ratio of postoperative UDVA to postoperative CDVA), residual refractive cylinder, IOL misalignment and surgically induced corneal astigmatism (SICA) were evaluated.

RESUlts: Mean follow-up in this study of 67 eyes (45 patients) was 6.3 months. Postoperatively, the mean UDVA was $0.61 \pm 0.26$ ( \pm SD) and the mean CDVA $0.81 \pm$ 0.21 . The UDVA was $20 / 40$ or better in $83 \%$ of eyes and $20 / 30$ or better in $50 \%$ of eyes. The mean visual potential index was 0.78 . The residual refractive cylinder was less than $0.75 \mathrm{D}$ in $62 \%$ of eyes and less than $1.00 \mathrm{D}$ in $81 \%$ of eyes. The mean IOL misalignment was $3.2 \pm 2.8$ degrees. The mean SICA was $-0.40 \pm 0.60 \mathrm{D}$ with a superior incision and $0.19 \pm 0.78 \mathrm{D}$ with a temporal incision $(p=0.034)$.

CONCLUSION: Implantation of toric IOLs during cataract surgery was effective and safe in correcting high amounts of corneal astigmatism. 


\section{Introduction}

Emmetropia is one of the targets in modern cataract surgery because spectacle freedom is becoming increasingly important. Aside from spherical refractive errors, astigmatism should be addressed at the time of cataract surgery to achieve the best postoperative visual outcomes. Toric IOLs provide an opportunity to achieve the optimal uncorrected distance vision and spectacle independence in patients with cataract and corneal astigmatism.

Several toric IOL models are available; these include the Acrysof IOL (Alcon Laboratories), the AT Comfort IOL (Carl Zeiss Meditec), and the T-flex IOL (Rayner). The Acrysof toric IOL is one of the most commonly used toric IOLs in cataract surgery. This IOL has been shown to be effective in reducing refractive astigmatism and providing good uncorrected visual outcomes and spectacle independence for distance vision. ${ }^{1-5}$ Even though the T-flex and AT Comfort toric IOLs are available in cylinder powers up to $11.00 \mathrm{D}$ and $12.00 \mathrm{D}$, respectively, the Acrysof toric IOL was initially only available in cylinder powers up to $3.00 \mathrm{D}$ (SN60T3 to SN60T5). Therefore, in patients with more than $2.00 \mathrm{D}$ of corneal astigmatism, Acrysof toric IOLs provided partial correction of astigmatism. These patients required additional astigmatism correction, such as spectacles or another surgical procedure. Surgical procedures that may be performed during or after cataract surgery include limbal relaxing incisions, excimer laser refractive procedures such as photorefractive keratectomy and laser in situ keratomileusis, and toric phakic anterior or posterior chamber IOL implantation. However, the refractive changes induced by the latter procedures may be relatively unpredictable $^{6}$, and complications such as wound gape ${ }^{6}$, perforation ${ }^{6}$, abnormal wound healing ${ }^{7,8}$, or infection ${ }^{9}$ may occur.

The Acrysof toric IOL line now has four additional models (SN60T6 to SN60T9) with cylinder powers up to $6.00 \mathrm{D}$ at the $\mathrm{IOL}$ plane, corresponding to $4.11 \mathrm{D}$ at the corneal plane. These new models provide the opportunity to correct approximately $99 \%$ of patients with corneal astigmatism. ${ }^{10}$ The purpose of this study was to evaluate the visual and refractive outcomes after implantation of these 4 new IOL models in patients with high amounts of corneal astigmatism.

\section{Methods}

\section{Patient Population}

This prospective clinical study was performed at the following hospitals: University Eye Clinic Maastricht, the Netherlands; Oftalvist Centro Integral Ocular, Jerez de la 
Frontera, Spain; and Fundación Oftalmológica del Mediterráneo, Valencia, Spain. The study enrolled patients who had cataract surgery and implantation of a toric IOL between July 2009 and June 2010. The study protocol adhered to the recommendations of the Declaration of Helsinki. All patients provided written consent. Inclusion criteria were age over 21 years, a decreased visual acuity due to cataract, and preoperative corneal astigmatism greater than 2.25 D. Exclusion criteria were irregular corneal astigmatism, Fuchs endothelial dystrophy, tear-film abnormalities, and a very small pupil.

Preoperatively, all patients had an extensive ophthalmic examination consisting of Snellen uncorrected distance visual acuity (UDVA), corrected distance visual acuity (CDVA), autorefractometry (Nidek), subjective refraction, fundoscopy, Goldmann applanation tonometry, corneal topography (Atlas, Carl Zeiss Meditec) and partial coherence interferometry ( $\mathrm{PCI})$ optical biometry (IOLMaster, Carl Zeiss Meditec).

\section{Intraocular Lenses}

The following Acrysof toric IOL models were examined in this study: SN60T6, SN60T7, SN60T8 and SN60T9. Cylinder powers at the IOL plane (corneal plane) were $3.75 \mathrm{D}$ (2.57 D), $4.50 \mathrm{D}(3.08 \mathrm{D}), 5.25 \mathrm{D}(3.60 \mathrm{D})$, and $6.00 \mathrm{D}(4.11 \mathrm{D})$, respectively. All toric IOL models are hydrophobic acrylic with open-loop modified L-haptics and a $6.0 \mathrm{~mm}$ optic diameter. The axis marks on the IOL indicate the flat meridian of the toric component on the posterior surface of the IOL. The IOL is available in spherical powers ranging from +6.00 to $+30.00 \mathrm{D}$. In all patients, the spherical power was calculated using $\mathrm{PCl}$ optical biometry measurements and calculated using the SRK/T formula (A-constant 118.6), target emmetropia.

The toric IOL cylinder power and alignment axis were calculated using a web-based toric IOL calculator program (available at: http://acrysoftoriccalculator.com). In all patients, the keratometry $(K)$ values of the optical biometer were used for toric IOL calculation. The incision location was according to the surgeon's preference as follows: temporal incision (FP and RM) and superior incision (NB and RN). The expected amount of surgically induced corneal astigmatism (SICA) varied between $0.00 \mathrm{D}$ and $0.50 \mathrm{D}$ and was based on the surgeon's personal experience.

\section{Surgical Technique}

Preoperatively, corneal reference marks were placed at 0, 180 and 270 degrees with the patient sitting upright to correct for cyclotorsion. The marks were made using a Nuijts/Lane toric reference marker (AE-2791TBL, American Surgical Instruments Corp.). Intraoperatively, the implantation axis was determined using the corneal reference 
marks and the alignment axis obtained from the toric calculator program. This axis was marked using a Mendez degree gauge (AE-2765N, American Surgical Instruments Corp.) and a Nuijts toric axis marker (AE-2740, American Surgical Instruments Corp.). The surgeon's standard phacoemulsification technique was performed through a 2.2 $\mathrm{mm}$ limbal incision. After insertion of the foldable toric IOL, the IOL was rotated to its final position by exact alignment of the reference marks on the toric IOL with the implantation axis marks. Postoperatively, all patients were prescribed a fixed combination eye drop of tobramycin $3 \mathrm{mg} / \mathrm{mL}$ and dexamethasone $1 \mathrm{mg} / \mathrm{mL}$ (Tobradex, Alcon Laboratories) in a tapering dose for the first 4 weeks and ketorolac 5 $\mathrm{mg} / \mathrm{mL}$ (Acular, Allergan) for the first week.

\section{Postoperative Examinations}

Postoperative examinations were performed at 1 month, 3 months, and 6 months and included UDVA, CDVA, subjective and objective (autorefractometry) refraction, slitlamp evaluation and corneal topography (at 6 months only). A visual potential index was calculated as the ratio of postoperative UDVA to postoperative CDVA. The orientation of the toric IOL axis was determined at the slitlamp.

\section{Statistical Analysis}

Patients were divided into subgroups according to the IOL model implanted as follows: T6 group (SN60T6); T7 group (SN60T7); T8 group (SN60T8); T9a group (SN60T9); consisting of eyes with an expected postoperative residual cylinder of $0.75 \mathrm{D}$ or less; and T9b group (SN60T9), consisting of eyes with an expected postoperative residual cylinder of more than $0.75 \mathrm{D}$. The expected residual cylinder was calculated using the toric IOL calculator program. The combined group of all eyes of groups T6, T7, T8 and T9a was designated as the TT group.

Snellen UDVA and CDVA were converted into logMAR values for the mathematic and statistical calculations. To report the visual outcomes, the mean \pm standard deviation (SD) LogMAR values were calculated back into Snellen values.

The actual amount of SICA was calculated using a vector analysis based on the preoperative and postoperative topography keratometry values. Individual cylinder and axis values were transformed into Cartesian coordinates ( $x$ and $y$ ) according to the method described by Holladay et al. ${ }^{11}$ These Cartesian coordinates may be used in mathematic and statistical calculations. The results are shown in a double-angle minuscylinder vector diagram. A double-angle vector diagram goes from 0 to 180 degrees in a full cycle (360 degrees), so that 0 degree and 180 degrees are equivalent. The SD is 
displayed as an ellipse surrounding the centroid (the mean SICA) in the double-angle power plots. ${ }^{11}$

All data were collected in an Excel database (Office 2003, Microsoft Inc.). Data analysis was performed using SPSS for Windows (version 16.0, SPSS Inc). Statistical analyses of the astigmatism data were performed using the Hotelling Trace multivariate analysis of variance.

\section{Results}

We evaluated 67 eyes of 45 patients. Table 6.1 shows the patients' demographics and preoperative data.

\section{Comorbidity}

In the T6 group, 2 patients had a history of retinal detachment (RD) treated by scleral buckle surgery, 1 patient was amblyopic, and 1 had a manifest nystagmus. In the T7 group, 2 patients were amblyopic and 1 had a history of RD, treated by scleral buckle surgery. In the T8 group, 1 patient was amblyopic. In the T9a group, 3 patients were amblyopic, 1 had a vitreoretinal procedure because of a macular hole, and 1 had a RD treated by scleral buckle surgery. In the T9b group, 1 patient had a corneal leukoma.

\section{Visual Acuity}

Figure 6.1A shows the postoperative UDVA and CDVA in relation to the preoperative CDVA. The mean preoperative CDVA in eyes that could be fully corrected (TT group) was $0.38 \pm 0.26$. Postoperatively, the mean UDVA and CDVA in the TT group were 0.61 \pm 0.26 and $0.81 \pm 0.21$, respectively.

Figure 6.1B shows the postoperative cumulative UDVA. In the TT group, $83 \%$ of eyes achieved an UDVA of 20/40 or better, and 50\% achieved an UDVA of 20/30 or better. In 10 eyes (17\%) in the TT group, the UDVA was worse than 20/40 due to amblyopia (5 eyes), IOL misalignment ( 3 eyes), and an unexpected residual refractive error (sphere and cylinder) ( 2 eyes). The visual potential index was 0.78 in the TT group, 0.76 in the T6 group, 0.71 in the T7 group, 0.71 in the T8 group, and 0.80 in the T9a group. 

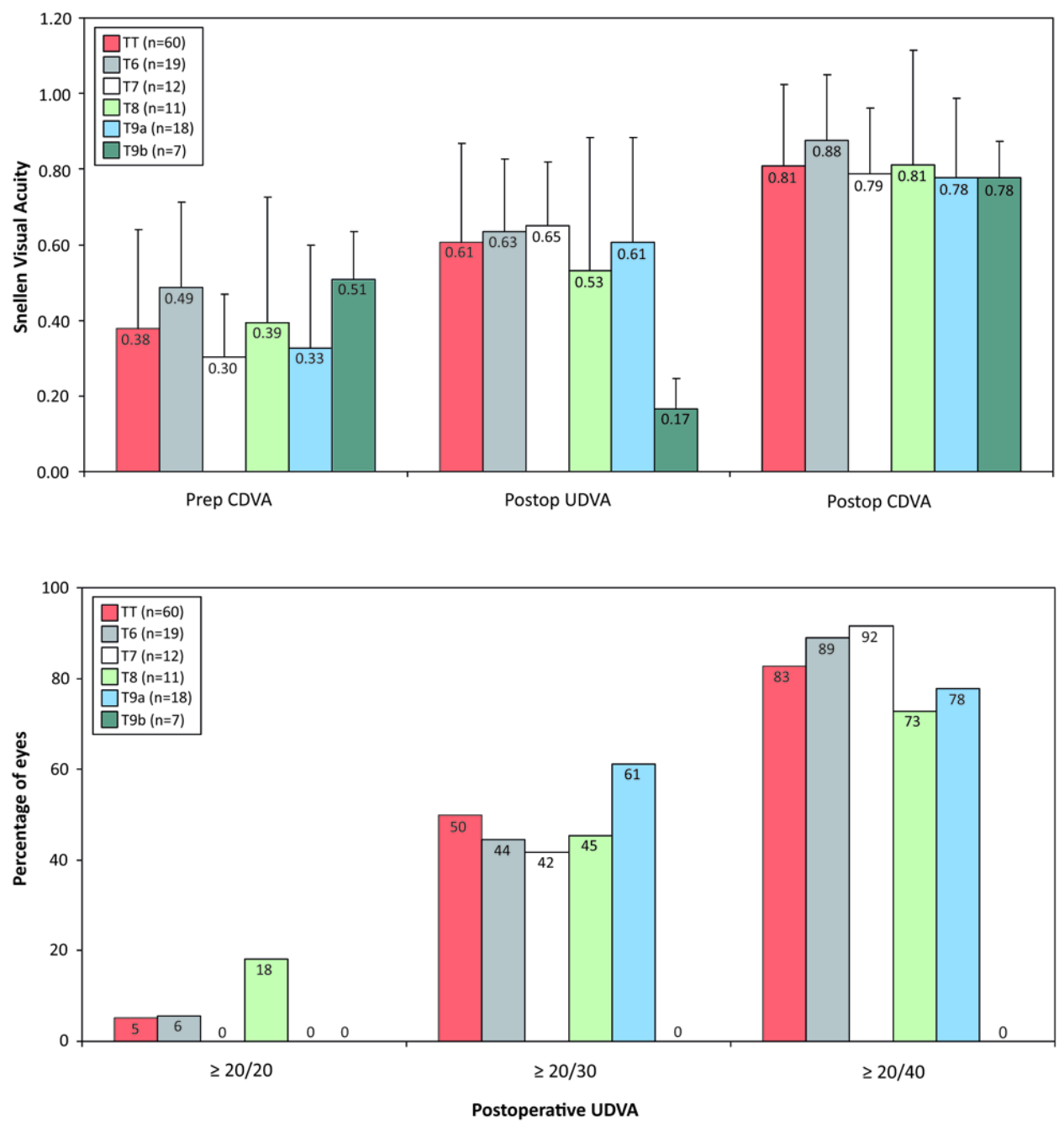

Figure 6.1 A: Postoperative UDVA and CDVA in relation to preoperative CDVA by group according to the toric IOL model. Error bars indicate the SD. $B$ : Cumulative postoperative UDVA according to the toric IOL model implanted. 

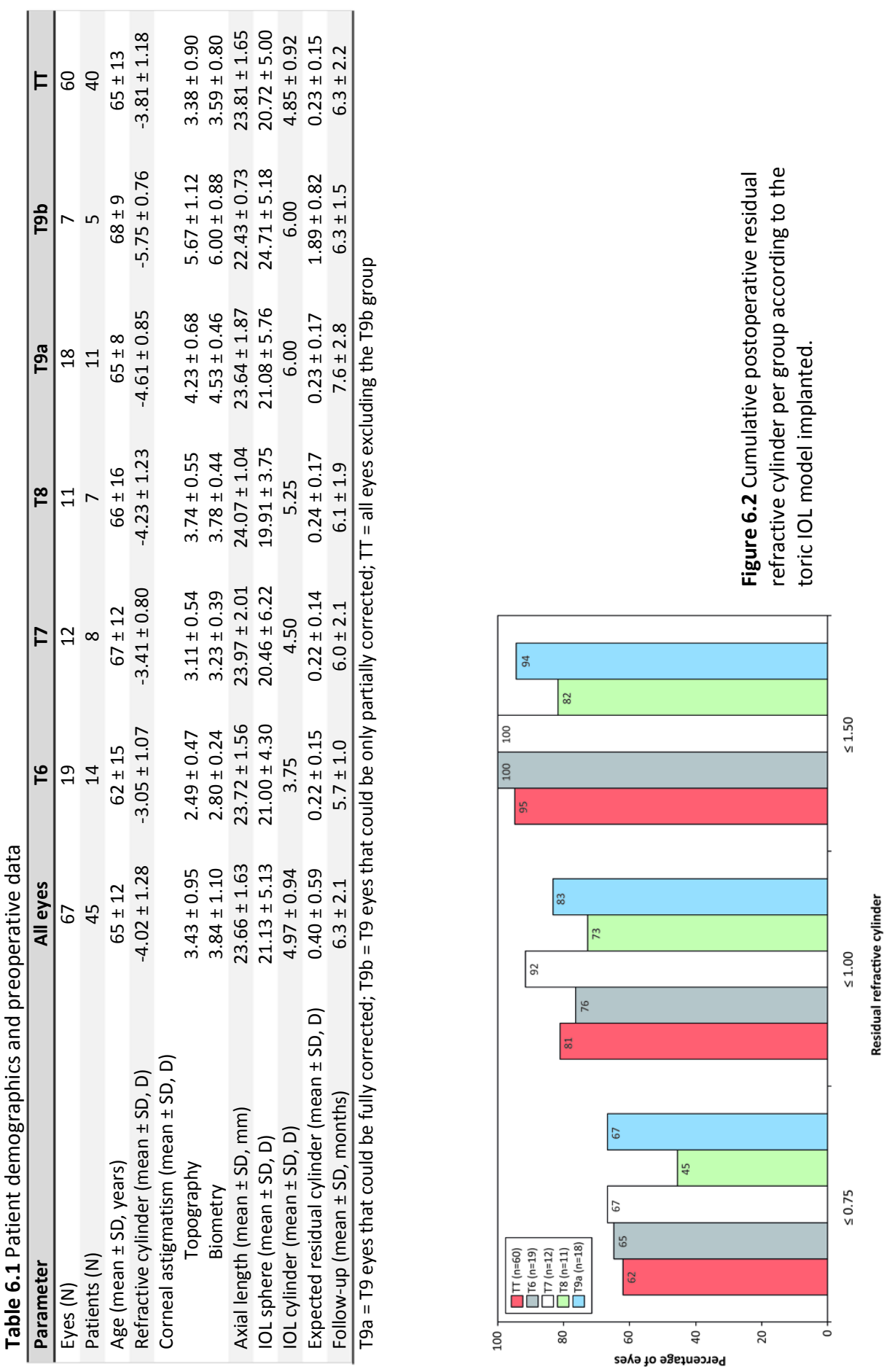


\section{Residual Refractive Cylinder}

Postoperatively, the mean residual refractive cylinder in the TT, T6, T7, T8, T9a, and T9b groups was $-0.75 \pm 0.49 \mathrm{D},-0.68 \pm 0.49 \mathrm{D},-0.71 \pm 0.33 \mathrm{D},-0.95 \pm 0.63 \mathrm{D},-0.72 \pm$ $0.49 \mathrm{D}$, and $-2.00 \pm 0.87 \mathrm{D}$, respectively. Figure 6.2 shows the cumulative residual refractive cylinder by subgroup. In the TT group, the residual refractive cylinder was $0.75 \mathrm{D}$ or less in 37 eyes (62\%) and $1.00 \mathrm{D}$ or less in 49 eyes (81\%). In the T8 group, 2 eyes (18\%) had a residual refractive cylinder of more than $1.50 \mathrm{D}$; 1 eye was amblyopic and 1 eye had IOL misalignment of 16 degrees. In the T9a group, 1 eye had a residual refractive cylinder of more than $1.50 \mathrm{D}$ due to an IOL misalignment of 9 degrees. The mean reduction in refractive cylinder was $79 \%$ in the TT group, $73 \%$ in the T6 group, $80 \%$ in the T7 group, $76 \%$ in the T8 group and $84 \%$ in the T9a group.

\section{Misalignment}

The mean misalignment was $3.2 \pm 2.8$ degrees (range 0 to 16 degrees). One eye had more than 10 degrees of misalignment (16 degrees); however this patient did not wish to have surgical IOL repositioning.

\section{Surgically Induced Corneal Astigmatism}

Figure 6.3 shows the amount of SICA following a $2.2 \mathrm{~mm}$ superior incision (29 eyes) or $2.2 \mathrm{~mm}$ temporal incision (19 eyes). Eyes not included in this analysis had an obliquely located incision $(n=7)$, or no preoperative or postoperative topography data $(n=12$ eyes). After a mean follow-up of 6 months, the mean SICA was significantly lower following a $2.2 \mathrm{~mm}$ temporal incision $(-0.19 \pm 0.78 \mathrm{D}$ at 7 degrees) than with a $2.2 \mathrm{~mm}$ superior incision $(-0.40 \pm 0.60 \mathrm{D}$ at 108 degrees) $(p=0.034)$.

\section{Complications}

One patient developed a macular hole 1 week postoperatively for which he had a vitreoretinal procedure. At 6 months postoperatively, the patient's Snellen UDVA was 0.85 and the CDVA was 0.90 . One patient had slight posterior capsule opacification in both eyes, that did not compromise visual acuity or require a capsulotomy. 


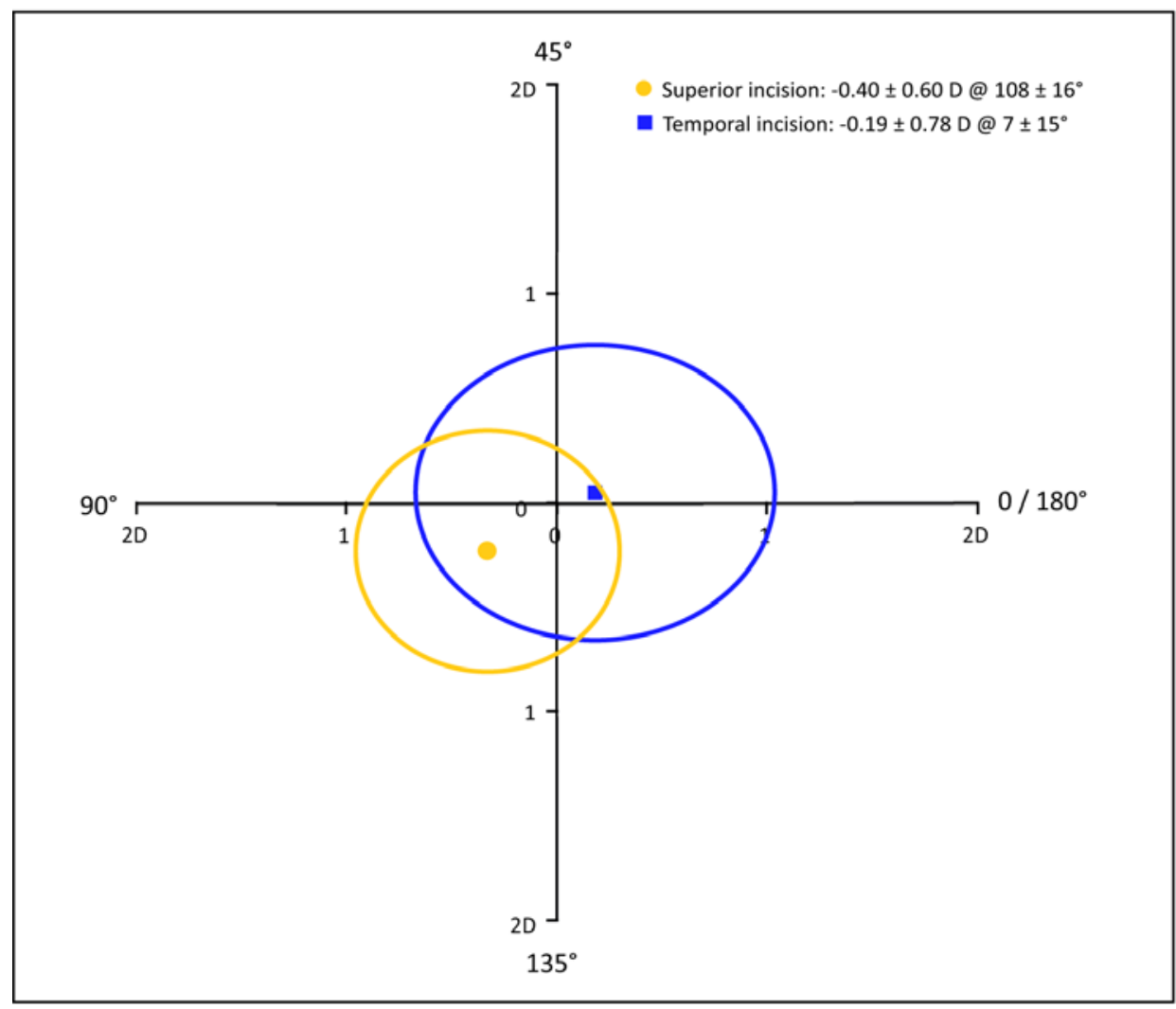

Figure 6.3 Double-angle vector diagram (minus cylinder) of the mean SICA 6 months postoperatively with an ellipse of $1 \mathrm{SD}$.

\section{Discussion}

In this study we evaluated toric IOL implantation in patients with high corneal astigmatism. We believe this is the first study evaluating the Acrysof toric SN60T6 to SN60T9 IOLs with cylinder powers ranging from 2.50 to $4.00 \mathrm{D}$ at the corneal plane. These new models provide the opportunity to correct approximately $99 \%$ of all patients with corneal astigmatism. ${ }^{10}$

Two previous studies evaluated the outcomes after implantation of high-cylinder power toric IOLs. Alio et al. evaluated AT Comfort toric IOL implantation in 21 eyes with a mean corneal astigmatism of $3.73 \pm 1.79$ D.12 The postoperative UDVA was 0.65 \pm 0.22 and $76 \%$ of eyes achieved an UDVA of $20 / 40$ or better. The mean residual refractive cylinder was $-0.45 \pm 0.63 \mathrm{D}$. Entabi et al. have evaluated T-flex toric IOL 
implantation in 33 eyes with a mean pre-existent corneal astigmatism of $2.94 \pm 0.89$ D. ${ }^{13}$ Postoperatively, the mean UDVA was $0.28 \pm 0.23 \log$ MAR (equivalent to 0.52 Snellen), and $70 \%$ of eyes achieved an UDVA of $20 / 40$ or better. The residual refractive cylinder was $-0.95 \pm 0.66 \mathrm{D}$. Our postoperative results are comparable to those in these 2 studies. In our study, the mean UDVA was $0.61 \pm 0.26$, with $83 \%$ of eyes having a UDVA of $20 / 40$ or better, and the mean residual refractive cylinder was $-0.75 \pm 0.49 \mathrm{D}$. Acrysof toric IOLs with lower cylinder powers (SN60T3 to SN60T5) have been used in many studies to correct low to moderate corneal astigmatism during cataract surgery. In a recent randomized controlled study of 256 eyes with a toric IOL, the UDVA was $20 / 40$ or better in $92 \%$ of eyes and $20 / 30$ or better in $79 \%$ of eyes. ${ }^{3}$ Approximately $90 \%$ of eyes had a residual refractive cylinder of $1.00 \mathrm{D}$ or less. In a large prospective cohort study, Ahmed et al. examined visual outcomes after bilateral SN60T3 to SN60T5 implantation in 117 patients. ${ }^{1}$ Six months postoperatively, the binocular UDVA was $20 / 40$ or better in $99 \%$ of patients and $20 / 20$ or better in $63 \%$ of patients. The mean residual refractive cylinder was $0.4 \pm 0.4 \mathrm{D}$, and $85 \%$ of patients achieved a residual refractive cylinder of $1.00 \mathrm{D}$ or less. Smaller cohort studies report similar results, with an UDVA of $20 / 40$ or better in $91 \%$ to $95 \%$ of cases and postoperative residual refractive cylinders ranging from $0.5 \mathrm{D}$ to $0.7 \mathrm{D} .^{2,4,14,15}$ In our study, the UDVA was $20 / 40$ or better in $83 \%$ of eyes, which is comparable to results in previous studies using the T3 to T5 toric IOL models. However, only $5 \%$ of patients in our study achieved an UDVA of $20 / 20$ or better, compared with $41 \%$ to $60 \%$ in studies evaluating these IOL models. ${ }^{1-3,5}$ This might be related to the relatively large proportion of our patients who had ocular comorbidities. Twenty-one percent of eyes (14/67) had an ocular comorbidity, such as amblyopia, or a history of RD or macular hole. In addition, all eyes in our study had high preoperative refractive errors that might have compromised the visual acuity due to, for example, anisometropic amblyopia or astigmatism-related (meridional) amblyopia. ${ }^{16,17}$ Our preoperative screening for amblyopia was not optimal and did not include measurement of visual acuity by isolated optotypes to avoid possible crowding phenomena. We compensated for the limited visual potential of patients in this study by calculating the visual potential index: ratio of postoperative UDVA to postoperative CDVA. We found a mean visual potential index of 0.76 , which indicates that the toric IOLs were effective in achieving $76 \%$ of the maximum CDVA in patients with high amounts of corneal astigmatism. For example, in our previous cohort study using low-cylinder power toric IOLs, the visual potential index was $0.83{ }^{2}$ Crucial to the efficacy of toric IOLs is the position of the IOL with regard to the intended alignment axis. Misalignment of the IOL can be caused by 2 factors: inaccurate placement of the IOL during surgery and postoperative rotation of the IOL. 
Rotational stability used to be an issue with older silicone toric IOL models, which were reported to rotate more than 10 degrees in $10 \%$ to more than $25 \%$ of eyes. ${ }^{18,19}$ Acrysof IOLs have been shown to rotate less than 1 degree on average within a 6-month period. $^{20}$ This IOL is made from an acrylic material that has been shown to form adhesions with the capsule, leading to rotational stability of the IOL in the capsular bag, within approximately 2 weeks. ${ }^{21,22}$ In addition, the Acrysof toric IOL has open-loop haptics, which are considered to make the IOL more stable in the first 2 weeks after surgery. ${ }^{23}$ This indicates that accurate placement of the toric IOL during surgery is the most important factor in preventing misalignment. If the toric IOL is misaligned from its intended axis, the cylinder correction is less effective and a remaining astigmatism occurs. Every degree of misalignment leads to approximately $3.5 \%$ of the preoperative astigmatism magnitude remaining. ${ }^{24}$ Previous studies on Acrysof toric IOLs report a mean misalignment of less than 4 degrees. ${ }^{1-4}$ The mean misalignment in our study was $3.2 \pm 2.8$ degrees. This corresponds to a remaining astigmatism magnitude of approximately $11 \%$ of the preoperative magnitude. In the case of a T9 toric IOL with a cylinder of $4.11 \mathrm{D}$ at the corneal plane, this misalignment would result in a remaining astigmatism magnitude of approximately $0.45 \mathrm{D}$. More accurate placement of toric IOLs during surgery might enhance their efficacy. This is especially important when implanting toric IOLs with a high cylinder power.

When considering the use of toric IOLs to correct corneal astigmatism during cataract surgery, it is important to select suitable patients. Patients with Fuchs endothelial dystrophy who might need a keratoplasty in the future are not good candidates for toric IOL implantation. Patients with regular bow-tie astigmatism are most suitable for toric IOL implantation. Preoperative corneal topography is therefore important to assess the patient's corneal astigmatism. However, recent studies show that toric IOL implantation is also effective in patients with nonprogressive keratoconus and in postkeratoplasty patients. ${ }^{25-27}$ Although toric IOLs cannot fully correct irregular astigmatism, they can reduce refractive astigmatism and improve visual acuity.

Accurate preoperative corneal astigmatism power and axis measurement is important for toric IOL power calculation. Previous studies describe various methods of keratometry used in toric IOL power calculation, including the IOLMaster automated keratometry $^{2,4}$, manual keratometry ${ }^{3}$, autokeratorefractometry ${ }^{14}$, corneal topography $^{28}$, or a combination of these techniques ${ }^{1,29}$. In this study, we determined the keratometric power and axis using IOLMaster automated keratometry, which minimizes problems related to human error and has been shown to be a reliable biometric tool for spherical power calculations. Previous studies have shown that 
keratometry measurements obtained with the IOLMaster are comparable to those taken using Scheimpflug imaging and manual keratometry. ${ }^{30-32}$

The expected amount of SICA has to be incorporated into the toric IOL power to allow selection of the most appropriate toric IOL and alignment axis. ${ }^{33}$ However, the exact amount of SICA is difficult to predict and is reported to depend on the amount of preoperative corneal astigmatism, the incision location and size, suture use, and patients' age. ${ }^{34-36}$ In our study, a temporal $2.2 \mathrm{~mm}$ incision induced a significantly lower amount of SICA than a superior $2.2 \mathrm{~mm}$ incision. Previous studies indicated that 2.2 $\mathrm{mm}$ temporal incisions induce $0.10 \mathrm{D}$ to $0.31 \mathrm{D}$ of SICA ${ }^{37,38}$, versus $0.40 \mathrm{D}$ for superior incisions ${ }^{39}$. We recommend incorporating an expected amount of approximately 0.20 $\mathrm{D}$ for a temporal incision and $0.40 \mathrm{D}$ for a superior incision into the toric $\mathrm{IOL}$ power calculation.

In conclusion, this study shows that implantation of an Acrysof toric IOL is an effective and safe method to correct high amounts of corneal astigmatism during cataract surgery.

\section{References}

1. Ahmed I, Rocha G, Slomovic AR, et al. Visual function and patient experience after bilateral implantation of toric intraocular lenses. I Cataract Refract Surg. Apr 2010;36(4):609-616.

2. Bauer NJ, de Vries NE, Webers CA, Hendrikse F, Nuijts RM. Astigmatism management in cataract surgery with the AcrySof toric intraocular lens. J Cataract Refract Surg. Sep 2008;34(9):1483-1488.

3. Holland E, Lane S, Horn JD, Ernest P, Arleo R, Miller KM. The AcrySof Toric Intraocular Lens in Subjects with Cataracts and Corneal Astigmatism A Randomized, SubjectMasked, Parallel-Group, 1-Year Study. Ophthalmology. Sep 14 2010;117(11):21042111.

4. Mendicute J, Irigoyen C, Aramberri J, Ondarra A, Montes-Mico R. Foldable toric intraocular lens for astigmatism correction in cataract patients. J Cataract Refract Surg. Apr 2008;34(4):601-607.

5. Ruiz-Mesa R, Carrasco-Sanchez D, DiazAlvarez SB, Ruiz-Mateos MA, Ferrer-Blasco $T$, Montes-Mico R. Refractive lens exchange with foldable toric intraocular lens. Am J Ophthalmol. Jun 2009;147(6):990-996, 996 e991.
6. Bayramlar $\mathrm{HH}$, Daglioglu MC, Borazan M. Limbal relaxing incisions for primary mixed astigmatism and mixed astigmatism after cataract surgery. J Cataract Refract Surg. Apr 2003;29(4):723-728.

7. Kato N, Toda I, Hori-Komai Y, Sakai C, Tsubota K. Five-year outcome of LASIK for myopia. Ophthalmology. 2008;115(5):839844 e832.

8. Thomas KE, Brunstetter $\mathrm{T}$, Rogers $\mathrm{S}$, Sheridan MV. Astigmatism: risk factor for postoperative corneal haze in conventional myopic photorefractive keratectomy. J Cataract Refract Surg. Dec 2008;34(12):2068-2072.

9. de Oliveira GC, Solari HP, Ciola FB, Lima AL, Campos MS. Corneal infiltrates after excimer laser photorefractive keratectomy and LASIK. J Refract Surg. Feb 2006;22(2):159-165.

10. Ferrer-Blasco T, Montes-Mico R, Peixoto-deMatos SC, Gonzalez-Meijome JM, Cervino A. Prevalence of corneal astigmatism before cataract surgery. J Cataract Refract Surg. Jan 2009;35(1):70-75.

11. Holladay JT, Moran JR, Kezirian GM. Analysis of aggregate surgically induced refractive change, prediction error, and intraocular 
astigmatism. J Cataract Refract Surg. Jan 2001;27(1):61-79.

12. Alio JL, Agdeppa MC, Pongo VC, El Kady B. Microincision cataract surgery with toric intraocular lens implantation for correcting moderate and high astigmatism: pilot study. J Cataract Refract Surg. Jan 2010;36(1):4452.

13. Entabi M, Harman F, Lee N, Bloom PA. Injectable 1-piece hydrophilic acrylic toric intraocular lens for cataract surgery: Efficacy and stability. J Cataract Refract Surg. Feb 2011;37(2):235-240.

14. Chang DF. Comparative rotational stability of single-piece open-loop acrylic and platehaptic silicone toric intraocular lenses. J Cataract Refract Surg. Nov 2008;34(11):1842-1847.

15. Mendicute J, Irigoyen C, Ruiz M, Illarramendi I, Ferrer-Blasco T, Montes-Mico R. Toric intraocular lens versus opposite clear corneal incisions to correct astigmatism in eyes having cataract surgery. J Cataract Refract Surg. Mar 2009;35(3):451-458.

16. Harvey EM. Development and treatment of astigmatism-related amblyopia. Optom Vis Sci. Jun 2009;86(6):634-639.

17. Dobson V, Miller JM, Clifford-Donaldson CE, Harvey EM. Associations between anisometropia, amblyopia, and reduced stereoacuity in a school-aged population with a high prevalence of astigmatism. Invest Ophthalmol Vis Sci. Oct 2008;49(10):4427-4436.

18. De Silva DJ, Ramkissoon YD, Bloom PA. Evaluation of a toric intraocular lens with a Z-haptic. J Cataract Refract Surg. Sep 2006;32(9):1492-1498.

19. Sun $X Y$, Vicary $D$, Montgomery $P$, Griffiths $M$. Toric intraocular lenses for correcting astigmatism in 130 eyes. Ophthalmology. Sep 2000;107(9):1776-1781; discussion 1781-1772.

20. Weinand F, Jung A, Stein A, Pfutzner A, Becker R, Pavlovic S. Rotational stability of a single-piece hydrophobic acrylic intraocular lens: new method for high-precision rotation control. J Cataract Refract Surg. May 2007;33(5):800-803.

21. Linnola RJ, Sund M, Ylonen R, Pihlajaniemi T. Adhesion of soluble fibronectin, vitronectin, and collagen type IV to intraocular lens materials. J Cataract Refract Surg. Jan 2003;29(1):146-152.

22. Lombardo M, Carbone G, Lombardo G, De Santo MP, Barberi R. Analysis of intraocular lens surface adhesiveness by atomic force microscopy. J Cataract Refract Surg. Jul 2009;35(7):1266-1272.

23. Buckhurst PJ, Wolffsohn JS, Davies LN, Naroo SA. Surgical correction of astigmatism during cataract surgery. Clin Exp Optom. Aug 242010.

24. Ma JJ, Tseng SS. Simple method for accurate alignment in toric phakic and aphakic intraocular lens implantation. I Cataract Refract Surg. Oct 2008;34(10):1631-1636

25. Navas A, Suarez R. One-year follow-up of toric intraocular lens implantation in forme fruste keratoconus. J Cataract Refract Surg. Nov 2009;35(11):2024-2027.

26. Stewart CM, McAlister JC. Comparison of grafted and non-grafted patients with corneal astigmatism undergoing cataract extraction with a toric intraocular lens implant. Clin Experiment Ophthalmol. May 24 2010;38(8):747-757.

27. Visser N, Gast ST, Bauer NJ, Nuijts RM. Cataract surgery with toric intraocular lens implantation in keratoconus: a case report. Cornea. Jun 2011;30(6):720-723.

28. Dardzhikova A, Shah CR, Gimbel HV. Early experience with the AcrySof toric IOL for the correction of astigmatism in cataract surgery. Can J Ophthalmol. Jun 2009;44(3):269-273.

29. Gayton JL, Seabolt RA. Clinical Outcomes of Complex and Uncomplicated Cataractous Eyes After Lens Replacement with the AcrySof Toric IOL. J Refract Surg. Apr 14 2010;14:1-7.

30. Findl O, Kriechbaum K, Sacu S, et al. Influence of operator experience on the performance of ultrasound biometry compared to optical biometry before cataract surgery. J Cataract Refract Surg. Oct 2003;29(10):1950-1955.

31. Savini G, Barboni P, Carbonelli M, Hoffer KJ. Accuracy of Scheimpflug corneal power measurements for intraocular lens power calculation. J Cataract Refract Surg. Jul 2009;35(7):1193-1197

32. Shirayama M, Wang L, Weikert MP, Koch DD. Comparison of corneal powers obtained from 4 different devices. Am J Ophthalmol. Oct 2009;148(4):528-535 e521.

33. Hill W. Expected effects of surgically induced astigmatism on AcrySof toric intraocular lens results. J Cataract Refract Surg. Mar 2008;34(3):364-367.

34. Drews RC. Five year study of astigmatic stability after cataract surgery with 
intraocular lens implantation: comparison of wound sizes. I Cataract Refract Surg. Feb 2000;26(2):250-253.

35. Storr-Paulsen A, Madsen $H$, Perriard A. Possible factors modifying the surgically induced astigmatism in cataract surgery. Acta Ophthalmol Scand. Oct 1999;77(5):548551.

36. Tejedor J, Perez-Rodriguez JA. Astigmatic change induced by $2.8-\mathrm{mm}$ corneal incisions for cataract surgery. Invest Ophthalmol Vis Sci. Mar 2009;50(3):989-994.

37. Lee KM, Kwon HG, Joo CK. Microcoaxial cataract surgery outcomes: comparison of
$1.8 \mathrm{~mm}$ system and $2.2 \mathrm{~mm}$ system. J Cataract Refract Surg. May 2009;35(5):874880.

38. Masket S, Wang L, Belani S. Induced astigmatism with 2.2 - and $3.0-\mathrm{mm}$ coaxial phacoemulsification incisions. J Refract Surg. Jan 2009;25(1):21-24.

39. Wang J, Zhang EK, Fan WY, Ma JX, Zhao PF. The effect of micro-incision and smallincision coaxial phaco-emulsification on corneal astigmatism. Clin Experiment Ophthalmol. Sep 2009;37(7):664-669. 


\section{Chapter 7}

\section{Visual outcomes and patient satisfaction after cataract surgery with toric multifocal intraocular lens implantation}

Nienke Visser, Rudy M.M.A. Nuijts, Niels E. de Vries and Noël J.C. Bauer Journal of Cataract \& Refractive Surgery 2011; 37: 2034-2042 


\section{Abstract}

PURPOSE: To evaluate visual outcomes and patient satisfaction after toric multifocal intraocular lens (IOL) implantation in patients with cataract and corneal astigmatism.

Setring: University Eye Clinic, Maastricht University Medical Center, the Netherlands.

METHODS: Patients with cataract, corneal astigmatism, and a motivation for spectacle independency underwent cataract surgery with implantation of a toric diffractive multifocal IOL (AT Lisa, Carl Zeiss Meditec). Three months postoperatively, the uncorrected distance (UDVA), intermediate (UIVA), and near visual acuities (UNVA); corrected distance (CDVA), intermediate (CIVA), and near visual acuities (CNVA), residual refractive astigmatism, defocus curve, contrast sensitivity and patient satisfaction were evaluated.

RESULTS: Forty-five eyes of 25 patients were included. Postoperatively, the mean UDVA was $0.04 \pm 0.15 \log M A R$ and $98 \%$ of eyes achieved an UDVA of 20/40 or better. The mean UNVA was $0.20 \pm 0.16 \log M A R$ and the mean UIVA $(60 \mathrm{~cm}) 0.40 \pm 0.16 \log$ MAR. Residual refractive astigmatism of -1.00 diopter (D) or less was achieved in approximately $90 \%$ of eyes. Contrast sensitivity levels were high. Approximately $50 \%$ of patients reported moderate glare, halos and starburst symptoms. Spectacle independency for distance and near vision was achieved by $95 \%$ and $79 \%$ of patients, respectively.

CONCLUSION: Multifocal toric IOL implantation in patients with cataract and corneal astigmatism provided good distance and near visual outcomes and acceptable intermediate visual outcomes, allowing patients with considerable amounts of corneal astigmatism to achieve spectacle independence at distance and near. 


\section{Introduction}

The goal in modern cataract surgery is not only to restore visual acuity and reach emmetropia but also to gain spectacle independence for distance and near vision. This can be achieved by implantation of a multifocal IOL during cataract surgery. However, corneal astigmatism of $1 \mathrm{D}$ or more is prevalent in approximately $30 \%$ of eyes. ${ }^{1-3}$ Not correcting the astigmatism component at the time of cataract surgery will fail to achieve spectacle independence. In addition, a recent study showed that postoperative astigmatism compromised distance and intermediate visual acuities more substantially in eyes with a multifocal IOL compared to eyes with a monofocal IOL. ${ }^{4}$ This indicates that astigmatism management is important when considering multifocal IOL implantation.

Patients with a considerable amount of corneal astigmatism who wish to have a multifocal IOL have several options. Limbal relaxing incisions or opposite clear corneal incisions can be performed to reduce astigmatism during cataract surgery. ${ }^{5,6}$ After cataract surgery, laser refractive surgery can be used to correct residual refractive errors, including cylinder errors. ${ }^{7-9}$ However, aside from the disadvantage of an additional surgery, these procedures are associated with complications, such as limited predictability, dry eye and wound-healing problems. ${ }^{10-12}$

Toric multifocal IOLs offer the opportunity to correct astigmatism and achieve spectacle independence at all distances in patients with corneal astigmatism. The purpose of this study was to evaluate the clinical outcomes after toric multifocal IOL implantation in patients with cataract and corneal astigmatism. Distance, intermediate and near visual acuities, residual astigmatism, defocus curve, contrast sensitivity and patient satisfaction were evaluated.

\section{Methods}

\section{Study Population}

This prospective cohort study was performed at the University Eye Clinic Maastricht, the Netherlands. Consecutive patients who wished to have toric multifocal IOL implantation were included in the study. Institutional review board approval was obtained and the tenets of the Declaration of Helsinki were followed.

Inclusion criteria were: visually significant cataract, corneal astigmatism of at least 1.00 D (measured by keratometry), a motivation for spectacle independence at distance and near, and age over 21 years. Exclusion criteria were: irregular corneal astigmatism, occupational night driver, Fuchs endothelial dystrophy, glaucoma, extensive macular 
disease, a history of retinal detachment or intraocular inflammation, and an abnormal iris or pupil configuration. Preoperatively, patients had an extensive ophthalmologic examination, including measurement of corrected distance visual acuity (CDVA), subjective refraction, objective refraction (Topcon), slitlamp examination, fundoscopy, Goldmann applanation tonometry, corneal topography (Atlas, Carl Zeiss Meditec) and optical biometry (IOLMaster, Carl Zeiss Meditec). Scotopic and photopic pupil diameters were measured using the corneal topography device.

\section{Intraocular Lens}

All patients had implantation of an AT Lisa toric IOL (previously known as Acri.Lisa toric 466TD, Carl Zeiss Meditec) (Figure 7.1). The multifocal aspheric IOL is made of hydrophilic acrylate with a hydrophobic surface. The single-piece plate haptic IOL has a total diameter of $11.0 \mathrm{~mm}$, an optic diameter of $6.0 \mathrm{~mm}$, and 0 degree of haptic angulation. The anterior surface of the IOL contains the toric component and the posterior surface the diffractive structures. Incident light is distributed $65 \%$ to distance focus and $35 \%$ to near focus, independent of pupil size. Available spherical powers range from -10.00 to $+32.00 \mathrm{D}$ in $0.50 \mathrm{D}$ increments and include a near addition of $+3.75 \mathrm{D}$. Cylinder powers range from +1.00 to $+12.00 \mathrm{D}$ in $0.50 \mathrm{D}$ increments. The IOL power was calculated using a online calculator (available at https://zcalc.meditec.zeiss.com/zcalc). The IOLs are custom-made and require an ordering time of 6 to 8 weeks. An expected amount of $0.50 \mathrm{D}$ of corneal flattening at the incised meridian was incorporated into the IOL power calculation.

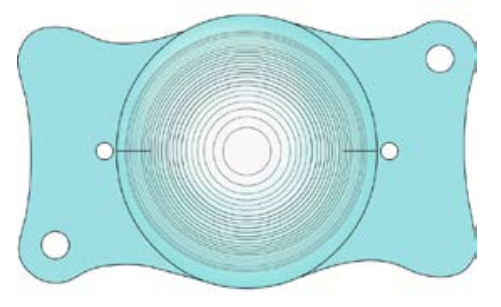

Figure 7.1 The AT LISA multifocal toric IOL.

\section{Surgical Technique}

The same surgeon (NB) performed all surgeries. Preoperatively, corneal reference marks were placed at 0,180 and 270 degrees using the Nuijts/Lane toric reference marker (American Surgical Instruments Corp.) and with the patient sitting upright to correct for cyclotorsion. Intraoperatively, the implantation axis was determined using the corneal reference marks and the alignment axis obtained from the IOL calculation. 
This axis was marked using a Mendez degree gauge and the Nuijts toric axis marker (both American Surgical Instruments Corp.).

A $2.2 \mathrm{~mm}$ limbal incision was made at the steep axis of the cornea. This was followed by creation of a well-centered capsulorrhexis of approximately $5.0 \mathrm{~mm}$ and standard divide-and-conquer phacoemulsification. After the foldable toric IOL was inserted, the ophthalmic viscosurgical device was removed and the IOL was rotated into final position by exact alignment of the reference marks on the toric IOL with the implantation axis marks. Postoperatively, all patients were prescribed a fixedcombination eye drop of tobramycin $3 \mathrm{mg} / \mathrm{mL}$ and dexamethasone $1 \mathrm{mg} / \mathrm{mL}$ (Tobradex, Alcon Laboratories) and nepafenac $1 \mathrm{mg} / \mathrm{mL}$ (Nevanac, Alcon Laboratories) in a tapering dose for the first 4 weeks.

\section{Outcome Measures}

Postoperative examinations were performed at 3 months. The uncorrected (UDVA) and corrected distance visual acuity (CDVA) were assessed using the $100 \%$ contrast Early Treatment Diabetic Retinopathy Study chart (ETDRS, Precision Vision, La Salle, IL) at $4 \mathrm{~m}$ (calibrated at 85 candela $(\mathrm{cd}) / \mathrm{m}^{2}$ ). Uncorrected (UNVA) and corrected near visual acuity (CNVA) were measured using a handheld logarithmic near visual acuity ETDRS chart (Precision Vision) at $40 \mathrm{~cm}$ under photopic conditions. Uncorrected (UIVA) and corrected intermediate visual acuity (CIVA) were measured at $60 \mathrm{~cm}$ and $80 \mathrm{~cm}$ using the logarithmic near visual acuity ETDRS chart. A binocular defocus curve was constructed using the ETDRS chart at $4 \mathrm{~m}$ and adding +3.00 to $-5.00 \mathrm{D}$ sphere in $0.50 \mathrm{D}$ increments to the patient's manifest refraction. The orientation of the toric IOL axis was determined using a slitlamp.

Subjective refractive astigmatism was analyzed using a vector analysis according to Alpins. ${ }^{13}$ Refractive astigmatism data were calculated to the corneal plane by adjusting for a back vertex distance of $12.0 \mathrm{~mm}$. Individual magnitude (diopters) and axis (degrees) values were transformed into rectangular $\mathrm{x}$ and $\mathrm{y}$ coordinates and used to calculate the following vectors. Target induced astigmatism (TIA) represents the change the surgery was intended to induce. Surgically induced astigmatism (SIA) is the astigmatic change the surgery actually induced. The difference vector represents the vector between the achieved astigmatic outcome and the target astigmatic outcome. The magnitude of error is the arithmetic difference between the magnitudes of the SIA and TIA. The magnitude of error is positive for overcorrection and negative for under correction. The angle of error is the angle between the SIA vector and TIA vector. Both the overall residual astigmatism magnitude and the residual astigmatism at the intended meridian of treatment (TIA meridian) were calculated. ${ }^{14}$ The correction index 
is the ratio of the magnitude of SIA to the magnitude of TIA. The correction index is preferably 1.0. It is greater than 1.0 if overcorrection occurred and less than 1.0 if undercorrection occurred. The index of success was calculated by dividing the difference vector by the TIA. This is a relative measure of success and is preferably zero.

Contrast sensitivity was measured using the CSV-1000 contrast test (Vector vision). ${ }^{15}$ This system consists of a translucent chart with background illumination, calibrated at $85 \mathrm{~cd} / \mathrm{m}^{2}$. It automatically adjusts for external light so that the testing light level is standardized. Examinations were performed monocularly and binocularly (if applicable) with manifest refraction in place. Absolute values of log contrast sensitivity were obtained for a spatial frequency of 3, 6, 12 and 18 cycles per degree (cpd) at 2.5 $\mathrm{m}$. In addition, the results were compared with monocular contrast sensitivities obtained in a previous study of multifocal IOLs with a +3.00 D or a +4.00 D add power (Restor SN6AD1 or SN6AD3, Alcon Laboratories). ${ }^{16}$ This study used the same test chart (CSV-1000) to measure contrast sensitivities.

In patients with binocular IOL implantation, a questionnaire was used to evaluate patient satisfaction, spectacle use, visual disturbance items and visual lifestyle at 3 months postoperatively. Patients rated visual disturbance items (glare, halos, starburst, blinding, ghost images, and diplopia) on a scale of 1 to 7 as follows: $1-2=$ no symptoms, 3-5 = mild symptoms, 6-7 = severe symptoms. The performance of specific distance (D), intermediate $(\mathrm{I})$ and near $(\mathrm{N})$ visual lifestyle activities (without spectacle use) was assessed on a scale of 1 to 7 (1-2 = no problems, 3-5 = mild problems, 6-7 = severe problems). These activities were nighttime driving (D), daytime driving (D), watching television $(D / I)$, shopping $(D / I / N)$, recognizing faces $(I)$, computer work $(I)$, cooking $(\mathrm{I} / \mathrm{N})$, reading a book $(\mathrm{N})$, and reading a newspaper $(\mathrm{N})$. Spectacle use was evaluated by asking how often patients used spectacles for distance, intermediate, and near vision (never, rarely, on occasion, often, always). Overall patient satisfaction was assessed by asking whether patients were satisfied with the postoperative result (yes or no) and if they would choose this option again (yes or no).

\section{Statistical Analysis}

All data were collected in an Excel database (Microsoft Office 2003, Microsoft Inc.). Statistical analysis was performed using SPSS for Windows (version 16.0, SPSS Inc.). 


\section{Results}

Forty-five eyes of 25 patients were included. Twenty patients had bilateral toric multifocal IOL implantation. Table 7.1 shows the patients demographics and preoperative data.

\section{Visual Acuity}

Table 7.2 shows the distance, intermediate and near visual acuities. In 1 eye, the UDVA was less than $20 / 40$ as a result of a perforating trauma that occurred when the patient was 3 years old. Figure 7.2 shows the binocular defocus curve with 2 peaks of optimum CDVA at $0.00 \mathrm{D}$ and $-2.50 \mathrm{D}$.

\section{Refraction}

Table 7.3 shows the results of the astigmatism vector analysis. Almost $90 \%$ of eyes had postoperative residual refractive astigmatism of $1.00 \mathrm{D}$ or less (Figure 7.3). One eye had a residual refractive astigmatism of more than $1.50 \mathrm{D}$ (refractive astigmatism of $1.75 \mathrm{D})$. In this eye, the toric IOL misalignment was 6 degrees. The residual refractive astigmatism in this patient may be the result of irregular astigmatism that was not discovered preoperatively. Postoperative corneal topography showed a band of peripheral thinning, consistent with pellucid marginal degeneration.

Table 7.1 Patient characteristics and preoperative data

\begin{tabular}{ll}
\hline Parameter & Value \\
\hline Eyes ( $\mathrm{n}$ ) & 45 \\
Patients (n) & 25 \\
Age (mean \pm SD, years) & $59 \pm 11$ \\
Female (\%) & $47 \%$ \\
CDVA (mean \pm SD, logMAR) & $0.20 \pm 0.23$ \\
Refractive cylinder (mean \pm SD, D) & $-2.47 \pm 1.47$ \\
Corneal astigmatism magnitude* (mean \pm SD, D) & $2.55 \pm 1.19$ \\
Pupil diameter (mean \pm SD, mm) & \\
$\quad$ Scotopic $\quad$ & $5.26 \pm 0.81$ \\
$\quad$ Photopic & $3.58 \pm 0.65$ \\
Axial length (mean \pm SD, mm) & $24.25 \pm 1.37$ \\
IOL sphere power (mean \pm SD, D) & $16.31 \pm 5.13$ \\
IOL cylinder power (mean \pm SD, D) & $3.22 \pm 1.60$ \\
Expected residual cylinder (mean \pm SD, D) & $-0.15 \pm 0.12$ \\
Follow-up (mean \pm SD, months) & $3.3 \pm 1.1$ \\
\hline * = obtained by IOLMaster keratometry
\end{tabular}

Contrast Sensitivity

Figure 7.4 shows the monocular and binocular contrast sensitivity under photopic conditions. The mean monocular contrast sensitivity was $1.73 \pm 0.24,1.89 \pm 0.27,1.45$ 
\pm 0.36 and $1.03 \pm 0.33 \log$ at $3,6,12$ and $18 \mathrm{cpd}$, respectively. In patients with binocular IOL implantation, the mean contrast sensitivity was $1.86 \pm 0.18$ at $3 \mathrm{cpd}, 2.02$ \pm 0.19 at $6 \mathrm{cpd}, 1.63 \pm 0.29$ at $12 \mathrm{cpd}$ and $1.19 \pm 0.24$ at $18 \mathrm{cpd}$. Figure 7.4 also shows the monocular contrast sensitivities from the previous study of Restor +3.0 D and Restor +4.0 D multifocal IOLs. The monocular contrast sensitivities of the AT Lisa toric IOL were significantly higher than those of the 2 Restor IOLs at spatial frequencies 6 $\operatorname{cpd}(p=0.001$; analysis of variance [ANOVA]), $12 \mathrm{cpd}(p<0.001 ;$ ANOVA) and $18 \mathrm{cpd}$ $(\mathrm{P}<0.001 ; \mathrm{ANOVA})$.

\section{Patient Satisfaction and Spectacle Dependency}

Nineteen (95\%) out of 20 patients with bilateral AT Lisa toric implantation completed the questionnaire. Figure 7.5A shows the presence of visual disturbance items. Approximately one half of the patients reported moderate symptoms of glare, halos, and starburst. Symptoms of blinding, ghost-images, and diplopia were reported in a minority of patients.

Figure 7.5B shows the percentage of patients with moderate or severe problems performing specific distance, intermediate, and near visual lifestyle activities (without spectacle use). The majority of patients reported problems with nighttime driving. Approximately $30 \%$ of patients reported moderate or severe problems with computer tasks and reading. Ten (53\%) of 19 patients reported complete spectacle independency for all distances (distance, intermediate, and near). Four patients (21\%) reported occasional use of spectacles for reading. Regarding intermediate vision, 4 patients $(21 \%)$ occasionally $(n=1)$ or often $(n=3)$ used spectacles for computer work. One patient (5\%) occasionally used spectacles for distance vision. Eighteen (95\%) of 19 patients reported being satisfied with the postoperative results and would choose to have a toric multifocal IOL again.

\section{Complications}

Two months postoperatively, 1 patient had a neodymium:YAG capsulotomy for clinically significant posterior capsule opacification, after which the CDVA improved from $20 / 40$ to 20/17. One patient presented with anterior uveitis 1 month after cataract surgery; she was treated for 4 weeks with corticosteroid eye drops (Pred Forte, Allergan).

Three months postoperatively, the mean IOL misalignment was $2.3 \pm 2.0$ degrees (median 2.0 degrees, range 0 to 7 degrees). No IOL was misaligned by 10 degrees or more. 
Table 7.2 Distance, intermediate and near visual acuities 3 months postoperatively

\begin{tabular}{|c|c|c|c|c|}
\hline Parameter & $\begin{array}{c}\text { Eyes } \\
(\mathrm{N})\end{array}$ & $\begin{array}{c}\text { logMAR } \\
(\text { mean } \pm \text { SD) }\end{array}$ & $\begin{array}{c}\geq 20 / 40 \\
(\%)\end{array}$ & $\begin{array}{c}\geq 20 / 25 \\
(\%)\end{array}$ \\
\hline \multicolumn{5}{|l|}{ Distance (4 m) } \\
\hline UDVA & 45 & $0.04 \pm 0.15$ & 98 & 71 \\
\hline CDVA & 45 & $-0.06 \pm 0.09$ & 100 & 91 \\
\hline Binocular CDVA & 20 & $-0.10 \pm 0.09$ & 100 & 95 \\
\hline \multicolumn{5}{|l|}{ Intermediate $(80 \mathrm{~cm})$} \\
\hline UIVA & 45 & $0.53 \pm 0.17$ & 13 & 0 \\
\hline CIVA & 45 & $0.52 \pm 0.19$ & 18 & 2 \\
\hline Binocular CIVA & 20 & $0.45 \pm 0.13$ & 15 & 0 \\
\hline \multicolumn{5}{|l|}{ Intermediate $(60 \mathrm{~cm})$} \\
\hline UIVA & 45 & $0.40 \pm 0.16$ & 33 & 2 \\
\hline CIVA & 45 & $0.40 \pm 0.18$ & 40 & 7 \\
\hline Binocular CIVA & 20 & $0.34 \pm 0.14$ & 40 & 5 \\
\hline \multicolumn{5}{|l|}{ Near $(40 \mathrm{~cm})$} \\
\hline UNVA & 45 & $0.20 \pm 0.16$ & 76 & 29 \\
\hline CNVA & 45 & $0.09 \pm 0.15$ & 91 & 49 \\
\hline Binocular CNVA & 20 & $0.03 \pm 0.11$ & 100 & 70 \\
\hline
\end{tabular}

Table 7.3 Astigmatism vector analysis according to Alpins method

\begin{tabular}{|c|c|}
\hline Alpins vector & Result \\
\hline \multicolumn{2}{|l|}{ Preoperatively } \\
\hline \multicolumn{2}{|l|}{ Refractive astigmatism } \\
\hline Arithmetic mean $(D \pm S D)$ & $2.36 \pm 1.41$ \\
\hline Vector mean (D @ ) & $0.82 @ 172$ \\
\hline \multicolumn{2}{|l|}{ Corneal astigmatism } \\
\hline Arithmetic mean $(D \pm S D)$ & $2.55 \pm 1.19$ \\
\hline Vector mean (D@ @ ) & $1.27 @ 88$ \\
\hline \multicolumn{2}{|l|}{ Target induced astigmatism } \\
\hline Vector mean (D @ ${ }^{\circ}$ ) & $1.27 @ 178$ \\
\hline \multicolumn{2}{|l|}{ Postoperatively } \\
\hline \multicolumn{2}{|l|}{ Refractive astigmatism } \\
\hline Arithmetic mean $(D \pm S D)$ & $0.71 \pm 0.42$ \\
\hline Vector mean (D @ ) & $0.56 @ 95$ \\
\hline Surgically induced astigmatism (D @ ${ }^{\circ}$ ) & $0.74 @ 173$ \\
\hline Difference vector (D @ ${ }^{\circ}$ ) & $0.56 @ 5$ \\
\hline Magnitude of error $(D \pm S D)$ & $-0.18 \pm 0.60$ \\
\hline Angle of error $\left({ }^{\circ} \pm S D\right)$ & $-3 \pm 17$ \\
\hline \multicolumn{2}{|l|}{ Residual astigmatism } \\
\hline Mean magnitude $(D \pm S D)$ & $0.71 \pm 0.42$ \\
\hline At meridian of treatment $(D \pm S D)$ & $0.19 \pm 1.07$ \\
\hline Correction index & 0.94 \\
\hline Index of success & 0.33 \\
\hline
\end{tabular}




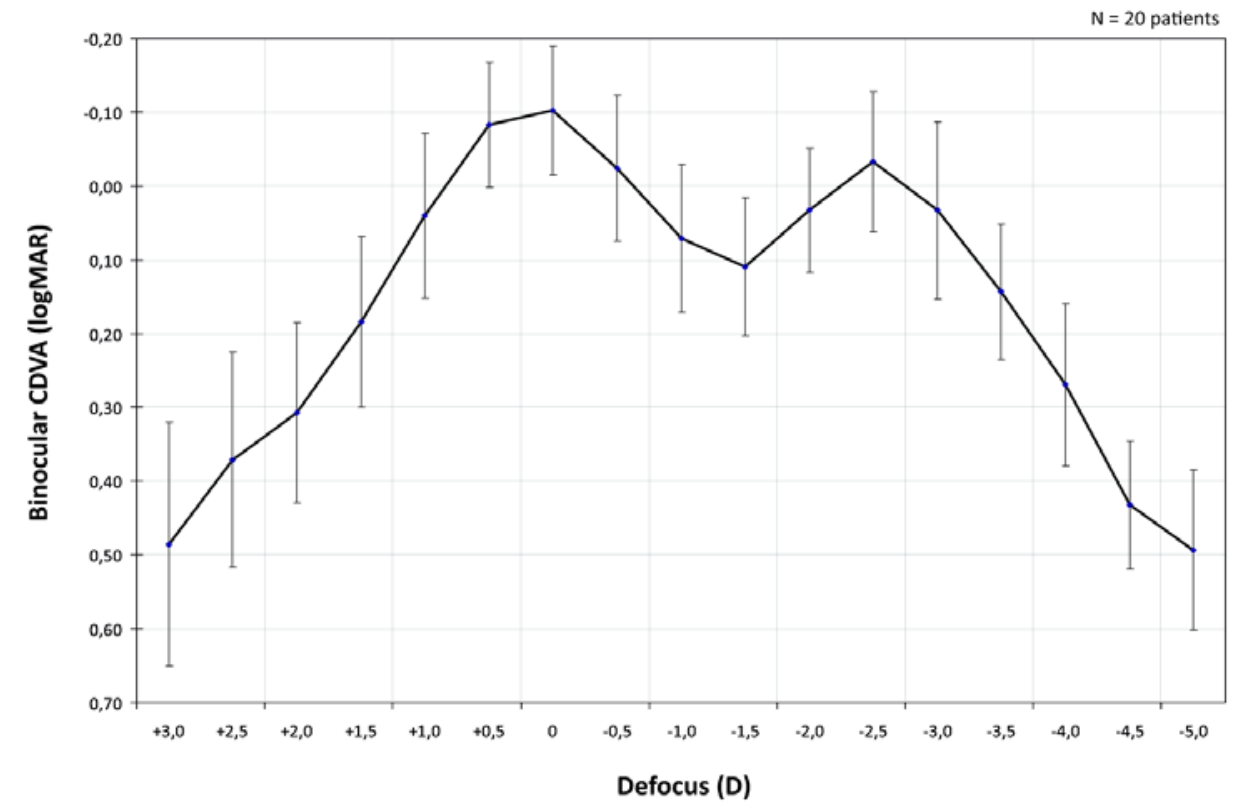

Figure 7.2 Defocus curve: mean CDVA as a function of diopters of defocus.

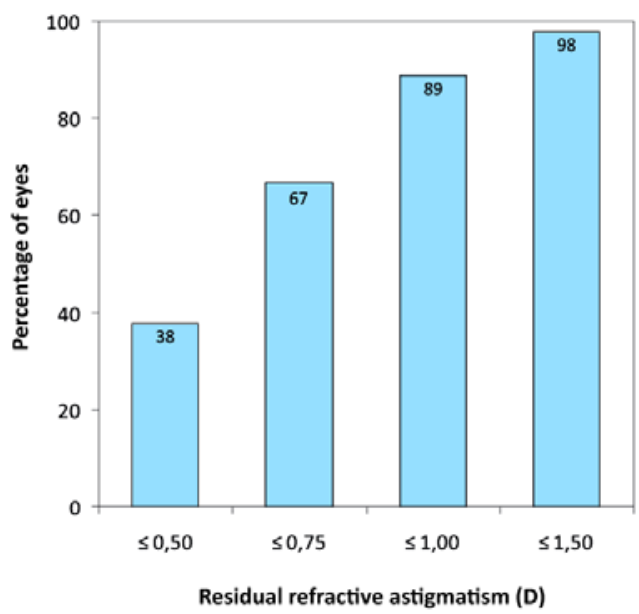

Figure 7.3 Cumulative postoperative residual refractive astigmatism. 


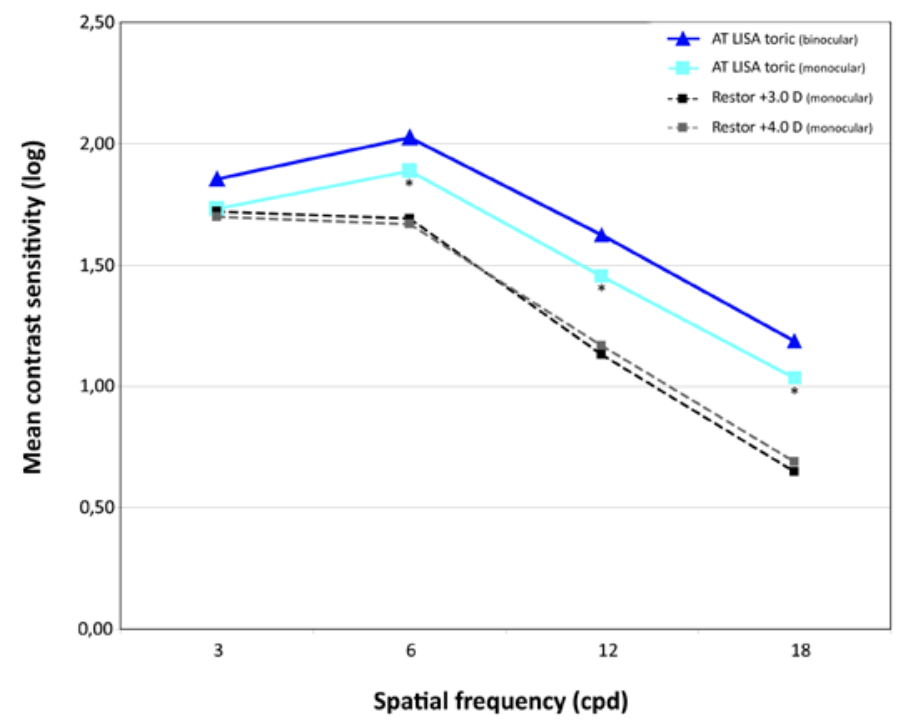

Figure 7.4 Monocular and binocular contrast sensitivity in patients with the AT LISA toric IOL, and in patients from a previous study of non-toric diffractive multifocal IOLs (add power +3.0 D or $+4.0 \mathrm{D}){ }^{16} *$ indicates a significant difference $(p<0.05$; ANOVA) between the toric IOL and the non-toric IOL.

\section{Discussion}

In the current study we evaluated the visual and refractive outcomes, contrast sensitivity, and patient satisfaction after toric multifocal IOL implantation in patients with cataract and corneal astigmatism. Three months postoperatively, the mean UDVA was $0.04 \pm 0.15 \log$ MAR and the mean UNVA was $0.20 \pm 0.16 \log M A R$. At the intermediate distances of $60 \mathrm{~cm}$ and $80 \mathrm{~cm}$, the mean UIVA was $0.40 \pm 0.16 \operatorname{logMAR}$ (equivalent to 20/50) and $0.53 \pm 0.17 \log M A R$ (equivalent to 20/68), respectively. Almost $90 \%$ of eyes had a residual refractive astigmatism of $1.00 \mathrm{D}$ or less.

At present, 4 different toric multifocal IOL models are available: the diffractive AT Lisa toric IOL with a +3.75 D add power, the diffractive Restor IQ toric IOL (Alcon Laboratories) with a $+3.00 \mathrm{D}$ add, the refractive M-flex T IOL (Rayner) with an add power of +3.00 or $+4.00 \mathrm{D}$, and the Lentis Mplus toric IOL (Oculentis) with a $+3.00 \mathrm{D}$ sector-shaped near vision segment. So far, to our knowledge, no studies on the Restor IQ toric IOL, M-flex T IOL or Lentis Mplus toric IOL have been published. One case series described refractive lens exchange with AT Lisa toric implantation in 10 eyes of 6 patients. ${ }^{17}$ In that study, postoperative UDVA was 20/40 or better in all eyes and the 
mean reduction in refractive astigmatism was 95\%. Near and intermediate visual acuities were not evaluated.

Diffractive multifocal IOLs redirect incoming light into two separate foci, one for distance vision and one for near vision. The AT Lisa toric IOL uses $65 \%$ of light for distance vision and $35 \%$ for near vision, independent of pupil size. This concept was developed because most patients prefer distance vision and because $35 \%$ of light for near vision is sufficient for reading under normal lighting conditions. Nontoric AT Lisa multifocal IOL implantation has been evaluated in several studies. ${ }^{18-21}$ This IOL has the same platform as the AT Lisa toric IOL. These studies showed postoperative monocular UDVA rates ranging from 0.07 to 0.23 logMAR. We found a slightly better UDVA 0.04 logMAR) and $71 \%$ of eyes in our study achieved an UDVA of 20/25 or better versus $53 \%$ in a previous study. ${ }^{18}$ Regarding near vision, previous studies report an UNVA

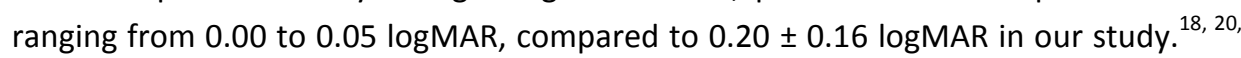
${ }^{21}$ However, previous studies measured near visual acuity at $33 \mathrm{~cm}$ distance whereas we used a distance of $40 \mathrm{~cm}$. We believe that the mean UNVA in our study is an effective visual acuity for reading. This is consistent with our finding that the majority of patients did not use spectacles for near vision.

Intermediate vision with diffractive multifocal IOLs is provided by the defocused images of both focus points. Due to this design, objects at intermediate distances produce images of a lesser quality than objects at distance or near. Previous studies using non-toric AT Lisa multifocal IOLs report binocular CIVA of 0.27 to 0.34 logMAR at $70 \mathrm{~cm} .{ }^{18,20,21}$ This is slightly better than the CIVA in our study $(0.34 \pm 0.14 \operatorname{logMAR}$ at $60 \mathrm{~cm}$ and $0.45 \pm 0.13 \log$ MAR at $80 \mathrm{~cm}$ ). These results are in accordance with the reported patient satisfaction in our study; approximately $30 \%$ of patients reported moderate to severe problems with activities at intermediate distances (computer work) and $21 \%$ of patients reported using spectacles for intermediate vision. This indicates that the visual outcomes for intermediate distances were less good than distance and near visual outcomes. For intermediate distances, multifocal IOLs with a +3.00 $\mathrm{D}$ add power have been shown to lead to better uncorrected visual outcomes than multifocal IOLs with a $+3.75 \mathrm{D}$ or $+4.00 \mathrm{D}$ add power. ${ }^{16,22,23}$

The monofocal toric AT Comfort IOL (Carl Zeiss Meditec) uses the same platform as the multifocal AT Lisa toric IOL. Alio et al. evaluated AT Comfort toric IOL implantation in 21 eyes of 12 patients. ${ }^{24}$ Postoperatively, the mean Snellen UDVA was $0.65 \pm 0.22$ and the mean residual refractive astigmatism was $-0.45 \pm 0.63 \mathrm{D}$. In our study, Alpins analysis showed a mean residual astigmatism of $0.19 \pm 1.07 \mathrm{D}$ at the meridian of treatment (steep meridian of the cornea) and an overall mean residual astigmatism magnitude of $0.71 \pm 0.42 \mathrm{D}$. Even though this was slightly higher than values reported 
A.

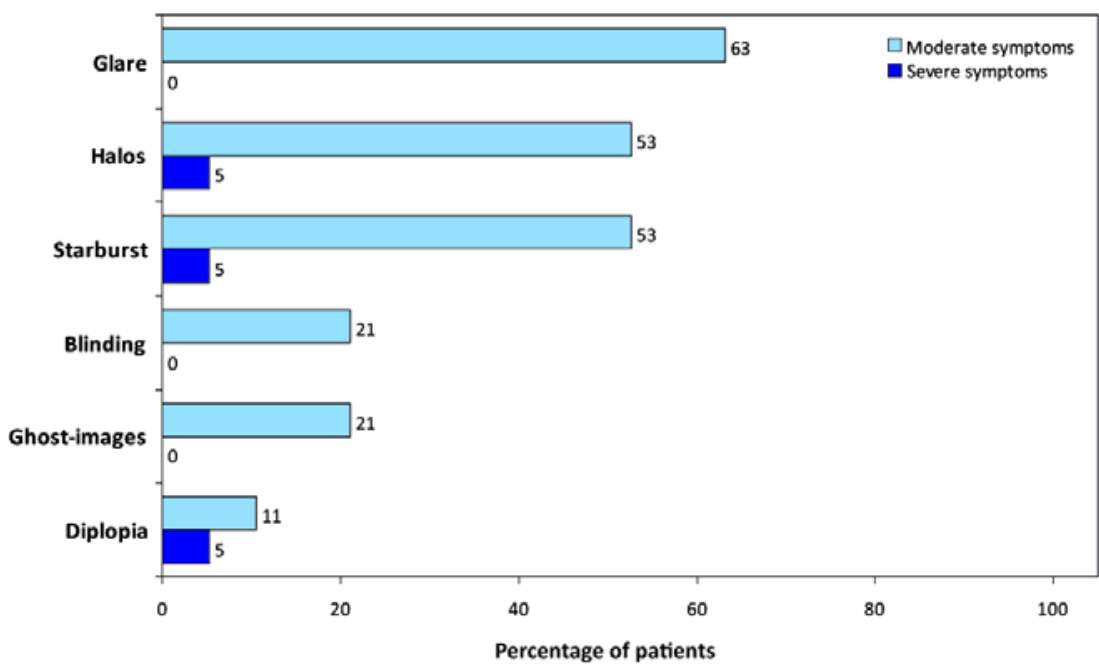

B.

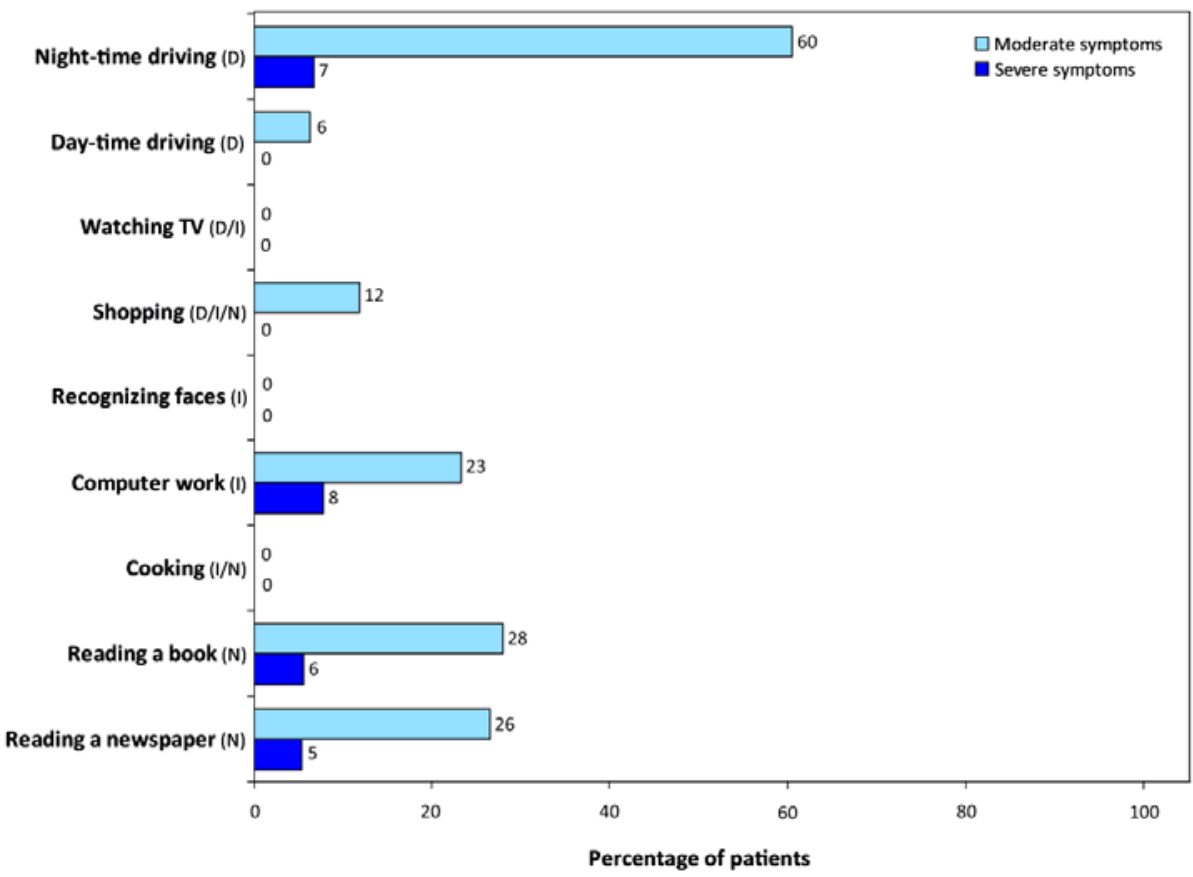

Figure 7.5 A: Prevalence of visual disturbance items in patients with bilateral toric multifocal IOLs. B: Prevalence of difficulties with the performance of specific distance (D), intermediate (I), or near (N) visual lifestyle activities (without spectacle use) in patients with bilateral toric multifocal IOLs. 
by Alio et al., the UDVA in our study was better (0.04 logMAR, equivalent to 20/22 Snellen). In addition, a correction index of $94 \%$ and index of success of $33 \%$ indicate that the AT Lisa toric IOL is effective in correcting astigmatism. Based on the slitlamp examination, the mean misalignment of AT Lisa IOLs was $2.3 \pm 2.0$ degrees. This is comparable to the mean angle of error obtained from Alpins vector analysis based on preoperative and postoperative refractive astigmatism ( $-3 \pm 17$ degrees). However, the large standard deviation of the angle of error indicates that several patients in our study had a misalignment of treatment of much more than 3 degrees. This may be due to errors in measurement of preoperative corneal astigmatism or errors in the intraoperative positioning of toric IOLs. A recent study examined the accuracy of toric IOL implantation and found a mean misalignment error of 5 degrees, which was much larger in individual cases. ${ }^{14}$ Intraoperative positioning of toric IOLs with greater accuracy is necessary to achieve the most optimum cylinder correction in all patients. This can be achieved using intraoperative wavefront aberrometry or eye-tracking technology. ${ }^{14,25}$

Regarding the defocus curve, we found a V-shaped curve with 2 peaks at $0.0 \mathrm{D}$ and -2.5 $\mathrm{D}$ and some loss of vision at the intermediate distances. The peaks correspond to the expected near and far foci. The range of focus for a functional vision of 0.3 logMAR (equivalent to $20 / 40$ Snellen) extends from +2.0 D to $-4.0 \mathrm{D}$ (6.0 D wide). Two previous studies of the aspheric non-toric AT Lisa IOL showed a range of focus from +1.0 D to $4.0 \mathrm{D}^{22,26}$ This indicates that the AT Lisa toric IOL has a wider range of focus than the non-toric version. When considering the binocular defocus curve of other multifocal IOLs, the range of focus for functional vision extends from +1.0 D to -3.5 $D$ for the aspheric Restor +3.0 D IOL and from +1.0 D to $-4.0 \mathrm{D}$ for the aspheric Restor +4.0 D IOL. $^{22,23,26}$

Multifocal IOLs split the available light between the distance focus and near focus. The contrast of the in-focus image on the retina is affected by the out-of-focus image. Patients with multifocal IOLs may therefore be more sensitive to changes in contrast and have been reported to have a lower contrast sensitivity than the normal population. ${ }^{27}$ We measured monocular and binocular contrast sensitivities under photopic conditions $\left(85 \mathrm{~cd} / \mathrm{m}^{2}\right)$ using the CSV-1000 system. In a normal population, contrast sensitivity levels measured with the same test chart were $1.56 \pm 0.15$ at $3 \mathrm{cpd}$, $1.80 \pm 0.17$ at $6 \mathrm{cpd}, 1.50 \pm 0.15$ at $12 \mathrm{cpd}$, and $0.93 \pm 0.25 \mathrm{cpd}$ at $18 \mathrm{cpd} .{ }^{15}$ This indicates that the contrast sensitivity after AT Lisa toric IOL implantation is comparable to that in the normal population at all spatial frequencies. We tested the contrast sensitivity at 1 distance $(2,5 \mathrm{~m})$ and under 1 illumination level $\left(85 \mathrm{~cd} / \mathrm{m}^{2}\right)$, because the CSV-1000 system is standardized for these testing conditions. Montés-Micó et al., 
found a lower contrast sensitivity at near and under dim illumination in patients with a multifocal IOL compared with results for a normal population and patients with a monofocal IOL. ${ }^{27}$ It is likely that the contrast sensitivity in our study would decrease at near distances because less than half (35\%) of the available light is used for near vision. We do not believe that contrast sensitivity would decrease at dim illumination because the AT Lisa IOL does not depend on pupil size. For all pupil diameters, $65 \%$ of light is directed to a distance focus and $35 \%$ to a near focus. Other studies evaluating the nontoric AT Lisa IOL found contrast sensitivities comparable to those in our study. ${ }^{18,20,21}$ However, a direct comparison of our results with those in these aforementioned studies is not possible because of different contrast sensitivity tests, different illumination levels, and different testing distances. ${ }^{28}$ Thus, we compared our results to values reported for Restor +3.0 D and Restor +4.0 D multifocal IOLs and measured under the same testing conditions and with the same test chart. ${ }^{16}$ The AT Lisa toric IOL showed a significantly better contrast sensitivity than the Restor multifocal IOL at most spatial frequencies.

Diffractive IOLs require steps between the diffractive ring zones of the IOL. These steps generally have sharp edges and produce unwanted visual phenomena, such as glare and halos. The diffractive AT Lisa toric IOL has a soft transition of phase zones between the main diffractive zones, which is thought to reduce disturbing light phenomena and improve image quality. In our study, approximately one half the patients reported moderate problems with glare, halos, starburst, and nighttime vision. Severe problems with disturbing light phenomena were rare and were reported by 2 patients only. In conclusion, AT Lisa toric IOL implantation in patients with cataract and corneal astigmatism resulted in good distance and near visual acuities, high contrast sensitivity, and high patient satisfaction. Intermediate visual performance was acceptable. This IOL allows patients with considerable amounts of corneal astigmatism to achieve spectacle independence for distance and near vision.

\section{References}

1. Hoffer KJ. Biometry of 7,500 cataractous eyes. Am J Ophthalmol. Sep 1980;90(3):360368.

2. Ferrer-Blasco T, Montes-Mico R, Peixoto-deMatos SC, Gonzalez-Meijome JM, Cervino A. Prevalence of corneal astigmatism before cataract surgery. J Cataract Refract Surg. Jan 2009;35(1):70-75.

3. Hoffmann PC, Hutz WW. Analysis of biometry and prevalence data for corneal astigmatism in 23,239 eyes. J Cataract Refract Surg. Sep 2010;36(9):1479-1485.

4. Hayashi K, Manabe S, Yoshida M, Hayashi $\mathrm{H}$. Effect of astigmatism on visual acuity in eyes with a diffractive multifocal intraocular lens. $J$ Cataract Refract Surg. Aug 2010;36(8):1323-1329.

5. Mendicute J, Irigoyen C, Ruiz M, Illarramendi I, Ferrer-Blasco T, Montes-Mico R. Toric intraocular lens versus opposite clear 
corneal incisions to correct astigmatism in eyes having cataract surgery. J Cataract Refract Surg. Mar 2009;35(3):451-458.

6. Muftuoglu O, Dao L, Cavanagh HD, McCulley JP, Bowman RW. Limbal relaxing incisions at the time of apodized diffractive multifocal intraocular lens implantation to reduce astigmatism with or without subsequent laser in situ keratomileusis. J Cataract Refract Surg. Mar 2010;36(3):456-464.

7. Leccisotti A. Secondary procedures after presbyopic lens exchange. J Cataract Refract Surg. Jul 2004;30(7):1461-1465.

8. Alfonso JF, Fernandez-Vega L, Montes-Mico $R$, Valcarcel B. Femtosecond laser for residual refractive error correction after refractive lens exchange with multifocal intraocular lens implantation. $A m$ J Ophthalmol. Aug 2008;146(2):244-250.

9. Muftuoglu $O$, Prasher $P$, Chu $C$, et al. Laser in situ keratomileusis for residual refractive errors after apodized diffractive multifocal intraocular lens implantation. J Cataract Refract Surg. Jun 2009;35(6):1063-1071.

10. Bayramlar HH, Daglioglu MC, Borazan M. Limbal relaxing incisions for primary mixed astigmatism and mixed astigmatism after cataract surgery. J Cataract Refract Surg. Apr 2003;29(4):723-728.

11. Thomas KE, Brunstetter $T$, Rogers $S$, Sheridan MV. Astigmatism: risk factor for postoperative corneal haze in conventional myopic photorefractive keratectomy. J Cataract Refract Surg. Dec 2008;34(12):2068-2072.

12. Schallhorn SC, Venter JA. One-month outcomes of wavefront-guided LASIK for low to moderate myopia with the VISX STAR S4 laser in 32,569 eyes. J Refract Surg. Jul 2009;25(7 Suppl):S634-641.

13. Alpins N. Astigmatism analysis by the Alpins method. J Cataract Refract Surg. Jan 2001;27(1):31-49.

14. Visser N, Berendschot TT, Bauer NJ, Jurich J, Kersting O, Nuijts RM. Accuracy of toric intraocular lens implantation in cataract and refractive surgery. J Cataract Refract Surg. Aug 2011;37(8):1394-1402.

15. Pomerance GN, Evans DW. Test-retest reliability of the CSV-1000 contrast test and its relationship to glaucoma therapy. Invest Ophthalmol Vis Sci. Aug 1994;35(9):33573361.

16. de Vries NE, Webers CA, Montes-Mico R, Ferrer-Blasco T, Nuijts RM. Visual outcomes after cataract surgery with implantation of a
+3.00 D or +4.00 D aspheric diffractive multifocal intraocular lens: Comparative study. J Cataract Refract Surg. Aug 2010;36(8):1316-1322.

17. Liekfeld A, Torun N, Friederici L. [A new toric diffractive multifocal lens for refractive surgery]. Ophthalmologe. Mar 2009;107(3):256, 258-261.

18. Alfonso JF, Fernandez-Vega L, Senaris A, Montes-Mico R. Prospective study of the Acri.LISA bifocal intraocular lens. J Cataract Refract Surg. Nov 2007;33(11):1930-1935.

19. Alio JL, Elkady B, Ortiz D, Bernabeu G. Clinical outcomes and intraocular optical quality of a diffractive multifocal intraocular lens with asymmetrical light distribution. J Cataract Refract Surg. Jun 2008;34(6):942948.

20. Fernandez-Vega L, Alfonso JF, Baamonde B, Madrid-Costa D, Montes-Mico R, Lozano J. Visual and refractive outcomes in hyperopic pseudophakic patients implanted with the Acri.LISA 366D multifocal intraocular lens. Am J Ophthalmol. Aug 2009;148(2):214-220 e211.

21. Fernandez-Vega L, Madrid-Costa D, Alfonso JF, Poo-Lopez A, Montes-Mico R. Bilateral implantation of the Acri.LISA bifocal intraocular lens in myopic eyes. Eur J Ophthalmol. Jan-Feb 2010;20(1):83-89.

22. Alfonso JF, Fernandez-Vega L, Puchades C, Montes-Mico R. Intermediate visual function with different multifocal intraocular lens models. J Cataract Refract Surg. May 2010;36(5):733-739.

23. Kohnen T, Nuijts R, Levy $P$, Haefliger $E$, Alfonso JF. Visual function after bilateral implantation of apodized diffractive aspheric multifocal intraocular lenses with a +3.0 D addition. J Cataract Refract Surg. Dec 2009;35(12):2062-2069.

24. Alio JL, Agdeppa MC, Pongo VC, El Kady B. Microincision cataract surgery with toric intraocular lens implantation for correcting moderate and high astigmatism: pilot study. J Cataract Refract Surg. Jan 2010;36(1):4452.

25. Packer M. Effect of intraoperative aberrometry on the rate of postoperative enhancement: retrospective study. J Cataract Refract Surg. May 2010;36(5):747755.

26. Alfonso JF, Puchades C, Fernandez-Vega L, Montes-Mico R, Valcarcel B, Ferrer-Blasco T. Visual acuity comparison of 2 models of bifocal aspheric intraocular lenses. J 
Cataract Refract Surg. Apr 2009;35(4):672676.

27. Montes-Mico R, Espana E, Bueno I, Charman WN, Menezo JL. Visual performance with multifocal intraocular lenses: mesopic contrast sensitivity under distance and near conditions. Ophthalmology. Jan 2004;111(1):85-96.

28. Franco S, Silva AC, Carvalho AS, Macedo AS, Lira M. Comparison of the VCTS-6500 and the CSV-1000 tests for visual contrast sensitivity testing. Neurotoxicology. Dec 2010;31(6):758-761. 


\section{Chapter 8}

\section{Vector analysis of corneal and refractive astigmatism changes following toric pseudophakic and toric phakic IOL implantation}

Nienke Visser, Tos T.J.M. Berendschot,

Noël J.C. Bauer and Rudy M.M.A. Nuijts Investigative Ophthalmology \& Visual Science 2012; 53:1865-1873 


\section{Abstract}

PURPOSE: To determine the efficacy of astigmatism correction with toric intraocular lens (IOL) and toric phakic IOL (plOL) implantation in eyes with no previous ocular surgery and in post-keratoplasty (PKP) eyes. In addition, changes in corneal astigmatism were determined.

Setring: University Eye Clinic, Maastricht University Medical Center, the Netherlands.

METHODS: Astigmatism was analyzed in 35 eyes with an Acrysof toric IOL, 35 eyes with an Artiflex toric plOL, 50 eyes with an Artisan toric plOL and 40 PKP eyes with an Artisan toric pIOL. Refractive astigmatism was analyzed using Alpins method. Surgically induced corneal astigmatism (SICA) was determined following a superior $2.2 \mathrm{~mm}, 3.4$ $\mathrm{mm}$ or $5.4 \mathrm{~mm}$ incision. Follow-up was 12 months.

RESULTS: Following toric IOL implantation, the index of success was 0.14 and overall residual astigmatism $0.37 \mathrm{D}$. Following toric plOL implantation, the index of success was 0.32 (Artiflex) and 0.18 (Artisan), and overall residual astigmatism was approximately $0.60 \mathrm{D}$. In PKP eyes, Artisan pIOLs resulted in an index of success of 0.28 and overall residual astigmatism of $1.56 \mathrm{D}$. The SICA following a $2.2 \mathrm{~mm}, 3.4 \mathrm{~mm}, 5.4$ $\mathrm{mm}$ (normal eyes) and $5.4 \mathrm{~mm}$ (PKP eyes) incisions was $-0.25 \pm 0.42 \mathrm{D}(\mathrm{p}=0.108),-0.31$ $\pm 0.43 \mathrm{D}(p<0.001),-0.48 \pm 0.55 \mathrm{D}(p<0.001)$ and $-0.49 \pm 1.48 \mathrm{D}(p=0.035)$, respectively. CONCLUSION: Toric IOLs and toric pIOLs provide an effective astigmatism correction. Incorporating the SICA into the toric pIOL power calculation may further increase their effectiveness. Incorporation of O D, $-0.30 \mathrm{D}$ or $-0.50 \mathrm{D}$ of SICA for a $2.2 \mathrm{~mm}, 3.4 \mathrm{~mm}$ or $5.4 \mathrm{~mm}$ superior incision, respectively, is recommended. 


\section{Introduction}

Toric pseudophakic intraocular lenses (IOLs) and toric phakic IOLs (pIOLs) may be used in cataract and refractive surgery to achieve spectacle independency for distance vision. Toric pseudophakic IOLs correct corneal astigmatism and have been shown to result in good visual and refractive outcomes. ${ }^{1-4}$ Two types of toric plOLs are currently available: the anterior chamber (iris-fixated) toric pIOLs and the posterior chamber toric pIOLs. Both types of lenses have been shown to be effective in correcting moderate to high amounts of refractive astigmatism. ${ }^{5-7}$ However, a vector analysis to determine the efficacy of the astigmatism correction with these toric IOLs or toric pIOLs is not commonly performed.

Toric pIOL implantation may also be performed in patients with high levels of astigmatism due to a penetrating keratoplasty (PKP). ${ }^{8-10}$ Approximately $30 \%$ of PKP patients have more than 5 diopters (D) of astigmatism. ${ }^{11}$ High degrees of astigmatism may not be suitable for spectacle correction due to anisometropia. ${ }^{12}$ Furthermore, due to contact lens intolerance in PKP patients, many patients require a surgical correction of astigmatism. An advantage of toric pIOL implantation in these patients is the ability to exchange and remove the pIOL in case of a future re-keratoplasty.

An important aspect to consider in both toric IOL and toric pIOL implantation is the change in corneal astigmatism induced by the incision. Most commonly used toric IOLs require a $2.2 \mathrm{~mm}$ incision, whereas foldable or rigid toric plOLs require a $3.4 \mathrm{~mm}$ or 5.4 $\mathrm{mm}$ incision, respectively. In PKP eyes the biomechanical wound healing response and the change in corneal astigmatism may differ from normal eyes.

The purpose of this study was to evaluate the vector changes in both refractive and corneal astigmatism following toric IOL and toric pIOL implantation and to determine the efficacy of the astigmatism correction. In addition, vector changes in refractive and corneal astigmatism in PKP eyes were compared to those in eyes with no previous ocular surgery.

\section{Methods}

\section{Study design and patient population}

This retrospective case series included patients who underwent toric IOL or toric pIOL implantation between January 2001 and October 2010. All surgeries were performed by two experienced surgeons (NB and RN) at the Maastricht University Medical Center, the Netherlands. The tenets of the Declaration of Helsinki were followed. 
Inclusion criteria for pseudophakic toric IOL implantation were regular corneal astigmatism of $1.25 \mathrm{D}$ or more and cataract. Exclusion criteria were tear-film abnormalities, Fuchs' endothelial dystrophy (more than 2+ guttata) or extensive visual loss due to macular disease or glaucoma. Inclusion criteria for toric pIOL implantation in normal eyes were a subjective refractive astigmatism of $1.5 \mathrm{D}$ or more, a stable refraction during the previous 2 years and unsatisfactory correction with spectacles or contact lenses. Exclusion criteria were an anterior chamber depth (ACD) of less than $3.2 \mathrm{~mm}$ (measured from the epithelium to the crystalline lens), endothelial cell density of less than 2000 cells $/ \mathrm{mm}^{2}$, abnormal iris or pupil, glaucoma, or uveitis. Inclusion criteria for toric pIOL implantation in PKP eyes were spectacle intolerance due to anisometropia and contact lens intolerance. Exclusion criteria were an ACD less than $3.2 \mathrm{~mm}$, endothelial cell density less than 500 cells $/ \mathrm{mm}^{2}$, glaucoma, or uveitis.

Preoperatively, all patients underwent a complete ophthalmic evaluation including subjective refraction, Snellen best-corrected distance visual acuity (CDVA), slit lamp examination, fundoscopy, applanation tonometry, optical biometry (IOLMaster, Carl Zeiss Meditec) and manual keratometry (Javal-Schiötz, Rodenstock). All patients underwent corneal topography with the Atlas (Carl Zeiss Meditec) or Eye Map (Alcon Laboratories) Placido-disk videokeratoscope. In case of pIOL implantation, patients additionally underwent noncontact specular microscopy (Noncon Robo SP-9000, Konan Medical Incorporation) and anterior segment optical coherence tomography (Visante, Carl Zeiss Meditec).

\section{Intraocular lens types}

The Acrysof toric IOL (Alcon Laboratories) is a foldable IOL made of hydrophobic acrylic material and has a $6.0 \mathrm{~mm}$ optic diameter. It is available in cylinder powers of $1.5 \mathrm{D}$ to 6.0 D (SN60T3 to SN60T9). The IOL cylinder power and alignment axis were calculated based on keratometry values ( $\mathrm{K}$ values) obtained by optical biometry and using an online calculator (available at: www.acrysoftoriccalculator.com). An expected amount of surgically induced corneal astigmatism (SICA) of 0.5 D (superior incision) was incorporated in the IOL calculation.

The iris-fixated Artiflex toric pIOL (Ophtec) is a 3-piece foldable IOL consisting of a silicone $6.0 \mathrm{~mm}$ optic and 2 rigid polymethylmethacrylate (PMMA) haptics. It is available in cylinder powers of $1.0 \mathrm{D}$ to $5.0 \mathrm{D}$. The iris-fixated Artisan toric pIOL (Ophtec) is made from non-foldable PMMA and has a $5.0 \mathrm{~mm}$ optic. Available cylinder powers range from 1.0 D to 7.5 D. For both plOLs, the lens power was calculated using the van der Heijde formula based on the mean $K$ value, $A C D$, refractive spherical equivalent and refractive cylinder power (corrected for a $12.0 \mathrm{~mm}$ vertex distance). 
The axis of surgical enclavation was derived from the subjective refraction. All power calculations were performed by Ophtec.

\section{Surgical techniques}

The marking steps required for both toric $\mathrm{OOL}$ and toric pIOL implantation were identical. Preoperatively, after administration of a topical anesthetic, the patient was positioned upright to correct for cyclotorsion and asked to fixate at an object at distance. Limbal reference marks were placed at 0, 180 and 270 degrees (3, 6 and 9 o'clock positions) with a Nuijts/Lane Toric Reference Marker with bubble-level (American Surgical Instruments Corp.). Intraoperatively, the limbal reference marks were used to mark the alignment axis. This was done with a Mendez degree gauge (American Surgical Instruments Corp.) and a Nuijts Toric Axis Marker (American Surgical Instruments Corp.).

In the case of cataract surgery with toric IOL implantation, a standard phacoemulsification was performed through a $2.2 \mathrm{~mm}$ superior limbal incision. In the case of refractive surgery with toric plOL implantation, a $3.4 \mathrm{~mm}$ (Artiflex) or a $5.4 \mathrm{~mm}$ (Artisan) superior corneoscleral incision was used. Following Artiflex plOL implantation, the wound was closed using two interrupted 10-0 nylon sutures. Following Artisan pIOL implantation, 5 interrupted $10-0$ nylon sutures were used to close the incision. Suture removal was performed between 1 and 3 months postoperatively.

\section{Postoperative examinations}

At 6 and 12 months postoperatively, all patients underwent subjective refraction, measurement of Snellen uncorrected distance visual acuity (UDVA) and CDVA and corneal topography. In each patient, preoperative and postoperative corneal topography was always performed with the same device (Atlas or Eye Map).

\section{Data analysis}

The accuracy of astigmatism correction was calculated by using a vector analysis according to Alpins. ${ }^{13}$ In patients implanted with a toric IOL, postoperative refractive astigmatism was compared to preoperative keratometric astigmatism (IOLMaster). In patients implanted with a toric pIOL, postoperative refractive astigmatism was compared to preoperative refractive astigmatism. Target astigmatism was zero, since emmetropia was the goal in all patients. Refractive astigmatism data were calculated to the corneal plane as follows. Subjective refraction at the spectacle plane was converted into the two principal lens powers. Both lens powers were than vertexed to the corneal plane by using equation (1) and a back vertex distance of $12 \mathrm{~mm}$. The 
difference between both lens powers at the corneal plane represents the amount of astigmatism at the corneal plane.

(1) $F_{\mathrm{c}}=\frac{1000 * \mathrm{~F}_{\mathrm{s}}}{1000-\left(\mathrm{F}_{\mathrm{s}} * \mathrm{~d}\right)}$

$\mathrm{F}_{\mathrm{C}}=$ Lens power (D) at corneal plane, $\mathrm{F}_{\mathrm{s}}=$ Lens power (D) at spectacle plane, and $\mathrm{d}=$ vertex distance $(\mathrm{mm})$.

Astigmatism magnitude (D) and axis (degrees) values were transformed into rectangular $\mathrm{x}$ and $\mathrm{y}$ coordinates and used to calculate the following vectors. ${ }^{13}$ The target induced astigmatism (TIA) vector represents the change (by magnitude and axis) the surgery was intended to induce. The surgically induced astigmatism (SIA) vector is the astigmatic change the surgery actually induced. The difference vector (DV) represents the vector that enables the achieved astigmatic outcome to achieve target astigmatism. This is an absolute measure of success and is preferably zero. The magnitude of error (ME) is the arithmetic difference between the magnitudes of the SIA and TIA. The ME is positive for overcorrection and negative for undercorrection. The angle of error ( $A E)$ is the angle between the SIA and TIA vectors. The AE is positive if the achieved correction is counterclockwise to the intended axis and negative if the achieved correction is clockwise to the intended axis. The flattening effect (FE) is the magnitude of astigmatism reduction achieved at the intended meridian of treatment (TIA meridian). The flattening index is calculated by dividing the FE by the magnitude of TIA and is preferably 1.0. The correction index was calculated as the ratio of the magnitude of SIA to the magnitude of TIA. The correction index is preferably 1.0. It is greater than 1.0 if overcorrection occurred and less than 1.0 if undercorrection occurred. The index of success was calculated by dividing the magnitude of DV by the magnitude of TIA. This is a relative measure of success and is preferably zero. The overall mean magnitude of residual astigmatism and the residual astigmatism at the meridian of treatment were calculated. ${ }^{14}$

The SICA was defined as the vector change between preoperative and postoperative corneal astigmatism. To calculate the SICA, corneal astigmatism data, obtained by corneal topography, were transformed into Cartesian coordinates ( $x$ and $y$ ) according to the method described by Holladay et al. ${ }^{15}$ The SICA was calculated using a standard vector analysis and is shown in double-angle minus-cylinder power plots. The standard deviations (SD) of the $x$ and $y$ coordinates are displayed as an ellipse surrounding the centroid (the mean SICA) in the double-angle plots. ${ }^{15}$ After the calculations were finished, the Cartesian coordinates were transformed back to the standard notation for astigmatism (cylinder and meridian). 


\section{Statistics}

All data were collected in an Excel database (Office 2007, Microsoft Inc.) and analyzed using SPSS for Windows (Version 16.0, SPSS Inc.). Snellen UDVA and CDVA were converted into LogMAR for mathematical and statistical calculations. Postoperative changes in astigmatism vectors within each group were analyzed using a repeated measures analysis of variance (ANOVA). A Hotelling Trace multivariate analysis of variance (MANOVA) was used to determine if vectors were significantly different from zero. Paired samples t-tests were used to analyze visual acuity and astigmatism parameters within a group. A p-value of less than 0.05 was considered statistically significant.

\section{Results}

Refractive and corneal astigmatism were analyzed in 35 normal eyes with an Acrysof toric IOL, 35 normal eyes with an Artiflex toric pIOL, 50 normal eyes with an Artisan toric pIOL and 40 PKP eyes with an Artisan toric pIOL. Patient characteristics are shown in Table 8.1.

\section{Visual outcomes}

The preoperative and postoperative UDVA and CDVA are shown in Table 8.2. In all subgroups, the postoperative CDVA was significantly better than the UDVA at 6 months $(p<0.001)$ and 12 months $(p=0.001)$ follow up. In none of the subgroups, the UDVA or CDVA changed significantly from 6 to 12 months.

Vector analysis of refractive astigmatism

Table 8.3 shows the results of Alpins vector analysis based on postoperative refractive astigmatism. Figure 8.1 demonstrates the variability in postoperative refractive astigmatism within each group.

Table 8.1 Preoperative patient characteristics

\begin{tabular}{|c|c|c|c|c|}
\hline Population & $\begin{array}{l}\text { Acrysof IOL } \\
\text { Normal eyes }\end{array}$ & $\begin{array}{l}\text { Artiflex pIOL } \\
\text { Normal eyes }\end{array}$ & $\begin{array}{l}\text { Artisan plOL } \\
\text { Normal eyes }\end{array}$ & $\begin{array}{l}\text { Artisan plOL } \\
\text { PKP eyes }\end{array}$ \\
\hline Eyes (N) & 35 & 35 & 50 & 40 \\
\hline Patients (N) & 20 & 20 & 33 & 39 \\
\hline Age (mean years $\pm S D$ ) & $65 \pm 12$ & $45 \pm 9$ & $40 \pm 10$ & $59 \pm 19$ \\
\hline Female (\%) & 74 & 74 & 52 & 56 \\
\hline
\end{tabular}


Table 8.2 Preoperative and postoperative LogMAR visual acuity

\begin{tabular}{|c|c|c|c|c|c|}
\hline & & $\begin{array}{l}\text { Acrysof IOL } \\
\text { Normal eyes }\end{array}$ & $\begin{array}{l}\text { Artiflex pIOL } \\
\text { Normal eyes }\end{array}$ & $\begin{array}{l}\text { Artisan pIOL } \\
\text { Normal eyes }\end{array}$ & $\begin{array}{l}\text { Artisan plOL } \\
\text { PKP eyes }\end{array}$ \\
\hline Preoperatively & CDVA & $0.41 \pm 0.31$ & $0.04 \pm 0.12$ & $0.12 \pm 0.15$ & $0.23 \pm 0.17$ \\
\hline \multirow[t]{2}{*}{6 Months } & UDVA & $0.10 \pm 0.10^{*}$ & $0.03 \pm 0.11^{*}$ & $0.15 \pm 0.18^{*}$ & $0.45 \pm 0.24 *$ \\
\hline & CDVA & $0.01 \pm 0.11$ & $-0.03 \pm 0.12$ & $0.04 \pm 0.11$ & $0.16 \pm 0.14$ \\
\hline \multirow[t]{2}{*}{12 Months } & UDVA & $0.12 \pm 0.11^{*}$ & $0.05 \pm 0.16^{*}$ & $0.13 \pm 0.13^{*}$ & $0.46 \pm 0.24 *$ \\
\hline & CDVA & $0.03 \pm 0.11$ & $-0.04 \pm 0.10$ & $0.04 \pm 0.10$ & $0.17 \pm 0.14$ \\
\hline
\end{tabular}

$*$ = significantly different from CDVA at the same time point (paired samples t-test; $\mathrm{P}<0.05$ ).

In the Acrysof toric IOL group, SIA was significantly different from TIA $(p<0.001)$. The DV was significantly different from zero at 6 months (0.21 D @ 27 degrees; $p=0.008$ ) and 12 months (0.18 D @ 10 degrees; $p=0.043$ ). Achieved astigmatism, ME, AE, flattening index, correction index, index of success and residual astigmatism did not change from 6 to 12 months postoperatively.

In the Artiflex toric pIOL group, the SIA was not significantly different from the TIA, and the DV at 6 and 12 months was not different from zero. The ME $(p=0.026)$, flattening index $(p=0.013)$ and correction index $(p=0.029)$ changed significantly from 6 to 12 months follow-up, whereas achieved astigmatism, $A E$, index of success and residual astigmatism did not change from 6 to 12 months follow up.

In the Artisan pIOL group (normal eyes), the SIA at 6 and 12 months postoperatively was not significantly different from the TIA. The DV at both 6 and 12 months was not significantly different from zero. Achieved astigmatism $(p=0.020), \operatorname{ME}(p=0.013)$, flattening index $(p=0.020)$ and correction index $(p=0.006)$ showed a significant change from 6 to 12 months follow up. The $A E$, index of success and residual astigmatism did not change significantly from 6 to 12 months follow up.

In the Artisan pIOL group (PKP eyes), the SIA was not significantly different from the TIA and the DV was not different from zero at 6 and 12 months. Achieved astigmatism, $M E, A E$, flattening index, correction index, index of success and residual astigmatism did not change from 6 to 12 months follow up. At 6 and 12 months postoperatively, all eyes had less than $3.0 \mathrm{D}$ of refractive astigmatism.

Vector analysis of corneal astigmatism

Postoperative changes in corneal astigmatism are shown in Table 8.4. Following a 2.2 $\mathrm{mm}$ superior incision, postoperative corneal astigmatism was not significantly different from the preoperative value. In addition, the amount of SICA at 6 and 12 months postoperatively was not significantly different from zero. Following a $3.4 \mathrm{~mm}$ and 5.4 $\mathrm{mm}$ superior incision in normal eyes, postoperative corneal astigmatism was significantly lower than the preoperative value. The amount of SICA was significantly 
different from zero in both the $3.4 \mathrm{~mm}$ incision group (12 months: -0.33 D @ 97 degrees, $\mathrm{p}<0.001$ ) and the $5.4 \mathrm{~mm}$ incision group (12 months: -0.60 D @ 90 degrees, $\mathrm{p}<0.001$ ). Following a $5.4 \mathrm{~mm}$ incision in PKP eyes, postoperative corneal astigmatism was not significantly different from preoperative astigmatism. The SICA was-0.91 D @ 76 degrees ( $p=0.018$ compared to zero) at 12 months. The SICA did not change significantly from 6 to 12 months postoperatively in any of the subgroups. Figure 8.2 shows the mean amount of SICA with an ellipse of 1 SD for each incision group.

\section{Complications}

In the Acrysof toric IOL group, one patient developed postoperative cystoid macular edema, which was treated with ketorolac (Acular, Allergan). In 4 eyes in the Artiflex toric pIOL group, postoperative depositions were seen on the anterior and/or posterior surface of the pIOL. Two eyes had a postoperative elevated intraocular pressure (IOP) which was treated with timolol (Timoptol XE, Merck Sharp \& Dohme). In the Artisan toric IOL group (normal eyes), one patient had a postoperative elevated IOP which was treated with timolol. In the Artisan toric IOL group (PKP eyes), a plOL claw repositioning was performed at 6 weeks postoperatively. One patient developed a high IOP, which was treated with timolol.

\section{Discussion}

The aim of this study was to determine the changes in refractive and corneal astigmatism following toric $\mathrm{IOL}$ and toric pIOL implantation. With a vector analysis based on refractive astigmatism the effectiveness of the astigmatism correction was determined. In addition, the amount of SICA following a $2.2 \mathrm{~mm}, 3.4 \mathrm{~mm}$ and $5.4 \mathrm{~mm}$ incision was determined at 6 and 12 months postoperatively. Even though the visual outcomes following toric IOL and toric pIOL implantation were good, the postoperative CDVA was significantly better than the UDVA in all subgroups. We believe more knowledge about the amount of SICA can further increase the effectiveness of toric IOLs.

To determine the effectiveness of the astigmatic correction with different toric IOLS and toric plOLs, a vector analysis according to Alpins was performed. Alpins astigmatism analysis is based on 3 fundamental vectors: the TIA, SIA and DV. ${ }^{13}$ These three vectors are then used to calculate different astigmatic parameters and indices that may be used to determine overall success of the astigmatism correction (index of success, flattening index), possible over- or undercorrection (ME, correction index), 
Table 8.3 Alpins vector analysis of the refractive astigmatism outcomes following toric IOL or toric phakic IOL implantation

\begin{tabular}{|c|c|c|c|c|}
\hline Alpins vector & $\begin{array}{c}\text { Acrysof IOL } \\
\text { Normal eyes }\end{array}$ & $\begin{array}{l}\text { Artiflex plOL } \\
\text { Normal eyes }\end{array}$ & $\begin{array}{l}\text { Artisan plOL } \\
\text { Normal eyes }\end{array}$ & $\begin{array}{c}\text { Artisan plOL } \\
\text { PKP eyes }\end{array}$ \\
\hline \multicolumn{5}{|l|}{ Preoperatively } \\
\hline \multicolumn{5}{|l|}{ Preoperative astigmatism } \\
\hline Arithmetic mean (D) & 2.82 & 1.98 & 3.48 & 6.11 \\
\hline Vector mean (D @ ) & $1.35 @ 97$ & $1.52 @ 180$ & $2.33 @ 1$ & $2.27 @ 154$ \\
\hline TIA vector mean (D @ ${ }^{\circ}$ ) & $1.35 @ 7$ & $1.52 @ 90$ & $2.33 @ 91$ & $2.27 @ 64$ \\
\hline \multicolumn{5}{|l|}{6 Months } \\
\hline Achieved vector mean $\left(D @{ }^{\circ}\right)$ & $0.21 @ 117$ & $0.04 @ 114$ & $0.01 @ 130$ & $0.04 @ 166$ \\
\hline SIA vector mean (D @ ) & $1.51 @ 9^{*}$ & $1.55 @ 90$ & $2.33 @ 91$ & $2.23 @ 64$ \\
\hline DV mean (D @ ${ }^{\circ}$ ) & $0.21 @ 27+$ & $0.04 @ 24$ & $0.01 @ 40$ & $0.04 @ 76$ \\
\hline Magnitude of error $(D \pm S D)$ & $0.04 \pm 0.40$ & $0.09 \pm 0.49$ & $-0.06 \pm 0.56$ & $-0.38 \pm 1.50$ \\
\hline Angle of error $\left({ }^{\circ} \pm S D\right)$ & $2 \pm 11$ & $0 \pm 14$ & $-2 \pm 16$ & $7 \pm 22$ \\
\hline Absolute angle of error $\left({ }^{\circ} \pm S D\right)$ & $6 \pm 9$ & $11 \pm 9$ & $12 \pm 11$ & $15 \pm 17$ \\
\hline Flattening effect $(D \pm S D)$ & $2.61 \pm 1.43$ & $1.83 \pm 0.92$ & $2.90 \pm 1.50$ & $4.34 \pm 2.66$ \\
\hline Flattening index & 0.93 & 0.91 & 0.83 & 0.77 \\
\hline Correction index & 0.99 & 1.03 & 0.96 & 0.99 \\
\hline Index of success & 0.15 & 0.31 & 0.21 & 0.30 \\
\hline \multicolumn{5}{|l|}{ Residual astigmatism } \\
\hline Overall mean $(D \pm S D)$ & $0.39 \pm 0.36$ & $0.54 \pm 0.45$ & $0.64 \pm 0.56$ & $1.65 \pm 1.37$ \\
\hline At meridian of TIA $(D \pm S D)$ & $0.37 \pm 0.59$ & $0.41 \pm 0.39$ & $0.61 \pm 0.55$ & $1.37 \pm 1.33$ \\
\hline \multicolumn{5}{|l|}{12 Months } \\
\hline Achieved vector mean $\left(D @{ }^{\circ}\right)$ & $0.18 @ 100$ & $0.06 @ 108$ & $0.20 @ 95 \neq$ & $0.01 @ 60$ \\
\hline SIA vector mean (D @ ) & $1.53 @ 7^{*}$ & $1.57 @ 90$ & $2.52 @ 91$ & $2.28 @ 64$ \\
\hline DV vector mean (D @ ${ }^{\circ}$ ) & $0.18 @ 10+$ & $0.06 @ 18$ & $0.20 @ 5$ & $0.01 @ 150$ \\
\hline Magnitude of error $(D \pm S D)$ & $0.07 \pm 0.40$ & $0.21 \pm 0.49 \ddagger$ & $0.14 \pm 0.54 \ddagger$ & $-0.32 \pm 1.51$ \\
\hline Angle of error $\left({ }^{\circ} \pm S D\right)$ & $2 \pm 11$ & $1 \pm 13$ & $-2 \pm 16$ & $4 \pm 21$ \\
\hline Absolute angle of error $\left({ }^{\circ} \pm S D\right)$ & $5 \pm 9$ & $10 \pm 9$ & $12 \pm 11$ & $15 \pm 16$ \\
\hline Flattening effect $(D \pm S D)$ & $2.64 \pm 1.42$ & $1.97 \pm 0.91$ & $3.06 \pm 1.52$ & $4.40 \pm 2.74$ \\
\hline Flattening index & 0.94 & $1.00 \ddagger$ & $0.89 \ddagger$ & 0.78 \\
\hline Correction index & 1.00 & $1.11 \ddagger$ & $1.04 \ddagger$ & 0.99 \\
\hline Index of success & 0.14 & 0.32 & 0.18 & 0.28 \\
\hline \multicolumn{5}{|l|}{ Residual astigmatism } \\
\hline Overall mean $(D \pm S D)$ & $0.37 \pm 0.36$ & $0.58 \pm 0.54$ & $0.59 \pm 0.60$ & $1.56 \pm 1.41$ \\
\hline At meridian of TIA $(D \pm S D)$ & $0.27 \pm 0.31$ & $0.44 \pm 0.38$ & $0.53 \pm 0.63$ & $1.40 \pm 1.40$ \\
\hline
\end{tabular}

" $=$ significantly different from TIA (repeated measures ANOVA; $\mathrm{P}<0.05$ )

$\dagger=$ significantly different from zero (Hotelling Trace MANOVA; $P<0.05$ )

$\ddagger$ = significantly different from 6 months (repeated measures ANOVA or paired t-test; $P<0.05$ ) 


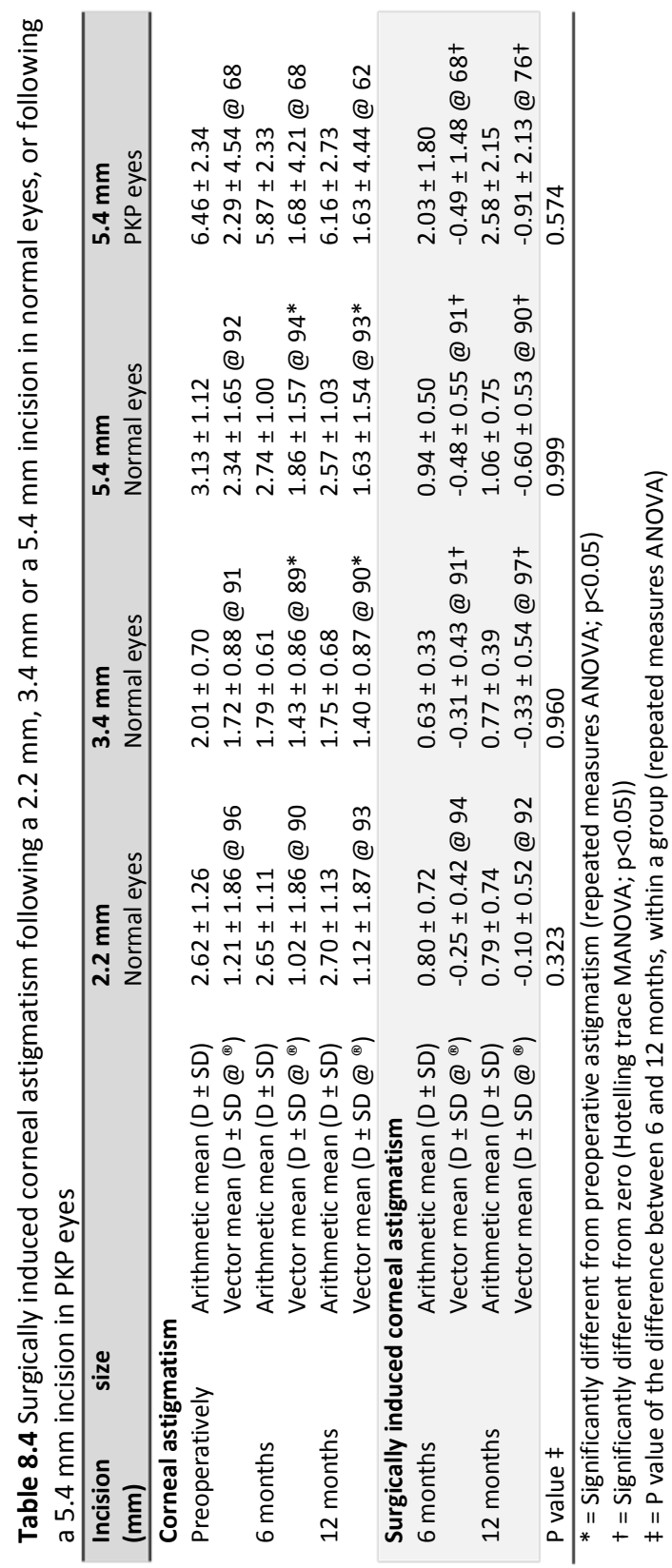



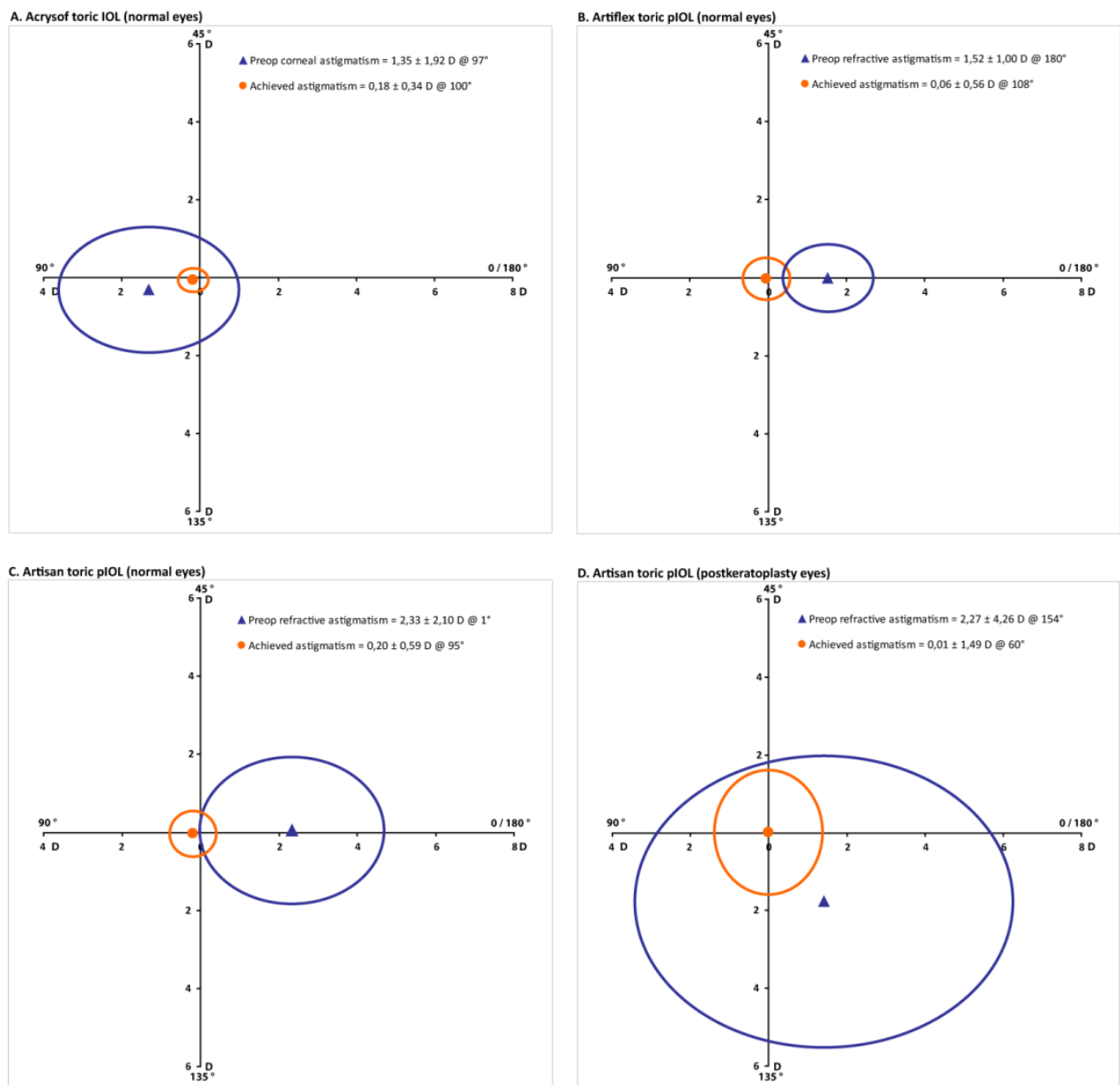

Figure 8.1 Double angle-vector diagrams of the preoperative and achieved refractive astigmatism outcomes at 12 months following Acrysof toric IOL (A), Artiflex toric pIOL (B) or Artisan toric plOL implantation in normal eyes (C) or Artisan toric plOL implantation in postkeratoplasty eyes (D).

Data is shown as an ellipse of 1 standard deviation with a center equal to the mean. 

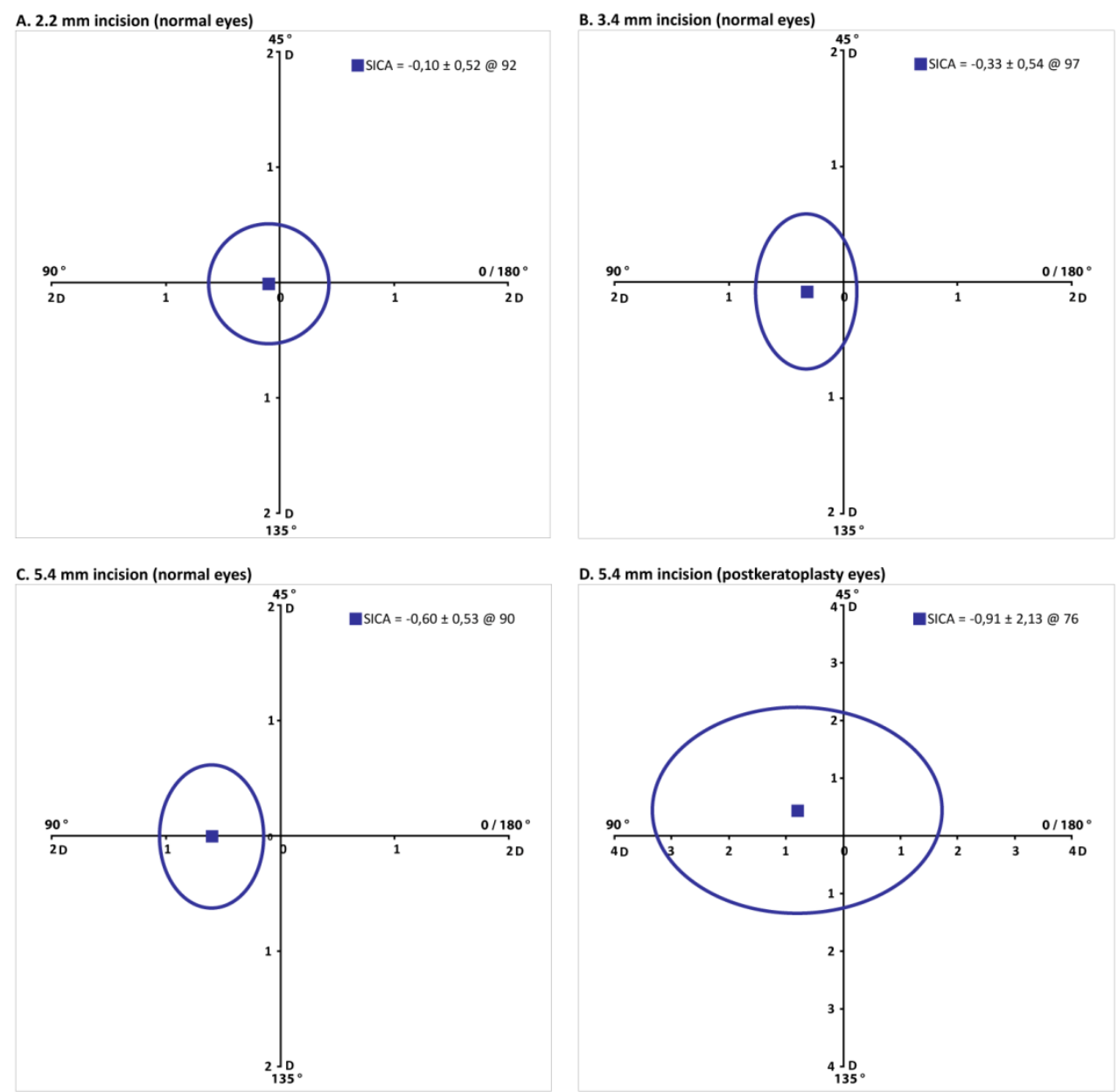

Figure 8.2 Double-angle vector diagrams of the SICA at 12 months following a $2.2 \mathrm{~mm}(\mathrm{~A}), 3.4$ $\mathrm{mm}(B), 5.4 \mathrm{~mm}$ incision in normal eyes (C) or a $5.4 \mathrm{~mm}$ incision in post-keratoplasty eyes (D). Data presented as mean with an ellipse of 1 SD. 
misalignment of treatment $(A E$, absolute $A E)$, and residual astigmatism ( $F E$, residual astigmatism). Following Acrysof toric IOL implantation, the ME was close to zero and the correction index was 1.00, indicating that on average no over- or undercorrection of astigmatism had occurred. Previous studies that have performed a vector analysis following toric IOL implantation report either a slight overcorrection ${ }^{16,17}$ or an undercorrection $^{1,18}$ of astigmatism. In addition, a recent study by Goggin et al. shows that the manufacturer underestimated the IOL cylinder power at the corneal plane, which may result in an overcorrection of astigmatism. ${ }^{19}$ In our study the absolute $A E$ was $5 \pm 9$ degrees, which is in accordance with the mean misalignment reported in previous studies. ${ }^{2,17,18,20}$ At 12 months postoperatively, the overall mean magnitude of residual astigmatism was $0.37 \pm 0.36 \mathrm{D}$, and $0.27 \pm 0.31 \mathrm{D}$ of astigmatism remained at the meridian of TIA. As discussed in our previous study, two views currently exist in the literature regarding the calculation of residual astigmatism: the overall magnitude of residual astigmatism and the magnitude of residual astigmatism at the meridian of treatment. ${ }^{14}$ Our results indicate that both methods result in similar amounts of residual astigmatism, although the amount of residual astigmatism at the meridian of treatment was always slightly lower than the overall mean. None of the measured astigmatism parameters nor the UDVA or CDVA changed significantly from 612 months follow up, indicating that visual and refractive outcomes were stable at 6 months following Acrysof toric IOL implantation.

In the Artiflex and Artisan pIOL groups, the ME and correction index showed an overcorrection of astigmatism The mean absolute AE was $10 \pm 9$ degrees and $12 \pm 11$ degrees in the Artiflex and Artisan pIOL groups, respectively. This indicates a slightly higher misalignment of treatment in toric pIOLs compared to toric pseudophakic IOLs. Residual astigmatism with both pIOLs was comparable: 0.58 to $0.59 \mathrm{D}$ overall and 0.44 to $0.53 \mathrm{D}$ at the meridian of treatment. In both pIOL groups, astigmatism parameters such as the ME, flattening index and correction index changed from 6 to 12 months postoperatively, indicating that the refractive outcomes are not entirely stable at 6 months. However, visual outcomes did not change between 6 and 12 months follow up.

Following Artisan toric pIOL implantation in PKP eyes the variability in the achieved astigmatic outcomes was much higher than that in normal eyes (demonstrated in Figure 8.1). At 12 months follow-up, the ME was $-0.32 \pm 1.51 \mathrm{D}$ and the correction index was 0.99 , indicating that an undercorrection of astigmatism occurred in these patients. The high mean absolute AE (15 \pm 16 degrees) resulted in large amounts of residual astigmatism $(1.56 \pm 1.41 \mathrm{D}$ overall and $1.40 \pm 1.40 \mathrm{D}$ at the meridian of treatment). None of the astigmatism parameters changed significantly from 6 to 12 
months follow-up. All eyes in our study achieved less than 3.0 D of refractive astigmatism, indicating that all patients were suitable for spectacle correction.

An important aspect to consider in toric IOL calculation is the vector change in corneal astigmatism (SICA) induced by the incision. Commonly used toric IOLs require an incision of $2.2 \mathrm{~mm}$ (Acrysof $\mathrm{IOL}$ ) or can even be implanted through a sub $2.0 \mathrm{~mm}$ incision (Rayner T-flex IOL; AT Torbi, Carl Zeiss Meditec). Following a $2.2 \mathrm{~mm}$ superior incision, a SICA of $-0.10 \pm 0.52$ D @ 92 degrees was found at 12 months postoperatively, which was not significantly different from zero. In addition, postoperative corneal astigmatism was not significantly different from preoperative corneal astigmatism. Studies on toric IOLs generally incorporate a SICA, ranging in magnitude from 0 to $0.70 D^{18,19,21-24}$ In addition, previous studies have reported a SICA ranging from -0.20 to $-0.40 \mathrm{D}$ following a $2.2 \mathrm{~mm}$ superior incision. ${ }^{4,25-27}$ However, none of these aforementioned studies have examined if the amount of SICA is significantly different from zero. In agreement with our results, Hoffmann et al. have reported a SICA of $-0.19 \pm 0.44 \mathrm{D}$ at 3 months postoperatively following a $2.2 \mathrm{~mm}$ temporal incision, which was not significantly different from zero. ${ }^{16}$ In addition, Goggin et al. have examined the test-retest variability of keratometry measurements and have shown that this may be up to $0.14 \mathrm{D}$ in magnitude. ${ }^{28}$ This indicates that a significant proportion of the SICA reported in previous studies may be due to test-retest variation in keratometry measurements. We believe that no SICA should be incorporated into the toric IOL power calculation for a superior $2.2 \mathrm{~mm}$ incision.

Anterior chamber iris-fixated toric pIOLs require a $3.4 \mathrm{~mm}$ incision for foldable plOLs or a $5.4 \mathrm{~mm}$ incision for rigid pIOLs. A SICA of $-0.31 \pm 0.43 \mathrm{D}$ for a $3.4 \mathrm{~mm}$ superior incision and $-0.48 \pm 0.55 \mathrm{D}$ for a $5.4 \mathrm{~mm}$ superior incision was found at 6 months follow-up in normal eyes. This value did not change significantly from 6 to 12 months postoperatively, indicating that the amount of SICA had stabilized at 6 months postoperatively. In both incision groups, postoperative corneal astigmatism was significantly different from the preoperative value and the amount of SIA was significantly different from zero. This indicates that the amount of SICA should be incorporated into the pIOL power calculation. However, the amount of SICA is currently not routinely incorporated into the pIOL power calculation performed by the manufacturer. Not incorporating the SICA into the PIOL power calculation may have resulted in the overcorrection of astigmatism observed in our study. In the literature, superior incisions of approximately $3.5 \mathrm{~mm}$ have been reported to produce a SICA ranging from -0.49 to $-0.89 \mathrm{D} .^{29-31}$ Bartels et al. have examined the SICA following a 5.5 $\mathrm{mm}$ incision and have shown a SICA ranging from -0.60 to $0.74 \mathrm{D}^{32,33}$ Our 
recommendation is to incorporate a SICA of $-0.30 \mathrm{D}$ for a $3.4 \mathrm{~mm}$ superior incision and $-0.50 \mathrm{D}$ for a $5.4 \mathrm{~mm}$ superior incision.

In PKP eyes, the SICA following a $5.4 \mathrm{~mm}$ incision was found to be $-0.49 \pm 1.48 \mathrm{D}$, which is comparable to the SICA in normal eyes. However, as visible in Figure 8.2, the variability in the amount of SICA in PKP eyes was much higher than in normal eyes. We hypothesized that the large variability in SICA might be due to a different biomechanical response of the cornea. In normal corneas, collagen fibers within the same lamellae have a parallel orientation and the orientation of the fibers throughout the corneal depth varies. Overall, the preferred orientation is along the horizontal (nasal - temporal) and vertical (inferior - superior) direction, which provides biomechanical strength. ${ }^{34}$ In PKP eyes, however, collagen fibers are cut and the donor cornea button is sutured into place with no regard to the orientation of the recipient and donor collagen lamellae. This might impair the structural integrity of the cornea and change the biomechanical response. Since the amount of SICA in PKP eyes in this study was found to be significantly different from zero, incorporation of a SICA of -0.50 $D$ into the toric pIOL power calculation for a superior $5.4 \mathrm{~mm}$ incision, is advised.

A limitation of this study is that preoperative and postoperative visual acuity was measured with a Snellen chart, instead of an ETDRS (LogMAR) chart. However, Snellen visual acuity was converted to LogMAR before any calculations were performed. A possible limitation is that for some patients both eyes were included in the analysis. Therefore, all analyses were also performed with only one eye for each patient (results not shown). These results were similar to the results for all eyes. Another limitation is that two different devices were used for corneal topography. To attempt to minimize this effect, the same device was used preoperatively and postoperatively in each patient. Finally, a limitation of this study is that corneal astigmatism data were obtained with Placido-disk videokeratoscopy. This type of corneal topography system reconstructs the anterior corneal surface by the reflections of light-emitting Placido rings. This does not represent the exact corneal shape since it does not include information about the posterior corneal surface and the corneal thickness. ${ }^{35}$ It would be worthwhile in the future to analyze astigmatism data in these patients with Scheimpflug imaging.

In conclusion, a vector analysis of the refractive astigmatism changes showed that toric IOLs and toric pIOLs provide an effective astigmatism correction. In case of toric IOL implantation through a superior $2.2 \mathrm{~mm}$ incision, incorporation of a SICA into the toric IOL power calculation is not necessary. In case of Artiflex or Artisan pIOL implantation through a superior 3.4 or $5.4 \mathrm{~mm}$ incision incorporation of a SICA of $-0.30 \mathrm{D}$ and -0.50 $D$, respectively, is recommended. In case of Artisan pIOL implantation in PKP eyes, 
incorporation of a SICA of $-0.50 \mathrm{D}$ is also recommended. Incorporating the SICA into the pIOL power calculation may further increase the effectiveness of the astigmatism correction.

\section{References}

1. Alio JL, Agdeppa MC, Pongo VC, El Kady B. Microincision cataract surgery with toric intraocular lens implantation for correcting moderate and high astigmatism: pilot study. J Cataract Refract Surg. Jan 2010;36(1):4452.

2. Holland E, Lane S, Horn JD, Ernest P, Arleo R, Miller KM. The AcrySof Toric Intraocular Lens in Subjects with Cataracts and Corneal Astigmatism A Randomized, SubjectMasked, Parallel-Group, 1-Year Study. Ophthalmology. Sep 14 2010;117(11):21042111.

3. Entabi M, Harman F, Lee N, Bloom PA. Injectable 1-piece hydrophilic acrylic toric intraocular lens for cataract surgery: Efficacy and stability. J Cataract Refract Surg. Feb 2011;37(2):235-240.

4. Visser N, Ruiz-Mesa R, Pastor F, Bauer NJ, Nuijts RM, Montes-Mico R. Cataract surgery with toric intraocular lens implantation in patients with high corneal astigmatism. J Cataract Refract Surg. Aug 2011;37(8):14031410.

5. Sanders DR, Schneider D, Martin R, et al. Toric Implantable Collamer Lens for moderate to high myopic astigmatism. Ophthalmology. Jan 2007;114(1):54-61.

6. Guell JL, Morral M, Gris O, Gaytan J, Sisquella M, Manero F. Five-year follow-up of 399 phakic Artisan-Verisyse implantation for myopia, hyperopia, and/or astigmatism. Ophthalmology. Jun 2008;115(6):1002-1012.

7. Lee SY, Kwon HJ, Ahn HS, Seo KY, Kim EK, Kim TI. Comparison of patient outcomes after implantation of Visian toric implantable collamer lens and iris-fixated toric phakic intraocular lens. Eye (Lond). Nov 2011;25(11):1409-1417.

8. Nuijts RM, Abhilakh Missier KA, Nabar VA, Japing WJ. Artisan toric lens implantation for correction of postkeratoplasty astigmatism. Ophthalmology. Jun 2004;111(6):1086-1094.

9. Tahzib NG, Cheng YY, Nuijts RM. Three-year follow-up analysis of Artisan toric lens implantation for correction of postkeratoplasty ametropia in phakic and pseudophakic eyes. Ophthalmology. Jun 2006;113(6):976-984.

10. Alfonso JF, Lisa C, Abdelhamid A, MontesMico R, Poo-Lopez A, Ferrer-Blasco T. Posterior chamber phakic intraocular lenses after penetrating keratoplasty. J Cataract Refract Surg. Jul 2009;35(7):1166-1173.

11. Claesson M, Armitage WJ. Ten-year followup of graft survival and visual outcome after penetrating keratoplasty in Sweden. Cornea. Dec 2009;28(10):1124-1129.

12. Mannis MJ, Zadnik K. Refracting the corneal graft. Surv Ophthalmol. May-Jun 1990;34(6):436-440.

13. Alpins NA, Goggin M. Practical astigmatism analysis for refractive outcomes in cataract and refractive surgery. Surv Ophthalmol. Jan-Feb 2004;49(1):109-122.

14. Visser N, Berendschot TT, Bauer NJ, Jurich J, Kersting O, Nuijts RM. Accuracy of toric intraocular lens implantation in cataract and refractive surgery. J Cataract Refract Surg. Aug 2011;37(8):1394-1402.

15. Holladay JT, Moran JR, Kezirian GM. Analysis of aggregate surgically induced refractive change, prediction error, and intraocular astigmatism. J Cataract Refract Surg. Jan 2001;27(1):61-79.

16. Hoffmann PC, Auel S, Hutz WW. Results of higher power toric intraocular lens implantation. J Cataract Refract Surg. Aug 2011;37(8):1411-1418.

17. Mojzis P, Pinero DP, Studeny $P$, et al. Comparative Analysis of Clinical Outcomes Obtained with a New Diffractive Multifocal Toric Intraocular Lens Implanted Through Two Types of Corneal Incision. J Refract Surg. May 20 2011:1-10.

18. Alio JL, Pinero DP, Tomas J, Aleson A. Vector analysis of astigmatic changes after cataract surgery with toric intraocular lens implantation. J Cataract Refract Surg. Jun 2011;37(6):1038-1049.

19. Goggin M, Moore S, Esterman A. Toric Intraocular Lens Outcome Using the 
Manufacturer's Prediction of Corneal Plane Equivalent Intraocular Lens Cylinder Power. Arch Ophthalmol. Aug 2011;129(8):10041008.

20. Ahmed I, Rocha G, Slomovic AR, et al. Visual function and patient experience after bilateral implantation of toric intraocular lenses. J Cataract Refract Surg. Apr 2010;36(4):609-616.

21. Bauer NJ, de Vries NE, Webers CA, Hendrikse F, Nuijts RM. Astigmatism management in cataract surgery with the AcrySof toric intraocular lens. J Cataract Refract Surg. Sep 2008;34(9):1483-1488.

22. Gayton JL, Seabolt RA. Clinical Outcomes of Complex and Uncomplicated Cataractous Eyes After Lens Replacement with the AcrySof Toric IOL. J Refract Surg. Apr 14 2010;14:1-7.

23. Koshy JJ, Nishi $\mathrm{Y}$, Hirnschall $\mathrm{N}$, et al. Rotational stability of a single-piece toric acrylic intraocular lens. J Cataract Refract Surg. Oct 2010;36(10):1665-1670.

24. Ernest P, Potvin R. Effects of preoperative corneal astigmatism orientation on results with a low-cylinder-power toric intraocular lens. J Cataract Refract Surg. Apr 2011;37(4):727-732.

25. Masket S, Wang L, Belani S. Induced astigmatism with 2.2- and 3.0-mm coaxial phacoemulsification incisions. J Refract Surg. Jan 2009;25(1):21-24.

26. Wang J, Zhang EK, Fan WY, Ma JX, Zhao PF. The effect of micro-incision and smallincision coaxial phaco-emulsification on corneal astigmatism. Clin Experiment Ophthalmol. Sep 2009;37(7):664-669.

27. Can I, Takmaz T, Yildiz Y, Bayhan HA, Soyugelen G, Bostanci B. Coaxial, microcoaxial, and biaxial microincision cataract surgery: prospective comparative study. J Cataract Refract Surg. May 2010;36(5):740-746.
28. Goggin M, Patel I, Billing K, Esterman A Variation in surgically induced astigmatism estimation due to test-to-test variations in keratometry. J Cataract Refract Surg. Oct 2010;36(10):1792-1793.

29. Tejedor J, Murube J. Choosing the location of corneal incision based on preexisting astigmatism in phacoemulsification. Am J Ophthalmol. May 2005;139(5):767-776.

30. Altan-Yaycioglu R, Akova YA, Akca S, Gur S, Oktem C. Effect on astigmatism of the location of clear corneal incision in phacoemulsification of cataract. J Refract Surg. May 2007;23(5):515-518.

31. Kamiya K, Shimizu K, Aizawa D, Igarashi A, Komatsu $M$. Surgically induced astigmatism after posterior chamber phakic intraocular lens implantation. $\mathrm{Br} \mathrm{J}$ Ophthalmol. Dec 2009;93(12):1648-1651.

32. Bartels MC, Santana NT, Budo C, van Rij G, Mulder PG, Luyten GP. Toric phakic intraocular lens for the correction of hyperopia and astigmatism. J Cataract Refract Surg. Feb 2006;32(2):243-249.

33. Bartels MC, Saxena R, van den Berg TJ, van Rij G, Mulder PG, Luyten GP. The influence of incision-induced astigmatism and axial lens position on the correction of myopic astigmatism with the Artisan toric phakic intraocular lens. Ophthalmology. Jul 2006;113(7):1110-1117.

34. Meek KM, Newton RH. Organization of collagen fibrils in the corneal stroma in relation to mechanical properties and surgical practice. J Refract Surg. Nov-Dec 1999;15(6):695-699.

35. Belin MW, Khachikian SS. An introduction to understanding elevation-based topography: how elevation data are displayed - a review. Clin Experiment Ophthalmol. Jan 2009;37(1):14-29 


\section{Chapter 9}

Cataract surgery with toric intraocular lens implantation in keratoconus: A case-report

Nienke Visser, Sacha T.J.M. Gast, Noël J.C. Bauer and Rudy M.M.A. Nuijts

Cornea 2011; 30: 720-723 


\section{Abstract}

PURPOSE: To present two cases in which cataract extraction with a foldable acrylic toric intraocular lens (IOL) implantation was used to correct (irregular) corneal astigmatism in patients with keratoconus and cataract.

DESIGN: Case report.

Methods: Case 1 was a 78-year old male with cataract and keratoconus in his left eye. He underwent phacoemulsification with a toric IOL (Acrysof SN60T9; cylinder power 6.0 D) implantation. Case 2 was a 64-year old female with bilateral cataract and keratoconus. She underwent phacoemulsification with toric IOL implantation in her right (Acrysof SN60T9; cylinder power 6.0 D) and left eye (Acrysof SN60T5; cylinder power 3.0 D). Postoperative follow-up in both cases was six months.

RESULTS: In case 1, the uncorrected distance visual acuity (UDVA) increased from $20 / 400$ to $20 / 50$. Refractive cylinder decreased from $-6.0 \mathrm{D}$ to $-1.5 \mathrm{D}$, which is a reduction of $75 \%$. In case 2 , the UDVA increased from $20 / 400$ to $20 / 130$ in the right eye and from $20 / 400$ to $20 / 30$ in the left eye. Refractive astigmatism decreased by $70 \%$ in both eyes. No IOL misalignment or other complications occurred.

CONCLUSION: Cataract extraction with toric IOL implantation can be used to correct (irregular) astigmatism and to improve visual functioning in patients with mild to moderate amounts of stable keratoconus and cataract. 


\section{Introduction}

Keratoconus is a progressive, non-inflammatory disease of the cornea characterized by thinning and protrusion of the cornea. This results in high irregular astigmatism and myopia and a reduced visual acuity. The onset is usually at puberty and progression mainly occurs until the $3^{\text {rd }}$ or $4^{\text {th }}$ decade in life. ${ }^{1}$ Treatment of keratoconus depends on the stage of the disease. In early to moderate keratoconus, spectacles and rigid-gaspermeable contact lenses (RGPCLs) are the most frequently used correction methods to achieve good visual acuity. ${ }^{2}$ Phakic toric IOLs have been described as an effective treatment option in patients with a stable keratoconus. ${ }^{3-5}$ In addition, in patients with combined cataract and keratoconus, toric pseudophakic IOLs may be a safe and effective option to correct refractive errors in non-progressive keratoconus. ${ }^{6,7}$ In advanced cases with severe irregular astigmatism, surgical treatments such as intracorneal ring segment implantation or penetrating or lamellar keratoplasty may be needed.

Visually significant cataract has been shown to occur at a younger age in keratoconus patients as compared to the general population. ${ }^{8}$ The introduction of toric pseudophakic IOLs with cylinder powers up to 6.0 diopters (D) offer the opportunity to correct higher levels of corneal astigmatism in patients with keratoconus. We present two patients who underwent cataract extraction with a high-cylinder power toric IOL implantation to correct corneal astigmatism due to keratoconus.

\section{Case reports}

\section{Case 1}

A 78-year-old man presented to our outpatient clinic with a gradually decreased visual acuity in both eyes due to bilateral cataract. On presentation in 2008 , uncorrected distance visual acuity (UDVA) in the right and left eye was 20/50 and 20/400, respectively. Spectacle corrected distance visual acuity (CDVA) was 20/50 in the right eye with S+0.75/ C- $0.75 \times 100^{\circ}$ and $20 / 400$ in the left eye with S-1.00/ C-6.00 $\times 85^{\circ}$. Until now, this patient had been satisfied with his spectacle correction and did not use RGPCLs. Examination showed substantial cortical and posterior capsular cataract in both eyes. Corneal topography was performed using Scheimpflug photography (Pentacam, Oculus Optikgeräte) and did not show irregular astigmatism or keratoconus in the right eye. Scheimpflug photography of the left eye showed a central corneal thickness of $475 \mu \mathrm{m}$ and an inferior-temporal displacement of the thinnest point $(446 \mu \mathrm{m})$ (Figure 9.1), indicative of keratoconus. Keratometry (K)-values for the 
steep and flat meridians were 43.9 D @6 degrees and 39.8 D @96 degrees, respectively. Biometry was performed with the IOLMaster (Carl Zeiss Meditec) to calculate the intraocular lens (IOL) power for emmetropia using the SRK/T formula.

Cataract extraction with a standard non-toric IOL implantation was performed in the right eye. Following surgery, the UDVA was 20/30 and the CDVA 20/25. Since the risk of progression of keratoconus in this 78-year-old patient in the left eye appeared minimal, we decided to perform a phacoemulsification with toric IOL implantation in this eye. Due to the highly irregular keratoconus, K-values obtained with the Pentacam were used for the IOL calculation. Manual keratometry (Javal-Schiötz) was used to obtain accurate determination of the meridians of corneal astigmatism. A web-based toric IOL calculator program was used to determine the optimal cylinder power and alignment axis of the IOL (available at http://www.acrysoftoriccalculator.com).

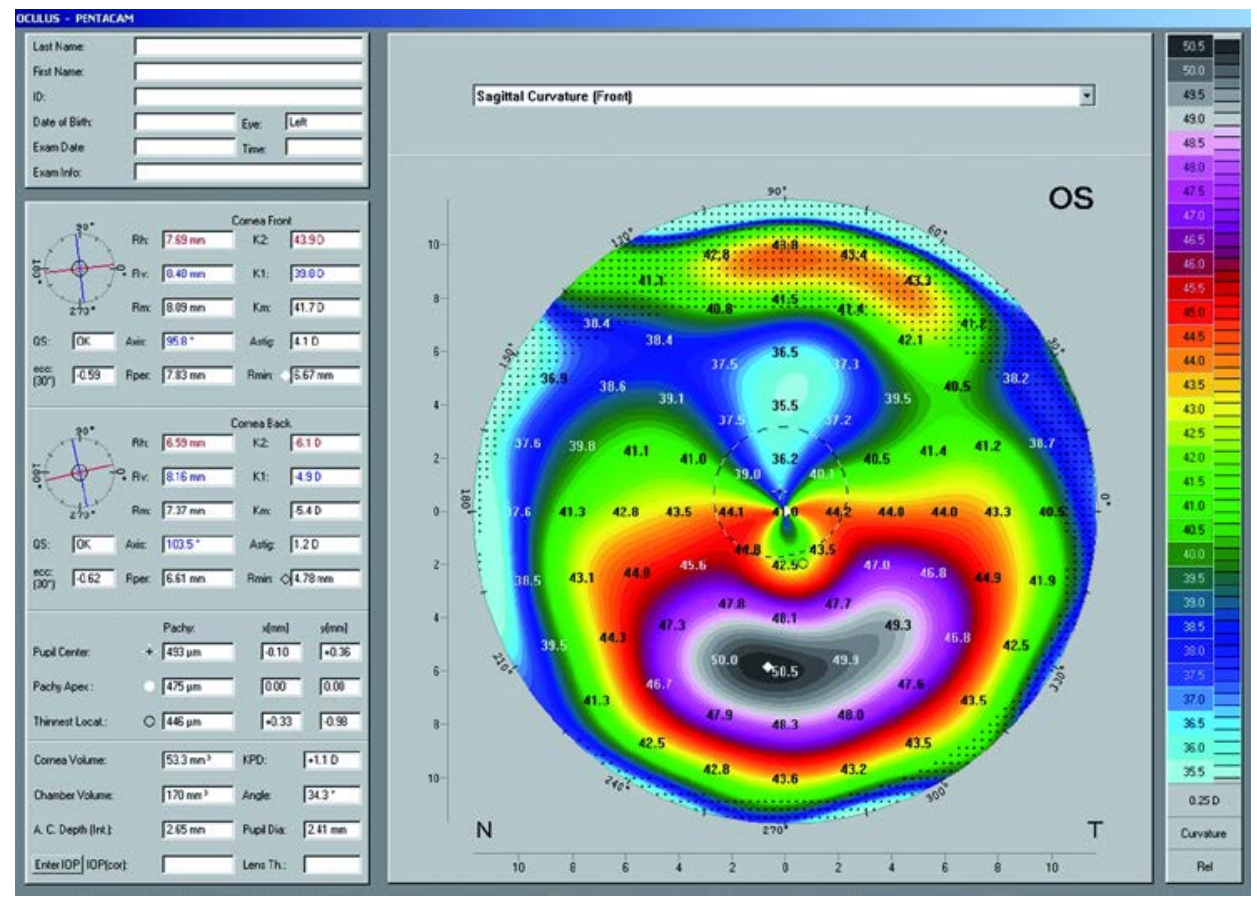

Figure 9.1 Pentacam sagittal curvature map of the anterior corneal surface of the patient in case 1 , showing an island of corneal steepening and protrusion. 


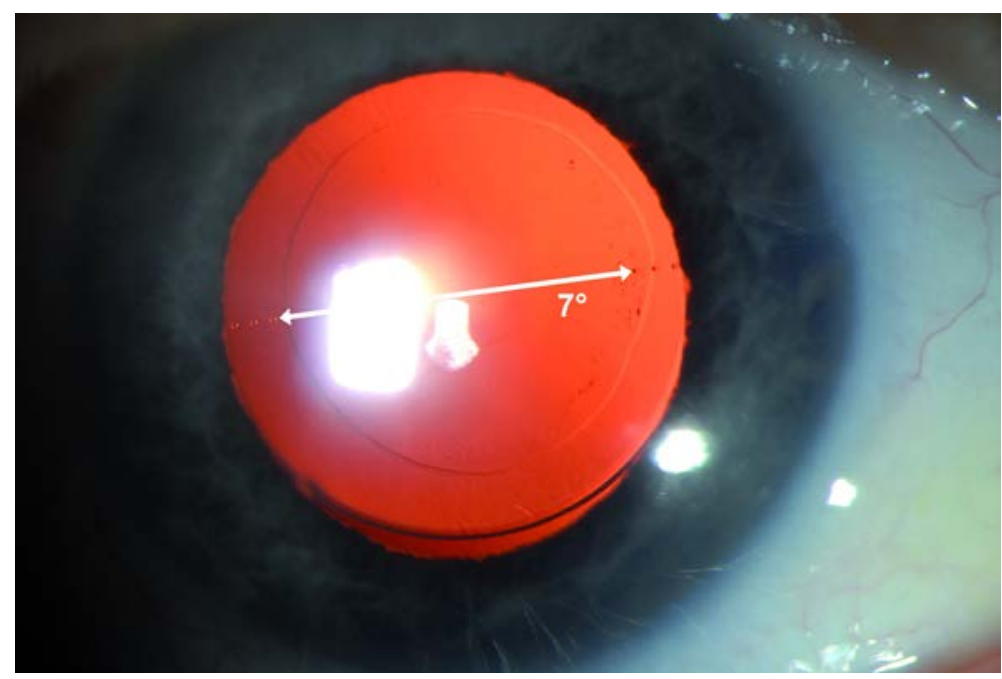

Figure 9.2 Slit-lamp photograph of the left eye of a patient with keratoconus and an Acrysof toric intraocular lens with a cylinder of 6.0 D at the IOL plane (case 1). The IOL alignment axis is at 7 degrees.

Preoperatively, limbal reference marks were placed using the Nuijts/Lane Toric Reference Marker (American Surgical Instruments Corp.) with the patient sitting upright to correct for cyclotorsion. Intraoperatively, the implantation axis was determined using the corneal reference marks and the alignment axis obtained from the toric IOL calculator program and the axis was marked using a Mendez ring and a Nuijts Toric Axis Marker (both American Surgical Instruments Corp.). A standard phacoemulsification was performed with a $2.2 \mathrm{~mm}$ limbal incision at 90 degrees. An hydrophobic acrylic toric IOL (Acrysof SN60T9, Alcon Laboratories) with a spherical power of $21.0 \mathrm{D}$ and a cylinder power of $6.00 \mathrm{D}$ at the $\mathrm{IOL}$ plane and $4.11 \mathrm{D}$ at the corneal plane was implanted and aligned at an axis of 9 degrees. A residual astigmatism of $0.46 \mathrm{D}$ at 9 degrees was anticipated based on the preoperative calculation. Postoperatively, topical tobramycin $0.3 \%$ combined with dexamethasone 0.1\% (Tobradex, Alcon Laboratories) and ketorolactrometamol 0.5\% (Acular, Allergan) were used four times daily for 3 weeks in a tapered regimen and three times daily for 1 week, respectively.

Six months postoperatively, the UDVA was 20/50 and the (spectacle) CDVA was 20/30 with a refraction of $\mathrm{S} 0.00 / \mathrm{C}-1.50 \times 120^{\circ}$. Refractive astigmatism had decreased from $6.00 \mathrm{D}$ to $-1.50 \mathrm{D}$, which is a reduction of $75 \%$. The toric IOL alignment axis, as determined by slit-lamp biomicroscopy, was placed at 7 degrees (Figure 9.2). Surgically induced corneal astigmatism (SICA), as determined by vector analysis according to 
Holladay et al., was $-1.31 \mathrm{D}$ at 100 degrees. ${ }^{9}$ No postoperative complications occurred and the patient was very satisfied.

\section{Case 2}

A 64-year-old woman presented to our outpatient clinic with a decreased visual acuity in both eyes. Her medical history showed high myopia and corneal astigmatism in both eyes, for which she had been using RGPCLs for the past 38 years in both eyes. Family history for keratoconus was negative. Slit-lamp examination showed bilateral cortical nuclear cataract and Vogt's striae, more prominent in the right than left eye. The UDVA was 20/400 in both eyes and the spectacle CDVA was 20/40 with S-12.00/ C-5.00 $x 40^{\circ}$ in her right eye and 20/30 with S-8.00/ C-2.50 x $170^{\circ}$ in her left eye. CDVA with contact lenses was 20/40 and 20/30 in the right and left eye, respectively. Scheimpflug photography was performed and showed a central corneal thickness of $472 \mu \mathrm{m}$ in both eyes and an inferior-temporal displacement of the thinnest point ( $457 \mu \mathrm{m}$ in the right eye and $467 \mu \mathrm{m}$ in the left eye), indicating irregular astigmatism due to keratoconus, more prominent in the right eye. K-values for the steep and flat meridians were $47.9 \mathrm{D}$ @ 134 degrees and 44.2 D @ 44 degrees in the right eye and 46.5 D @ 66 degrees and $44.4 \mathrm{D} @ 156$ degrees in the left eye. Lens power calculation was performed as described in case 1.

Phacoemulsification with toric IOL implantation was performed in both eyes. In the right eye a toric IOL (Acrysof SN60T9) with a spherical power of +6.0 D and a cylinder power of $6.00 \mathrm{D}$ was implanted at an axis of 121 degrees. In the left eye a toric IOL (Acrysof SN60T5) with a spherical power of +6.0 D and a cylinder power of 3.00 D at the IOL plane and $2.06 \mathrm{D}$ at the corneal plane was implanted at 63 degrees. A residual astigmatism of $0.76 \mathrm{D}$ at 121 degrees in the right eye and $0.42 \mathrm{D}$ at 63 degrees in the left eye was anticipated based on preoperative IOL calculations.

Six months postoperatively, the UDVA and (spectacle) CDVA in the right eye were 20/130 and 20/40 (S-2.50/ C-1.50 x 85 ${ }^{\circ}$ ), respectively. The UDVA and (spectacle) CDVA in the left eye were $20 / 30$ and $20 / 25$ (S-0.25/ C- $0.75 \times 180^{\circ}$ ), respectively. Refractive astigmatism had decreased by $70 \%$ in both eyes. The IOL axis was at 120 degrees in the right eye and 60 degrees in the left eye. The SICA was -0.65 D at 109 degrees in the right eye and $-0.34 \mathrm{D}$ at 134 degrees in the left eye. The patient was satisfied with postoperative visual outcomes. No complications occurred. 


\section{Discussion}

We present two cases with non-progressive keratoconus and cataract who underwent cataract extraction and high-cylinder power toric IOL implantation. Both patients showed a marked improvement in UDVA and a 75 to $80 \%$ reduction in refractive astigmatism. The recent introduction of the Acrysof toric T6 to T9 IOLs, with cylinder powers up to $6.00 \mathrm{D}$ at the $\mathrm{IOL}$ plane and approximately $4.00 \mathrm{D}$ at the corneal plane, makes this lens suitable for keratoconus patients with higher amounts of corneal astigmatism.

Phakic IOLs have been used successfully to correct high refractive errors in keratoconus patients without cataract. ${ }^{3,4,10,11}$ In other cases of high amounts of corneal astigmatism and ametropia, for example in post-keratoplasty patients, toric phakic IOLs have been shown to be effective in reducing the refractive error. ${ }^{12}{ }^{13}$ Cataract surgery with a toric IOL implantation has also been performed in patients with high amounts of post-keratoplasty astigmatism and showed good results. ${ }^{14,}{ }^{15}$ An option in patients with keratoconus and a clear natural lens is refractive lens exchange with a toric IOL implantation in the capsular bag. ${ }^{6}$ After implantation of acrylic toric IOLs with a relatively low cylinder powers (2.25 and $3.00 \mathrm{D})$ in 2 patients, the UDVA improved from $20 / 800$ to $20 / 25$ in both cases and refractive astigmatism was reduced by approximately $80 \% .{ }^{6}$ In another case report, cataract extraction with a silicone toric IOL implantation was performed in 2 keratoconus patients and showed similar good results. ${ }^{7}$ However, toric IOL models made from silicone material, such as the Staar toric IOL (Staar Surgical) and MicroSil toric IOL (HumanOptics), showed relatively high postoperative rotation rates and often required surgical realignment. ${ }^{16,17}$ Toric IOLs $^{1}$ made of acrylic material, such as the Acrysof IOLs, are rotationally stable due to presumed adhesions of the acrylic material of the IOL to the anterior and posterior capsule. ${ }^{18}$ Weinand et al. determined the rotational stability of this IOL type using digital images taken immediately postoperatively and 6 months postoperatively and found a mean rotation of 0.9 degrees (range 0.1 to 1.8 degrees). ${ }^{19}$

Cataract surgery with toric IOL implantation is a suitable option to correct high levels of astigmatism and myopia in keratoconus patients if the risk of progression is minimal. Before implanting the toric IOL, the patients' individual risk of progression should be analyzed. A careful history taking is needed to explore the level of spectacle CDVA the patient had before cataract formation occurred and to determine whether signs of keratoconus progression are present. Risk factors that have been associated with progression of keratoconus include young age, a positive family history of keratoconus, steep keratometric values at baseline, changes in refractive error and 
possibly eye rubbing. ${ }^{20,21}$ In practice, clinical findings and corneal topography abnormalities, such as a high central K-value and an increased amount of steepening of the inferior cornea compared with the superior cornea, may be used to assess the risk of progression. ${ }^{21}$ Due to the age of the two patients in our case report, we regarded the risk of progression to be minimal. However, if progression would occur after cataract extraction with toric IOL implantation, collagen cross-linking may still be performed in order to stabilize the keratoconus.

Toric IOLs are most suitable for keratoconus patients with mild to moderate amounts of irregular astigmatism who can be satisfactory corrected using spectacles. It is possibly a less suitable option for patients in whom RGPCLs have been prescribed primarily to correct high levels of irregular astigmatism. ${ }^{22}$ We have selected to implant toric IOLs in keratoconus patients if a spectacle CDVA level of 20/40 postoperatively appeared achievable. If the preoperative difference between CDVA with RGPCLs and CDVA with spectacles is high, implantation of a toric IOL may not be suitable. In patients with keratoconus and extensive cataract, only the medical history can provide data in this respect. Both patients that we describe in this case report were informed about these issues and were satisfied with the postoperative visual outcomes.

The amount of SICA following a $2.2 \mathrm{~mm}$ incision at 90 degrees was relatively variable in both cases: $-1.31 \mathrm{D}$ at 100 degrees in the first case, and $-0.65 \mathrm{D}$ at 109 degrees (right eye) and -0.34 D at 134 degrees (left eye) in the second case. In normal eyes, $2.2 \mathrm{~mm}$ superiorly located incisions have been shown to induce approximately 0.30 to $0.50 \mathrm{D}$ of corneal astigmatism. ${ }^{23,24}$ We hypothesize that the SICA in keratoconus patients might be more variable due to altered biomechanical properties of the cornea. ${ }^{25}$

IOL power calculation may be challenging in keratoconus patients with high levels of astigmatism and myopia. Accurate axial length and corneal astigmatism measurements must be obtained. Because of the irregular astigmatism in both patients, we have used the K-values obtained with the Pentacam. To determine the astigmatism meridians in these patients, we have used the manual Javal-Schiötz keratometer, which we regard as the gold standard for astigmatism meridian determination. The spherical power of the IOL was calculated using the SRK/T formula. Thebpatiphat et al. have compared the SRKI, SRKII and SRK/T IOL calculation formulas in patients with keratoconus and suggest that the SRKII formula might provide the most accurate IOL power in patients with mild keratoconus. ${ }^{8}$ However, in moderate and severe keratoconus, IOL calculations were less accurate and no differences in calculation formulas could be found. The best lens formula in these patients should therefore be further examined. Cataract extraction with toric IOL implantation in patients with stable keratoconus and cataract provides the opportunity to correct (irregular) astigmatism and to achieve 
optimal visual outcomes. We believe that this option is most suitable for keratoconus patients with mild to moderate amounts of irregular astigmatism. Larger case-series should be performed to confirm the long-term efficacy and stability of toric IOL implantation in patients with a presumably stable keratoconus.

\section{References}

1. Rabinowitz YS. Keratoconus. Surv Ophthalmol. Jan-Feb 1998;42(4):297-319.

2. McGhee CN. 2008 Sir Norman McAlister Gregg Lecture: 150 years of practical observations on the conical cornea--what have we learned? Clin Experiment Ophthalmol. Mar 2009;37(2):160-176.

3. Alfonso JF, Fernandez-Vega L, Lisa C, Fernandes P, Gonzalez-Meijome JM, Montes-Mico R. Collagen copolymer toric posterior chamber phakic intraocular lens in eyes with keratoconus. J Cataract Refract Surg. Jun 2010;36(6):906-916.

4. Budo C, Bartels MC, van Rij G. Implantation of Artisan toric phakic intraocular lenses for the correction of astigmatism and spherical errors in patients with keratoconus. J Refract Surg. May-Jun 2005;21(3):218-222.

5. Kamiya K, Shimizu K, Hikita F, Komatsu M. Posterior chamber toric phakic intraocular lens implantation for high myopic astigmatism in eyes with pellucid marginal degeneration. J Cataract Refract Surg. Jan 2010;36(1):164-166.

6. Navas A, Suarez R. One-year follow-up of toric intraocular lens implantation in forme fruste keratoconus. J Cataract Refract Surg. Nov 2009;35(11):2024-2027.

7. Sauder G, Jonas JB. Treatment of keratoconus by toric foldable intraocular lenses. Eur J Ophthalmol. Jul 2003;13(6):577-579.

8. Thebpatiphat N, Hammersmith KM, Rapuano CJ, Ayres BD, Cohen EJ. Cataract surgery in keratoconus. Eye Contact Lens. Sep 2007;33(5):244-246.

9. Holladay JT, Moran JR, Kezirian GM. Analysis of aggregate surgically induced refractive change, prediction error, and intraocular astigmatism. J Cataract Refract Surg. Jan 2001;27(1):61-79.

10. de Vries NE, Tahzib NG, Webers CA, Hendrikse F, Nuijts RM. Use of Verisyse/Artisan phakic intraocular lens for the reduction of myopia in a patient with pellucid marginal degeneration. Cornea. Feb 2008;27(2):241-245.

11. Kamiya K, Shimizu K, Ando W, Asato Y, Fujisawa T. Phakic toric Implantable Collamer Lens implantation for the correction of high myopic astigmatism in eyes with keratoconus. J Refract Surg. Oct 2008;24(8):840-842.

12. Akcay L, Kaplan AT, Kandemir B, Gunaydin NT, Dogan OK. Toric intraocular Collamer lens for high myopic astigmatism after penetrating keratoplasty. J Cataract Refract Surg. Dec 2009;35(12):2161-2163.

13. Tahzib NG, Cheng YY, Nuijts RM. Three-year follow-up analysis of Artisan toric lens implantation for correction of postkeratoplasty ametropia in phakic and pseudophakic eyes. Ophthalmology. Jun 2006;113(6):976-984.

14. Kersey JP, O'Donnell A, Illingworth CD. Cataract surgery with toric intraocular lenses can optimize uncorrected postoperative visual acuity in patients with marked corneal astigmatism. Cornea. Feb 2007;26(2):133-135.

15. Statham M, Apel A, Stephensen D. Correction of astigmatism after penetrating keratoplasty using the Acri.Comfort toric intraocular lens. Clin Exp Optom. Nov 11 2009.

16. Chang DF. Early rotational stability of the longer Staar toric intraocular lens: fifty consecutive cases. J Cataract Refract Surg. May 2003;29(5):935-940.

17. Dick HB, Krummenauer F, Trober L. [Compensation of corneal astigmatism with toric intraocular lens: results of a multicentre study]. Klin Monatsbl Augenheilkd. Jul 2006;223(7):593-608.

18. Linnola RJ, Sund M, Ylonen R, Pihlajaniemi T. Adhesion of soluble fibronectin, laminin, and collagen type IV to intraocular lens materials. J Cataract Refract Surg. Nov 1999;25(11):1486-1491. 
19. Weinand F, Jung A, Stein A, Pfutzner A, Becker R, Pavlovic S. Rotational stability of a single-piece hydrophobic acrylic intraocular lens: new method for high-precision rotation control. J Cataract Refract Surg. May 2007;33(5):800-803.

20. Gordon MO, Steger-May K, Szczotka-Flynn L, et al. Baseline factors predictive of incident penetrating keratoplasty in keratoconus. Am J Ophthalmol. Dec 2006;142(6):923-930.

21. Li X, Yang H, Rabinowitz YS. Longitudinal study of keratoconus progression. Exp Eye Res. Oct 2007;85(4):502-507.

22. Goggin $M$, Alpins $N$, Schmid LM. Management of irregular astigmatism. Curr Opin Ophthalmol. Aug 2000;11(4):260-266.
23. Lee KM, Kwon HG, Joo CK. Microcoaxial cataract surgery outcomes: comparison of $1.8 \mathrm{~mm}$ system and $2.2 \mathrm{~mm}$ system. J Cataract Refract Surg. May 2009;35(5):874880.

24. Wang J, Zhang EK, Fan WY, Ma JX, Zhao PF. The effect of micro-incision and smallincision coaxial phaco-emulsification on corneal astigmatism. Clin Experiment Ophthalmol. Sep 2009;37(7):664-669.

25. Meek KM, Tuft SJ, Huang Y, et al. Changes in collagen orientation and distribution in keratoconus corneas. Invest Ophthalmol Vis Sci. Jun 2005;46(6):1948-1956. 


\section{Chapter 10}

\section{Residual astigmatism following toric intraocular lens implantation related to pupil size: A case report}

Nienke Visser, Noël J.C. Bauer and Rudy M.M.A. Nuijts Journal of Refractive Surgery 2012; 28: 729-732 


\section{Abstract}

PURPOSE: To present two patients with residual astigmatism following toric IOL implantation.

DESIGN: Case report.

RESULTS: A 58-year-old woman underwent toric IOL implantation (spherical power 29.5 D, cylinder power $3.00 \mathrm{D})$ to correct $2.33 \mathrm{D} @ 80$ degrees of corneal astigmatism. Postoperatively, the UDVA was 20/30 and the CDVA 20/22 (S0.00/ C-1.75 x 95 ${ }^{\circ}$, indicating an overcorrection of astigmatism. Slitlamp examination showed no IOL misalignment. Wavefront aberrometry showed a large pupil diameter ( $>6 \mathrm{~mm}$ ) and a lower corneal astigmatism in a $6 \mathrm{~mm}$ zone (-1.40 D @ 174 degrees) compared to a 4 mm zone (-2.21 D @ 171 degrees). The second patient, a 60-year-old male, underwent multifocal toric IOL implantation (spherical power $22.5 \mathrm{D}$, cylinder power $2.25 \mathrm{D}$ ) to correct 1.51 D @ 173 degrees of corneal astigmatism. Postoperatively, the UDVA was $20 / 50$ and the CDVA $20 / 20\left(S+0.25 / C-1.00 \times 102^{\circ}\right.$ ), indicating an undercorrection of astigmatism. Slitlamp examination showed no misalignment.

CoNCLUSION: Unexplained residual astigmatism following toric IOL implantation may be caused by multiple factors: the effect of the spherical power and anterior chamber depth on toric IOL calculations, the effect of posterior corneal astigmatism, and the effect of a large pupil size. The first two issues may be compensated for by improving toric IOL calculations. The latter indicates that pupillometry is indicated in relatively young patients who wish to undergo toric IOL implantation. 


\section{Introduction}

Toric intraocular lenses (IOLs) are increasingly used to correct corneal astigmatism at the time of cataract surgery. Several variables are known to affect the efficacy of toric IOLs, including IOL calculation formulas ${ }^{1}$, IOL misalignment during surgery ${ }^{2}$ and postoperative IOL rotation ${ }^{3}$. In this case report we present two patients with unexplained residual refractive astigmatism following toric IOL implantation. In addition, we show how wavefront aberrometry may be used to find the source of residual refractive astigmatism following toric IOL implantation.

\section{Case reports}

\section{Case 1}

A 58-year-old woman was referred to our clinic with residual refractive astigmatism following cataract surgery with toric IOL implantation in her right eye. The IOL spherical power for emmetropia had been calculated using IOLMaster biometry (Carl Zeiss Meditec). The toric IOL cylinder power and alignment axis were calculated using a web-based IOL calculator (available at http://www.acrysoftoriccalculator.com) and based on automated keratometry values obtained with the IOLMaster (2.33 D @ 80 degrees). The expected surgically induced corneal astigmatism (SICA) was -0.25 D. A standard phacoemulsification was performed with a $2.2 \mathrm{~mm}$ limbal incision located at 95 degrees. An Acrysof SN60T5 (Alcon Laboratories) toric IOL with a spherical power of $29.5 \mathrm{D}$ and a cylinder power of $3.00 \mathrm{D}$ (2.06 D at the corneal plane) was implanted and aligned at 78 degrees. Residual astigmatism of $0.01 \mathrm{D}$ at 78 degrees was anticipated. No intra-operative complications occurred.

Four months postoperatively, she was referred to our clinic for analysis of residual refractive astigmatism. The UDVA in the right eye was 20/30 and the CDVA 20/22 with a subjective refraction of S0.00/ C- $1.75 \times 95^{\circ}$, indicative of an overcorrection of astigmatism. Slitlamp examination showed a toric IOL aligned at 80 degrees. Scheimpflug imaging (Pentacam, Oculus) demonstrated regular bow-tie corneal astigmatism. Postoperative anterior chamber depth (ACD) was $2.34 \mathrm{~mm}$ and pachymetry $533 \mu \mathrm{m}$ (estimated lens position of $2.87 \mathrm{~mm}$ ). The effective cylinder power at the corneal plane, calculated using a vertex formula, was 2.55 D. Combined wavefront aberrometry and corneal topography (KR-1W Wavefront Analyser, Topcon) was performed to determine if the correct IOL cylinder power had been implanted. Figure 10.1 shows the ocular, corneal and internal astigmatism values for a $4 \mathrm{~mm}$ and a $6 \mathrm{~mm}$ pupil size. Internal astigmatism was -3.16 D @ 87 degrees (6 mm zone), which 
corresponded with the intended toric IOL cylinder power (-3.00 D @ 78 degrees). While performing aberrometry without mydriasis, we measured a photopic pupil diameter of $6.2 \mathrm{~mm}$. Corneal astigmatism in the $6 \mathrm{~mm}$ zone was $-1.40 \mathrm{D} @ 174$ degrees, compared to $-2.21 \mathrm{D} @ 171$ degrees in the $4 \mathrm{~mm}$ zone. To treat the astigmatism overcorrection, we advised to perform an IOL exchange with a lower cylinder power toric IOL (SN60T3, cylinder power $1.50 \mathrm{D}$ ). If an IOL exchange is not possible we advised to perform a laser-assisted sub-epithelial keratectomy However, the patient preferred to use spectacles with a cylinder correction and did not wish to undergo surgery.

\section{Case 2}

A 60-year old male presented to our clinic with a decreased visual acuity in his right eye due to cataract. IOLMaster biometry was performed and demonstrated 1.51 D @ 173 degrees of corneal astigmatism. Corneal topography showed regular corneal astigmatism. After discussing the available options, he wished to undergo cataract surgery with implantation of a multifocal toric IOL. The multifocal toric IOL cylinder power and alignment axis were calculated using a web-based IOL calculator (available at http://www.acrysoftoriccalculator.com). The expected SICA was -0.30 D. A standard phacoemulsification was performed with a $2.2 \mathrm{~mm}$ limbal incision located at 95 degrees. A Restor SND1T4 (Alcon Laboratories) multifocal toric IOL with a spherical power of 22.5 D, an add power of 3.00 D, and a cylinder power of 2.25 D (1.50 D at the corneal plane) was implanted and aligned at 175 degrees. Residual astigmatism of 0.24 D x 175 degrees was anticipated. No intra-operative complications occurred.

Two weeks postoperatively, the UDVA was 20/50 and the CDVA 20/20 with a subjective refraction of $\mathrm{S}+0.25 / \mathrm{C}-1.00 \times 102^{\circ}$, indicating that an undercorrection had occurred. The IOL alignment axis was 170 degrees. Postoperative ACD was $4.03 \mathrm{~mm}$ and pachymetry $527 \mu \mathrm{m}$ (estimated lens position of $4.55 \mathrm{~mm}$ ). The effective cylinder power at the corneal plane, calculated using a vertex formula, was $1.85 \mathrm{D}$. Combined wavefront aberrometry and corneal topography (KR-1W Wavefront Analyser, Topcon) was performed to determine if the correct IOL cylinder power had been implanted. Internal astigmatism was -2.26 D @ 170 degrees (4 mm zone) which corresponded with the intended toric IOL cylinder power (-2.25 D @ 175 degrees). Photopic pupil diameter was $2.9 \mathrm{~mm}$. 


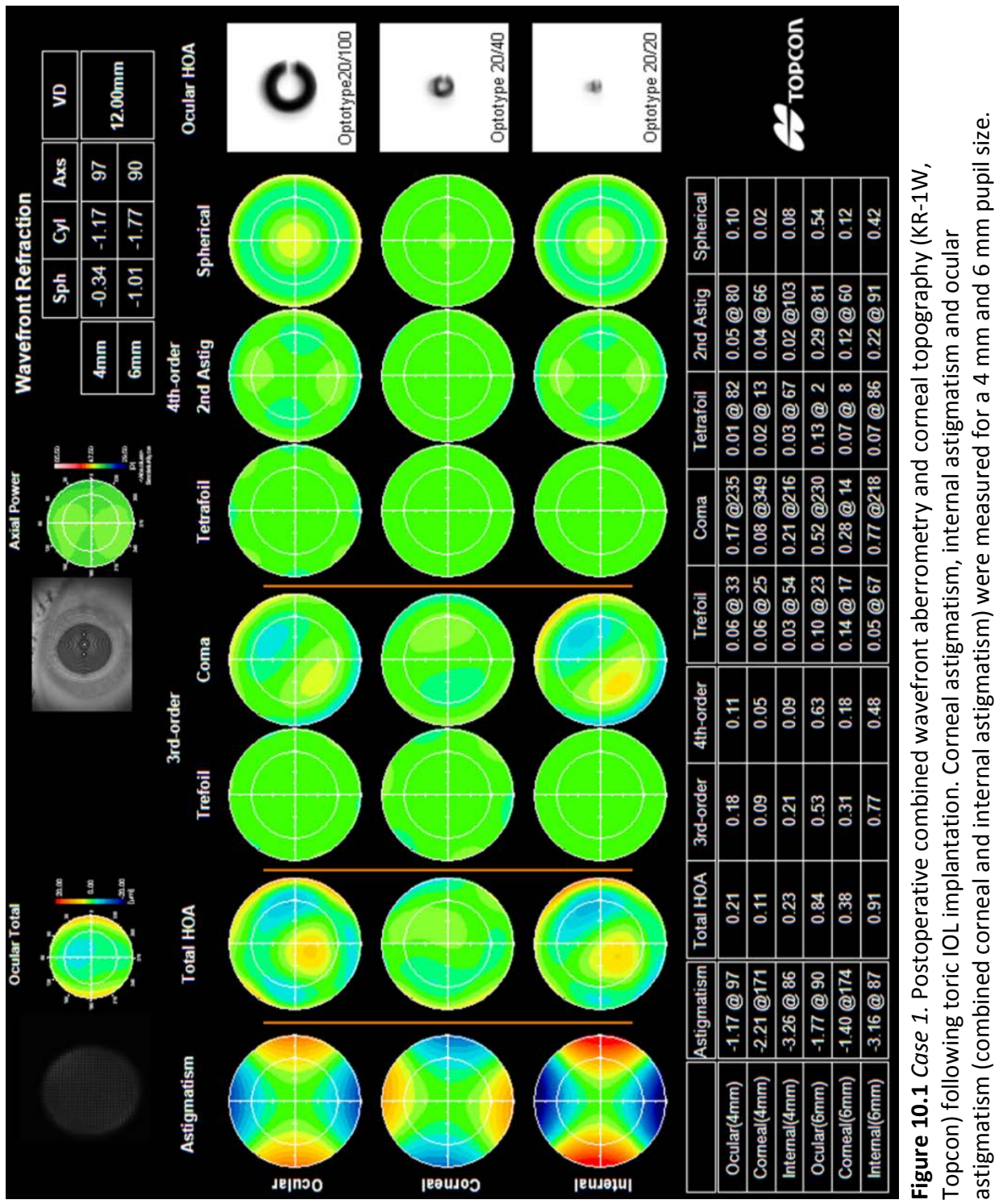


To treat the astigmatism undercorrection, an IOL exchange with a higher cylinder power multifocal toric IOL (SND1T5, cylinder power of 3.00 D) was performed. Postoperatively, the UDVA was 20/20.

\section{Discussion}

In this case report, we presented two patients with residual refractive astigmatism following toric IOL implantation. We believe that a combination of factors is responsible for the overcorrection and undercorrection of astigmatism that occurred in these patients: the effect of the spherical power and ACD in toric IOL calculations ${ }^{1}$, the effect of posterior corneal astigmatism ${ }^{4}$, and the effect of a large pupil size.

Firstly, as shown by Goggin et al., the IOL spherical power and estimated lens position ( $A C D$ plus pachymetry) determine the effective cylinder power of a toric IOL at the corneal plane. ${ }^{1}$ In the first patient, the calculated effective cylinder power at the corneal plane was $2.55 \mathrm{D}$, compared to an estimated power of $2.06 \mathrm{D}$ used by the manufacturer. This effect may partly explain the overcorrection of astigmatism in our first patient.

Secondly, as shown by Koch, the posterior corneal surface affects total corneal astigmatism. The posterior corneal surface acts as a minus lens and is generally steep vertically. It therefore creates a plus power along the horizontal meridian and induces against-the-rule (ATR) corneal astigmatism. ${ }^{4}$ In the first patient with WTR corneal astigmatism, the posterior corneal surface already corrects part of the corneal astigmatism, thereby reducing overall corneal astigmatism. In the second patient, anterior cornea astigmatism showed an ATR configuration. We believe that in this patient, the increase in ATR corneal astigmatism resulted in the undercorrection of astigmatism. According to Koch, this effect may be accounted for in toric IOL calculations by decreasing corneal astigmatism by $0.5 \mathrm{D}$ in patients with WTR astigmatism and increasing corneal astigmatism by $0.3 \mathrm{D}$ in patients with ATR astigmatism. $^{4}$

Thirdly, we believe that the relatively large pupil diameter and the subsequent influence of the prolate or aspherical shape of the cornea also contributed to the overcorrection of astigmatism in the first patient. The normal aspherical shape of the cornea implies that the centre of the cornea is steeper than the periphery. In this patient, corneal astigmatism in a $6 \mathrm{~mm}$ pupil zone was much lower compared to a 4 $\mathrm{mm}$ pupil zone. As a result, the strength of the toric IOL was overpowered by approximately $1 \mathrm{D}$. Various methods may be used to measure corneal astigmatism, including automated keratometry, manual keratometry and corneal topography. ${ }^{5,6}$ 
However, these methods determine corneal astigmatism based on a central 2.0 to 3.0 $\mathrm{mm}$ zone of the cornea. This may be an effective measure of corneal astigmatism in the majority of patients, but it may be inadequate in younger patients with larger pupil diameters. We recommend measuring the pupil diameter in relatively young patients before implanting a toric IOL. If the photopic pupil diameter is larger than $4 \mathrm{~mm}$ we recommend using corneal astigmatism values for a larger zone of the cornea.

Combined wavefront aberrometry and corneal topography can differentiate between aberrations caused by the cornea or by the internal ocular system ${ }^{7}$ and may help to find the source of residual astigmatism. The advantage of the Topcon KR-1W is that corneal topography and aberrometry measurements are performed simultaneously, thereby minimizing potential errors that may be caused by realignment of the eye. $A$ previous study showed that combined aberrometry and corneal topography may be used to determine the postoperative toric IOL alignment axis. ${ }^{8}$ In addition, in our case report, we have used aberrometry to determine the source of residual refractive astigmatism following toric IOL implantation.

In conclusion, unexplained residual refractive astigmatism following toric IOL implantation was the results of multiple factors: the effect of the spherical power and ACD on toric IOL calculations, the effect of posterior corneal astigmatism, and the effect of a large pupil size. The first two issues may be compensated for by improving toric IOL calculations. In addition, we recommend performing pupillometry in relatively young patients who wish to undergo cataract surgery with toric IOL implantation. If the photopic pupil diameter is larger than $4 \mathrm{~mm}$ we recommend to incorporate corneal astigmatism values for a larger zone of the cornea into the toric IOL calculation.

\section{References}

1. Goggin M, Moore S, Esterman A. Outcome of toric intraocular lens implantation after adjusting for anterior chamber depth and intraocular lens sphere equivalent power effects. Arch Ophthalmol. Aug 2011;129(8):998-1003.

2. Visser N, Berendschot TT, Bauer NJ, Jurich J, Kersting O, Nuijts RM. Accuracy of toric intraocular lens implantation in cataract and refractive surgery. J Cataract Refract Surg. Aug 2011;37(8):1394-1402.

3. Shimizu K, Misawa A, Suzuki Y. Toric intraocular lenses: correcting astigmatism while controlling axis shift. J Cataract Refract Surg. Sep 1994;20(5):523-526.
4. Koch DD. Corneal optics for IOL selection: Cracking the code. ASCRS, Charles D. Kelman Innovator's Lecture. Chicago; 2012.

5. Ahmed I, Rocha G, Slomovic AR, et al. Visual function and patient experience after bilateral implantation of toric intraocular lenses. J Cataract Refract Surg. Apr 2010;36(4):609-616.

6. Holland E, Lane S, Horn JD, Ernest P, Arleo R, Miller KM. The AcrySof Toric Intraocular Lens in Subjects with Cataracts and Corneal Astigmatism A Randomized, SubjectMasked, Parallel-Group, 1-Year Study. Ophthalmology. Sep 14 2010;117(11):21042111. 
7. Visser N, Berendschot TT, Verbakel F, Tan AN, de Brabander J, Nuijts RM. Evaluation of the comparability and repeatability of four wavefront aberrometers. Invest Ophthalmol Vis Sci. Nov 4 2010;52(3):1302-1311.
8. Carey PJ, Leccisotti A, McGilligan VE, Goodall EA, Moore CB. Assessment of toric intraocular lens alignment by a refractive power/corneal analyzer system and slitlamp observation. J Cataract Refract Surg. Feb 2010;36(2):222-229. 


\section{Chapter 11}

General discussion 
This thesis shows that toric IOLs provide an effective treatment option to correct corneal astigmatism at the time of cataract surgery. We showed in chapter 5 that bilateral toric IOL implantation resulted in a better uncorrected distance visual acuity, lower residual astigmatism and higher spectacle independency for distance vision, compared with bilateral monofocal IOL implantation. Toric multifocal IOLs offer good uncorrected distance and near visual acuity in patients with cataract and corneal astigmatism (Chapter 7). Also, toric IOLs may be a good option in selected patients with mild to moderate irregular astigmatism due to for example keratoconus (Chapter 9). Additional refinements in preoperative measurement of corneal astigmatism, toric IOL calculation and intraoperative toric IOL alignment may further improve the accuracy of astigmatism correction in the future and are discussed below.

\section{Corneal astigmatism measurement}

A possible source of unexpected residual astigmatism following toric IOL implantation is inaccurate preoperative corneal astigmatism measurement. Hirnschall et al. recently evaluated several factors influencing residual astigmatism following toric IOL implantation and showed that preoperative deviations between keratometric and topographic astigmatism had the largest influence on residual astigmatism. ${ }^{1} \mathrm{We}$ showed in Chapter 2 that the repeatability of keratometric and topographic astigmatism magnitude was 0.14 to $0.18 \mathrm{D}$ with different devices. However, the repeatability of astigmatism meridians was approximately 20 degrees, which is clinically relevant when implanting a toric IOL. To ensure accurate measurements, a series of repeated measurements should be obtained in each patient to ensure that the repeatability of both the magnitude and meridian is acceptable.

More accurate techniques to measure corneal astigmatism preoperatively may further increase the effectiveness of toric IOLs. A new device, the Cassini topographer (iOptics), measures corneal astigmatism using the reflections of 700 multicolour lightemitting diodes which are projected onto the cornea in an asymmetrical pattern. The multiple colours and asymmetrical point sources may make this technique more accurate in irregular corneas. Recent studies compared the repeatability of the Cassini device with other Scheimpflug, Placido-disk and keratometry devices. ${ }^{2}$ Regarding the comparability of these devices, results are contradictory. Klijn et al. found no clinically significant differences between the Cassini and other devices. ${ }^{2}$ Hidalgo et al. found that astigmatism K-values obtained with the Cassini were about $0.4 \mathrm{D}$ higher compared to the Pentacam and limits of agreement were relatively large. ${ }^{3}$ In normal eyes, the reported repeatability in measuring astigmatism magnitude ranges from 0.1 to $0.4 \mathrm{D}$ 
and from 2.3 to 5.5 degrees for astigmatism meridian. ${ }^{2-4}$ Kanellopoulos and Asimellis found a repeatability of $0.89 \pm 1.45 \mathrm{D}$ in measuring the steep meridian in 95 eyes with keratoconus, compared to $0.41 \pm 0.50 \mathrm{D}$ in normal eyes. ${ }^{5}$ Shetty et al. evaluated the repeatability and agreement of different Scheimpflug devices (Pentacam, Gallilei and Sirius) in keratoconus eyes. ${ }^{6}$ The Pentacam showed the best repeatability in measuring anterior and posterior keratometry. The Gallilei and Sirius showed comparable repeatability results (low within-subject coefficient of variation) for lower anterior and posterior K-values. However, in eyes with higher K-values (anterior keratometry >50 D or posterior keratometry <-6 D) , the Gallilei and Sirius resulted in a lower repeatability compared to the Pentacam. ${ }^{6}$ Flynn et al. did report a lower repeatability and reproducibility for Pentacam keratometry values (wider range in 95\% limits of agreement) in patients with advanced keratoconus, compared to patients with early keratoconus. $^{7}$

The posterior cornea may also result in corneal astigmatism measurement errors. Corneal astigmatism is determined by both the anterior and posterior corneal surface. Until recently, total corneal astigmatism was estimated using light reflections or illuminated rings on the anterior corneal surface, and assuming a fixed anterior-toposterior corneal ratio. It was not possible to measure the posterior corneal curvature. Also, the influence of the posterior corneal surface was thought to be negligible since the difference between the refractive indices of the cornea and aqueous are small. New technologies such as the rotating Scheimpflug camera allow to measure both the anterior and posterior corneal surface. As demonstrated by Koch, the posterior cornea acts as a minus lens. ${ }^{8}$ Although the mean magnitude of posterior corneal astigmatism is only approximately $-0.3 \mathrm{D}$, values over $-0.5 \mathrm{D}$ are reported in approximately $10 \%$ of eyes. $^{8-11}$ Also, the magnitude of posterior corneal astigmatism increases with increasing magnitude of anterior corneal astigmatism. ${ }^{12}$ Not taking the posterior cornea into account results in an overestimation in WTR and underestimation in ATR corneal astigmatism. ${ }^{13}$ When selecting a toric IOL, a slight undercorrection should be aimed for in patients with WTR anterior astigmatism, whereas a slight overcorrection should be aimed for in ATR anterior astigmatism. Another option is to use a newer generation toric IOL calculator which predicts posterior corneal astigmatism based on anterior keratometry. ${ }^{14}$ This method has been shown to result in a lower predicted residual astigmatism compared to toric IOL calculations performed by the manufacturer and also compared to calculations based on the measured amount of posterior astigmatism. ${ }^{15}$ However, this method does not compensate for abnormally high posterior astigmatism that may be seen in patients with high anterior astigmatism. 
The question of the minimal amount of corneal astigmatism that can be effectively addressed with a toric IOL is not answered yet. Several toric IOL models are currently available with low cylinder powers (Chapter 1). Toric IOLs with a cylinder power of at least $1.50 \mathrm{D}$ have shown to be effective and result in a better UDVA and lower spectacle independence compared to monofocal IOLs. ${ }^{16-20}$ In the randomized controlled arm of the study of Waltz et al., patients with low amounts of corneal astigmatism ( 0.75 to $1.50 \mathrm{D})$ were randomized for either toric or monofocal IOL implantation. ${ }^{19}$ Postoperatively, UDVA was significantly better in the toric group compared to the control group $\left(0.10 \pm 0.14\right.$ versus $0.16 \pm 0.16$ LogMAR). ${ }^{19}$ However, Spectacle independency was comparable in the toric (83\%) and control groups (71\%). ${ }^{19}$ Toric IOLs are probably less effective in patients with less than $1.25 \mathrm{D}$ of corneal astigmatism due to variations in surgically induced corneal astigmatism, age-related changes from WTR to ATR astigmatism, errors in corneal astigmatism measurement (including the effect of the posterior cornea), errors in toric IOL calculation due to not incorporating the effect of the sphere and estimated lens position. ${ }^{8,12,21}$ Based on current evidence, it appears that a minimal amount of corneal astigmatism of approximately $1.25 \mathrm{D}$ should be present before toric IOL implantation is considered.

\section{Toric IOL power calculation}

The power of the toric IOL may be calculated using a calculation scheme published in the literature ${ }^{22,23}$ or online $e^{14}$, but is most commonly calculated using a calculator program provided by the manufacturer. Most manufacturers currently use a fixed ratio between cylinder power at the IOL plane and corneal plane. However, as shown by Goggin et al, the effective cylinder power of the IOL at the corneal plane is determined by the estimated lens position and spheroequivalent power of the IOL. ${ }^{24}$ Therefore, the relation between cylinder power at the IOL plane and at the corneal plane is not a fixed amount. ${ }^{24,25}$ To calculate the effective cylinder power at the corneal plane, the IOL spherical and cylindrical power are first converted into the two principal lens powers, after which both lens powers are calculated to the corneal plane using a standard vertex formula. The difference between both lens powers at the corneal plane is then used to select the most appropriate IOL cylinder power. ${ }^{26}$ Especially in patients with high myopia or high hyperopia the fixed ratio used by manufactures is incorrect and may result in overcorrection and undercorrection, respectively. ${ }^{27}$

Another factor to consider in toric IOL calculation is the expected (vector) change in corneal astigmatism induced by the incision. As shown in Chapter 1, most toric IOLs require a $2.2 \mathrm{~mm}$ incision for implantation. In our study (Chapter 8 ), the change in 
corneal astigmatism following a $2.2 \mathrm{~mm}$ superior incision was $-0.10 \pm 0.52 \mathrm{D}$ at 12 months postoperatively. This amount was not significantly different from zero. Other studies using a vector analysis to analyse SICA have found values ranging from -0.10 to -0.40 D. ${ }^{18,23,28,29}$ Even though the mean amount of SICA in our study was only $-0.10 \mathrm{D}$, the relatively large standard deviation indicates a large variability. It is not possible to estimate the exact SICA preoperatively, since the patients' biomechanical response of the cornea is unpredictable and depends on many factors including incision location and size, amount of corneal astigmatism, suture use and patient age. ${ }^{30-35}$ The most accurate method for surgeons is to determine their own SICA based on (vector) changes in corneal astigmatism. In patients with irregular astigmatism due to, for example, keratoconus, the SICA may be more unpredictable (Chapter 9). Finally, the test-retest variability of measuring astigmatism magnitudes is 0.14 to $0.18 \mathrm{D}$, which indicates that a proportion of the SICA may be due to test-retest variations (Chapter 2). ${ }^{36}$

\section{Toric IOL alignment}

Every degree of toric IOL misalignment leads to residual astigmatism. Misalignment may be caused by 2 factors: inaccurate alignment of the IOL during surgery; and postoperative rotation of the IOL. The total misalignment of acrylic toric IOLs is generally 2 to 4 degrees. ${ }^{16-18} \mathrm{~A}$ misalignment of more than 10 degrees is an indication for re-alignment and has been reported in 3 to $11 \%$ of eyes for currently used toric IOL models (Chapter 1). In Chapter 4 we showed that the alignment error of a commonly used ink-marking method for toric IOL alignment is 4.9 degrees with a maximum of 11 degrees. Popp et al. compared the accuracy of 4 manual marking techniques and showed an error ranging from 2.3 to 4.7 degrees. ${ }^{37}$ Other disadvantages of ink-marking techniques include possible fading out of the ink marks, horizontal or vertical translocation of the marks or washout of the ink marks at the time of surgery. Currently, new techniques have become available to improve the accuracy of toric IOL alignment. Real-time eye tracking based on iris and blood-vessel characteristics may be used to align toric IOLs. Preoperatively, a detailed image of the eye is captured in which blood-vessels and iris-characteristics are visible. ${ }^{38}$ Simultaneously, keratometry is performed and the location of the steep corneal meridian is shown in this image. Intraoperatively, the preoperative image is matched with the live surgery image from the operating microscope, based on blood-vessel and iris characteristics. An overlay showing the alignment axis is visible in the operating microscope. Elhofi and Helaly have performed a randomized controlled trial comparing this eye-tracking based 
technology with manual ink markings (pendulum marker at the slitlamp). ${ }^{39}$ Postoperatively, the mean misalignment was $2.4 \pm 2.0$ versus $4.3 \pm 2.7$ degrees, respectively. ${ }^{39}$ Vector analysis showed a lower residual astigmatism in the eye-tracking group, however, no significant difference was found in postoperative UDVA: $0.12 \pm$ 0.12 versus $0.18 \pm 0.14$ LogMAR. $^{39}$ A prospectively study performed by Bachernegg et al. reported a mean error of 0 degrees (range 0 to 5 degrees) in aligning toric IOLs using eye-tracking technology. ${ }^{40}$

Intraoperative wavefront aberrometry enables intraoperative measurement of residual refraction. In theory, it allows accurate positioning of toric IOLs, based on live intraoperative residual refractive cylinder results. Fram et al. recently used aphakic intraoperative refractive measurements to estimate IOL sphere power during cataract surgery in patients with a history of refractive laser correction. ${ }^{41}$ They showed promising results with IOL power prediction errors comparable to those obtained with the Haigis-L formula in patients without historical data. However, some issues remain. Huelle et al. could only obtain repeatable intraoperative aberrometry measurements of sufficient quality in $47 \%$ (32/68) eyes during cataract surgery. ${ }^{42}$ In addition, limits of agreement for repeated measurements were large: +0.66 to $-0.69 \mathrm{D} .^{42}$ Based on the acquired intraoperative aberrometry results, only $41 \%$ and $70 \%$ of eyes would achieve a postoperative spherical equivalent of \pm 0.50 and \pm 1.00 , respectively. ${ }^{42} \mathrm{~A}$ retrospective study recently compared toric IOL implantation with and without intraoperative aberrometry. ${ }^{43}$ Aphakic measurements were taken during surgery to determine IOL sphere and cylinder power and pseudophakic measurements were taken to refine axis placement. ${ }^{43}$ Postoperative residual astigmatism was lower in the aberrometry group compared to the non-aberrometry group $(0.46 \pm 0.42 \mathrm{D}$ versus 0.68 $\pm 0.34 \mathrm{D}$, respectively) and more patients achieved an UDVA of $20 / 25$ or better $(67 \%$ versus $39 \%$, respectively). ${ }^{43}$ However, this retrospective study does not address any problems regarding measurement quality or repeatability. Use of an eyelid speculum has been shown to result in clinically significant changes in cylinder magnitude and axis. ${ }^{44}$ Other factors that may affect intraoperative aberrometry are: corneal wound integrity, corneal hydration, intraocular pressure and anterior chamber depth variations. $^{42}$ Intraoperative spherical equivalent correlated only moderately with refraction obtained one week postoperatively (Pearson's correlation coefficient 0.56.). ${ }^{45}$ These results indicate that currently, the quality and accuracy of intraoperative aberrometry in measuring residual refractive cylinder magnitude and axis is insufficiently to be used to align toric IOLs.

Toric IOL misalignment may also be due to postoperative IOL rotation. Exact postoperative IOL rotation can be evaluated using digital images obtained immediately 
postoperatively and several months postoperatively. Weinand et al. showed that the rotation of acrylic IOLs at 6 months postoperatively was 0.9 degree on average with a maximum of 1.8 degrees. $^{46}$ Shah et al. evaluated postoperative IOL rotation using digital images and found a linear correlation between axial length and IOL rotation. ${ }^{47}$ This may be clinically relevant in patients with high axial lengths and presumably large capsular bags. For example, an axial length of $27 \mathrm{~mm}$ was associated with a mean postoperative rotation of 2.5 degrees. ${ }^{47}$ Miyake et al. evaluated toric IOL rotation using digital photographs during a follow-up period of 2 years. ${ }^{48}$ Six of 378 eyes (1.6\%) showed postoperative toric IOL rotation of 20 degrees or more; all of which were eyes with an axial length of $25.0 \mathrm{~mm}$ or longer. ${ }^{48}$ This rotation occurred early postoperatively: 1 day (5 eyes), 1 week ( 1 eye) or 10 days ( 1 eye) postoperatively. ${ }^{48}$ Other factors that may result in higher postoperative IOL rotation are incomplete removal of the ophthalmic viscosurgical device at the end of surgery or a large capsulorrhexis. $^{48-50}$

\section{Conclusion}

This thesis shows that toric IOLs are an effective treatment option in patients with cataract and corneal astigmatism. Based on current evidence, it appears that a minimal amount of corneal astigmatism of $1.25 \mathrm{D}$ should be present before toric IOL implantation is considered. Additional refinements in corneal astigmatism measurement accuracy, toric IOL calculation software, and toric IOL alignment may further improve the efficacy of astigmatism correction with toric IOLs.

\section{References}

1. Hirnschall N, Hoffmann PC, Draschl P, Maedel S, Findl O. Evaluation of factors influencing the remaining astigmatism after toric intraocular lens implantation. J Refract Surg. Jun 2014;30(6):394-400.

2. Klijn S, Reus NJ, Sicam VA. Evaluation of keratometry with a novel Color-LED corneal topographer. I Refract Surg. Apr 2015;31(4):249-256.

3. Hidalgo IR, Rozema JJ, Dhubhghaill SN, Zakaria N, Koppen C, Tassignon MJ. Repeatability and inter-device agreement for three different methods of keratometry: Placido, Scheimpflug, and color LED corneal topography. J Refract Surg. Mar 2015;31(3):176-181.
4. Kanellopoulos AJ, Asimellis G. Distribution and Repeatability of Corneal Astigmatism Measurements (Magnitude and Axis) Evaluated With Color Light Emitting Diode Reflection Topography. Cornea. Aug 2015;34(8):937-944.

5. Kanellopoulos AJ, Asimellis G. Color lightemitting diode reflection topography: validation of keratometric repeatability in a large sample of wide cylindrical-range corneas. Clin Ophthalmol. 2015;9:245-252.

6. Shetty R, Arora V, Jayadev C, et al. Repeatability and agreement of three Scheimpflug-based imaging systems for measuring anterior segment parameters in 
keratoconus. Invest Ophthalmol Vis Sci. Aug 2014;55(8):5263-5268.

7. Flynn TH, Sharma DP, Bunce C, Wilkins MR. Differential precision of corneal Pentacam HR measurements in early and advanced keratoconus. Br J Ophthalmol. Dec 112015.

8. Koch DD, Ali SF, Weikert MP, Shirayama M, Jenkins R, Wang L. Contribution of posterior corneal astigmatism to total corneal astigmatism. J Cataract Refract Surg. Dec 2012;38(12):2080-2087.

9. Nemeth G, Berta A, Lipecz A, Hassan Z, Szalai E, Modis L, Jr. Evaluation of posterior astigmatism measured with Scheimpflug imaging. Cornea. Nov 2014;33(11):12141218.

10. Preussner PR, Hoffmann P, Wahl J. Impact of Posterior Corneal Surface on Toric Intraocular Lens (IOL) Calculation. Curr Eye Res. Sep 26 2014:1-6.

11. Zhang L, Sy ME, Mai H, Yu F, Hamilton DR. Effect of posterior corneal astigmatism on refractive outcomes after toric intraocular lens implantation. J Cataract Refract Surg. Jan 2015;41(1):84-89.

12. Miyake T, Shimizu K, Kamiya K. Distribution of posterior corneal astigmatism according to axis orientation of anterior corneal astigmatism. PLoS One. 2015;10(1):e0117194.

13. Koch DD, Jenkins RB, Weikert MP, Yeu E, Wang L. Correcting astigmatism with toric intraocular lenses: effect of posterior corneal astigmatism. J Cataract Refract Surg. Dec 2013;39(12):1803-1809.

14. Barrett GD. Barrett Toric Calculator. www.ascrs.org/barrett-toric-calculator. Accessed 20-5-2016.

15. Abulafia A, Hill WE, Franchina M, Barrett GD. Comparison of Methods to Predict Residual Astigmatism After Intraocular Lens Implantation. J Refract Surg. Oct 2015;31(10):699-707.

16. Ahmed I, Rocha G, Slomovic AR, et al. Visual function and patient experience after bilateral implantation of toric intraocular lenses. J Cataract Refract Surg. Apr 2010;36(4):609-616.

17. Holland E, Lane S, Horn JD, Ernest P, Arleo R, Miller KM. The AcrySof Toric Intraocular Lens in Subjects with Cataracts and Corneal Astigmatism A Randomized, SubjectMasked, Parallel-Group, 1-Year Study. Ophthalmology. Sep 14 2010;117(11):21042111.
18. Visser N, Beckers HJ, Bauer NJ, et al. Toric vs Aspherical Control Intraocular Lenses in Patients With Cataract and Corneal Astigmatism: A Randomized Clinical Trial. JAMA Ophthalmol. Dec 1 2014;132(12): 1462-1468.

19. Waltz KL, Featherstone K, Tsai L, Trentacost D. Clinical outcomes of TECNIS toric intraocular lens implantation after cataract removal in patients with corneal astigmatism. Ophthalmology. Jan 2015;122(1):39-47.

20. Emesz M, Dexl AK, Krall EM, et al. Randomized controlled clinical trial to evaluate different intraocular lenses for the surgical compensation of low to moderateto-high regular corneal astigmatism during cataract surgery. J Cataract Refract Surg. Dec 2015;41(12):2683-2694.

21. Goggin M, Moore S, Esterman A. Toric Intraocular Lens Outcome Using the Manufacturer's Prediction of Corneal Plane Equivalent Intraocular Lens Cylinder Power. Arch Ophthalmol. Aug 2011;129(8):10041008.

22. Langenbucher A, Viestenz A, Szentmary N, Behrens-Baumann W. Toric intraocular lenses--theory, matrix calculations, and clinical practice. J Refract Surg. Jul 2009;25(7):611-622.

23. Hoffmann PC, Auel S, Hutz WW. Results of higher power toric intraocular lens implantation. J Cataract Refract Surg. Aug 2011;37(8):1411-1418

24. Goggin M, Moore S, Esterman A. Outcome of toric intraocular lens implantation after adjusting for anterior chamber depth and intraocular lens sphere equivalent power effects. Arch Ophthalmol. Aug 2011; 129(8):998-1003.

25. Holladay JT. Exact toric intraocular lens calculations using currently available lens constants. Arch Ophthalmol. Jul 1 2012; 130(7):946-947.

26. Novis C. Astigmatism and the toric intraocular lens and other vertex distance effects. Surv Ophthalmol. Nov-Dec 1997; 42(3):268-270.

27. Savini G, Hoffer KJ, Ducoli P. A new slant on toric intraocular lens power calculation. $J$ Refract Surg. May 2013;29(5):348-354.

28. Visser N, Ruiz-Mesa R, Pastor F, Bauer NJ, Nuijts RM, Montes-Mico R. Cataract surgery with toric intraocular lens implantation in patients with high corneal astigmatism. $J$ 
Cataract Refract Surg. Aug 2011;37(8):14031410.

29. Ernest P, Potvin R. Effects of preoperative corneal astigmatism orientation on results with a low-cylinder-power toric intraocular lens. J Cataract Refract Surg. Apr 2011;37(4):727-732.

30. Kohnen T, Dick B, Jacobi KW. Comparison of the induced astigmatism after temporal clear corneal tunnel incisions of different sizes. J Cataract Refract Surg. Jul 1995;21(4):417-424.

31. Lyhne N, Corydon L. Two year follow-up of astigmatism after phacoemulsification with adjusted and unadjusted sutured versus sutureless $5.2 \mathrm{~mm}$ superior scleral incisions. J Cataract Refract Surg. Dec 1998; 24(12):1647-1651.

32. Storr-Paulsen A, Madsen $H$, Perriard A. Possible factors modifying the surgically induced astigmatism in cataract surgery. Acta Ophthalmol Scand. Oct 1999;77(5):548551.

33. Tejedor J, Murube J. Choosing the location of corneal incision based on preexisting astigmatism in phacoemulsification. Am J Ophthalmol. May 2005;139(5):767-776.

34. Borasio E, Mehta JS, Maurino V. Surgically induced astigmatism after phacoemulsification in eyes with mild to moderate corneal astigmatism: temporal versus onaxis clear corneal incisions. J Cataract Refract Surg. Apr 2006;32(4):565-572.

35. Masket S, Wang L, Belani S. Induced astigmatism with 2.2 - and $3.0-\mathrm{mm}$ coaxial phacoemulsification incisions. J Refract Surg. Jan 2009;25(1):21-24.

36. Goggin M, Patel I, Billing K, Esterman A. Variation in surgically induced astigmatism estimation due to test-to-test variations in keratometry. J Cataract Refract Surg. Oct 2010;36(10):1792-1793.

37. Popp N, Hirnschall N, Maedel S, Findl O. Evaluation of 4 corneal astigmatic marking methods. J Cataract Refract Surg. Dec 2012;38(12):2094-2099.

38. Visser N, Berendschot TT, Bauer NJ, Jurich J, Kersting $\mathrm{O}$, Nuijts RM. Accuracy of toric intraocular lens implantation in cataract and refractive surgery. J Cataract Refract Surg. Aug 2011;37(8):1394-1402.

39. Elhofi AH, Helaly HA. Comparison Between Digital and Manual Marking for Toric Intraocular Lenses: A Randomized Trial. Medicine (Baltimore). Sep 2015;94(38): e1618.
40. Bachernegg A, Ruckl T, Riha W, Grabner G, Dexl AK. Rotational stability and visual outcome after implantation of a new toric intraocular lens for the correction of corneal astigmatism during cataract surgery. J Cataract Refract Surg. Sep 2013;39(9):13901398.

41. Fram NR, Masket S, Wang L. Comparison of Intraoperative Aberrometry, OCT-Based IOL Formula, Haigis-L, and Masket Formulae for IOL Power Calculation after Laser Vision Correction. Ophthalmology. Jun 2015;122 (6):1096-1101.

42. Huelle JO, Druchkiv V, Habib NE, Richard G, Katz T, Linke SJ. Intraoperative aberrometrybased aphakia refraction in patients with cataract: status and options. $\mathrm{Br} J$ Ophthalmol. Feb 182016.

43. Hatch KM, Woodcock EC, Talamo JH. Intraocular lens power selection and positioning with and without intraoperative aberrometry. J Refract Surg. Apr 2015; 31(4):237-242.

44. Stringham J, Pettey J, Olson RJ. Evaluation of variables affecting intraoperative aberrometry. J Cataract Refract Surg. Mar 2012;38(3):470-474.

45. Chen M. Correlation between ORange (Gen 1, pseudophakic) intraoperative refraction and 1-week postcataract surgery autorefraction. Clin Ophthalmol. 2011;5:197-199.

46. Weinand $F$, Jung $A$, Stein A, Pfutzner A, Becker R, Pavlovic S. Rotational stability of a single-piece hydrophobic acrylic intraocular lens: new method for high-precision rotation control. J Cataract Refract Surg. May 2007;33(5):800-803.

47. Shah GD, Praveen MR, Vasavada AR, Vasavada VA, Rampal G, Shastry LR. Rotational stability of a toric intraocular lens: Influence of axial length and alignment in the capsular bag. J Cataract Refract Surg. Jan 2011;38(1):54-59.

48. Miyake T, Kamiya K, Amano R, lida $Y$, Tsunehiro S, Shimizu K. Long-term clinical outcomes of toric intraocular lens implantation in cataract cases with preexisting astigmatism. J Cataract Refract Surg. Oct 2014;40(10):1654-1660.

49. Hyon JY, Yeo HE. Rotational stability of a single-piece hydrophobic acrylic intraocular lens during removal of ophthalmic viscosurgical devices. Am J Ophthalmol. Feb 2010;149(2):253-257 e251. 
50. Torquetti L. Toric intraocular lens rotation related to the capsulorhexis. I Cataract Refract Surg. Feb 2015;41(2):483. 


\section{Chapter 12}

Valorisatie addendum 


\section{Valorisatie}

Kennisvalorisatie is het proces van waarde creatie uit kennis, door kennis geschikt en/of beschikbaar te maken voor economische en/of maatschappelijke benutting en te vertalen in concurrerende producten, diensten, processen en nieuwe bedrijvigheid. ${ }^{1}$ Kort gezegd: kennisvalorisatie is het benutten van wetenschappelijke kennis in de praktijk.

\section{Cataract chirurgie}

Cataract (staar) is een veel voorkomende aandoening waarbij een vertroebeling van de ooglens optreedt. Hierdoor ontstaat geleidelijk een slechter zicht en uiteindelijk, indien dit niet wordt behandeld, blindheid aan beide ogen. Wereldwijd is cataract de meest voorkomende oorzaak van blindheid: de World Health Organization (WHO) schat dat $50 \%$ van de blindheid wereldwijd veroorzaakt wordt door cataract. ${ }^{2,3}$ Dit komt overeen met 20 miljoen blinde mensen wereldwijd. Naast blindheid is cataract ook een van de meest voorkomende oorzaken van slechtziendheid (visus slechter dan 0,3). ${ }^{2}$ De prevalentie van cataract neemt toe op oudere leeftijd. In een Nederlandse populatie is $18 \%$ van de bevolking in de leeftijd 55 tot 74 jaar slechtziend door cataract. ${ }^{4}$ Bij mensen ouder dan 74 jaar is dit zelfs 35\% tot 42\%. ${ }^{4}$ Naar schatting waren er in 2011 ongeveer 942.600 mensen in Nederland met enige vorm van cataract. ${ }^{5}$ In de periode 1991-2011 was er een sterke toename van het aantal mensen met cataract in Nederland: in deze periode werd er een verdubbeling in het aantal patiënten met cataract gemeten. ${ }^{5}$ Door de toenemende vergrijzing zal het aantal patiënten met cataract waarschijnlijk verder toenemen.

Tegenwoordig kan cataract behandeld worden door de vertroebelde ooglens operatief te verwijderen en daarvoor in de plaats een intraoculaire kunstlens te plaatsen. Door de toenemende vergrijzing in Nederland is het aantal cataractoperaties toegenomen van 80.000 in 1998 tot 180.000 ingrepen in $2013 .{ }^{6}$ Figuur 1 laat per land in Europa het aantal cataractoperaties zien per 100.000 inwoners. Nederland neemt met 880 cataractoperaties per 100.000 inwoners een middenpositie in binnen Europa.

Volgens de Nederlandse Zorgautoriteit bedroeg de totale omzet in de oogheelkunde in $2011 € 606$ miljoen waarvan €230 miljoen, ongeveer 40\%, aan cataract gespendeerd werd. $^{7}$ De kosten van een cataractoperatie variëren in Nederland van 800 tot 1300 euro per oog. In Figuur 2 ziet u een vergelijking van de kosten van cataractoperaties in Nederland, vergeleken met andere landen. In 2012 was de gemiddelde kostprijs van 
een cataractoperatie in Nederland (\$1534, overeenkomend met $€ 1219$ ) laag vergeleken met andere landen.

Naast de kostenaspecten is het ook van belang om de effecten van cataractoperaties op de kwaliteit van leven mee te nemen. Een cataractoperatie aan het eerste oog leidt bijvoorbeeld tot minder valincidenten op oudere leeftijd., ${ }^{8,9}$

\section{Patiënten met astigmatisme}

Tegenwoordig heeft de patiënt keuze uit vele verschillende intraoculaire kunstlenzen. De keuze van de geschiktste kunstlens is afhankelijk van de voorkeur van de patiënt en de anatomie van het oog. Door het merendeel van de patiënten wordt gekozen voor een monofocale kunstlens. Monofocaal wil zeggen dat lichtstralen tot één punt gebroken worden op het netvlies. Meestal wordt gekozen voor een scherpe vertevisus en zal er postoperatief een bril nodig zijn om te kunnen lezen.

Ongeveer $20 \%$ van de patiënten met cataract heeft ook een substantiële hoeveelheid cornea astigmatisme. ${ }^{10,11}$ Bij patiënten met cornea astigmatisme heeft de cornea een abnormale kromming, waardoor lichtstralen in één meridiaan anders worden gebroken dan in de meridiaan loodrecht hierop. Hierdoor vallen de lichtstralen niet samen op het netvlies en ontstaat er een onscherp beeld. De standaardbehandeling bij

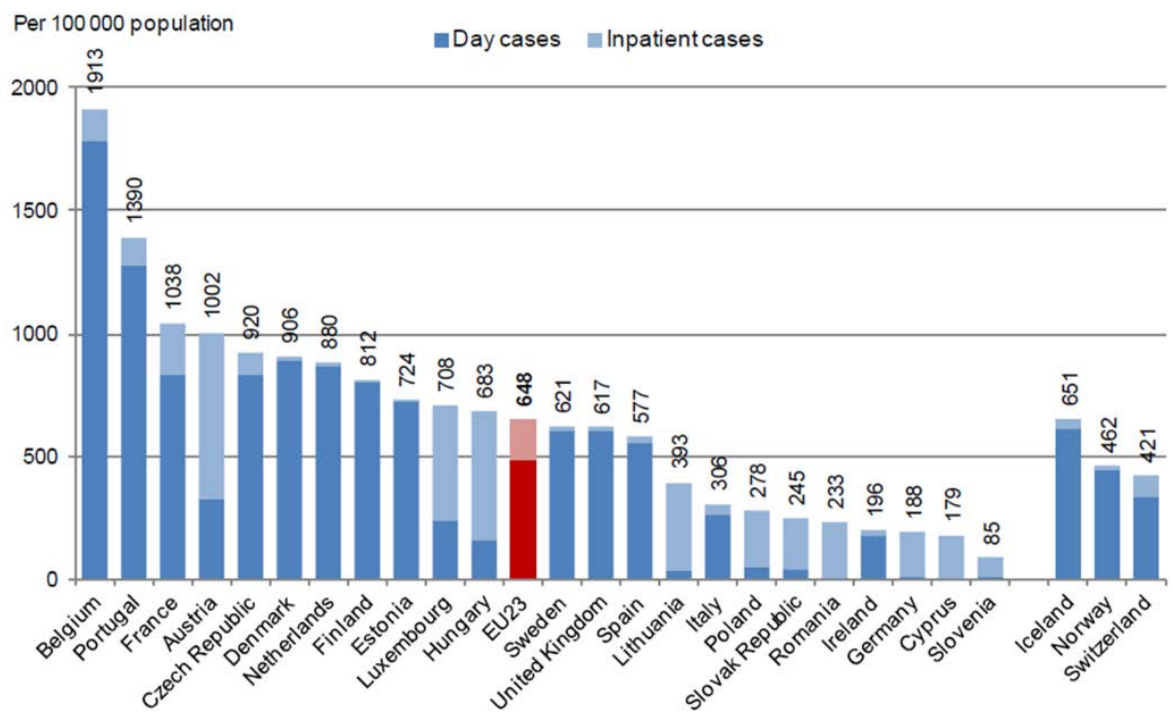

Figuur 12.1 Aantal cataractoperaties per 100.000 inwoners in Europa. Bron: OECD Health Data 2012; Eurostat Statistics Database. 


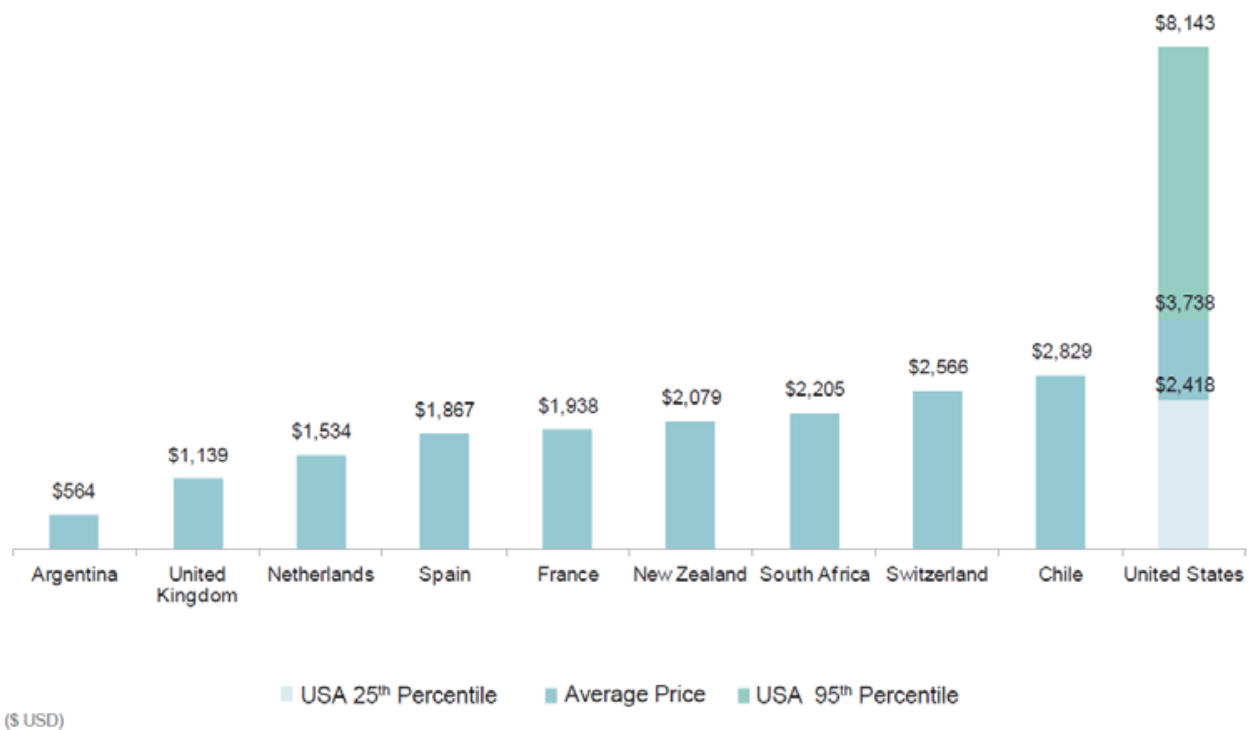

Figuur 12.2 Kosten van cataractoperaties in verschillende landen binnen en buiten Europa. Bron: International Federation of Health Plans - 2013 Comparative Price Report.

patiënten met cataract en astigmatisme bestaat uit het vergruizen en opzuigen van de lens en implanteren van een monofocale kunstlens. Het astigmatisme wordt daarbij niet behandeld. Postoperatief is er voor een scherpe vertevisus een bril nodig om het astigmatisme te corrigeren. Patiënten hebben tevens een leesbril nodig.

Een recente innovatie op het gebied van cataractoperaties is de ontwikkeling van torische kunstlenzen. Deze torische kunstlenzen kunnen bij patiënten met cornea astigmatisme worden gebruikt om de vormafwijking van de cornea te compenseren. Torische lenzen bieden patiënten met cornea astigmatisme daarom de mogelijkheid om een optimale visus bij vertezien te behalen zonder brilcorrectie. Wij hebben een gerandomiseerde klinische studie uitgevoerd om de effectiviteit en de veiligheid van torische kunstlenzen te vergelijken met standaard monofocale kunstlenzen.

De resultaten van dit proefschrift laten zien dat na gebruik van torische kunstlenzen ruim $80 \%$ van de patiënten brilonafhankelijk is voor vertezien. Patiënten met torische kunstlenzen hebben verder een significant betere ongecorrigeerde visus bij vertezien en een lager refractie astigmatisme. Met betrekking tot de patiëntveiligheid is het complicatieprofiel van torische kunstlenzen vergelijkbaar met monofocale kunstlenzen.

Bij patiënten die tijdens de cataractoperatie een torische kunstlens hebben gekregen kan een goede leesvisus worden bereikt door het gebruik van een goedkope leesbril 
(kostprijs glazen vanaf $€ 10$ ). Dit voorkomt de aanschaf van dure multi- of bifocale brillen (kostprijs glazen vanaf €250) waarin een astigmatisme correctie en een correctie voor lezen en vertezien is verwerkt. Torische kunstlenzen zijn vanwege extra preoperatieve onderzoeken, de meerprijs van de kunstlens en extra tijd tijdens de operatie wel een duurdere behandeling dan het gebruik van monofocale kunstlenzen. Wij hebben daarom tevens een kosten-effectiviteitsanalyse uitgevoerd om te bepalen of de behandeling met torische kunstlenzen kosteneffectief is ten opzicht van de standaard behandeling met monofocale kunstlenzen. ${ }^{12}$ Uit deze kosteneffectiviteitsanalyse is gebleken dat de kosten van brilaanschaf $€ 349$ in de monofocale groep en $€ 179$ in de torische groep waren. De kosten van het implanteren van torische kunstlenzen waren hoger in vergelijking met monofocale kunstlenzen, waardoor het gebruik van torische kunstlenzen niet kosteneffectief is vergeleken met monofocale kunstlenzen.

Patiënten met cataract en cornea astigmatisme hebben tegenwoordig ook de optie om te kiezen voor multifocaal torische kunstlenzen. Multifocale kunstlenzen zijn enkele jaren geleden ontwikkeld om zonder brilcorrectie een scherpe vertevisus en leesvisus te behalen. Door de speciale vorm van deze kunstlenzen worden beelden van verschillende afstanden scherp op de retina geprojecteerd. Multifocaal torische kunstlenzen zijn geschikt voor mensen met cornea astigmatisme die na een staaroperatie graag brilonafhankelijk voor vertezien en lezen willen worden. Er zijn op dit moment verschillende typen multifocale torische kunstlenzen beschikbaar. Dit proefschrift laat zien dat na gebruik van diffractieve multifocaal torische kunstlenzen (AT LISA kunstlens) 95\% van de patiënten brilonafhankelijk was voor verte zien en $79 \%$ voor lezen. Nadelen van dit type kunstlenzen zijn met name verlies aan contrast en visuele bijverschijnselen als halo's en verblinding door felle lichtbronnen.

\section{Doelgroepen implementatie}

\section{Verzekeraars:}

Het standpunt van het Zorginstituut Nederland (voorheen College voor Zorgverzekeringen; CVZ) uit 2010 ten aanzien van torische kunstlenzen bij patiënten met cataract en astigmatisme was dat behandeling van cataract en astigmatisme door het plaatsen van torische kunstlenzen geen zorg was conform de stand van de wetenschap en praktijk. ${ }^{13}$ De reden hiervoor was dat er te weinig vergelijkende wetenschappelijke studies beschikbaar waren en de effectiviteit van torische kunstlenzen niet was aangetoond. Wij hebben op basis van de resultaten van onze gerandomiseerde studie (Hoofdstuk 5) het Zorginstituut Nederland aanbevolen om het 
standpunt uit 2010 ten aanzien van torische kunstlenzen te actualiseren. Onze aanbeveling was om bij patiënten met cornea astigmatisme de kosten van de standaard cataractoperatie te vergoeden (basiszorg) en de meerprijs van torische kunstlenzen zelf door patiënten te laten bijbetalen. Patiënten kunnen op deze manier zelf de afweging maken tussen de hogere kosten van de torische kunstlenzen en de besparing in de postoperatieve brilkosten. Het Zorginstituut Nederland heeft onze aanbeveling overgenomen en constateert dat bij patiënten met cataract en astigmatisme het gebruik van torische kunstlenzen voldoet aan de stand van de wetenschap en praktijk. Dit standpunt is per april 2014 aangepast. $^{14}$

Patiënten met cataract en een zeer hoog cornea astigmatisme (hoger dan 4,5 D) of met keratoconus (Krumeich klasse 1 of 2) kunnen onvoldoende gecorrigeerd worden met standaard monofocale kunstlenzen. Brilgebruik bij zeer hoog cornea astigmatisme tast de beeldkwaliteit aan en leidt tot optische vervormingen. Patiënten kunnen wegens een hoog cornea astigmatisme praktische problemen ervaren als zij zijn aangewezen op een postoperatieve brilcorrectie. Het Zorginstituut Nederland heeft daarom in de nieuwe richtlijn opgenomen dat deze patiënten 'redelijkerwijze zijn aangewezen' op torische kunstlenzen voor de behandeling van cataract met astigmatisme. De behandeling van deze patiënten wordt daarom volledig vergoed uit de basisverzekering. ${ }^{14}$

Het gebruik van multifocale kunstlenzen tijdens cataractoperaties voldoet sinds 2011 aan de stand van de wetenschap en praktijk. ${ }^{15}$ De kosten van de cataract operatie worden vergoed als basiszorg. De meerprijs van multifocale kunstlenzen wordt betaald door de patiënt. Patiënten kunnen op deze manier zelf de afweging maken tussen de hogere kosten van multifocale kunstlenzen ten opzichte van brilonafhankelijkheid.

\section{Beroepsbelangenverenigingen:}

De resultaten van dit proefschrift zijn in 2012, 2013 en 2014 gepresenteerd op het jaarlijkse congres van het Nederlands Oogheelkundig Gezelschap (NOG) en in 2012 op het jaarlijkse congres van de Nederlandse Intraoculaire Implant Club (NIOIC). Het NOG en het NIOIC zijn beroepsbelangenverenigingen van oogartsen in Nederland. Tevens zijn de resultaten uit dit proefschrift in 2012, 2013 en 2014 gepresenteerd op het congres van de European Society of Cataract and Refractive Surgeons (ESCRS).

In de huidige Cataract Richtlijn van het NOG uit 2013 wordt aanbevolen om patiënten met cataract en cornea astigmatisme voorafgaand aan een cataractoperatie voorlichting te geven over de keuze voor torische kunstlenzen. ${ }^{16}$ Deze richtlijn dient als leidraad voor alle oogartsen in Nederland. Naar schatting worden torische kunstlenzen op dit moment bij 3 tot $6 \%$ van alle cataractoperaties in Nederland gebruikt. ${ }^{7}$ 
Patiënten:

Alle patiënten die aan cataract geopereerd worden ondergaan preoperatief een aslengte-meting om de benodigde sterkte van de kunstlens te bepalen. Bij deze meting wordt ook bepaald of patiënten een substantiële hoeveelheid (meer dan 1,25 D) cornea astigmatisme hebben en mogelijk baat hebben bij torische kunstlenzen. Zoals beschreven in de huidige Cataract Richtlijn krijgen patiënten voorafgaand aan de staaroperatie voorlichting over de verschillende kunstlenzen. Indien zij een substantiële hoeveelheid cornea astigmatisme hebben zullen torische kunstlenzen ook besproken worden.

Patiënten met cataract en cornea astigmatisme die kiezen voor torische kunstlenzen hebben postoperatief meestal (in $80 \%$ van de gevallen) geen bril nodig voor vertezien. Zonder bril zien deze patiënten significant beter in de verte dan patiënten met standaard monofocale kunstlenzen. Met bril zien patiënten met torische kunstlenzen even goed als patiënten met standaard monofocale kunstlenzen. Postoperatief kan na torische kunstlens implantatie een goede leesvisus worden bereikt door het gebruik van een goedkope leesbril (kostprijs glazen gemiddeld €179). Dit voorkomt de aanschaf van duurdere multi- of bifocale brillen (kostprijs glazen gemiddeld €349) waarin een astigmatisme correctie en een correctie voor lezen en vertezien is verwerkt. Patiënten kunnen op deze manier zelf de afweging maken tussen de hogere kosten van de torische kunstlenzen en de besparing in de postoperatieve brilkosten.

\section{Referenties}

1. Rapport Waardevol: Indicatoren voor valorisatie. Utrecht: Technologiestichting STW, Rathenau Instituut en Technopolis; 2011.

2. World Health Organization. Prevention of Blindness and Visual Impairment. Causes of blindness and visual impairment [www.who.int]. Accessed 5-11-2015.

3. Resnikoff S, Pascolini D, Etya'ale D, et al. Global data on visual impairment in the year 2002. Bull World Health Organ. Nov 2004;82(11):844-851.

4. Klaver CC, Wolfs RC, Vingerling JR, Hofman A, de Jong PT. Age-specific prevalence and causes of blindness and visual impairment in an older population: the Rotterdam Study. Arch Ophthalmol. May 1998;116(5):653658.
5. Rijksinstituut voor Volksgezondheid en Milieu. Volksgezondheid en Zorg. Gezichtsstoornissen [www.volksgezondheid enzorg.info]. Accessed 5-11-2015.

6. Henry Y. Cataract Kwaliteitsregistratie. Nederlands Oogheelkundig Gezelschap. Groningen; 2015.

7. Nuijts RMMA. Eye on innovation: Inauguration lecture. Maastricht 26-092014.

8. Gillespie LD, Robertson MC, Gillespie WJ, et al. Interventions for preventing falls in older people living in the community. Cochrane Database Syst Rev. 2012(9):CD007146.

9. Karlsson MK, Vonschewelov T, Karlsson C, Coster M, Rosengen BE. Prevention of falls in the elderly: a review. Scand J Public Health. Jul 2013;41(5):442-454. 
10. Ferrer-Blasco T, Montes-Mico R, Peixoto-deMatos SC, Gonzalez-Meijome JM, Cervino A. Prevalence of corneal astigmatism before cataract surgery. J Cataract Refract Surg. Jan 2009;35(1):70-75.

11. Hoffmann PC, Hutz WW. Analysis of biometry and prevalence data for corneal astigmatism in 23,239 eyes. J Cataract Refract Surg. Sep 2010;36(9):1479-1485.

12. Simons RWP, Visser $\mathrm{N}$, van den Biggelaar FJHM, et al. Trial-based cost-effectiveness analysis of toric versus monofocal intraocular lenses in cataract patients with bilateral corneal astigmatism. Submitted. 2016.
13. den Dekker J. Plaatsing van torische lenzen bij cataract en astigmatisme - Standpunt CVZ. College voor zorgverzekeringen. [http://www.cvz.nl].

14. Standpunt torische lenzen bij staar met astigmatisme. Zorginstituut Nederland. [www.zorginstituutnederland.nl]. Accessed 20-6-2016.

15. Multifocale en accommoderende lenzen bij staaroperatie. College voor zorgverzekeringen. [www.zorginstituut nederland.nl]. Accessed 5-11-2015.

16. Richtlijn Cataract. [http://www.oogheel kunde.org/professionals/evidence-basedrichtlijnen]. Accessed 22- 6-2016. 


\section{Summary/ Samenvatting}




\section{Summary}

Approximately 20 to $30 \%$ of patients with cataract have a substantial amount of corneal astigmatism. Toric intraocular lenses (IOLs) allow to correct corneal astigmatism at the time of cataract surgery and offer patients spectacle independence for distance vision. The aim of this thesis is to evaluate the use of toric IOLs in cataract surgery. In addition, we evaluated multiple factors that may further optimize outcomes with these IOLs.

In Chapter 1, we provide a historical overview on the development of toric IOLs. Over the years, many improvements have been made regarding IOL design and material. We discuss practical issues regarding patient selection, IOL calculation and surgical techniques for toric IOL alignment. This chapter also provides an overview of currently available toric and multifocal toric IOLs. Several randomized controlled studies have shown that toric IOL implantation is a safe and effective treatment option to correct corneal astigmatism during cataract surgery.

In Chapter 2, we compare corneal astigmatism measurements obtained by different methods: automated keratometry measured by three different devices (IOLMaster, Carl Zeiss Meditec; Lenstar, Haag Streit; and SMI Reference Unit, Sensomotoric Instruments), manual keratometry (Javal-Schiötz, Rodenstock), Placido disk videokeratoscopy (KR-1W, Topcon) and Scheimpflug imaging (Pentacam, Oculus Optikgeräte). Except for equivalent $\mathrm{K}$ values obtained by Scheimpflug imaging, measurements obtained by different devices were comparable. The repeatability of astigmatism magnitudes was acceptable; however, the repeatability of astigmatism meridians was less good. We therefore advise to obtain multiple astigmatism measurements per patient to ensure that both the astigmatism magnitude and meridians are reproducible.

In Chapter 3 we compare ocular and corneal aberrations measured with four different aberrometers: Hartmann-Shack technology (Irx3, Imagine eyes; and Keratron, Optikon), ray-tracing technology (iTrace, Tracey technologies) and automated retinoscopy (OPD-scan, Nidek). Ocular and corneal aberrations were not comparable when measured with these different devices. Since no golden standard is available, it is unclear which device is most accurate. Hartmann-Shack aberrometry showed the best repeatability in measuring ocular aberrations and ray-tracing aberrometry in measuring corneal aberrations. 
Chapter 4 evaluates the accuracy of a commonly used manual 3-step procedure for toric alignment. Orienting the toric IOL with great accuracy is necessary in all patients to achieve the optimum astigmatism correction. We analysed all 3 steps for toric IOL implantation: reference axis marking, alignment axis marking and IOL alignment. Together, these 3 errors lead to a mean total error in toric IOL alignment of almost 5 degrees. This results in residual astigmatism of $17 \%$ and is especially relevant if a high cylinder power toric IOL is used.

In the following chapters we evaluate clinical outcomes following toric IOL implantation. Chapter $\mathbf{5}$ describes the results of a randomized controlled trial comparing spectacle use following bilateral toric versus monofocal IOL implantation (control group) in patients with cataract and corneal astigmatism. Following bilateral toric IOL implantation, $84 \%$ of patients were spectacle independent for distance vision, compared to $31 \%$ in the control group. Patients in the toric IOL group had better uncorrected distance visual acuity (UDVA) and lower residual refractive astigmatism. No differences were found in contrast sensitivity, higher-order aberrations or refractive error-related quality of life.

Chapter 6 describes a clinical study in which the effectiveness of toric IOLs in correcting high amounts of corneal astigmatism is evaluated. Preoperatively, mean corneal astigmatism was $3.84 \mathrm{D}$. Postoperatively, half of patients achieved an UDVA of $20 / 30$ or better and residual refractive astigmatism was less than $1.0 \mathrm{D}$ in about $80 \%$ of eyes. These results show that toric IOLs are effective in correcting high amounts of corneal astigmatism.

Chapter 7 evaluates the clinical outcomes following multifocal toric IOL implantation. These IOLs allow patients with cataract and corneal astigmatism to achieve spectacle independency at both distance and near. Spectacle independency for distance and near vision was achieved by $95 \%$ and $79 \%$ of patients, respectively. Multifocal toric IOL implantation resulted in good distance and near visual outcomes and acceptable intermediate visual outcomes.

In Chapter 8 we determine the efficacy of astigmatism correction following toric IOL implantation using a vector analysis. We evaluate the use of toric IOLs in 3 clinical settings: toric IOLs in cataract surgery; toric phakic IOLs in refractive surgery; and toric phakic IOLs to correct post-keratoplasty (PKP) astigmatism. Use of toric IOLs in cataract 
surgery resulted in a mean residual astigmatism of $0.37 \mathrm{D}$, and an index of success of 0.14 . The index of success is a relative measure of success and preferably zero. Following toric phakic IOL implantation, overall residual astigmatism was approximately $0.60 \mathrm{D}$ and the index of success was 0.32 (Artiflex phakic) and 0.18 (Artisan phakic). In PKP eyes, residual astigmatism was $1.56 \mathrm{D}$ and the index of success 0.28. Incorporating surgically induced corneal astigmatism into toric phakic IOL power calculations may further increase their effectiveness.

Chapter $\mathbf{9}$ and 10 describe the use of toric IOLs in special cases. In Chapter $\mathbf{9}$, cataract surgery with toric IOL implantation was evaluated in two patients with irregular corneal astigmatism due to keratoconus. We report that toric IOLs can be used to correct irregular astigmatism and improve visual functioning in patients with mild to moderate amounts of stable keratoconus. In Chapter $\mathbf{1 0}$ we present two patients with unexpected residual astigmatism following toric IOL implantation. Residual astigmatism following toric IOL implantation may be caused by multiple factors: IOL misalignment, the effect of the spherical power and anterior chamber depth on toric IOL calculations, the effect of posterior corneal astigmatism, and the effect of a large pupil size. Improving toric IOL calculations may compensate for the effective cylinder power and posterior corneal astigmatism. We recommend to perform pupillometry in relatively young patients who wish to undergo toric IOL implantation. 


\section{Samenvatting}

Ongeveer 20 tot $30 \%$ van alle patiënten met cataract heeft ook een substantiële hoeveelheid cornea astigmatisme. Torische intraoculaire lenzen (IOLs) bieden de mogelijkheid om tijdens een cataractoperatie cornea astigmatisme te corrigeren. Postoperatief kunnen patiënten zonder bril een optimale vertevisus bereiken. Het doel van dit proefschrift is om het gebruik van torische IOLs in cataractchirurgie te evalueren. Tevens hebben we verschillende factoren geanalyseerd die de uitkomsten met deze IOLs mogelijk nog verder kunnen optimaliseren.

Hoofdstuk 1 geeft een overzicht van de ontwikkeling van torische IOLs. In de loop der jaren zijn er vele aanpassingen geweest in het ontwerp en materiaal van deze lenzen. We bespreken praktische zaken aangaande patiënt selectie, IOL berekening en chirurgische technieken voor het plaatsen van deze lenzen. Dit hoofdstuk geeft verder een overzicht van studies in de wetenschappelijke literatuur waarin torische IOLs en multifocale torische IOLs zijn onderzocht. Enkele gerandomiseerde klinische studies in de literatuur tonen aan dat torische IOL implantatie een veilige en effectieve behandeling is om cornea astigmatisme te corrigeren tijdens cataractchirurgie.

In Hoofdstuk 2 vergelijken we verschillende methoden om cornea astigmatisme te meten: geautomatiseerde keratometrie gemeten met drie verschillende apparaten (IOLMaster, Carl Zeiss Meditec; Lenstar, Haag Streit; en SMI Reference Unit, Sensomotoric Instruments), handmatige keratometrie (Javal-Schiötz, Rodenstock), Placido disk videokeratoscopie (KR-1W, Topcon) en Scheimpflug imaging (Pentacam, Oculus Optikgeräte). Cornea astigmatisme waardes gemeten met verschillende apparaten waren goed vergelijkbaar, behalve equivalent $\mathrm{K}$ waardes gemeten met Scheimpflug imaging. De reproduceerbaarheid in het meten van de astigmatisme grootte was met alle apparaten acceptabel. Echter de reproduceerbaarheid in het meten van de astigmatisme richting (meridiaan) was minder goed. Wij adviseren daarom om per patiënt meerdere metingen te verrichten en erop te letten dat de astigmatisme grootte en meridiaan reproduceerbaar zijn.

In Hoofdstuk 3 vergelijken we verschillende aberrometers om oculaire en corneale aberraties te meten. We vergelijken Hartmann-Shack technologie (Irx3, Imagine eyes; en Keratron, Optikon), ray-tracing technologie (iTrace, Tracey technologies) en geautomatiseerde retinoscopie (OPD-scan, Nidek). De resultaten van deze studie laten zien dat oculaire en corneale aberraties gemeten met verschillende apparaten niet 
goed vergelijkbaar zijn. Aangezien er geen gouden standaard is, is onbekend welk apparaat het nauwkeurigst meet. Hartmann-Schack aberrometrie heeft de beste reproduceerbaarheid in meten van oculaire aberraties en ray-tracing aberrometrie in het meten van corneale aberraties.

In Hoofdstuk 4 wordt de nauwkeurigheid van een veel gebruikte handmatige markeringstechniek voor het implanteren van torische IOLs onderzocht. Voor een optimale astigmatisme correctie is het van belang dat de torische IOL nauwkeurig op de juiste as wordt geplaatst. We hebben alle stappen voor torische IOL implantatie geanalyseerd: markeren van de referentie as, markeren van de implantatie as en torische IOL implantatie. Deze 3 stappen leiden samen tot een gemiddelde fout van 5 graden bij het implanteren van torische IOLs. Dit resulteert in een rest astigmatisme van $17 \%$ en is met name van belang bij torische IOLs met een hoge cylinder sterkte.

In de volgende hoofdstukken worden klinische resultaten na torische IOL implantatie besproken. In Hoofdstuk 5 wordt een gerandomiseerde klinische studie beschreven waarin bilaterale torische IOL implantatie is vergeleken met bilaterale monofocale IOL implantatie (controle groep) bij patiënten met cataract en cornea astigmatisme. $\mathrm{Na}$ bilaterale torische IOL implantatie was $84 \%$ van de patiënten brilonafhankelijk voor vertezien, vergeleken met $31 \%$ in de controle groep. Patiënten in de torische groep hadden postoperatief een betere ongecorrigeerde vertevisus en lager refractie astigmatisme. Er zijn geen verschillen gevonden in contrast gevoeligheid, hogere-orde aberraties en refractie afwijking-gerelateerde kwaliteit van leven tussen de beide groepen.

In Hoofdstuk 6 wordt een klinische studie beschreven waarin de effectiviteit van torische IOLs in het corrigeren van hoog cornea astigmatisme wordt onderzocht. Preoperatief was het gemiddelde cornea astigmatisme 3,84 D. Postoperatief behaalde de helft van de patiënten een ongecorrigeerde vertevisus van minimaal 20/30. In ruim $80 \%$ van de ogen was het rest astigmatisme minder dan $1 \mathrm{D}$. Deze resultaten laten zien dat torische IOLs effectief zijn in het corrigeren van hoog cornea astigmatisme.

In Hoofdstuk 7 worden de klinische resultaten na multifocaal torische IOL implantatie beschreven. Multifocaal torische IOLs bieden patiënten met cataract en cornea astigmatisme de mogelijkheid om brilonafhankelijk te worden voor vertezien en lezen. Postoperatief was $95 \%$ van de patiënten brilonafhankelijk voor vertezien en $79 \%$ voor 
lezen. Multifocaal torische IOL implantatie resulteerde in een goede verte- en leesvisus en een acceptabele intermediaire visus.

In Hoofdstuk 8 hebben we de effectiviteit van astigmatisme correctie met torische IOLs bepaald met behulp van een vector analyse. We hebben het gebruik van torische IOLs geanalyseerd in 3 klinische toepassingen: torische IOLs in cataract chirurgie; torische phake IOLs in refractie chirurgie; en torische phake IOLs ter correctie van postkeratoplastiek (PKP) astigmatisme. Gebruik van torische IOLs in cataract chirurgie resulteerde in een gemiddeld rest astigmatisme van 0,37 D en een index of success van 0,14 . De index of success is een relatieve maat voor success en is idealiter 0 . Gebruik van torische phake IOLs in refractie chirurgie resulteerde in een rest astigmatisme van ongeveer 0,60 D en een index of succes van 0,32 (Artiflex phake IOL) en 0,18 (Artisan phake IOL). Torische phake IOLs ter correctie van PKP astigmatisme resulteerde in een rest astigmatisme van $1,56 \mathrm{D}$ en een index of success van 0,28 . Door bij torische phake IOL calculaties rekening te houden met chirurgisch geïnduceerd astigmatisme kunnen de resultaten met deze phake IOLs verder worden verbeterd.

Hoofdstuk 9 en 10 beschrijven gebruik van torische IOLs in speciale situaties. In Hoofdstuk 9 beschrijven we 2 patiënten met irregulair astigmatisme door keratoconus die een cataract operatie ondergaan met implantatie van een torische IOL. Torische IOLs kunnen gebruikt worden om irregulair astigmatisme door keratoconus te corrigeren, mits er sprake is van milde tot matige stabiele keratoconus. In Hoofdstuk 10 presenteren we 2 patiënten met onverwachts rest astigmatisme na torische IOL implantatie. Mogelijke oorzaken voor rest astigmatisme zijn IOL misalignment, een afwijkende effectieve cylinder sterkte, abnormaal posterior cornea astigmatisme en een abnormale pupil grootte. Door torische IOL calculaties verder te optimaliseren kan rekening gehouden worden met de effectieve cylinder sterkte en posterior cornea astigmatisme. Wij adviseren verder om bij jonge patiënten voorafgaand aan torische IOL implantatie ook pupillometrie te verrichten. 


\section{Dankwoord}


Dit proefschrift is tot stand gekomen met medewerking van velen. Een aantal mensen wil ik in het bijzonder bedanken.

Allereerst Prof. dr. R.M.M.A. Nuijts. Beste Rudy, ik zal nooit vergeten dat ik na mijn afstuderen vanuit Utrecht naar Maastricht kwam om te praten over mogelijkheden op onderzoeksgebied. Na een uur had je me een promotieplek aangeboden, in combinatie met een opleidingsplaats. Ik heb enorm veel bewondering voor je harde werken, kennis \& kunde en je lage slaapbehoefte! Onze samenwerking heb ik als heel plezierig ervaren. Bedankt voor alle mogelijkheden die je mij biedt. Ik kijk ernaar uit om nog veel van je te leren tijdens mijn Cornea fellowship.

Dr. N.J.C. Bauer. Beste Noël, ik wil je graag bedanken voor je vertrouwen en de prettige samenwerking tijdens mijn onderzoek, maar ook tijdens mijn opleiding en perifere stage.

I would like to thank the members of the assessment committee, Prof. dr. C.D. Dirksen, Prof. dr. O. Findl, Prof. dr. G.P.M. Luyten, Prof. dr. L.W. van Rhijn and Prof. dr. C.A.B. Webers for their willingness to read this manuscript.

Prof. dr. C.A.B. Webers. Beste Carroll, als mijn opleider wil ik u graag bedanken voor de mogelijkheden en faciliteiten om mijn onderzoek af te ronden tijdens mijn opleiding en tijdens mijn fellowship. Alle AIOS, stafleden, Astrid Hacking en andere medewerkers van de afdeling Oogheelkunde wil ik bedanken voor hun hulp bij het uitvoeren van het onderzoek. Zonder jullie hulp was ik nog bezig met het includeren van patiënten! Fleur en Pieter bedankt voor het doorlezen. Ellen Vrancken en Marjo Locht, dank voor al jullie hulp bij de administratieve en organisatorische obstakels tijdens het afronden van mijn proefschrift.

De (ex)onderzoekers bij de Oogheelkunde wil ik bedanken voor de super leuke tijd: Annelie, Aukje, Frank, Frenne, Lukas, Margriet, Mari, Muriel, Paul, Rob en Yanny. Onze gesprekken gingen soms over de ups en downs van onderzoek, maar vaker over semiwetenschappelijke zaken. Minstens zo belangrijk!

De medeauteurs wil ik graag bedanken voor hun samenwerking en hulp bij het tot stand komen van de artikelen. Tos, dank voor je advies over analyses en statistiek. Zonder jouw hulp was de vector analyse nog steeds abracadabra. 
Graag wil ik mijn vrienden bedanken. Kirsten, onze reizen in Nieuw-Zeeland en Ibiza waren fantastisch! Helaas wonen we niet meer op fietsafstand; maar dit is wel een goede reden om regelmatig een weekendje af te spreken. SUMMA's Josine, Philip, Petra, Ricky en Hendrik: bedankt voor al jullie gezelligheid, zinvolle en minder zinvolle discussies. De UF'jes Danielle, Evert, Eugenie, Gido, Maaike en Marco: ik hoop dat er nog vele kampeerweekenden zullen volgen!

Mijn paranimfen Judith Gijzels en Petra Visser: Judith, zonder jouw steun, raad en afleiding zouden mijn promotietraject en opleiding een stuk lastiger zijn geweest. Met voldoende bochtjes kom je altijd beneden toch? Je staat altijd voor me klaar en ik waardeer onze vriendschap erg. Lieve Peet, jouw relativeringsvermogen en humor maken dat ik me altijd realiseer dat het leven niet draait om RCTs of posterieur astigmatisme.

Tot slot wil ik mijn ouders bedanken. Lieve pap en mam bedankt voor jullie liefde en eeuwige vertrouwen. Gelukkig weten jullie de weg naar Maastricht goed te vinden! Zonder jullie steun was ik nooit geweest waar ik nu ben. Ik draag het boekje daarom aan jullie op. 
Curriculum Vitae 
Nienke Visser was born in Harlingen, the Netherlands, on July 5th 1982. She graduated from the Atheneum at RSG Simon Vestdijk in Harlingen in 2000. In 2000 she started a bachelor in Biomedical Sciences, at Utrecht University, and graduated in 2003. After the bachelor degree she decided to study medicine and was admitted through the Selective Utrecht Medical Master (SUMMA) at Utrecht University in 2004. She became interested in ophthalmology and spend a clinical and research internship under supervision of professor McGhee at the University of Auckland, New Zealand. She also did a research project under supervision of professor Rothova at Utrecht University. In 2009 she started a PhD research project at the University Eye Clinic Maastricht under supervision of professor Nuijts. This research led to the current thesis and was presented at congresses of the European Society of Cataract and Refractive Surgeons, American Society of Cataract and Refractive Surgeons, and numerous national meetings. From 2011 to 2016 she was a resident in ophthalmology at the University Eye Clinic Maastricht. In 2016 she became a Fellow of the European Board of Ophthalmology. She is currently undertaking a fellowship in cornea and anterior segment surgery under supervision of $d r$. Saelens and professor Nuijts and is working in both the University Eye Clinic Maastricht and Zuyderland Hospitals in Brunssum and Heerlen. 
List of Publications 
Visser N, van Rijn BB, Rijkers GT, Franx A, Bruinse HW. Inflammatory Changes in Preeclampsia: Current Understanding of the Maternal Innate and Adaptive Immune Response. Obstet Gynecol Surv 2007; 62 (3): 191-201.

Visser N, McGhee CNJ, Patel DV. Laser-scanning in vivo confocal microscopy reveals two morphologically distinct populations of stromal nerves in normal human cornea. Br. J. Ophthalm. 2009; 93 (4): 506-509.

Visser N, Rothova A, de Groot-Mijnes J, de Visser L. Searching for intraocular antibody production against Parvovirus B19, Mumps virus and Measles virus in patients with intermediate or posterior uveitis. Br. J. Ophthalm. 2009; 93 (6): 841-842.

Cheng YY, Visser N, Schouten JS, Wijdh RJ, Pels E, van Cleynenbreugel H, Eggink CA, Zaal MJ, Rijneveld WJ, Nuijts RM. Endothelial Cell Loss and visual outcome of Deep Anterior Lamellar Keratoplasty versus Penetrating Keratoplasty: A randomized multicenter clinical trial. Ophthalmology 2011; 118 (2): 302-309.

Visser N, Berendschot TTJM, Verbakel F, Tan AN, de Brabander J, Nuijts RMMA. Evaluation of the comparability and repeatability of four wavefront aberrometers. IOVS 2011; 52 (3): 1302-1311.

Visser N, Gast STJM, Bauer NJC, Nuijts RMMA. Cataract surgery with toric intraocular lens implantation in keratoconus: a case-report. Cornea 2011; 30 (6): 720-723.

Visser N, Nuijts RMMA, de Vries NE, Bauer NJC. Visual outcomes and patient satisfaction after cataract surgery with toric multifocal intraocular lens implantation. $J$ Cataract Refr Surg 2011; 37 (11): 2034-2042.

Visser N, Ruiz-Mesa R, Pastor F, Bauer NJC, Nuijts RMMA, Montes-Mico R. Cataract surgery with toric intraocular lens implantation in patients with high amounts of corneal astigmatism. J Cataract Refr Surg 2011; 37 (8): 1403-1410.

Visser N, Berendschot TTJM, Bauer NJC, Jurich J, Kersting O, Nuijts RMMA. Accuracy of toric intraocular lens implantation in cataract and refractive surgery. J Cataract Refract Surg 2011; 37 (8): 1394-1402. 
Visser N, Berendschot TTJM, Bauer NJC, Nuijts RMMA. Vector analysis of corneal and refractive astigmatism changes following toric pseudophakic and toric phakic IOL implantation. IOVS 2012; 53 (4): 1865-1873.

Visser N., Bauer N.J., Nuijts RMMA. Residual Astigmatism Following Toric Intraocular Lens Implantation Related to Pupil Size. J Refract Surg. 2012; 28 (10): 729-732.

Visser N, Berendschot TTJM, Verbakel F, de Brabander J, Nuijts RMMA. Comparability and repeatability of corneal astigmatism measurements using different measurement technologies. J Cataract Refract Surg 2012; 38 (10): 1764-1770.

Visser N, Bauer NJC, Nuijts RMMA. Toric intraocular lenses: Historical overview, patient selection, IOL calculation, surgical techniques, clinical outcomes and complications. J Cataract Refractive Surg 2013; 39 (4): 624-637.

Bellucci R, Bauer NJC, Daya SM, Visser N, Santin G, Cargnoni M, Nuijts RMMA, Lisa Toric Study Group. Visual acuity and refraction with a diffractive multifocal toric intraocular lens. J Cataract Refract Surg. 2013; 39 (10): 1507-1518.

Visser N, Beckers HJM, Bauer NJC, Gast STJM, Zijlmans BLM, Berendschot TTJM, Webers CAB, Nuijts RMMA. Toric versus aspherical control intraocular lenses in patients with cataract and corneal astigmatism: Results of an RCT. JAMA Ophthalmol. 2014; 132 (12): 1462-1468.

Simons RWP, Visser N, van den Biggelaar FJHM, Nuijts RMMA, Webers CAB, Bauer NJC, Beckers HJM, Dirksen CD. Trial-based cost-effectiveness analysis of toric versus monofocal intraocular lenses in cataract patients with bilateral corneal astigmatism. Submitted 
